$*$

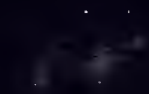

พ

新的

$=$

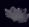





\section{人}

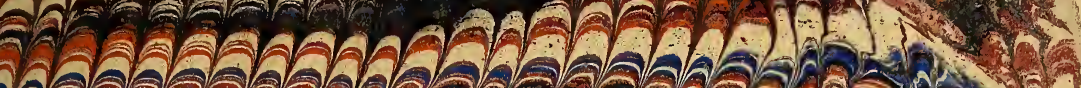

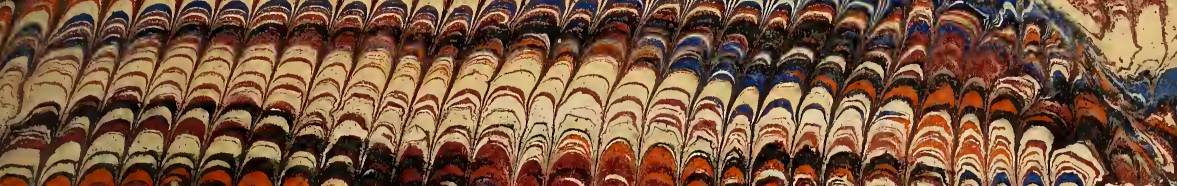

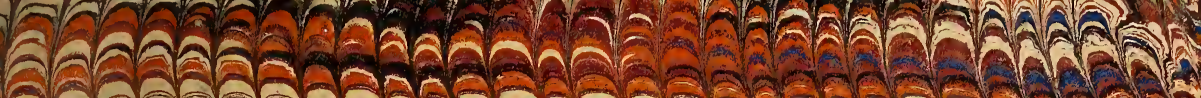

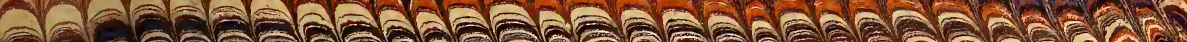

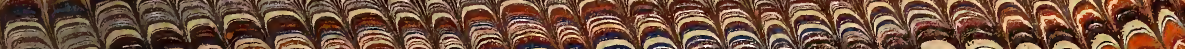
- 1 -

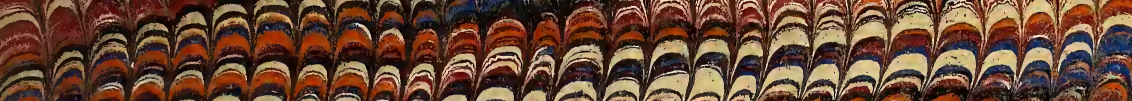

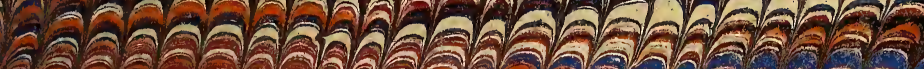

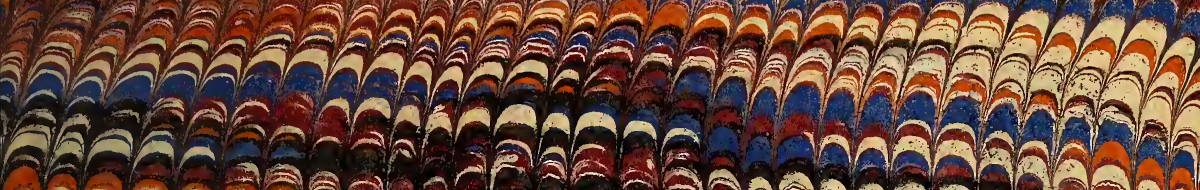

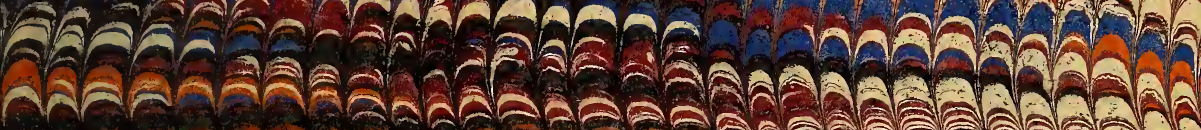

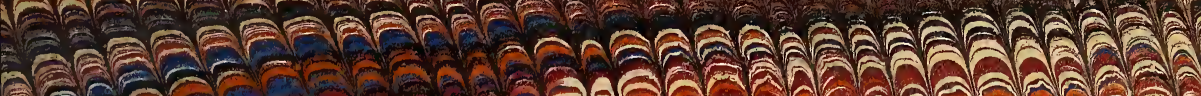

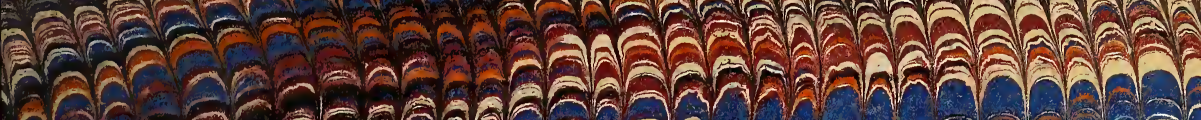

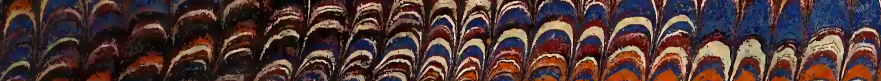

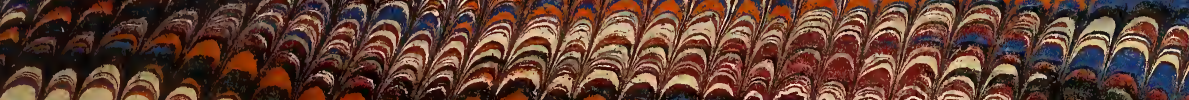
ล

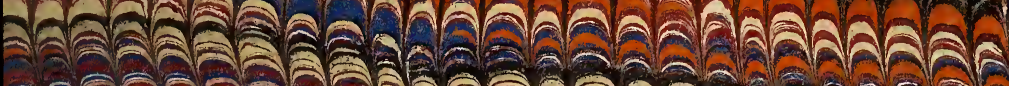
กี่ 政

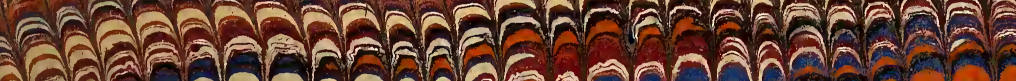

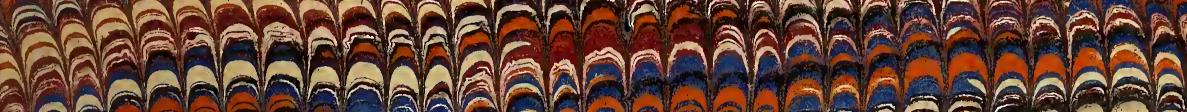

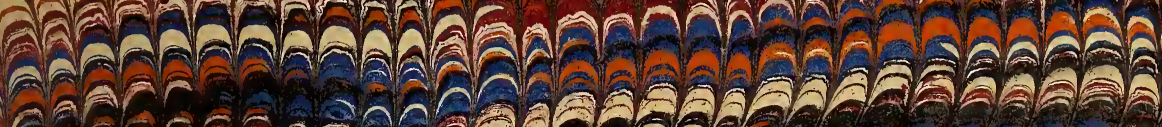

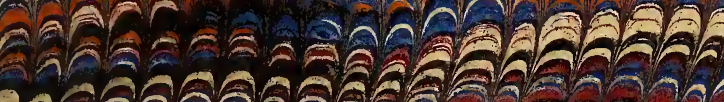

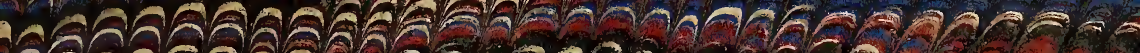

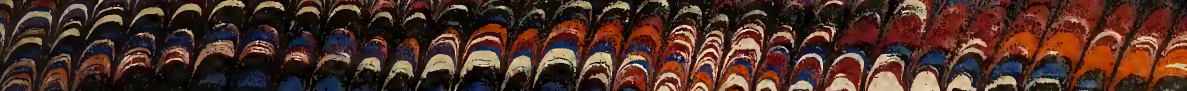

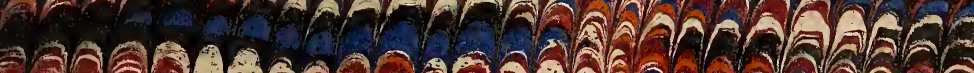
1.

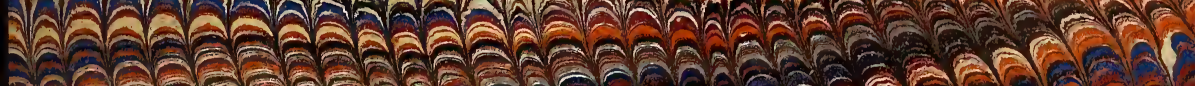

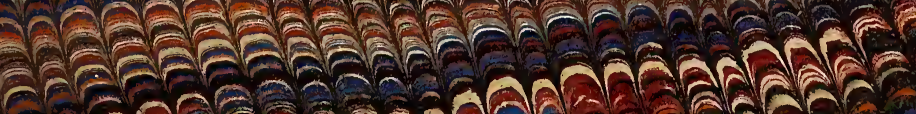

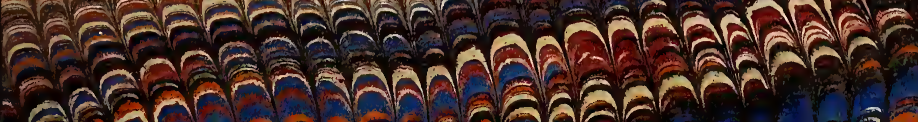








\title{
POMOLOGICAL MANUAL;
}

$\mathrm{OR}$,

\author{
A TREATISE ON FRUITS:
}

CONTAINING

\author{
DESCRIPTIONS OF A GREAT NUMBER
}

OF THE MOST VALUABLE VARIETIES

\section{FOR THE ORCHARD AND GARDEN.}

\author{
"When Autumn basks, with fruit empurpled deep \\ My pleasing theme continual prompts my thought : \\ Presents the downy peach; the shining plum; \\ The ruddy, fragrant nectarine; and dark, \\ Beneath his ample leaf, the luscious fig."”
}

\section{BY WILLIAM ROBERT PRINCE, Author of a Treatise on the Tine, sc. AIDED BY}

WILLIAN PRINCE,

Proprietor of the Linnæan Botanic Garden and Nurseries; Vice-President of the New-York Horticultural Society; Member of the Linnæan Eociety of Paris ; of the Horticultural Societies of London and Paris; of the Imperial Society of the Georgofili at Florence; Honorary Member of the Massachusetts Horticultural Society, etc. etc.

PAR'T II.

SECOND EDITION.

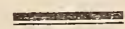

\section{NEW.YORK :}

PUBLISHED BI T. \& J. SWORDS, G. \& C. \& H. CARVILL, E. BIISS, COLLINS \& CO. G. THORBURN \& SONS, NEW-YORK; IVILLIAII THORBURN, ALBANT; ROSSI TER \& KNOX. IROCHESTER; CARY \& HART, GREGG \& ELLIOTT, AND JUDAH DOBSON, PHILADELPHIA ; LORD \& HOLBROOK, AND J. B. RUSSELL, BOSTON GIDEON B. SMITH, BALTIMORE; JAMES WINSTON, RICHMOND; JOSEPH SIMIONA, CHARLESTON, S. C.; AND S. C. PARKHURST, CINCINNATI. 
ENTERED, according to the Act of Congress, in the year 1832, by WiLLIAM ROBERT PRINCE,
in the Clerk's Office of the District Court of the Southern District of New-York.

5835

pas

pat ia

J. SEYMOUR, PRINTER, JOHNOSTREET. 


\section{INDEX TO PART II.}

\section{ADOPTED NAMES.}

\section{PEACHES}

ALBERGE, Late yellow . ................. yellow clingstone -...........

Algiers Yellow -................................

Belle Bausse -........................

Blood clingstone, French-............ , Prince's -.............

Che vreuse clingstone -.................

Columbia

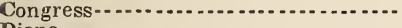

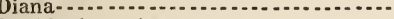

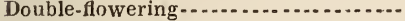

Dwarf Orleans........................

Early white clingstone.............. red clingstone-................

Favier

French Willow-lcaved-................

Gold and Purple..........................

Green Winter-.....................

Heath-1....... Kenrick's-1.2.

Hyslop's clingstone -...................

Kennedy's Carolina

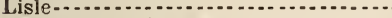

Melocoton, Red-cheek -....................

Mignorne frizée .......................

$$
\text { , Large early }
$$

Monstrous freestone Lemon-....................

Montauban-................................

Newington, Old ...................... , Early

Nutmeg, Green , Brown

Oldmixon freestone-................. clingstone--

Orange clingstone-

Pavie de Pamiers

Pêche de Pau ..........................

Persique ................................ clingstone-..................

Portugal ...............................

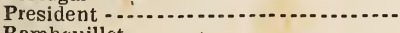

Rambouillet-...........................

Rareripe, Red..

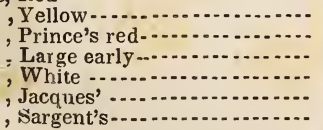

Royal- , Sargent's

Royal George clingstone-.................

Sernach-.............................

Spanish-............

Surprise ... . ............

Sweetwater - ..........

Spring Grove

Teindoux - .....................

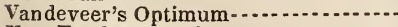

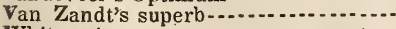

White winter.

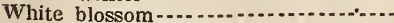

Yellow preserving

Cherry
NECTARINES.

Desprès............................ 40

Elruge, Common -.................. 41

, Miller's ....................... 42

Fairchild's early ...................... 46

French yellow-...................... 40

Golden -.............................. 47

Italian Brugnon, or Brinion ........... 46

Late yellow

Lewis' ............................... 47

Murry ................................ 46

Old Newington.................... 45

Peterborough......................... 47

Red Roman -......................... 45

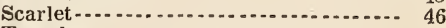

Temples ............................. 47

Vermash-.......................... 45

Violet, Early

, Itarge early .................... 38

, Late marbled -.................... 39

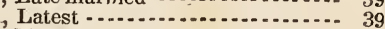

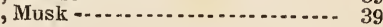

White

French $\ldots \ldots \ldots \ldots . .43$

\section{PLUMS.}

Apricot-plum of Tours .............. 71 , Early

, White............ .67

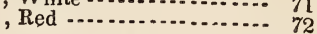

Beach-................................ 108

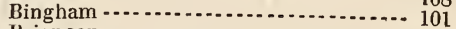

Briancon-.......................... 105

Bricette -..................................... 103

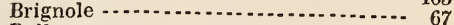

Bullace -............................. 67

Cherry-plum, American-............ 105

European-............ 80

Cheston -............................ 92

Chicasaw, Red ...................... 104

Coe's Golden drop

Cooper's large red.................... 97

Cyprian-............................. 96

Damas Dronet...................... 86

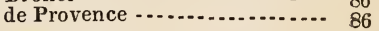

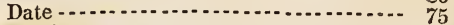

Agen

Damask, Maugeron .. ................ 81

Early black ................. 82

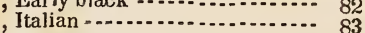

, Spanish-...................... 83

, Musk -........................ 83

, September -................ 84

, Violet...................... 84

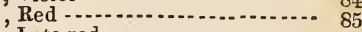

, Late red -..................... 85

, Largest of Tours - ............. 86

Damson,' Prince's early ............... 87

Small red ................... 87

Shropshire.................. 90

, Large early ................... 87

, Small white-................ 88

, Large white-................. 88

, Late white ................... 88

, Late black -................... 89

Late purple-................... 89

Diaper, 'White .......................... 69 
Diaper, Red

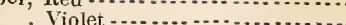

Drap d'Or-......................... 75

Duane's Purple French -............... 100

Egg, Yellow ....................... 57

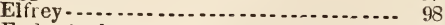

Fotheringham-................... 92

French Copper...................... 93

Gage, Green -........................ 48

, Double flowering ............... 49

Purple-....................... 50

Blue............................... 51

, Red .......................... 51

Bleeker's -..................... 52

Frost -......................... 52

, Prince's imperial................. 56

, Prince's yellow .................. 108

German Plum-........................ 78

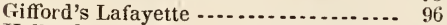

Holland -............................ 78

Huling's superb ...................... 55

Imperatrice, blue..............- .60

white $. . . \ldots . . . . . . . . .61$

Imperial, violet $\ldots . . . \ldots \ldots \ldots \ldots \ldots . . .65$

Whith variegated leaves-- 60

Yellow

Isabella -............................ 107

Isle Verte $-\ldots \ldots \ldots \ldots \ldots \ldots$

Jacinthe

Jerusalem ......................... 95

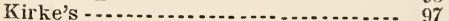

Large early Montreuil-.............. 92

Peach-....................... 106

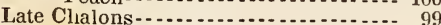

Lucombe's Nonsuch................... 99

Maitre Claude-......................... 52

Mimm's-........................... 90

Monsieur .......................... 69

Early -....................

, Surpasse....................

Morocco

Moucheté-........................... 93

Moyen de Bourgogne ................. 95

Muscle-................................ 105

Nectarine-......................... 102

Orleans-............................. 67

, Smith's-.................... 68

Wilmot's early -............. 68

Perdrigon, White...................... 64

Early -.................... 65

Norman -............... 65

Violet-........................ 66

Red -....................... 67

Primordian, White................. 79

Prince's................. 79

Prune d'Ast-.......................... 100

Prune, German (...................... 77

Red St. Martin -..................... 74

Rognon d'Ane -................... 100

Royal.................................. 72 , Early

St. Catharine

Saint Julien, Commone.................... 73

Sloe

Small Reine Claude.................. 49

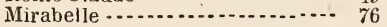

Stoneless

Swiss

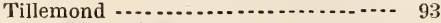

Tomlinson's Cliar lotte-............... 59

Tours, Early-.......................... 64 , Royal - . 64

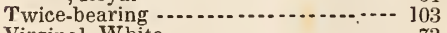

Virginal, White-1..................... 73

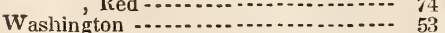

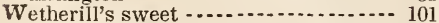

White pear-plum

Wine - .

Winesour........................ 101

\section{CHERRIES.}

Allen's late Farourite .............. 123

All Saints-......................... 152

Belle de Choisy ...................... 137

Bigarreau, China-..................... 126

, Napoleon ................... 126

, Red -....................... 126

White -... .............. 125

, Pigeon-heart -............... 127

, Large Red -................... 127

Large White............. .127

, Common French ............ 128

, Flesh coloured -.............. 128

, Lal ge late Red .............. 128

, Large heart shaped-......... 129

, Ear ly White -................. 129

, Early Red -................... 130

, Black -...................... 130

Late Black -................. 130

, Hildesheim ................ 131

Bird Cherry, European ................ 154

Black Carone......................... 111

Mazard ....................... 109

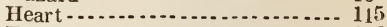

Eagle -......................... 116

Bleeding heart ...................... 120

Carnation-........... 138

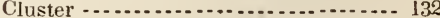

Coeur de Poule ........................ 124

Davenport .......................... 154

Double-flowering, Large-.............. 111

Dwarf-............. 151

Downer's late red $-. . . \ldots \ldots . . . . . . . . .154$

Downton -.......................... 124

Duke, Prince's-........................ 136

May

Late ........................ 134

Arch .......................... 135

Holman's ..................... 135

Dwarf Siberian ...................... 153

Early May .......................... 131

Richmond-...............

Elkhorn -............................ 117

Gascoigne's heart ..................... 121

Graffion, or Amber................ 137

Gridley

Griotte d'Ostheim ................... 145

, Guigne -...................... 149

Early . . . . . . . . . . . . .

, Spanish-..................... 136

, Holland-........................ 141

,Short-stem..................... 141

, Late large Black -............... 145

, Northern ..................... 146

Ratafia........................ 147

, Small Ratafia-................. 147

, Common French ............. 148

Large-......................... 148

, Poitou -....................... 148

,Heart-shaped .................. 149

Guigne Bigaudelle .................. 113

, Late white .................... 113

, Late red ....................... 113

Lundie-....................... 118

, Transparent -................. 119

, Early -......................... 111

Pointed -........................ 119

, Red .......................... 112

Black........................... 112

, Drooping - ................... 119

, Small Black-.................. 112

Early White -................. 112

Guindolle, Large..................... 149

Guindoux, Parisian -................ 140

Hertfordshire Black-................. 121

Kentish Red ........................... 142

Knight's early Black -............... 120

Lukeward's heart -.................... 12.

Marasquin -.......................... 132

Merise, Large black -.................. 110

Tellow fruited ............... 110 
Montinorency, Long-stem -.............. 139 Short-stem -............ 139

Morello, Common-.................... 143 I Plumstone..................... 144 German -.................. 147

Peach-blossomed -.................... 151

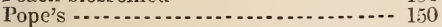

Prolific;

Prussian -............................. 150

Remington White-heart-............. 117

Softstone-.... ........................ 145

Striped-leaved (......................... 151

Tartarian Black...................... 113

White-1................... 114

Villennes -............................ 140

Waterloo - .......................... 118

Weeping (.............................. 153

White Ileart -..................... 115

Willow-leaved ........................ 141

Yellow Honey Spanish

ALMIONDS.

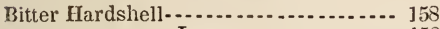
, Large-...

Bitter Softshell-....................... 159

Dwarf single-flowering -............... 160 double-flowering-............. 161

Great-fruited-........................ 157

Ladies' Thin shell - .................... 156

Large fruited ............... 155 double-flowering ............... 161

Peach -................................. 159

Pistachia-............................ 157

Silvery Oriental-....................... 160

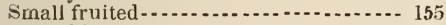
bitter

Sultan

\section{RASPBERRIES.}

Barnet -................................... 165 Brentford Red ......................... 167

Canada Red............................ 168

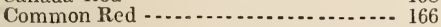
Cretan Red ............................ 169

Pennsylvanian -...................... 167 Prolific Red ............................. 169

Red Antwerp -......................... 164

Short-jointed Cane-...................... 168

Tall Red Cane-....................... 168

Virginia Red

Yellow Antwerp ........................... 165

\section{STRAWBERR1ES.}

Alpine, Red.................................... 180 White -..................... 181 White Bush-................. 181 Red Bush -.................... 181

Black Prince-....... 186 Old Pitmaston -.................... 186

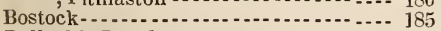

Bullock's Blood ......................... 185

Carolina, Dwarf white ................ 183

, Round white-................ 183

Charlotte-............................... 189

Chili, True -.......................... 181

, Yellow

Chinese................................. 184

Downton-............................... 174

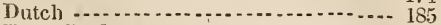

Elton Seedling

Gibb's Seedling, black-.............. 186

Hautbois, Black...................... 171

French Musk-............ 174

Common -................. 182

Prolific -.................... 171

Globe -................... 183

Large flat-................. 193
Hudson's Bay-...................... 189

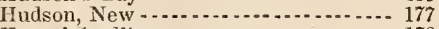

Keens' Seedling-...................... 170

Imperial-....................... 176

Knight's narrow leaved scarlet-........ 171

Large scarlet Lima ..................... 178

Melon -............................. 188

Mulberry . . .

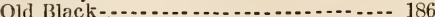

Pine, Blood -.......................... 184

, Glazed........................... 185

old or Carolina.................. 186

, Variegated -...................... 184

Roseberry -.......................... 173 Black.................... 176

Scarlet, American-................. 187 , Austrian -.................... 178

, Autumn -.................... 187

, Bath........................... 185

, Bishop's seedling ............... 187

Carmine -....................... 186

, Cluster- .......................... 189

, Cockscomb -.................. 190

, Early -......................... 186

, Garnestone -................... 188

, Grimstone -.................... 188

Grove-end -................... 186

, Knight's large ................. 191

, Large early ...................... 177

Lew isham $\mathrm{m...2..............} 191$

Methven -.................... 191

Nairn's - . .

Oblong -..................... 191

Pitmaston black-.............. 192

Scone-........................ 192

Sir Joseph Banks' -............. 190

, Vernon's-...................... 190

Wilmot's late .................. 190

Southborough Seedling................ 175

Surinam ............................. 184

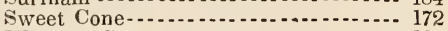

Wilmot's Superb..................... 182

Wood, English red ................. 179 English white-................ 179

Long conical-................. 170

\section{PEARS.}

Alexandre de Russie .................. 197

Ambrosia - ............................. 193

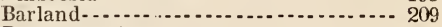

Belle lucrative ...................... 198

Beurré Knox-.......................... 198

Bezy vaet $\ldots \ldots \ldots \ldots$

Bishop's Thumb ....................... 199

Bleeker's Meadow-..................... 215

Blodget

Bonchrétien fondante -............... 199

, Flemish -................... 206

Cabot-............ 214

Charles d'Autriche-................... 195

Colmar, Autumr1 . . .

Darimont Sovereign

Dillen.................................. 200

Dearborn's Seedling

Double d'Automne -................... 195

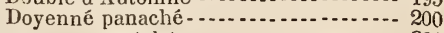

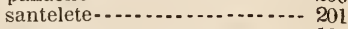

Elton - ................................ 196

Fondante des bois ................... 212

Frederic de Wurtemberg .............. 211

Fulton -................................ 214

Gendeseim ........................... 201

Glout morceau

Green winter sylvanche ............... 214

Grumkower ....................... 207

Hacon's incomparable .............. 201

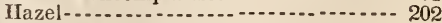

Henry the fourth

Holmore .................. 209

Honey

Huffeap............................. 209 


\section{INDEX.}

Incommunicable .................. 203

Innominée........................ 213

Keizer ... . . .

Lamas . . . . . . . . . . . . . . .

London Sugar-............................ 193

L.ongland -................... 210

Monrfowl Egg-...................... 196

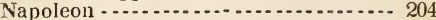

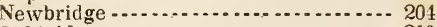

Oldfield .............................. 210

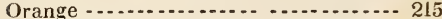

Poire de Louvaine.................. 205

Neill ........................... 205

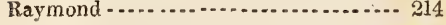

Riche depoulle............... .205

St. Germain Prunes.................. 211

Sabine d'été -........................... 194

Seigneur d'été ......................... 194

Teinton Squash

Tillington -.......................... 208

Urbaniste -......................... 206

Williams's double-bearing-........... 215

Yat, or Yut ......................... 194

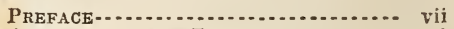

AbBreviations of REFERENCES ........ xvi

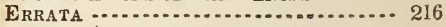




\section{PREFACE TO PART II.}

IN tendering to the public the second volume of the Pomological Manual, it may be proper to indulge in a few remarks, explanatory of the views and objects of the author. It being found impossible to comprise descriptions of all the valuable varieties of fruits within the limits of the two volumes, more particularly as the varieties of apples alone would occupy nearly or quite an entire volume of the present size, it has been deemed the best course to concentrate, in the first and second volumes, as great a variety as possible of the other classes of fruits, leaving the apples to form an after volume, which will contain, in addition thereto, the descriptions of other classes of fruits not comprised in the two first volumes, as well as some additional varieties of the classes previously noticed. The great number of specimen trees at present under culture in the experimental grounds of the establishment whence this work emanates, is calculated to afford the most important facilities for future investigations, and for the correction of errors still existing in the nomenclature of fruits. The eollection of apples has been rnade an object of great interest, it being a fruit whose culture is of the highest importance to our country; and the care and circumspection that have been exercised, in order to concentrate the choicest varieties, can scarcely fail to terminate in the nappiest results.

One great object of the labors of the author, and of his father and brother, whose aid is combined with his own, has been to furnish the public with precise descriptions of the different varieties of fruits cultivated in their nurseries, and they trust they shall succeed in that object. Wherever, in describing a fruit, a reference is made to their catalogue, the identity is either known or believed to exist, and each year will afford additional opportunities for a satisfactory confirmation of all doubtful points. It is possible, however, that an occasional error may arise from misplaced reliance in a correspondent, who may err in his communications; or in the identity of articles obtained from him-but they trust that their unceasing zeal will eventually eradicate any discrepancies on this head.

It needs only to be added, that in the whole progress of this work, the utmost candor has been, and will continue to be exercised, and all important facts within the knowledge of the author, and of those associated with him, will be fully communicated. This work, when completed, will eomprise all that is useful or important in the more ancient publications, and also all descriptions of choice fruits contained in the New Duhamel, the Transactions of the London Horticultural Society, the Transactions of the Horticultural Society of Paris, the Pomological Magazine, the Pyrus Malus Brentfordiensis, Lindley's Guide to the Orchard and Kitchen Garden, the different publications of Van Mons and other Flemish and German pomologists, and of the other modern writers of authority, and will further combine, as an object of the highest importance, the descriptions of all the choicest varieties of fruits which have originated in our own country.

In "Lindley's Guide," above referred to, an introductory article is given on the subject of "Amelioration and Propagation," the purport of which accords so generally with the views of the author of the present work, that he has quoted it here entire. The greater part of the fruits comprised in Mr. Lindley's publication, having been described in the course of the present work, before his had reached this country, there consequently remains a portion only to be in. cluded in an after volume, which has been already prepared for publication. 
"In all books upon gardening a great variety of modes of operating are comprehended, each of which has, it may be supposed, its own peculiar merit under particular circumstances. In several the very same mode is repeatedly recommended, with slight variations of phraseology, in speaking of many different subjects; and it has at last become a common complaint, among those who seek for information from books upon horticultural subjects, that they can find plenty of rules of action, but very few reasons.

"No greater boon could be bestowed upon the gardening world than to reduce all horticultural operations to their first principles, and to lay bare the naked causes why in one case one mode of procedure is advisable, and another in another. But there are few persons who are competent to undertake this task; it requires a combination of great physiological knowledge, with a perfect acquaintance with the common manipulation of the gardener's art, and much experience in all the little accidents which are scarcely appreciable by the most observing cultivator, with which the mere man of science can necessarily have no acquaintance, but upon which the success of a gardener's operations often mainly depends; which are to the cultivator signs as certain of the issue of his experiments, as to the mariner are the almost invisible changes in the appearance of the heavens by which the weather is prognosticated.

"Deeply impressed with a persuasion of the justice of the foregoing obserrations, and sincerely regretting that there should be no present expectation of such a task being undertaken by any one fully competent to it, the Editor of this work ventures to throw himself upon the indulgence of the public by attempting, not to carry into efiect such a plan.himself, but to sketch out, in regard to the Fruit Garden, what he thinks the method should be upon which a more competent person would do well to proceed.

"All our fruits, without exception, have been so much ameliorated by one circumstance or another, that they no longer bear any resemblance in respect of quality to their original. Who, for instance, would recognise the wild parent of the Coe's or Green Gage-Plum in the savage Sloe, or that of the Ribston and Golden Pippin Apples in the worthless acid Crab? Or what resemblance can now be traced between the delicious Beurré Pears, whose flesh is so succulent, rich, and melting, and that hard, stony, astringent fruit, which even birds and animals refuse to eat? Yet these are undoubted cases of improvement resulting from time and skill patiently and constantly in action. The constant dropping of water will not more surely wear a way the hardest stone, than will the reasun of man in time compel all nature to become subservient to his wants or wishes. But it would be of little service to mankind that the quality of any fruit should be improved, unless we found some efficient and certain mode of multiplying the individuals when obtained. Hence there are two great considerations to which it is, above all things, necessary that the attention of the cultivator should be directed, viz. Amelioration and Propagation.

"Amelioration consists either in acquiring new and improved varieties of fruit, or in increasing their good qualities when acquired. It will be as well to consider these two subjects separately.

"By what means the first tendency to change their nature was given to domesticated plants, we are entirely ignorant. It is probable that it was originally due to accident, and also that it was still mere chance which continued to operate down to very modern times. Philosophers are unacquainted with the reason why there should be any tendency to variation from the characters first stamped on any species by Nature; but all know that this tendency does exist, and in a most remarkable degree in many species. There is in all beings a disposition to deviate from their original nature when cultivated, or even in a wild state; but this disposition is so strong in some as to render them particularly well adapted to become subject to domestication: for instance, the dog, the pigeon, and the barn-yard fowl, are cases in which this tendency is most strongly marked in animals; and domesticated fruits are a parallel case in the vegetable world.

"Without, then, vainly endeavouring to discover the first cause of this disposition to form varieties, let us take it as a naked fact that the disposition exists. Cultivators increase this disposition chiefly in two ways; either by constantly selecting the finest existing varieties for seed, or by intermixing the pollen and stigma of two varieties for the purpose of procuring something of an intermediate nature. The ancients were unacquainted with either of these practices, and con. 
sequently their gardens contained few things which would now be deemed worthy of cultivation. The power of obtaining cross-bred varieties at pleasure has only existed since the discovery of sexes in plants ; but as it exerts a most extensive influence over alterations in the vegetable kingdom, it may be considered the most important controlling power that we possess.

"In sowing seeds for the purpose of procuring improved varieties, care should be had, not only that the seeds be taken from the finest existing kinds; but also that the most handsome, the largest and the most perfectly ripened specimens should be those that supply the seed. A seedling plant will always partake more or less of the character of its parent, the qualities of which are concentrated in the embryo when it has arrived at full maturity. How this concentration takes place, we are as ignorant as why certain constitutional peculiarities are in men transferred from father to son, and from generation to generation; but we know that it does take place. Now if the general qualities of a given variety are concentrated in the embryo under any circumstances, it is reasonable to suppose that they will be most especially concentrated in a seed taken from that part of a tree in which its peculiar good qualities reside in the highest degree. For, instance, in the fruit of an apple growing upon a north wall there is a smaller formation of sugar than in the same variety growing on a south wall; and it can he easily understood that the seed of that fruit which is itself least capable of forming saccharine secretions, will acquire from its parent a less power of the same nature than if it had been formed within a fruit in which the saccharine principle was abundant. It should therefore be always an object with a gardener, in selecting a variety to become the parent of a new sort, to stimulate that variety by every means in his power, to produce the largest and the most fully ripened fruit that it is capable of bearing. The importance of doing this is well known in regard to Melons and Cucumbers, and also in preserving fugitive varieties of flowers; but it is not generally practised in raising fruit trees.

"The power of procuring intermediate varieties by the intermixture of the pollen and stigma of two cifferent parents is, however, that which most deserves consideration. We all know that hybrid plants are constantly produced in every garden, and that improvements of the most remarkable kind are yearly occurring in consequence. Experiments are, however, it may be supposed, sometimes made without the operator being exactly aware either of the precise nature of the action to which he is trusting for success, or of the limits within which his experiments should be confined.

"Cross fertilization is effected, as every one knows, by the action of the pollen of one plant upon the stigma of another. The nature of this action is highly curious. Pollen consist of extremely minute hollow balls or bodies; their cavity is filled with fluid, in which swim particles of a figure varying from spherical to oblong, and having an apparently spontaneous motion. The stigma is composed of very lax tissue, the intercellular passages of which have a greater diameter than the moving particles of the pollen.

"When a grain of pollen comes into contact with the stigma, it bursts and discharges its contents among the lax tissue upon which it has fallen. The moving particles descend through the tissue of the style, until one, or sometimes more, of them finds its way, by routes specially destined by nature for this service, into a little opening in the integuments of the ovulum or young seed. Once deposited there, the particle swells, increases gradually in size, separates into radicle and cotyledons, and finally becomes the embryo,-that part which is to give birth, when the seed is sown, to a new individual.

"Such being the mode in which the pollen influences the stigma and subsequently the seed, a practical consequence of great importance necessarily follows, viz. that in all cases of cross fertilization, the new variety will take chiefly after its polleniferous or male parent; and that at the same time it will acquire some of the constitutional peculiarities of its mother.* Thus, the male parent of the Downton Strawberry was the Old Black, the female a kind of Scarlet; in Coe's Golden Drop Plum, the father was the Yellow Magnum Bonum, the mother the Green Gage; and in the Elton Cherry the White Heart was the male parent, and the Graffion the female.

* In early crosses between distinct species, this is particularly manifest ; but in those of varieties long domesticated it is less apparent, the distinctions between the parents them. selves being less fixed, and less clearly marked. 
"The limits within which experiments of this kind must be confined are, how" ever, narrow. It seems that cross fertilization will not take place at all, or very rarely, between different species, unless these species are nearly related to each other; and that the offspring of the two distinct species is itself sterile, or if it possesses the power of multiplying itself by seed, its progeny returns back to the state of one or other of its parents. Hence it seldom or never has happened that domesticated fruits have had such an origin. We have no varieties raised between the Apple and the Pear, or the Quince and the latter, or the Plum and Cherry, or the Gooseberry and the Currant. On the other hand, new varieties obtained by the intermixture of two pre-existing varieties are not less prolific, but, on the contrary, often more so than either of their parents ; witness the numerous sorts of Flemish Pears which have been raised by cross fertilization from bad bearers, within the last twenty years, and which are the most prolific fruit trees with which gardeners are acquainted; witness also Mr. Knight's Cherries, raised between the May Duke and the Graffion, and the Coe's Plum already mentioned.

"It is, therefore, to the intermixture of the most valuable existing varieties of fruit that gardeners should trust for the amelioration of their stock. By this operation the pears that are in eating in the spring have been rendered as delicious and as fertile as those of the autumn; and there is no apparent reason why those very earlv, but worthless sorts, such as the Muscat Robert, which usher in the season of Pears, should not be brought to a similar state of perfection.

"There is no kind of fruit, however delicious, that may not be deteriorated, or however worthless, that may not be ameliorated, by particular modes of management; so that after a given variety shall have heen created, its merits may still be either elicited or destroyed by the cultivator. In this place those practices only need be considered that tend to improvement.

"Some fruits of excellent quality are bad bearers : this defect is remedied by a variety of different methods, such as, 1 . By ringing the bark; 2. By bending branches downwards; 3. By training; and, 4. By the use of different kinds of stocks. All these practices are intended to produce exactly the same effect by different ways. Physiologists know that whatever tends to cause a rapid diffusion of the sap and secretions of any plant, causes also the formation of leaf buds instead of flower buds; and that whatever, on the contrary, tends to cause an accumulation of sap and secretions, has the effect of producing flower buds in abundance. This circumstance, which at first sight seems to be difficult to account for physiogically, is no doubt to be explained by the difference between leaf buds and flower buds themselves. In a leaf bud, all the appendages or leaves, are in a high state of development, and the central part or axis, around which they are arranged, has a tendency to extend itself in the form of a branch as soon as the necessary stimulus has been communicated to the system by the light and warmth of spring. In a flower bud, the appendages or leaves are in that imperfectly formed, contracted state, which we name caly $\mathrm{x}$, corolla, stamens, and pistilla; and the central part around which they are arranged, has itself no tendency to elongate under the influence of the usual stimulants. Hence, a flower bud, or flower, is nothing but a contracted branch; as is proved by the occasional elongation of the axis in flowers that expand during unusually hot damp weather late in the spring, becoming branches, bearing sepals and petals instead of leaves. It is, therefore, easily to be understood why, so long as all the motions in the fluids and secretions of a tree go on rapidly, with vigor, and without interruption, only rudiments of branches (or leaf buds) should be formed; and why, on the other hand, when the former become languid, and the parts are formed slowly, bodies of a contracted nature, with no disposition to extension, (or flower buds) should appear.

"It will be found that the success of the practices above enumerated, to which the gardener has recourse in order to increase the fertility of his fruit trees, is to be explained by what has just been said. In ringing fruit trees, a cylinder of bark is cut from the branch, by which means the return of the elaborated juices from the leaves down the bark is cut off, and all that would have been expended below the annular incision is confined to the branch above it. This produces an accumulation of proper juice; and flower buds, or fertility, are the result. But there is a defect in this practice, to which want of success in many cases is no doubt to be attributed. Although the returning fluid is found to accumulate above the annular incision, yet the ascending sap flows along the alburnum inte 
the buds with nearly as much rapidity as ever, so that the accumulation is bat imperfectly produced. On this account the second practice, of bending branches downwards is found to be attended with more certain consequences. The effect of turning the branches of a tree from thair natural position to a pendulous or a horizontal one is, to impede both the ascent and the descent of the fluids in a gradual but certain manner. The tissue of which branches are composed is certainly permeable to fluids in every direction; and there can be no doubt that the vital action of the vessels of a plant is performed both in the natural and in an inverted position. So long as that erect direction of the branches which is natural to them is exactly maintained, the flow of their fluids, being subject to no interruptions, will take place in the freest possible manner; but the moment this natural direction is deviated from, the vessels become more or less compressed, their action is impeded, and finally, if the inversion is perfect, it becomes so slow that an accumulation of the proper juices necessarily takes place through every part of the system.

"One of the objects of training is to produce the same effect. Branches are bent more or less from their naturally erect position; their motion, in consequence of the action of winds upon them, which is known to facilitate the movement of the fluids, is totally destroyed; and hence arises the accumulation of proper juice which is necessary to their fertility. Nor is the influence of the stock of an essentially different nature. In proportion as the scion and the stock approach each other closely in constitution, the less effect is produced by the latter; and, on the contrary, in proportion to the constitutional difference between the stock and the scion, is the effect of the former important. Thus, when Pears are grafted or budded on the wild species, Apples upon Crabs, Plums upon Plums. and Peaches upon Peaches or Almonds, the scion is, in regard to fertility, exactly in the same state as if it had not been grafted at all. While, on the other hand, a great increase of fertility is the result of grafting Pears upon Quinces, Peaches upon Plums, Apples upon Whitethorn, and the like. In these latter cases, the food absorbed from the earth by the root of the stock, is communicated slowly and unwillingly to the scion; under no circumstances is the communication between the one and the other as free and perfect as if their natures had been more nearly the same; the sap is impeded in its ascent, and the proper juices are impeded in their descent, whence arises that accumulation of secretion which is sure to be attended by increased fertility. No other influence than this can be exercised by the scion upon the stock. Those who fancy that the contrary takes place ; that the Quince, for instance, communicates some portion of its austerity to the Pear, can scarcely have considered the question physiologically, or they would have seen that the whole of the food communicated from the alburnum of the Quince to that of the Pear, is in nearly the same state as when it entered the roots of the former. Whatever elaboration it undergoes must necessarily take place in the foliage of the Pear; where, far from the influence of the Quince, secretions natural to the variety go on with no more interruption than if the Quince formed no part of the system of the individual.

"If we consider upon what principle the favour of particular fruits may be improved, we shall find that it is entirely due to the increased action of the vital functions of leaves. When the sap is first communicated by the stem to the leaves, it has experienced but few chemical changes since it first entered the roots. Such changes as it has undergone have been due rather to the solution of some of the pre-existing peculiar secretions of the individual by the sap in its way upwards through the alburnum, than to any other cause. As soon, however, as it enters the leaves, it becomes altered in a variety of ways, by the combined action of air, and light, and evaporation; for which purposes the leaf is admirably adapted by its anatomical structure. Thus altered in the leaves, it ceases to be what we call sap, but becomes the proper juice; or, in other words, acquires the peculiar character of the final secretions of the individual from which it is formed. Discharged by the leaves into the bark, it is then conveyed by myriads of channels of cellular substance throughout the whole system. From these secretions, of whatever nature they may be, the fruit has the power of attracting such portions as are necessary for its maturation. Hence it follows, that the more we can increase the peculiar secritions of a plant, the higher will become the quality of its fruit; and that, on the other hand, the less the plant is in condition to form those secretions, the less will be the quality of the fruit. It 
is for the purpose of producing the former effect that pruning and training trees are more especially destined. In pruning, we remove all those superfluous branches which overshadowed the remainder $y$ and we endeavor to expose every part to the freest action of light and air. In training, the same thing takes place, but is increased; there is not a branch that is not fully exposed to the most direct rays of light, and to the freest circulation of air, and even to the unimpeded action of the sun in aspects exposed to the south, east, or west. This action is obviously most powerful on the south, and hence the higher quality of fruits matured upon that exposure than on any other; while, on the other hand, fruits raised upon a northern aspect are well known to be less highly flavored than those from even an open standard. For a similar reason, forced fruits, which are obtained at a period when there is little light, cannot be compared with those which are matured in the full blaze of a summer sun; and hence melons grown in frames covered with mats, and carefully excluded from the influence of that solar light which is indispensable to them, have, whatever may be their external beauty, none of that luscious flavor which the melon, when well cultivated, possesses in so eminent a degree.

"The next subject of consideration is the mode of multiplying improved varieties of fruit, so as to continue in the progeny exactly the same qualities as existed in the parent. Unless we have the power of doing this readily, the advantages of procuring improved races would be very much circumscribed; and the art of horticulture, in this respect, would be one of the greatest uncertainty. The usual mode of increasing plants, that mode which has been more especially provided by nature, is by seeds; but, while seeds increase the species without error, the peculiarities of varieties can rarely be perpetuated in the same manner. In order to secure the multiplication of a variety, with all its qualities unaltered, it is necessary that portions should be detached from the original individual, and converted into new individuals, each to undergo a similar dismemberment, with similar consequences. It happens that while in animals this is impracticable, except in the case of polypes, the system of life in a plant is, of all others, the best adapted to such a purpose. We are accustomed to consider individual plants of exactly the same nature as individual animals; this is, however, a vulgar error, which is dissipated by the slightest inquiry into the nature of a plant. A plant is really an animated body, composed of infinite multitudes of systems of life; all indeed, united in a whole, but each having an independent existence. When, therefore, any number of these systems of life is removed, those which remain, as well as those which are separated, will, under fitting circumstances, continue to perform their natural functions as well as if no union between them had ever existed. These systems of life are buds, each having a power of emitting descending fibres in the form of roots, and also of ascending in the form of stem. The first of these buds is the embryo; the others are subsequently formed on the stem emitted by the embryo. As these secondary buds develope, their descending roots combine and form the wood, their ascending stems give rise again to new buds. These buds are all exactly like each other; they have the same constitution, the same organic structure, and the individuals they are capable of producing are, consequently, all identically the same; allowance, of course, being made for such accidental injuries or alterations as they may sustain during their subsequent growth. It is upon the existence of such a remarkable physiological peculiarity in plants, that propagation entirely depends ; an evident proof of which may be seen in this circumstance. Take a cutting of a vine consisting only of the space which lies between two buds, or an internodium, as botanists would call such a piece, and no art will succeed in ever making it become a new plant, no matter how considerable the size of the internodium may be.* But, on the other hand, take the bud of a vine without any portion of the stem adhering to it, and it will throw out stem and root, and become a new plant immediately. If we examine the various modes employed in horticulture for propagating plants, we shall find that, however different they may be in appearance, they all consist in the application of these principles under various forms. It will be most convenient to consider these methods separately.

Propagation is effected by the arts of Increasing by Eyes, Striking from Cuttings, Laying, Budding, and Grafting.

* This is, of course, said without reference to the power which some plants possess of developing latent buds, a subject which is foreign to the present inquiry. 
"Increasing by Eyes is the simplest of all these methods : it consists in nothing but extracting a single system of life, or a bud, from a given plant, placing it in due heat and moisture, and surrounding it with fitting food, and thus causing it to grow as a solitary individual, instead of as one of the community to which it originally belonged.

"Striking from Cuttings is a slight modification of the last method. Instead of taking a single bud, a stem containing two, three, or more buds, is placed in circumstances fitted for the maintenance of its life. In thiscase, the chances of success are increased by the additional number of buds which are the subject of experiment. That bud which is the nearest the bottom of the cutting, emits its roots at once into theearth, and so establishes a communication between the general system of the cutting and the medium from which its food is to be derived. The other buds, by pushing their stems upwards into light, attract the nutriment absorbed by the roots, and so stimulate the latter to increased action. Ultimately the roots of all the buds descend between the bark and the wood until they reach the earth, into which they finally pass, like those of the first bud. There is another circumstance which renders the operation of striking plants from cuttings less precarious than from eyes. In both cases, the buds have, at the outset, to feed upon matter in their vicinity, until they shall have formed roots which are capable of absorbing food from the earth; but in eyes, the nutritive matter can exist only in such portions of the stem as may have been cut away with themselves; while, on the other hand, in cuttings, the stem itself forms an important reservoir of nutriment. This is a consideration, the practical importance of which will be obvious to every cultivator. As it is from the buds alone of cuttings that roots proceed, it follows, that in cases of difficulty, when plants strike unwillingly, any thing which may facilitate the immediate introduction of roots into the soil will be advantageous. It is for this reason that a good operator always takes care, that the lower end of his cutting is pared down as close to the base of a bud as may be practicable without actually destroying any part of the bud itself; by this means the first emitted roots, instead of having to find their way downwards between the bark and wood, strike at once into the earth, and become a natural channel by which nutriment is conveyed into the general system of the cutting.

Laying is nothing but striking from cuttings that are still allowed to maintain their connection with the mother plant by means of a portion at least of their stem. Where roots are emitted with great readiness, simply bending a branch into the soil, leaving its point above ground, is sufficient to ensure the success of the operation; but in cases of difficulty other expedients are resorted to, all which will still be found to have reference to the emission of roots by buds. One common practice is, to head down the branch that is laid into the earth; this is to call into action the buds below the incision, by stopping the general axis of development. Another method is to tongue the layer, that is, to split the stem just up to the origin of a bud; a practice that has the effect of enabling the roots to be emitted into the soil through the wound more readily than if they had to pierce through the bark; the resistance offered to their passage through the bark is in many cases so great as to compel them to continue to make wood rather than to appear in the form that is necessary for the success of the cultivator.

"Budding and Grafting are operations that equally depend for their success upon the property that buds possess of shooting roots downwards and stems upwards; but in these practices the roots strike between the bark and wood of the stock, instead of into the earth, and form new layers of wood instead of subterranean fibres. The success of such practices, however, depends upon other causes than those which influence the growth of cuttings. ' It is necessary that an adhesion should take place between the scion and the stock, so that when the descending fibres of the buds shall have fixed themselves upon the wood of the stock, they may not be liable to subsequent separation. No one can have studied the economy of the vegetable kingdom without having remarked that there is a strong tendency to cohesion in bodies or parts that are placed in contact with each other. Two stems are tied together for some purpose: when the ligature is removed, they are found to have grown into one : two Cucumbers accidentally placed side by side, or two Apples growing in contact with each other, form double Cucumbers or double Apples; and most of the normal modifications of the leaves, floral envelopes, or fertilizing organs, are due to rarious degrees of cohesion in contigu- 
ous parts. This cohesion will be aiways found to take place in the cellular tissue only, and never in the vascular tissue. In the stems of all such trees as are grafted by orchardists, the cellular tissue is found alive only in the medullary rays and the liber; it is therefore essential, in the first place, that those parts, both in the stock and the scion, should be placed in contact. In regard to the medullary rays, these are so numerous and so closely placed, that it is scarcely possible that a portion of one stem should be applied to another without the medullary rays of both touching each other at many points. No care, therefore, is required to ensure this, which may be safely left to chance. But in regard to the liber, as this is confined to a narrow strip in both stock and scion, great care must be taken that they are both placed as exactly in contact with each other as possible, so that the line of separation of the wood and bark should, in both stock and scion, be accurately adjusted. The success of grafting depends rery much upon attention to this. But there are other reasons why this accuracy in adjusting the line between the bark and wood of the stock and scion is so important. It is at that part that the roots of the latter pass downwards orer the former; and it is also there that the substance called cambium. which serves as food for the young descending fibres, is secreted. It is obvious, that the nore accurate the adjustment of the line separating the wood from the bark, the more ready will be the transmission of young fibres from the one to the other; and that the less the accuracy that may be observed in this respect, the greater the difficulty of such transmission will be. Provided the stock and scion be of exactly the same size, the adjustment can scarcely fail to be accurate in the most unskilful hands; it is in the more common case of the scion being much smaller than the stock, that this is to be most particularly attended to.

"Budding differs from grafting in this, that a portion of a stem is not made to strike root on another stem, but that, on the contrary, a bud deprived of all trace of the woody part of a stem is introduced beneath the bark of the stock, and there induced to strike root. In this operation no care is requisite in securing the exact contact of similar parts, and a free channel for the transmission of the roots of the bud between the bark and wood of the stock; for, from the rery nature of the operation of budding, this must of necessity be ensured. The bark of the bud readily coheres with the wood of the stock, and secures the bud itself against all accident or injury. But if precautions of the same nature as in grafting are not requisite in budding, others are of no less moment. It is indispensable that the bud which is employed should be fully formed, or what gardeners call ripe; if it is imperfectly formed, or unripe, it may not be capable of that subsequent elongation upwards and downwards upon which the whole success of the practice depends. Secondly, great care should be taken, in raising the bark of the stock for the insertion of the bud, that the cambium be not disturbed or injured. The cambium is a secretion between the wood and bark, not only destined to support the descending fibres of the buds, but also to generate the new cellular substance within which the descending fibres are finally found imbedded. If, in the preparation of the bark for receiving the bud, this cambium be injured or disturbed, it becomes much less capable of effecting the cohesion that is necessary, than if uninjured. In budding, therefore, the bark should be carefully lifted up, and not forced from the wood with a bone or metal blade, as is usually the case; for although it is no doubt true, that an operation clumsily performed will often succeed, yet it should be remembered, that if skilfully managed, it would be attended with much more perfect success; and that a habit of constantly operating with delicacy will enable a gardener to succeed with certainty in cases in which a bungling practitioner would be sure to fail. Little do those who crush with rude hands the tender limbs of plants, reflect how delicate is that organization upon which the life of their victim is dependent.

"Transplanting is, perhaps, that operation in which the greatest difficulty is generally found to exist, and in which the causes of success or failure are often the least understood. Volumes have been written upon the subject, and the whole range of vegetable physiology has been called in aid of the explanation of the theory; yet I am much mistaken if it cannot be proved to depend exclusively upon the two following circumstances: 1 . The preservation of the spongioles of the roots; and, 2 . The prevention of excessive evaporation.

"It is well known that plants feed upon fluid contained in the soil, and that their roots are the mouths through which the food is conveyed into their body. 
But the absorption of fluid does not take place either by all the surface of their roots, nor even of their fibres, but only by the extremities of the latter, consisting of bundles of vessels surrounded by cellular tissue in a very lax spongy state, whence those extremities are called spongioles. That it is only through the spongioles that absorption to any amount takes place, is easily shown by growing a plant in water, and alternately preventing the action of the spongioles, when languor and a cessation of vital action comes on, and preventing the action of the general surface of the roots, leaving the spongioles at liberty, when the vital energies are immediately renewed. These spongioles are exceedingly delicate in their organization, and a very slight degree of violence destroys them. It is scarcely possible to remove the soil from the roots without injuring them in some degree, and if transplantation is effected violently or carelessly, they are in a great measure destroyed. In proportion to the size or age of a tree, is the difficulty of preserving them increased; and hence at the same time the difficulty of transplantation is augmented. If, by any method, the spongioles could be preserved unharmed, there would be no reason whatever why the largest forest tree should not be removed as easily as the young plants in a nursery; but their preservation in such cases is impossible, and therefore the transplantation of trees of great magnitude cannot be effected. It is because of the security of the spongioles from injury when the earth is undisturbed, that plants reared in pots are transplanted with so much more success than if taken immediately from the soil. Hence, also, when earth is frozen into a huge ball around the root of a plant, transplantation is effected with the same kind of certainty. The practice of cutting the roots of large trees the year previous to removing them is attended with success for a similar reason. Wherever the roots are cut through, the new fibres which are emitted, provided a plant is in health, in short tufts, and each terminated by a spongiole, are much more easily taken out of the ground without injury than if they were longer and more scattered among the soil. When destroyed, the spongioles are often speedily replaced, particularly in orchard trees, provided a slight degree of growth continues to be maintained. This is one of the reasons why trees removed in October succeed better than if transplanted at any other time. The growth of a tree at that season is not quite over; and the first impulse of nature, when the tree finds itself in a new situation, is to create new mouths by which to feed when the season for growing again returns.

"Evaporation takes place in plants to an inconceivable degree in certain circumstances. It is known by the experiments of Dr. Hales, that a sunflower plant will lose as much as $1 \mathrm{lb}$. 14oz. by perspiration in twelve hours; and that in general, "in equal surfaces and equal times, a man would perspire $\frac{1}{50}$, the plant $\frac{1}{155}$, or as $50: 15 ; "$ and that taking all things into account, a sunflower perspires 17 times more than a man. The same most accurate observer found that a cabbage perspired in twelve hours $1 \mathrm{lb} .9 \mathrm{oz}$; ; a Paradise Stock in a pot 11oz.; and a Lemon Plant, $8 \mathrm{oz}$. Guettard states that he found Cornus Mascula perspire twice its own weight in a day; and $\mathrm{Mr}$. Knight has remarked a Vine in a hot day losing moisture with such rapidity that a glass placed under one of its leaves was speedily covered with dew, and in half an hour the perspiration was running off the glass. In damp or wet weather this evaporation is least; in hot dry weather it is greatest. This loss has all to be supplied by the moisture introduced into the system by the spongioles; and hence, if the spongioles are destroyed, and evaporation takes place before they can be replaced, a plant must necessarily die. This is the reason why deciduous trees cannot be transplanted when in leaf; it is impossible to remove them without injuring their spongioles, and it is equally impossible to hinder the evaporation by their leaves : but if they are kept in pots, it matters not at what season their removal takes place, because as their spongioles are then uninjured, even excessive evaporation would be made good by their action. It it is well known that certain evergreens, such as Hollies, Laurels, \&c. can be transplanted in almost all months; this arises from their perspiration being being much less copious than in diciduous trees, wherefore the spongioles have less difficulty in supplying the loss occasioned by it; yet even evergreens cannot be removed in the hottest months in the year, because then the action of such spongioles as may be saved in the operation would not be sufficient to supply the waste by evaporation. Plants first begin- 
ning to grow in the spring, with their leaves just turning green, are in a most unfit state to remove; for, when transplanted, their roots will not have time to form a sufficient number of new spongioles to supply the loss to which the rapid perspiration by the leaves at that season will give rise. It is upon this same principle, that if deciduous plants are taken from the ground in the summer, they are put into pots and placed in a hot-bed to recover; not for the sake of the heat, but because the atmosphere of a hot-bed is so charged with humidity that perspiration cannot go on, so that the vital energies of the plant, instead of being wasted by evaporation, are directed to the formation of new mouths by which to feed.

"This is but a brief outline of what the principles are upon which the common operations of the Fruit Garden depend; yet it is hoped that it may not be without its use in calling attention to the rationalia of what may seem extremely simple and well understood practices, but which are undoubtedly neither so perfect, nor generally so skilfully performed, as to be incapable of amendment."

\section{ABBREVIATION \\ OF ADDITIONAL AUTHORITIES QUOTED IN PART II.}

Pursh. Pursh Flora Americæ Septentrionalis.

Knight in Hort. Trans. Knight in Transactions of the London Horticultural Society.

Poit. A Poiteau.

Lang. Langley Pomona.

Lind. Lindley, Guide to the Orchard and Kitchen Garden.

Mass. Hort. Massachusetts Horticultural Society.

Mil. Gard Dic. Miller's Gardener's Dictionary.

May. Pom. Fran. Mayer Pomona Franconica.

Pr. Cat. 26 ed. Wm. Prince and Sons' Catalogue, 26th edition.

Thatcher, Thatcher's American Orchardist.

sickler. Sickler Der Teutsche Obstagartner.

Kraft. Pom. Aust. Kraft Pomona Austriaca.

Bigelow. Bigelow Florula Bostoniensis.

Decand Decandolle.

Loud. Hort. Brit. Loudon's Hortus Britannicus.

Le Berr. Le Berrier Traité des Jardinz.

Law. Lawrence Agriculture and Gardening.

Michaux. Flora Bureali Americana.

Desf. Desfontaines.

Nut. Nuttall Genera of A merican Plants.

Loud. Gard. Mag. Loudon's Gardener's Magazine.

Hort. Gard. Col. Collection of Trees in the Garden of the London Hoticuitural Dooiety.

Pom. Heref. Pomona Herefordiensis: 


\section{POMOLOGICAL MANUAL.}

\section{PEACHES.}

[Continued.]

EARLY NEWINGTON,-Pr. Cat: Mrl. For Coxe.

Smith's early Newington.

Smith's Newington. Lond. Hort. cat.

Early, or Smith's Newington. Mil.

New.York Early Newington. Coxe.

Miller and Forsyth quote the "Pavie blanc" of Duha" mel; which is the Magdalen clingstone of the present work, as a synonyme of this variety; the justice of which application I have not sufficiently tested to enable me to affirm or contradict. This is one of the best early clingstones. The form is round; the size medium; the colour a fine red next the sun, and white on the other side; the flesh is white, with some red next the stone; firm, rich, very juicy and vinous when at perfect maturity, and like other clingstone varieties, it should be allowed to become fully ripe, for otherwise it is impossible to form a just estimate of the fruits of this class.

The tree is productive, and the fruit matures in August. The "New-York Early Newington" of Coxe, is probably synonymous with the kind I have just described. The French Pavie Newington has large flowers : I have not yet seen ripe fruit of it.

OLD NEWINGTON. Pr. CAT. MiL. LoNd. hort. CAT. Lang. For.

Large Newington. Coxe.

This is a large and exceedingly fine clingstone, of a round form ; the skin is whitish on one side, and red on the other; the colcur of the flesh is a yellowish white, except at the stone, where it is deep red. In quality it is melting, juicy, exceed

vOL. II. 
ingly rich, vinous and high flavoured. The tree is very productive, and is extensively planted for supplying the markets with the fruit, which ripens about the tenth of September ; the flowers are of small size.

\section{LARGE EARLY MIGNONNE. Pr. cat.}

$\left.\begin{array}{l}\begin{array}{l}\text { Grosse Mignonne hative, } \\ \text { Mignonne hative, }\end{array}\end{array}\right\}$ of French publications.

This is a variety of the Grosse Mignonne, with fruit of smaller size, and ripening at an earlier period. It has frequently a mamelon at the extremity of the fruit, and it partakes in its good qualities of the character of its class. The flowers are large, and the leaves are attended with globular glands. Its period of maturity is the beginning of August.

\section{MIGNONNE FRIZÉE. Bon. JARD.}

Frizzled Mignonne. Auth.

The principal trait which distinguishes this variety, is found in the formation of its flowers; which are so curled and frizzled, that when the tree is in bloom, it is difficult at a distance to recognize it as a peach tree. The flowers are of the larger class, and the leaves are attended with globular glands. The fruit ripens at the end of August.

\section{DOUbLE FLOWERING. Pr. cat.}

Double blossomed. Lond. Hort. cat.

Rose peach.

Pêcher à fleur semidouble. Duh.

Pêcher à fleurs doubles. Bon Jard.

Nain à fleurs doubles. Bon Jard.

This is a tree of beautiful appearance when in flower, yet it yields but few fruit; the blossoms are large, fifteen to sixteen lines in diameter, composed of fifteen to thirty petals of a lively rose colour, with more or less stamens, according to the multiplicity of the petals, and with from one to four styles. These flowers are produced in such abundance, as to give to the tree the appearance of being clad with roses.

The leaves are dark green, very finely indented, and ter- 
minate in a very acute point; the peaches which succeed are, single, double, treble, or quadruple; the two latter soon fall, but a portion of the two former generally attain to maturity. They are of medium size, rather oblong, twenty-one to twentytwo lines in diameter, and rather more in length; they are seldom of the same form, some have a small mamelon at the extremity, others have none, and nearly all of them are of larger size at the head, than next to the peduncle. The skin is velvety, yellowish green, and sometimes of a partial fawn colour next the sun; the flesh is white, and the juice of a rather pleasant taste.

The stone is an inch in length, and eight lines in breadth, terminating by a very acute point; the fruit ripens in September. This tree is only cultivated for ornament, and there are few others which impart as much beauty to the garden at the early period at which its flowers expand themselves, and these continue their bloom for a much longer period than other peaches. The Bon Jardinier mentions a dwarf variety with double flowers, which I have ascertained only exists in imagination : the one I have described can, however, be readily made dwarf by inoculation on suitable stocks.

Montauban. Pr. cat. Mil. Lang. For. Lond. hort. cat.

This fruit is of rounded form, and medium size, with a suture at one side; it is dark red approaching to purple next the sun, but of a yellowish green on the other side; the flesh is white, with sometimes a tinge of red next to the stone; it is melting, rich, juicy, and of pleasant flavour. The tree is productive, and the fruit, which is a freestone, ripens in the month of August.

Belle BaUsse. Pr. cat. Lond. hort. cat.

Belle Bauce. Bon Jard.

This fruit is in its general character nearly allied to the Grosse Mignonne, and from the high esteem in which that variety is held, this fact is of itself sufficient commendation. Its quality is equally good, its size larger, and it ripens about 
fifteen days later than that variety, its period of maturity being in September. It is also considered by many as excelling it in beauty.

\section{FRENCH WILLOW LEAVED.}

\section{Pêcher à feuilles de Saule. Bon Jard.}

This tree has linear leaves resembling those of the willow; the fruit is round, of medium size, a whitish colour, and ripens in October. It requires a warm exposure, and only succeeds when in such a situation, or in a southern climate.

\section{GOLD AND PURPLE. Pr. CAT,}

Golden purple.

This clingstone variety has small flowers; the fruit is about the size of the Red Rareripe, which it resembles in shape; its flavour is agreeable, though not equal to the Carolina clingstone; it is of the finest gold colour on one side, and the deepest crimson on the other. There is no tree more productive; and when you consider at one view the beauty of the fruit, and the immense quantities which load the branches, the appearance is truly striking. Its period of ripening here is about the 20th of August.

\section{VANDERVEER'S OPTIMUM. Pr. CAT.}

Rapelyea's peach.

This fine clingstone variety is a seedling from the Old Newington, and received its title from respect to Dr. Vanderveer, an intelligent pomologist of this vicinity. It is extensively cultivated by Mr. Rapelyea of this vicinity for supplying the markets. The fruit is of large size, and Dr. V. remarks that one cheek is generally larger than the other. Its colour is a pale whitish yellow with russet spots, with a red cheek next the sun; the flesh is very delicate, sweet, and juicy. The period of maturity is about a week later than that of its parent, which is so well known as one of our greatest favourites; the leaves are quite large, and the tree is of vigorous growth, and very productive. 
PERSIQUE. Pr. cat. Mil. Duh. Jard. Fruite. For.

CoXe. Loxd. HORT. CAT.

Persèque. Gros Persèque. Persèque Callongé. Bon Jard.?

The flowers of this tree are small and pale red; the fruit is of fine size, of rather greater height than breadth, irregularly rounded, being somewhat angular, or attended with swellings, and scattered over with small protuberances; of which one at the base by the side of the peduncle is the most remarkable, and resembles an excrescence. The skin is velvety, much tinged with red next the sun; the flesh is white, but light red next the stone, rather firm before its full maturity, but at that period somewhat melting and replete with juice, which is of a rich and agreeable taste, sometimes accompanied by a slight degree of acidity. The stone is large, considerably flattened, and terminated by a long point. This peach is a very good one, and also one of the latest, not ripening at Paris until the end of October; the tree is exceedingly fruitful, and said to be capable of reproduction from the seed without degenerating. The fruit, before fully ripe, may be transported to some distance, and is suitable to cultivate for the market; it is also one of the best of its season, ripening here about the last of September, or early in October. It is somewhat singular that it should be placed in the New Duhamel under the head of freestone varieties, and in the Bon Jardinier under that of clingstones.

\section{PAVIE DE PAMIERS. Dur. Pr. cat.}

\section{Palmer's clingstone. Persec, or Persego, of Languedoc.}

This tree produces small flowers, of a lively and rather dark red hue; the fruit is large, being often eight inches in circumference ; the skin, which adheres closely to the flesh, is covered with a fine down, tinged with a fine red colour next to the sun; the flesh is white, except around the stone, where it is a very dark red; and although firm, it is nevertheless very melting, with a profusion of sweet juice. This peach becomes mature in the south of France early in August; it 
is widely disseminated in Languedoc, where it is called by the last two synonymes above quoted, and where it has become so naturalized that the inhabitants generally propagate it from the stones; which produce, without inoculation, very excellent and beautiful fruit. This variety was introduced to our country the present year for the first time, by the author of this work, and is already in a course of propagation. In this latitude it will not probably mature its fruit until September.

RED RaRERIPE. Pr. cat. Coxe. Lond. hor'r. cat.

Morris's red Rareripe, of numerous catalogues. Monsieur Jean, of Coxe?

This variety is supposed to have been brought to Flushing by the French, at the first settlement of the place. It is one of the finest early peaches, and succeeds the Nutmeg varieties, its period of ripening being about the tenth to the fifteenth of August. It is of large size, and round form; its colour is bright red next the sun, whitish and partially marbled on the other parts, presenting when ripe a beautiful appearance; the flesh is very sweet, delicate, rich, melting, and exceedingly juicy, and separates with much facility from the stone. It is the first peach which is met with in abundance in our markets, as the persons engaged in raising fruit for that object, seem to have almost totally neglected the Nutmegs, and the fine Early Yellow Rareripe, although they would doubtless derive great advantage from their culture. It seems probable that the Monsieur Jean may be synonymous with the one here described.

YELLOW RARERIPE. Pr. cat. Lond. hort. cat. Alberge, or Yellow Rareripe. Maria Antoinette.

This is an early variety, being one of those that follow next after the Nutmegs. It is of a rather oval form; the skin is for the most part of a fine yellow colour, but has a red cheek, and is also somewhat mottled on the sunny side; the flesh is yellow, melting, sweet, juicy, and very luscious, and parts freely from the stone. This may be justly considered one of the finest and most valuable peaches, and has a great affinity 
to the Yellow Melocoton, but is considerably earlier. I discovered the original seedling tree, when a schoolboy, growing in a field about two miles from the village of Flushing. And what is somewhat singular, the exceedingly valuable seedling apple which I have named the Sinequanon, I found growing in the same enclosure. This peach has been renamed in some gardens the Maria Antoinette; and I have noticed that in one catalogue, this name has caused further error, it having been there noted as a French variety. The tree bears abundantly.

\section{GREEN WINTER, Pr. cat.}

This is a round clingstone of small size, suitable for preserves; the flowers are of large size. In the month of October it is at maturity; the skin is perfectly green, and the fruit generally fair, and one and a quarter to one and a half inches in diameter; the flesh is very firm, and adheres closely to the stone. It is not valuable as a table fruit, but makes beautiful preserves,-which retain their green colour perfectly. It is usually the latest fruit of the peach kind to be met with in the markets.

\section{ORANGE CLINGSTONE. Pr. cat.}

This is a perfectly round fruit, whose skin is of a beautiful orange colour. The flesh is of the same colour, and of a pleasant aromatic flavour; the flowers are of large size. The tree is productive, the fruit bears transportation well, and ripens in the month of August.

\section{VAN ZAND'T'S SUPERB. Pr. cat.}

\section{Waxen Rareripe.}

This is a delicious freestone, which originated in the garden of Benson Van Zandt, Esq. of Flushing. The form inclines to an oval; the flesh is melting, juicy, and of fine flavour; but its greatest peculiarity is in the colour of its skin, which is considerably mottled, and of a most beautiful waxen appearance. In point of beauty in this respect, there is perhaps no peach that surpasses it. Two seedling trees growing near each other in the same garden, produce identically the same fruit. The flowers are of small size. 


\section{PRINCE'S RED RARERIPE. Pr. CAT.}

This is a seedling from the common Red Rareripe, rather larger than it in size; and resembling it in colour; the flesh is melting, rich, and juicy. The tree is very productive; the fruit is a freestone, ripens in August, and is well calculated for supplying the markets.

\section{ALGIERS' YELLOW. Pr. CAT.}

Algiers' yellow winter clingstone. Yellow October clingstone.

I first obtained the present variety in 1801 , from an amateur in Philadelphia. This peach, even at the end of September, is greenish, and of very indifferent appearance; but in the course of the month of October it swells and becomes a handsome round fruit, of medium size, and of a beautiful yellow colour. I have often found them in this state so late in the season that nearly all the leaves had fallen, and the remaining ones were so yellow as to resemble the fruit in colour. It is not a superior fruit, but of good quality and pleasant flavour for one that ripens at so late a period; the flesh strongly adheres to the stone. The tree is not a good bearer, and the flowers are of a large size. This variety was also imported from England, many years since, under a different and erroneous title. I do not perceive any peach so named in the Catalogue of the London Horticultural Society. It appears to be allied to the class called Alberge by the French.

Teindoux. Pr. cat. Duh. Lond. hort. cat.

\section{Teint Doux. | I Tein Dou. For.}

The leaves of this tree are attended at their base with rounded glands, and its flowers, which are of medium size, are eleven or twelve lines in breadth. The fruit is twenty-six lines in diameter, and twenty-four in height, and divided into two sections, somewhat unequal, by a suture which is nearly of the same extent upon both sides; there are commonly at the extremity two small cavities, in the middle of which rises a small elevation in the form of a mamelon. The skin is slightly coloured next to the sun, and detaches readily from 
the flesh, which is white and melting, with highly pleasant sweet juice. The stone is oblong, seventeen lines in length, and rather less than twelve in breadth; it appears more flattened at its smallest diameter than is generally the case with others, being only eight lines in thickness at its largest section. The fruit is at maturity the end of September.

\section{DIANA. Pr. cat. Coxe.}

This is a freestone fruit of medium size, and excellent flavour; the flesh melting and juicy. Its colour is whitish, approaching to straw colour at its maturity, which takes place in August. The flowers are of the medium size.

KENNEDY'S CAROLINA. Pr. cat. LoNd. hort. cat.

Large yellow Pine-apple. Coxe.

Kennedy's Carolina Clingstone.

Early Lemon. Yellow Pine-apple.

This is unquestionably one of the finest clingstone varieties known, both as regards size and quality. It belongs to the largest class of peaches; is of an oval or oblong shape, pointed at the extremity, and terminating in a mamelon; the skin is deep yellow, except next the sun, where it has a dark crimson cheek; the flesh is of a fine yellow colour, rich, sprightly, and high-flavoured, with a degree of acidity; it closely adheres to the stone, and immediately around it is tinged with deep red. The tree is one of the most productive, yielding large and regular crops, so much so as to be often overloaded, in which case it is preferable to thin out the fruit, and to leave only a reasonable proportion. It ripens about the middle of September. This variety was brought from South Carolina, before the revolution, by a Mr. Kennedy, of New-York, who, on account of its excellence, sent a message to the grandfather of the author, knowing him to be very curious in fruits, and requested him to call and obtain scions from it.

SPRING GROVE: Pon. MAG. LOND. HORT. cat.

The description of this new variety $\mathbf{I}$ quote from the Pomological Magazine. It was raised by Mr. Knight, from Neil's

VOL. II. 
Early Purple and the pollen of the Red Nutmeg, the former having crenated leaves, with globose glands and large flowers; and the latter having crenated leaves with reniform glands and large flowers; in these respects this agrees with its female parent. It ripens about the end of August, and differs from the Grosse Mignonne, and Neil's Early Purple, in being much rounder than they are. A very good variety; its fruit not quite so large as that of some others, but remarkably handsome and well flavoured; flowers pale blush, the centre purplish red; fruit middle-sized, globular, broadest at the base, with a shallow suture; bright crimson on the sunny side, greenish yellow on the other; flesh whitish to the stone, from which it parts freely, very juicy, rich, and high-flavoured.

\section{DWARF ORLEANS. Pr. CAT.}

\section{Dwarf Peach. Pot Peach.}

Pecher nain. Duh. Lond. Hort. cat. Nain d'Orleans.

This tree attains only to two or three feet in height; its flowers are of a delicate rose-colour, and fourteen to fifteen lines in diameter; they are formed in rows around the branches, and so closely set, that when expanded, they cover the limbs, more than forty flowers being sometimes counted upon a small branch of three inches long. The leaves are longer than those of any other variety, pendent, and much indented, especially towards their base, where the teeth are of the greatest depth. The fruit is of medium size, and disproportionate to the size of the tree, being nearly two inches in length, and as much in diameter; it is divided on its side by a rather deep suture, which is terminated at the extremity by a remarkable cavity. The skin is usually of a greenish hue, never coloured, unless at the head, which is slightly tinged with red. "The flesh is melting, but the juice is most generally bitter and of a disagreeable flavour; the stone is whitish. This fruit ripens in October; it is only cultivated as a curiosity, being very suitable to plant in pots, and made use of in that manner as 
an ornament to the dessert. The tree is more tender than other varieties, and in northern climates requires to be covered with a box, or to have some other slight protection.

\section{WHITE BLOSSOM. PR, CAT.}

\section{Willow peach. White stone.}

White-blossomed Incomparable. Lond. Hort. Cat.

The bark of this tree, when the leaves have fallen, is of a pale straw colour, which gives to it a very peculiar appearance ; the flowers are perfectly white, of large size, and quite showy, so that it is altogether dissimilar to others at the period of its bloom likewise. The fruit is perfectly white, of an oval form, and handsome appearance; the flesh is also white, melting, juicy, and pleasant, and parts freely from the stone. It is much used for preserves when not over ripe, and is at full maturity in September. This variety originated on Long Island, and re-produces from the stone trees similar in the appearance of the wood, but varying in the quality of the fruit and the size of the blossoms. The Snow-peach is a variety with smaller flowers. I have put down as a synonyme the White-blossomed Incomparable of the London Horticultural Society's Catalogue, and it may be the same; as trees were sent to England, more than fifty years ago, from the nursery at Flushing, and possibly they may have possessed the same variety in England anterior to its production here. The original tree of this variety was discovered in a hedge in King's county, from which scions were obtained by the grandfather of the author, who sent a great many of the trees to Europe before the revolution.

\section{COI.UMBIA. Pr. CAT. CoXe.}

The form of this fruit is somewhat flat or compressed, its diameter being greater than its height; it has also a suture running from the stem to the extremity; the skin is thick and rough, of a dingy red hue, spotted over with dark reddish touches; the flesh is of a bright yellow colour, melting, rich, and juicy, the grain or fibre bearing a similarity to that of an 
over-ripe Pine-apple. It is a freestone variety of great excellence, and ripens about the first of September. Mr. Coxe remarks that this peculiar peach was produced from a stone brought to New-Jersey from Georgia, and that he gave it the name by which it is distinguished.

\section{ROYAL GEORgE CLINGSTONE. Coxe. Pr. cat.}

This tree produces small flowers; the fruit is very handsome, of a pale yellowish white colour, tinged with red on the sunny side; it is of large size and oblong form, terminating with a mamelon at the extremity; the flesh is juicy, and of excellent flavour. The frui $i$ is at maturity in August.

YELLOW PRESERVING. Pr. cat. Coxe.

This tree has large flowers; the fruit is a small freestone, of a greenish yellow hue; the flesh wholly of a yellowish colour, even around the stone, dry, and with but little flavour. Its period of maturity is in September.

HILL'S MADEIRA. Pr. Cat. Coxe.

This is described by Mr. Coxe as a very large peach; but the fruit from which he drew his description was probably produced under circumstances peculiarly favourable, and I am informed by Mr. C. R. Smith that its size varies exceedingly, and in proportion to the advantages of situation. I have not succeeded in having large fruit on my trees; but it may be that their location was not sufficiently favourable. This fruit is white, with a faint tinge of red next the sun; the flesh is tender, melting, juicy, and high flavoured; it ripens in September. Mr. Coxe remarks that the tree was raised by the late Henry Hill, Esq. of Philadelphia, from a stone brought from Madeira, and that the fruit has weighed twelve ounces.

\section{PÊCHE DE PAU. Duh. Pr. cat.}

Pèche de peau, ou d'Italie.

The flowers of this variety are small, the fruit large, round, and terminating by a very projecting and curved mamelon. The flesh is white, slightly approaching a greenish hue, and 
becomes melting when the fruit is at perfect maturity, with high-flavoured and pleasant juice. Duhamel states that it is very late in ripening, and consequently in the more northern latitudes it does not come to perfection except in seasons when the end of summer and the autumn are dry and very warm. I obtained this variety only the present year, after having made repeated efforts, it being very rarely to be met with even in France. From the description given by Duhamel, it would appear to be best suited to the States south of the Potomac; but it is quite probable it may succeed in this vicinity, as our summers have so much heat.

LISLE. Pr. cat. Mil. For.

\section{La petite Violette hative. Mil.??}

This fruit is of rounded form and medium size; the skin is of a fine violet colour next the sun; the flesh is melting, and full of vinous juice; of a pale yellow colour, except around the stone, where it is very red. It is a clingstone, and ripens early in September. I have not seen this fruit myself, and rely upon Miller and Forsyth for the above description. Miller quotes the "Petite Violette Hative" of Duhamel, which is a Nectarine, as a synonyme of this ; Forsyth copies the description given by Miller, but omits the synonyme. I do not find this variety in the London Horticultural Society's Catalogue, which would seem to throw some doubt on the subject.

\section{Rambouillet. Pr. cat. Mil. Lang. For. LOND. HORT. CAT}

\section{Rumbullion. Cannon's Rambouillet.}

This fruit is of rather large size and oval form, with a deep suture; it is of a fine red next the sun, and yellowish on the shaded side; the flesh is a bright yellow, deep red next the stone, melting, with rich and vinous juice. It ripens in September.

POR'TUGal. Pr. cat. Mrl. For. Loid. hórt. cat.

This is a very large round clingstone, of a beautiful red colour on the sunny side, and often marbled; the flesh is firm, 
rich, juicy, and vinous, and its colour white, but of a pale red next to the stone, which is of small size. It is at maturity in September.

\section{YELLOW ALBERGE CLINGSTONE. Pr. cat.}

Yellow Alberge. For. Pavie Alberge. Duh.

Persais d'Angoumois. Duh. syn.

Pavie jaune. Lond. Hort, cat.

Persécque jaune. Yellow Persique.

The leaves of this tree are attended with reniform glands; the flowers are small, being not more than seven or eight lines in breadth; the fruit is of fine size and beautiful form, often measuring two to two and a half inches in its greatest diameter, by one or two lines less in height; it is furrowed on one side by a rather deep suture, one border of which is more projecting than the other; and it is terminated at the head by a very conspicuous mamelon. The skin is velvety, yellow where shaded, and speckled with a considerable number of small reddish points, which become more numerous as they approach the sunny side, where they are so close to each other that they give it entirely a reddish hue; the flesh is firm, rather dry, and almost breaking; its colour is yellow, except around the stone, to which it strongly adheres, and where it is a rather dark red. In the first edition of Duhamel it is mentioned that it becomes very melting, but this is not the case in the vicinity of Paris, where, however, it is as yet very seldom to be met with, as the authors of the New Duhamel make mention. The period at which this peach ripens is towards the end of September. It is deemed an excellent fruit, and greatly cultivated in Angoumois, whence the author of this work received it about four years since.

\section{LATE YELLOW ALBERGE. PR. CAT.}

Alberge jaune tardive, of French catalogues.

This is a late clingstone variety, and one of those which $\mathbf{I}$ have recently introduced from the south of France. It does not attain to maturity until the end of September or the beginning of October: its appearance is fair, the form somewhat 
oval, and its colour a pale yellow. A tree of this variety produced fruit with me the last season for the first time. It is much esteemed in the country where it originated, and will no doubt be equally so here; - but the opportunities of testing it have as yet been too limited to allow me to speak decidedly of its qualities from personal investigation.

\section{OLDMIXON FREESTONE. Pr. CAT.}

\section{oldmixon clearstone. Coxe.}

This tree produces small flowers; the fruit is of large size, and the form flat or compressed. The colour of the skin is white where shaded, with a red cheek on the sunny side; and it is deemed quite a beautiful fruit. The flesh is tender, rich, juicy, and luscious. Its period of ripening is August.

\section{OLDMIXON CLINGSTONE. Pr. Cat. Coxe.}

\section{Catharine? Auth.}

This is said to be an imported variety, brought to this country by Sir John Oldmixon, to which the title here adopted was applied, for the purpose of distinction, in the absence of a knowledge of its true name, a point which I trust I shall be enabled ere long to solve. It is a very fine fruit, and is raised in great quantities for the supply of the markets; it is round, of large size, and has a beautiful red cheek next the sun; the flowers are of small size. It bears carriage well, and ripens the first week in September.

\section{FAVOURITE RED. Pr. cat.}

Favourite. Coxe.

This tree has small flowers; the fruit, on the contrary, is of large size, the form oblong, and the flesh tender and rich. The skin is red and white, and the fruit of beautiful appearance. It is a freestone variety, and at maturity early in August.

GREEN NUTMEG. Pr. CAT.

Early Anne. Coxe. Lond. Hort. cat. Anue. Mil. For.

This variety is said to have originated in Berkshire, (England,) and $\mathbf{I}$ do not find it described by Duhamel or any other 
French writer. The foliage of the tree has a particular flourishing appearance. The flowers are pale red; the fruit is of a round form, with a partial suture at one side, and from one and a quarter to one and a half inches in diameter; its colour is yellowish green, with a touch of red nexi the sun on a part of those most exposed to its rays; the flesh is a yellowish white, melting, juicy, and of very pleasant flavour. The tree is a good bearer, and the fruit ripens during the first days of August. It is much esteemed for preserves, and when not fully ripe the fruit is well adapted for that purpose, and resembles green limes. Murray's Early Anne is a variety raised from the seed of this.

\section{SWEE'T-WATER Pr. cat. LOND. hoRT, cat.}

Early Sweet-uater. Lond. Hort. Cat.

This tree has large flowers, the foliage and growth much resemble the preceding one, of which it is a seminal variety, and originated in this village about twenty years since. The size is double that of its parent, measuring from two to two and a quarter inches" in diameter, and sometimes still more. Its form is round, and its colour whitish green at maturity, which takes place at the same time as the Green Nutmeg, or four or five days later. The flesh is very tender, melting, rich, and juicy; and when all the properties of this variety are considered, it may be justly deemed the finest of all the Nutmegs, and it is the earliest peach we have whose size is above mediocrity. It is a freestone like all the other Nutmeg varieties.

BROWN NUTMEG. Pr. cat. - and of the English CA'TALOGUES.

$\left.\begin{array}{l}\text { Red Nutmeg, } \\ \text { Scarlet Nutmeg, }\end{array}\right\}$ of many American collections.

Early purple Avant. For.

Forsyth places the "Avant peche jaune" of Duhamel as as a synonyme of the present variety, but very erroneously so, as they are widely distinct. This is much the smallest of the two, and does not exceed an inch in its greatest diameter, 
and one inch and a quarter in length; the form inclines to oval, and it has generally a mamelon at the extremity; the skin is downy, yellowish on one side, and a dingy red on the other; the flesh is of pleasant flavour, but from the small size of the fruit, its principal value is derived from its ripening so very early, it being one of the first at maturity, which takes place in July. This tree is readily known by its foliage, even from the other varieties of the Nutmeg; and nearly the whole of this class of peaches may be distinguished by the peculiarity of their growth. There is a variety called the Blush Nutmeg, which is considerably larger than the one just described, and approaches the Green Nutmeg in point of size; its colour is a pale red on one side, and greenish on the other. This is by some erroneously called the Red Nutmeg, few persons having the genuine kind.

\section{LARGE EARLY RARERIPE. Pr. cAT.}

New.York Rareripe. Coxe.

Royal Kensington. For. Lond. Hort. Cat.

Large Early. Lond. Hort. Cat.

York Rareripe. Large early York.

This choice and beautiful variety was raised by the grandfather of the author, from the stone of the Red Rareripe, and was transmitted by the present William Prince, a few years after our revolution, to Mr. William Forsyth, author of the Treatise on Fruit trees, who had then the direction of the Royal Gardens at Kensington, near London, and it probably received the title of Royal Kensington from him. The flowers are of small size; the fruit of a round form, and the skin of a rather darker red on the sunny side than its parent; the flesh is also rather more firm, equally rich, juicy, and of a luscious flavour; it parts freely from the stone. The tree is very productive, and is extensively planted for supplying the markets with fruit; its size, fine appearance, and other qualities, causing it to be much sought after. It ripens about the middle of August.

VOL. II. 


\section{WHITE RARERIPE. PR。 CAT.}

\section{Morris' white. Morris' white Rareripe.}

This variety originated in the nursery of the grandfather of the author. The fruit is of fair size, measuring rather more than two inches in each direction; the form varies in some degree, a part of the fruit being oval, while another portion inclines to a round shape; the skin is a pale yellow, in some cases without any redness upon it, but it frequently has a dash of red on the sunny side, or is partially striped or mottled with red over a small part of its surface, where most exposed to the sun; the flesh is a pale, greenish yellow, rich, juicy, and of excellent flavour, and separates freely from the stone. The tree is vigorous, and bears abundantly, and the fruit ripens at the end of August.

\section{JaCQUES' RaReriPe. Pr. cat. Thatcher.}

FES. AMER. GARD.

\section{Jacques' yellow Rareripe.}

This peach, which I received from the vicinity of Boston, is said to have originated there. The flowers are of a medium size; the fruit is of good size, of a yellow colour with a red cheek, and of an excellent quality. Some specimens of this fruit have been produced weighing from seventeen to nineteen ounces, but the tree was in an exceedingly rich soil and highly favorable situation, this being far beyond the usual size. It ripens from the beginning to the middle of September.

\section{SARGENT'S RARERIPE. Pr. Cat.}

\section{Pearl-street.}

This variety originated in the garden of Daniel Sargent, Esq. Pearl-street, Boston, and from these circumstances has derived its titles. The flowers are of large size, and the fruit of a yellow colour, good size, and excellent flavour. The tree is very productive, but somewhat subject to the mildew upon the extremities of the young shoots. The fruit ripens about the middle of September. 


\section{HYSLOP'S CLINGSTONE. Pr. cat.}

This variety was so called, in consequence of its being cultivated by David Hyslop, Esq. of Brookline, near Boston, who disseminated scions of it more than twenty years ago. I am not apprised whether it originated with him, or if it may not have been previously cultivated by others under a different title. The fruit is of a large size, and its form rather round, but inclining to oval; the skin is white, coloured with deep pink or crimson on the sunny side; the flesh very juicy, and of a superior vinous flavour. A very intelligent Boston correspondent remarks to me, that this peach is for the climate of New-England what the Heath clingstone is to Virginia, and that it is there esteemed the best of all very late peaches. It ripens in October, but may be preserved until in November.

\section{EARLY RED CLINGSTONE. Pr. CAT. LONd. HoRT. CAT.}

This fruit has been cultivated in the Flushing nurseries for sixty years or more; its origin is not known, but it may have been brought from France by the French protestants who settled there at the time of the revocation of the edict of Nantz, they having brought the Pomme d'Api, Summer Bon Chretien, and other fine fruits, at that period. It is an excellent peach, and ripens as early as the Red Rareripe. The flowers are of small size, and the ends of the young shoots are subject to blanch or mildew.

\section{CONGRESS. PR. CAT. LOND. HORT. CAT.}

This tree produces flowers of medium size; the fruit is large, and of an oval form; the skin is of a greenish colour on one side, and red on the other; the quality is tolerably good, and it is at maturity in the month of August. This tree was first cultivated by Alfred Livingston, Esq. who established an extensive nursery at West-Chester, in this State, and from whom it probably received its name. 
ROYal. Pr. cat. Pum, mag. Mit. For.

La Royale. Duh. Nois. man.

Bourdine. Duh. Nois. man. Lond. Hort. Cat.

Teton de Venus. 3 Hitt. Jard. fruit. Nois. man.

Late Admirable. Lond. Hort. Cat., No. 3.

The following description is taken from the Pomological Magazine published at London:

"This magnificent peach ripens in September, and is by far the most valuable of our late varieties. These, in an English autumn, are too often remarkable for nothing but their want of colour and flavour; but the Royal yields to no summer peach in the richness of its juice, the delicacy of its flesh, or the beauty of its colour. Every writer agrees upon this point, and we scarcely remember an autumn which was too unfavourable for bringing it to perfection. There is no doubt whatever of the identity, of the Royal, the Bourdine, the Téton de Venus, and the Late Admirable" [of the English collections; the French Late Admirable being different.-AUTH.] "The Royal and Late Admirable are admitted to be the same. Butret, a writer of the highest authority in all that relates to the peach, declares that the Téton de Venus, the Royal, and the Bourdine, are absolutely the same. Even M. Noisette, in his Manual Complet, although he retains the Téton de Venus and Bourdine as distinct, remarks that the Bourdine is nothing but the other in perfection. And finally, the observations of Mr. Thompson, in the garden of the Horticultural Society, go completly to prove the identity of the whole. Leaves crenated, with globose glands; flowers small, pale red; fruit large, roundish, inclining to oblong; suture deeply impressed along one side, having the flesh swelling boldly and equally on both sides, with a slight impression on the summit, where there is usually a small nipple-but in this respect the fruit varies; skin covered with a short, close down, streaked with dull tawny red next the sun, pale green or strawcoloured in the shade; cavity of the stalk rather small; flesh delicate, white, melting, juicy, and high-flavoured, with a 
slight tinge of rose next the stone, from which it parts freely; stone above the middle size, oval, constantly with a long sharp point."

\section{MONSTROUS LEMON. Pr. cat.}

Largest Lemon. Lond. Hort. Cat.

This tree is of vigorous growth, and produces small flowers; the fruit is of the largest size, and in the gardens of two persons at New-York has weighed seventeen ounces; the flowers are but thinly scattered over the branches, and the tree does not bear well, unless the situation is a sheltered one; the fruit is late in ripening, and in this latitude seems to require the warmth of a city, or a favorable sheltered situation, to perfect its maturity. This variety was first discovered in the garden of Mr. Tiebout, of York Island, and was sent, some years since, to the London Horticultural Society, with several hundred other varieties of fruits, at their express desire.

\section{HEATH. Pr. ca't. Coxe. Lond. hort. cat.}

Heath clingstone. Lond. Hort. Cat.

The flower of this tree is of small size, and the leaf has smooth edges; the fruit is very large, of oval or oblong form, terminated by a mamelon at the extremity; the skin is white with a partial tinge of cream colour when the fruit acquires its maturity, and those most exposed to the sun have a slight touch of pale red next the sun; the flesh is peculiarly rich and highly flavored, very tender, melting, and abounding. with a greater profusion of juice than almost any other peach ; it strongly adheres to the stone which often divides, so as to expose the kernel. The tree is hardy and of vigorous growth, and so abundant in bearing, that it is often necessary to thin out the fruit on young trees, to prevent their being exhausted thereby, and their growth consequently impeded or stinted. It requires the ground around it to be kept cultivated or mellow, which will cause the fruit to be large and fair, and it is found to be in general longer-lived than other trees of its class. The fruit begins to ripen in September, but by being carefully placed on 
shelves in the fruit-room, it may be preserved till November, and the juice acquires an additional richness after being thus preserved for some days, but if kept too long in that state, it shrivels and loses a portion of its juice and fine flavour. It is in great repute for preserves in sugar and brandy, and there can scarcely exist another peach superior to it for these purposes.

The following history of its origin from the pen of William Prince, the present senior proprietor of the Flushing Nurseries, differs from that of Mr. Coxe: it is possible that two seedling varieties originating in different places may have produced fruit so similar as to blend them with each other.

"The original tree was discovered growing wild on the farm of the late Judge Willet, of Flushing, and it was called Heath clingstone, from the circumstance of its being found in a barren field or heath, as the old English settlers sometimes termed such lands as were left uncultivated. My father cultivated it many years before the revolution. It has the peculiar property of perpetuating itself from seed with but a partial variation in most cases, from the original; the fruit of some of the seedling trees being rather more firm, and that of others varying a little in the period of maturity, but the whole having a general affinity."

KENRICK'S HEATH. Pr. CAT.

This freestone variety I received from the Messrs. Kenrick, who obtained it from the late Gen. Heath, of Roxbury, near Boston. The flowers are of medium size; the fruit is oblong, with a deep cavity at the insertion, and a slight mamelon at the extremity; it has also a groove, or suture, extending almost from the base to the summit, which is sometimes very deep, but in general only slightly depressed; the skin is a greenish yellow, touched with reddish purple on the sunny side, and sometimes of a purplish hue around the insertion; the flesh is greenish, extremely juicy, of a pleasant subacid, but not high flavour, and is occasionally somewhat stringy; the stone separates from the flesh and is apt to split. This fruit is one of 
the largest cultivated in New-England, frequently weighing half a pound, and sometimes more, and is strongly marked by peculiarity of appearance; it ripens at Boston about the 20th of September, and in this vicinity a week earlier; the tree is of the most vigorous growth, aud produces good crops.

\section{RED.CHEEK MELOCOTON. Pr. CaT.}

\section{Red-cheek Malacotan. Coxe. Red.cheek Malagaton. Yellow Malagaton. Alberge Incomparable.}

This is one of the most delicious freestone varieties, and the fruit is of a large size and oval form, with a mamelon at the extremity; its colour is yellow, with a red cheek on the sunny side; the flesh is also yellow, exceedingly melting, rich, juicy and luscious, and separates very freely from the stone; the flowers are of small size. It ripens about the 20th of August, and the tree is healthy, vigorous, and very productive.

The following statement of the origin of this fruit, from the pen of the present senior proprietor of the Flushing Nurseries may be deemed interesting.

"This variety originated in my father's garden, the form and colour of the fruit greatly resemble the Kennedy's Carolina clingstone. A tree of the latter having thrown out a shoot from below the inoculation, formed thereby a forked top. My father, in passing one day, gathered some fruit from the inoculated branches, without noticing that the fruit on the other section of the tree was different, the appearance being so similar. The next day he sent a servant to gather some fruit from the same tree, and on eating it found the peaches then brought to be freestones. He immediately told the servant that he could not have gathered them from the right tree, but he declaring that he had done so, my father went to examine it, and found it as above stated; the inoculated part being of the clingstone kind, and the natural branches producing this fine freestone variety. He admired it so much, that he propagated it extensively, and gave it the name, of Red-cheek Malagaton; the common appellation of Malagaton being at that day given around the country, to all the yellow peaches, 
which had no red on them. I notice there are some varieties of peach termed Malacotoon, by Quintinye and Evelyn, and Langley mentions a clingstone peach called Malacotune. The terms Melocoton and Malacoton, are Spanish words, and mean simply a peach, or a peach tree, and from these no doubt all the corruptions have originated which now exist."

\section{SPANISH. Pr. cat.}

\section{Large Spanish.}

This is a clingstone, obtained many years since, from an intelligent cultivator at Baltimore. It is of a large size and the form nearly round: the skin is of a fair whitish colour, with a blush next the sun; the flowers are of small size. The tree is of vigorous growth, and produces good crops; the fruit is of pretty good quality, and ripens at a very late period, not being at maturity till October.

\section{WHITE WINTER. Pr. cat.}

This clingstone variety. was imported from England as a Nectarine. The flowers are of small size, and the fruit of an oval form; the skin and flesh are both white, which colour extends quite to the stone; and it is on that account preferred for brandy preserves, and also for those in sugar. It is deemed a valuable fruit for these purposes, and does not ripen until the month of October. The tree grows vigorously and bears well. There is another late variety, called the Freestone Winter, which is an inferior fruit, of a greenish colour, with a tinge of red on one side; its only value being the lateness of its maturity.

\section{PRINCE'S BLOOD CLINGSTONE. Pr. Cat.}

\section{Blood clingstone. Claret clingstone.}

This very superior variety of its class was raised from seed by the grandfather of the author. The flowers are small; the fruit is oval and of large size, surpassing the French variety; the skin is of a dark purplish colour, and very downy; the flesh is of a crimson or purplish tint, but of indifferent Havour. The peaches of this class, it is well known, are not 
valued for the table, but are much used for preserves, compotes, and pickles, and for size and beauty, there is perhaps none to equal the present one.

FRENCH BLOOD CLINGSTONE. Pr. cat.

Sanguinole adherente. Sanguinole à chère adherente. Claret clingstone.

This variety has large flowers, the fiuit is similar in character to the preceding, but of a less size; it is used for the same purposes, and ripens in September. There is a Blood clingstone, cultivated in the Southern States, called there Georgia, or Indian Peach, but it is probably synonymous with one of the varieties $I$ have described.

\section{SURPRISE. AUTH.}

This title I have given to a most peculiar fruit, first brought to notice by my esteemed friend and correspondent, the Rev. J. Kirkpatrick. The outward appearance is very similar to the Blood peach, the skin being of a dingy red or purplish hue, but the flesh is of a deep yellow colour, with crimson veins running from the skin to the centre. The flavour is very good, often deemed excellent, and it separates from the stone. The fruit is of very large size, and the tree produces abundantly. This variety is beyond all doubt of American origin.

CHEVREUSE CLINGSTONE. Pr. cat.

This variety I received from the Mediterranean. It has not yet borne fruit sufficiently to decide upon its merits; it is of good size, and of an oval form; the skin is of a greenish yellow colour, with a red cheek next the sun. It ripens at the end of September.

\section{PRESIDENT. Pr. cat. Pox. mag. Lond. hotr. cat.}

This fruit, so much cultivated in our gardens, and so well known for its excellence, originated at Bedford, on Long Island, and was sent to the London Horticultural Society, some few years since, and I copy the following remarks rela-

VOL. II. 
tive to it from the Pomological Magazine, a work published under the auspices of that society.

"A good deal of curiosity has been felt in England, with respect to the peaches of North America, of the merits of which much has been reported by travellers from that country. There is no doubt that those kinds, beneath the fierce summer sun of the United States, fully merit the eulogium that has been passed upon them; but it is equally certain, that they are almost uniformly worthless in the climate of Great Britain. There are, however, some exceptions, two of which deserve particularly to be recorded; of these, the George the Fourth is one, and that which is now represented is the other. The President peach is, with us, a rich, melting, juicy fruit, ripening in the end of September, and is, therefore, valuable on account of the late period of its maturity. Of course it requires a south wall, and care must be taken that it is perfectly ripe before being gathered. Flowers small, deep red; leaves crenated, with globose glands; fruit large, roundish, approaching to oval, with a shallow suture; skin very downy, dull red next the sun, pale yellowish green in the shade; flesh whitish, juicy, rich, and high flavoured, parting freely from the stone, which is large, pointed, and very rugged."

\section{FAVIER. Pr. cat.}

This tree produces small blossoms; the fruit is of medium size, so far as opportunities have yet allowed me to judge; the skin on the side next the sun, is quite red, but its colour diminishes towards the shaded side; even there, however, it generally has some touches of red and numerous dots of the same hue; the form is roundish, but in some cases the diameter exceeds its height. On some specimens of the fruit I have noticed a plainly marked suture running through one side, and a partial one on the other side, while other specimens presented scarcely any appearance of a suture, its usual location being merely marked on one side by a variation in the colour of the skin; there is a cavity at the extremity of the fruit but no mamelon; the flesh is a pale yellowish white, with considerable 
redness next the stone; it is melting, juicy, rich,and of excellent flavour, and separates readily from the stone. This is a new variety which $I$ introduced from the Mediterranean, and ripens about the tenth of September.

\section{SERNACH. Pr. cat.}

This tree has large blossoms, and being a new variety which I but recently introduced from the Mediterranean, I have seen only two of the fruit, which were of medium size, and from which I take my description. The form is very peculiar, being oval and very much contracted at the base, and swelling gradually as it approaches the summit, where its size is the largest. In this respect it bears some affinity to the shape of the Blue Imperatrice plum, and is what may be termed pear shaped; the suture extends entirely round the fruit, apparently dividing it into two sections, with a mamelon at the extremity; the skin is a yellowish white, varying next the sun to a fine red colour; the flesh is a pale yellowish white, with some redness next the stone, and is rich, juicy, and pleasant. This fruit is a freestone, and what is singular, both the specimens I examined parted the stone readily as I divided the peach, and each had two kernels. I cannot say whether this was accidental, or if it is the peculiar character of the variety. Its period of ripening is about the tenth of September.

\section{EARLY WHI'TE CLINGSTONE. Pr. CA'T.}

This tree has small flowers; the fruit is of medium size, and rather less in some cases; its skin is pale yellow, marbled with red next the sun; the suture terminates in a depression or cavity at the extremity of the fruit, without any mamelon; the flesh is yellowish green, juicy and of pleasant flavour. It ripens at the beginning of September, and makes good preserves.

ORANGE FREESTONE. Pr. cat.

This variety is of uncertain origin, and received its present title from the father of the author, on account of its shape. It 
is almost round, its diameter, however, rather exceeds its length, and at the extremity it has a small mamelon. It justly ranks as one of the largest and finest freestones; the skin is yellowish white, but where exposed to the sun, it acquires a tinge of red on one side; it separates very readily from the fiesh, when at full maturity; which is rich, juicy, sweet, and of high flavour, and in these points is perhaps surpassed by no other variety. The tree is of vigorous growth, and quite productive; the blossoms are of medium size, and the fruit ripens about the tenth of September.

\section{MONSTROUS FREESTONE. Pr. CAT.}

\section{English Malta. Noblesse.}

The fruit of this variety bears a striking similarity both in form, colour, and quality, to the preceding; but the growth of the tree is different, the young branches are stronger and the buds larger. I have noticed that the leaves are generally attended with three glands. I imported this tree from London by the name of Malta, but found the title to be incorrect. It has been by some called the Noblesse, but the leaves of that variety are devoid of glands, not to enumerate other differences. The tree grows vigorously, and bears well. In the absence of all knowledge of the true title, I have applied the one here adopted.

\section{PERSIQUE Clingstone. Pr. cat.}

\section{Perseque. Pr. Hort.}

This tree produces small flowers; the fruit is of large size, of oval form and beautiful appearance when at perfection; the skin is of a fine red colour next the sun, and of a paler hue on the other side; the flesh is juicy, and of very pleasant flavour. The tree is exceedingly productive, and like the Heath clingstone, is apt to be overloaded. I think this one of the most valuable varieties that can be cultivated for supplying the markets late in the season, the fruit not being ripe until the end of September or beginning of October: its large size and fine colour render it particularly attractive. 


\section{NECTARINES.}

\section{Early ViOlet. Pr. cat. Knight in Hort. Trass.}

Violet. Pom. Mag. Hitt's Treatise.

Petite Violette hative. Duh. Jard. fruit.

Brugnon petite violette hative.

Violette hative. $\left\{\begin{array}{l}\text { Bon. Jard. Nois. man. Lind. in Lond. } \\ \text { Hort. Trans. Lond. Hort. cat. and } \\ \text { of the English nurseries. }\end{array}\right.$

Lord Selsey's Elruge. Lond. Hort. cat.

Large scarlet, of some collections?

I Cannot adopt the same title as the Pomological Magaine, as it is so extremely indefinite. The synonymes quoted above I doubt not are all correctly applied, with the exception of the one last named, which I quote from the Pomological Magazine. The trees in my collection received under the title of "Large Scarlet," from one of the most accurate nurseries in London, produce very deep red flowers, and differ very materially from the present variety, which I will now proceed to describe.

The flowers are small, and the leaves are attended with reniform glands at their base; the fruit is seventeen to eighteen lines in diameter, and often a line more in height, and is commonly terminated by a small mamelon. The skin is smooth, dark red approaching to violet on the sunny side, and light green, varying to whiteness on the shaded side; the skin separates readily from the flesh, which is whitish, slightly coloured with red next the stone, melting, replete with sweet, vinous, and highly perfumed juice. The stone, which pretty easily detaches from the flesh, is a very light brownish red. The period of maturity is the beginning of September, and in order to taste the fruit in perfection, it should not be gathered until perfectly ripe; the tree is generally very productive, 
yielding, even when quite small, an abundance of fruit. I extract the following description of this fruit from the Pomological Magazine.

"This excellent nectarine is commonly cultivated under its French name; we do not, however, approve of using a foreign nomenclature when we have an old established name of our own. It is not unfrequently sold for the Red Roman, a very different fruit. Ripens from the end of August to the middle of September, and deserves cultivation on account of its excellent flavour and great beauty.

"A large Elruge Nectarine, described by Mr.John Bowers, in the fifth volume of the Horticultural Society's Transactions, page 523, as growing in a fruiting house in Lord Selsey's garden at West Dean, in Sussex, has been subsequently ascertained to be this variety. Leaves crenated with reniform glands. Flowers small, bright red. Fruit rather larger than that of other nectarines, and somewhat broader at the base than at the apex; cavity of the foot-stalk middle sized; the point which makes the base of the style seldom projects, but is generally in a shallow cleft, which runs across the apex; skin where exposed, dark purplish red, intermixed or mottled with pale brown dots; next the wall pale yellowish green. Flesh whitish, or very pale yellowish green, edged with red at the stone, from which it parts freely; melting, juicy, and rich. Stone middle sized, roundish, obovate, its fissures not so deep nor so sharp as those of the Elruge, their ridges flattish but rough, and of a red colour, by which it may always be distinguished from the fruit just named, the stone of which is pale, with no rays of red passing from it into the flesh."

\section{LARGE EARLY VIOLET. Pr. cat.}

Grosse violette hative. Duh. I Violette de Courson. Brugnon grosse violette hative.

Grosse violetie. Bon. Jard. Lond. Hort. Cat.

The principal difference between this fruit and the preceding one is, in point of size, it being much larger, and measuring twenty-four to twenty-six lines in diameter, by a line or two 
less in height; the skin is also rather marbled than washed with a reddish violet colour, and the flesh less vinous; its period of ripening is the middle of September.

\section{LATE MARBLED VIOLET. Pr. cat.}

Violette tardive. Duh. Lond. Hort. Cat.

Violette marbrée.

Violette panachée. $\}$ Duh. syn.

The flowers of this tree are very small and of a pale red colour; the fruit is of medium size, of rather greater height than diameter, somewhat of a round form, and often partially angular; the skin is smooth, greenish on the shaded side, touched with red and violet spots next the sun; the flesh is white, partially approaching a yellow hue, and red next the stone ; it is melting, separates readily from the stone, of a pleasant vinous taste when at perfect maturity, which in northern climates it only attains when the autumn is dry and warm, as it does not ripen until sometime in the month of October. This is a rare variety which $I$ introduced from the Mediterranean the present year.

\section{LATEST VIOLET.}

Violette très tardive. Duh. | Pêche noix. Duh. syn.

This fruit resembles the preceding in almost every point; it only differs in being of an uniform red colour next the sun, its flesh greenish, and in ripening at a still later period. In a dry and warm autumn and in the best exposure, it does not acquire its maturity until the end of October in the latitude of Paris, and where the circumstances are not thus favourable, it does not ripen at all. It seems, therefore, to be calculated only for the more southern climates.

\section{MUSK VIOLET. Pr. Cat, COXE.}

Brugnon violet. N. Duh.

Brugnon violet musqué. O. Duh.

Violette musquée. Lond. Hort. Cat. | Violet musk.

The flowers of this tree are pale red, usually rather large 
but sometimes of smaller size; the fruit is about two inches in diameter; its skin is smooth, white with a yellowish tinge where shaded, and of a fine violet red next to the sun; the flesh is firm without being dry, of a white colour approaching to yellow, full of sweet juice, which is vinous, musky, and of excellent taste; the stone adheres strongly to the flesh. This fruit ripens at the end of September. Duhamel says that it should not be gathered until it begins to shrivel, and even that it should be placed for some time in the fruit-room in order to acquire its juice perfectly.

FRENCH YELLOW. Pr. CAT.

Brugnon jaune. Duh. Calvel.

This variety which is cultivated in the southern departments of France, differs from the preceding in several points; being at first greenish, and even next the sun acquiring only a yellow colour; its flesh is more melting, sweet, accompanied with a slight degree of acidity, and adheres less to the stone. In warm climates it ripens in September. I received this variety from the Mediterranean this year for the first time.

\section{DEsPrÉs. Port. Jard. FrutT. Bon Jard.}

\section{Desprèz. Early yellow?}

This variety was introduced to the Parisian gardens from Belgium in 1810. It is, however, even at this date but seldom met with in the French collections. The leaves are long, of a light green hue, and bordered with small indentures; the flowers are the size of those of the Grosse Mignonne peach and of a rather pale colour; the fruit is sometimes round and in other cases oblong, varying in diameter from fifteen to eighteen lines; the skin which is perfectly smooth and shining, is at first light green, it then acquires a yellowish white hue, and finally becomes partially marbled with red next to the sun at its maturity, which takes place about the 15th of August. The flesh is white, melting, vinous and full of very sweet juice. This new variety is recommended by French writers as highly worthy of extensive propagation, and is stated to be one of the 
earliest varieties of the nectarine. I have a tree which I obtained from Holland that I strongly suspect will prove identical with this.

\section{COMmon elruge. Pr. cat. Po.r. mag.}

Elruge. Lind. in Lond. Hort. Trans. Not of Miller.

I quote the following detailed description from the Pomological Magazine:

"The name of Elruge nectarine has long found a place in the lists of English fruit trees, and is supposed to be the anagram of Gurles, a nurseryman, by whom it was either raised or sold. But it is singular, that from some unexplained cause, the kind to which the name was originally applied, and which is described by Miller, has been almost lost from cultivation, while that which is now represented has usurped its place. This fact was first pointed out by Mr. George Lindley, in the Transactions of the Horticultural Society, and has been since universally admitted. Hence, there are two Elruge nectarines in our gardens, one called Miller's Elruge, and the other Common Elruge. This last is the subject of the following remarks. It is to be suspected, that all the descriptions of modern authors refer to this rather than to Miller's.

"It is probable that the Claremont nectarine is a synonyme of this, and there is reason to believe, that the Vermash, figured by Hooker in his Pomona Londinensis, is also a representation of the same variety. The latter is, however, undoubtedly a distinct kind.

"The Common Elruge nectarine ripens on a south wall, in the end of August and beginning of September; it will also acquire maturity on a west wall. We have even seen an instance of its producing a perfectly well-grown ripe fruit in the end of September, upon an open standard tree. This occurred in the garden of the Horticultural Society in 1827.

"One of our very best and most high flavoured of our nectarines, and one of those which are most generally cultivated. It is very like the Violette hative, from which it is known by its parting more freely from the stone, and by the channel in its

VOL. II. 
side being deeper and less pitted with little excavations. Leaves crenated, with reniform glands; flowers very small, pale dull red; fruit large, roundish, inclining to oval, channel shallow at the base, becoming gradually deeper towards the apex; skin deep violet, or blood colour when exposed, with minute brownish specks, paler in the shade; flesh whitish, melting, very juicy, rich and high flavoured, a little stained with red next the stone, from which it parts freely; stone middle-sized, oval, slightly pointed, pale, in which it differs from the Violette hative, the stone of which is deep red."

\section{MILLER'S ELRUGE. Pom. Mag.}

Elruge, of Miller. Lond. Hort. cat.

Elruge. Mil. For. | Clermont. For. syn.
Elrouge.

The fruit of this variety is of medium size; the colour is dark red, or purple next to the sun, and pale yellow or greenish on the shaded side; the flesh is melting, vinous, and juicy, and separates freely from the stone. Its time of ripening is early in August.

White NECTARINE. Pr. Cat. Poy. Mag. For.Lond. Hort. 'Trans.

Old White, of English Nurseries.

White, or Flanders. Hook. Pom. Lond.?

Brugnon blanc musquée. May, Pom. Fran.

Nectarine blanche de Weitzenfeld, according to Mayer.

The ample opportunities for correct decisions which the London Horticultural Society possess, give to their conclusions a high degree of authority, in accordance with which I have adopted the synonymes above quoted from the Pomological Magazine. It will be seen, however, that I have omitted one which is adopted in that work; the "New White of the Nurseries," as I find the variety I have received by that title, from the English nurseries to be a freestone. It is also stated in the New Duhamel, that the variety therein described as the "Violette blanche," and which was obtained from Belgium under the title of "Brugnon blanc, is likewise a freestone, and 
from that circumstance I have attached a mark of doubt to the second synonyme, and which may possibly be applicable also to one or both of those last quoted. I now proceed to give the remarks and descriptions as contained in the Magazine referred to :

"It is probable that there is no difference between the various kinds of White Nectarines now in cultivation; at least, the differences, if they exist, are so unimportant as to be little deserving of notice. It is supposed that the sort mentioned in the Transactions of the Horticultural Society, under the name of the Cowdray White, is a rather large kind. Ripens in August and September, and is remarkable for its fine rich flavour and abundant juice. This variety is not noticed by Miller. Leaves broad, crenated, with reniform glands ; flowers large; fruit middle-sized, roundish, very pale yellowish green, becoming almost white in the shade, and slightly tinged with red next the sun; flesh tender and juicy, with a fine vinous flavour ; stone rather small, adhering to the flesh."

FRENCH WhITE. Pr. cat.

\section{Violette blanche; N. Duh. Brugnon blanc.}

The leaves of this variety are large, attended with reniform glands; the flowers are a delicate rose colour, and are sixteen to eighteen lines in diameter; the fruit has a smooth shining skin, which is white approaching to a yellow hue; it varies somewhat in the shape, being in some cases oblong, and in others round; the ordinary diameter is from eighteen to twenty lines. The flesh is entirely white, at first rather firm, afterwards melting and full of juice, of a very pleasant vinous flavour; the stone is oval, terminated by a blunt point, and separates readily from the flesh. This fruit ripens from the middle to the end of August. In Belgium it is known by the synonyme last quoted, and was thence brought to Paris in 1808. The tree is said to be rather delicate in northern latitudes, but I have never yet seen a nectarine tree of any variety whatever, affected by the winter in this vicinity. I introduced this variety from the south of Europe the present year. 


\section{LATE YELI.OW. Pr. CAT,}

$\left.\begin{array}{l}\begin{array}{l}\text { Violette jaune. N. Duh. } \\ \text { Rousanne. }\end{array} \text { Maune lisse, } \\ \text { Lissé jaune, }\end{array}\right\}$ o. Duh.

Jaune lisse-Yellow. Coxe. Jaune lisse tardive.

The flowers of this tree are stated by Duhamel to be small, or at most, of medium size; but the Bon Jardinier says they are of large size, and those of my trees are of that description; the fruit is round and twenty two to twenty four lines in diameter; the skin is smooth, yellow, partially marbled with red on the sunny side; the flesh is yellow, with very pleasant sweet juice, possessing the flavour of the apricot. This fruit ripens about the middle of October, and requires a dry and warm autumn to ripen well, and to attain that agreeable taste which it will not otherwise possess.

\section{CHERRY NECTARINE. Pr. cat.}

Pêche Cérise. O. Duh. Lond. Hort. cat.

Violette Cérise. N. Duh.

The flowers of this tree are of a very pale rose colour almost white, and nine lines in diameter; the leaves are attended with reniform glands. This is one of the smallest fruits of its class, being no more than fourteen to fifteen lines in diameter, by thirteen in height; often about eighteen lines by fifteen; and in a few instances twenty by eighteen, the latter being the dimensions given by Duhamel. The form is round, and the fruit is furrowed on one side by a very distinct longitudinal suture, which terminates at the head by a mamelon, always very visible, and somewhat pointed. The skin is smooth, delicate, and shining, of a fine red colour on the sunny side, and of a waxen white on other parts; it separates readily from the flesh when the fruit is at maturity. These shades give to this fruit a highly pleasing appearance, and cause it to present a similarity to the Pomme d'Api, or Lady apple. The flesh is white, melting, and not highly flavoured; it detaches easily from the stone, which is oval, but nearly round, 
whitish, and only partially coloured. This fruit ripens commonly at the end of August, and in early seasons at the beginning of that month, and sometimes, under very favourable circumstances, even the latter part of July: it is very beautiful, and serves to ornament the desert.

\section{OLD NEWINGTON. Pr. cat.}

Newington. Mil. Lond. Hort. Cat. Late Newington. Lang. For. Scarlet Newington.

This tree has indented leaves and large flowers; the fruit is also of a large size; the skin is of a beautiful red colour next the sun, and a fine yellow on the other side; the flesh is yellow except next the stone, to which it adheres closely, and where it is of a deep red hue; its quality is excellent, being rich and juicy. This variety is much esteemed and ripens in September.

\section{RED ROMAN. Pr. cat. For. Coxe.}

Roman. Lond. Hort. Cat. Old Roman. Roman red. Mil. Brugnon musquée. For. syn.?

This fruit is fair and of large size; the form is round, the skin dark red next to the sun, and of a yellowish hue on the other side; the flesh is firm, of a yellowish white colour, except next the stone, where it is very red; it abounds with rich juice when the fruit is fully ripe, at which period the skin becomes shrivelled. This is a clingstone variety and greatly resembles the old Newington, from which it is principally distinguished by having a smooth leaf, that of the latter being indented. Both are highly esteemed varieties, and ripen in September.

\section{VERMash. Pr. cat. Lond. Hort. cat.}

T'rue Vermash. Hook. Pom. For.

This fruit is of rather small size, and of a round form, tapering towards the eye, the skin is of a very deep red colour next the sun, and of a greenish hue on the other side; the flesh is white, with à circle of red next the stone, which is small and 
from which it parts freely ; it is also rich, melting, and juicy, with a pleasant degree of acidity. The fruit is at maturity in August.

FAIRCHILD'S EARLY. Pr. Cat. Mrl. For.

Fairchild's. Lond. Hort. cat.

This is one of the earliest varieties; the fruit is round and of small size, of a beautiful red colour on the sunny side and yellow on the other; the flesh is not very juicy but of a pleasant taste and flavour. It is a freestone, and ripens early in August.

SCARLET. MIL. FoR. LOND. HORT, CAT.

Early Scarlet. Large Scarlet. ?

This tree produces small deep red flowers; the fruit is of fine size, of a beautiful scarlet colour next the sun, and pale red on the shaded side; the flesh separates from the stone. It is at maturity in August.

ITALIAN BRUGNON. Pr. CAT.

Brugnon or Italian. Nil.

Brugnon. ? Lang. Pom. For.

Italian. $\}$ Lond. Hort. cat. Coxe.

English Brugnon.

The French word Brugnon, signifies merely Nectarine, and consequently this term, which is used by several authors as a title for the present variety, has no definite meaning, and cannot serve to distinguish it. I have therefore varied it to the one here adopted. This tree has smail deep red flowers, the fruit is of a large size, a dark red on the sunny side and pale yellow on the other; the flesh is frm, rich, of good flavour, and very red at the stone, to which it adheres. It ripens in August.

MURRY. Pr.cat. For. Lond. hort. cat. Coxe.

\section{Black Murry.}

This is a fruit of medium size, and round form; the colour of its skin is a dull red next to the sun, and yellowish green on the other side; the flesh is firm, adheres to the stone, and is of good flavour. The fruit ripens in September. 
TEMPle's. Pr. cat. Laige. Mil. For.

LOND. HOR'T. CATT.

This fruit is oval and of medium size; its colour is pale red next the sun and yellowish green on the other side; when it is at perfect maturity the skin becomes shrivelled; the flesh is of fine flavour and abounds with rich juice. This is a freestone, and is at maturity in September.

GOLDEN. Pr. cat. Lang. Mir. For. Lond. hort. cat. Orange.-Fine golden fleshed.

This is a round fruit, of large size; it is of the finest orange colour, delicately and beautifully mottled with red next to the sun, which gives to it a clear waxen appearance, so that it greatly resembles an artificial preparation. There is perhaps no fruit whatever more beautiful than this, when it is in perfection. The flesh is yellow, firm, adheres to the stone and is of pleasant flavour; the tree bears well; the flowers are of small size, and the fruit ripens in September.

Peterborough. Pr. cat. Mil. For. Lond. hort. cat. Late Green.-Vermash.

This tree produces small deep red flowers; the fruit is of medium size, round form, and always of a green colour; the part next the sun being of the deepest green and the other side of a paler hue; the flesh is firm and of pleasant flavour; the fruit ripens in September.

LEWIS' NECTarine. Pr. cat. Fes. amer. gard.

Boston. Lond. Hort. Cat. Lewis' Boston yellow.

This is said to have originated from seed at or near Boston. It is a beautiful fruit of a dark crimson colour inclining to a purple on the sunny side, and yellow on the other; the flesh is yellow and of superior quality. There is another variety said to have been raised from the seed of this one, which is sometimes called Boston Seedling, and represented to be of large size, and resembling this in its appearance. 


\section{PLUMS.}

GREEN GAGE. Pr. Chit. Pr. hort. Lond. hori. cat. Coxe.

Queen Claudia. Large Queen Claude. Reine Claude. Grosse Reine Claude. Duh.

Reine Claude. Lond. Hort. cat.

Dauphine-Abricot vert

Sucrin rert-Verte bonne. $\}$ Duh. Syn.

Large green Claudia. Great Queen Claudia.

Murray's Reine Claude. Huling's Reine Claude.

La Grosse Reine Claude, or Dauphine. Mil.

Reine Claude blanche, la grosse.

Gros Damas vert.

THE form of this plum is nearly round, it being eighteen lines in length and the same in diameter; the peduncle is eight lines long, and inserted in a slight cavity; the skin, which is marked with reddish dots on the side next the sun, is greenish on all other parts of it, with some partial touches of pale straw colour when it attains to full maturity; but it never becomes yellow, in which respect it differs from the small Reine Claude, and the Double flowering Gage. The flesh is of a greenısh hue, melting, with abundance of very sweet and highly perfumed juice of an exquisite taste; it does not adhere to the stone, which is eight and a half lines long and six and a half broad. The fruit attains its maturity about the middle of August, and in rainy seasons is subject to crack when ripe. It is one of the finest plums for the table; it is also used to make preserves in sugar and in brandy, as well as compotes, all of which are of excellent quality. The sweet preserves made from it in France, are commonly known by the name of marmelades. It is not so suitable to make prunes, for in consequence of being so very juicy, there is not sufficient substance when it becomes dried, although the taste is excellent. This tree forms strong shoots; the bark is smooth, of a brown colour, a little reddish on the sunny side near the extremities, and greenish on the opposite side; the buds are of medium 
size, near to each other and have large projecting shoulders. It is well calculated to form dwarfs or espaliers. There are some fine seminal varieties of this plum, one of which has oval fruit, and $I$ have recently received a new late variety from the South of France.

\section{DOUble FLOWERING GaGE. Pr. cat.}

Semi-double flowering Reine Claude. Pr. cat. 26 ed.

Prunier à fleur semi-double. Duh.

Prune semi-double.

Reine Claude à fleur semi-double. Lond. Hort. cat.

Prune à fleurs semi-doubles.

This is a variety of the Green Gage with double flowers, which render it highly ornamental when in bloom; the blossoms are numerous and produced in clusters; the fruit is of the same shape and nearly as large as the Green Gage, but much inferior in quality; its form is almost round, its peduncle at most about six lines in length, and the skin, which is at first of a greenish hue, becomes yellow as it approaches maturity; the flesh, which adheres strongly to the stone, is yellowish, quite pleasant but not very rich, and is deficient in flavour. This plum ripens during the last two weeks of the month of August: the tree is more appreciated for the beauty of its flowers than for its fruit, and it is therefore better suited for pleasure grounds than for orchards. I have noticed that the trees, so far as they have met my observation, are remarkable for the roughness of their bark.

\section{SMALL REINE CLAUDE. Pr. CAT.}

Small Queen Claude. Pr. cat. 26th ed.

Petite Reine Claude. Duh. Mil.

Reine Claude blanche petite espèce. 'Lond. Hort. cat.

Small Green Gage. Auth.

Little Queen Claudia. Little Reine Claude.

This plum is of the same size and form as the White Apricot plum; it differs principally from that in having its skin speckled over with reddish dots, more especially on the side exposed to the sun; the flesh is also sweet and more perfumed, but is nevertheless far from being equal to the delicious flavour

vol. 1 . 
of the true Green Gage. The fruit ripens during the latter part of August; the tree is of very thrifty growth and soon attains to a large size; the young shoots are much longer and more slender than those of the Green Gage, and of a darker red on the sunny side; the buds are long, very pointed, and lie almost close to the branch; the shoulder is rather large; the leaves are of smaller size than those of the Green Gage, and in fact the trees of these two varieties are so very dissimilar in their general appearance as to render it almost impossible even for a casual observer to mistake them. This variety has obtained place in some collections under the name of the Red Diaper, it having been disseminated from a nursery by that title, without a due examination of its fruit. I have recently received a new variety of this plum from the South of France.

PURPle Gage. Pr. cat. Pumr. mag.

Reine Claude Violette. $\left\{\begin{array}{l}\text { N. Duh. Bon. Jard. Nois man. } \\ \text { Lond. Hort. cat. }\end{array}\right.$

Die Violette Kônigen Claudie. Sickler.

This fruit is almost round, and seventeen to eighteen lines in diameter. It is esteemed in France to be one of the finest varieties; the tree is of strong and vigorous growth and seems to flourish exceedingly in our climate. I copy the following description from the Pomological Magazine:

"A blue Gage plum has been long known and little esteemed in our gardens : it is the Azure Hative of the French. As the Reine Claude is the Green Gage of the English, it might have been supposed that a Reine Claude Violette, would have been the same as this Blue Gage; such, however, is not the fact: the fruit now figured under the name of the Purple Gage, being a variety of very high quality, fully equal to the Green Gage in all respects, and having this superiority, that while the latter is apt to crack in wet summers, and will never keep at all after having been gathered, this, on the contrary, will endure, if the climate be dry, through August and September, even till October and is scarcely at all disposed to crack. 
"The origin of the variety is unknown; it must, however, be recent, as it is not mentioned by Duhamel, or any of the old French writers, and is even omitted by Noisette in his Jardin Fruitier.

"A good bearer as a standard, ripening in August and September. It is also well adapted to an east or west wall, where its flavour becomes improved; wood strong, spreading, shortjointed, smooth, brownish violet where exposed; leaves middle-sized, oval on the young shoots, obovate on the spurs, doubly and somewhat irregularly serrated; above smooth, shining, deep green; below slightly pubescent; they are darker than those of the Green Gage. Petioles firm, half an inch to an inch in length, with globose glands near the base of the leaf; flowers middle-sized; petals roundish oblong; stamens shorter than the style; fruit, except in colour, very like the Green Gage, middle-sized, roundish oval, somewhat flattened at the ends; suture moderately depressed along oneside; stalk about an inch long, rather thick; skin violet, powdered with a light blue bloom, beneath which it is engrained with pale yellow dots; flesh greenish amber, rich, sugary, and strikingly high flavoured; stone oval, inclining to ovate, compressed."

BLUE GaGE. Pr. cal'. MIL. Lond. Hort. Cat'.

Azure hative. Poit. et Turp.

This fruit is of a medium size, and of a roundish form; the skin is of a blue colour; the flesh rather riclı and of good flavour. It is at maturity in the month of September. It seems uncertain whether Mr. Coxe refers to the same fruit as described here. He mentions his variety as having been imported from France; but as there is no plum called Gage in that country, it must have been imported under some other name.

\section{RED Gage. Pr. CAT.}

This is a tree of the most thrifty growth and produces good crops: the fruit is of the same size as the Green Gage and 
closely resembles it in form; the skin is of a brick red colour, inclining to brown; the flesh is rich and of excellent flavour. This variety was originated in the year 1790, by the grandfather of the author from the seed of the Green Gage. There are several varieties of the Yellow Gage, which produce fruit of an excellent quality.

\section{BLEEKER'S GAGE. Pr. CAT.}

Bleeker's German Gage. Pr. Hort.

German, or Bleeker's Gage.

This plum I received from Isaac Denniston, Esq. of Albany; he states that it was raised by Mr. Bleeker of that city, about the year 1810, from seed received from Germany. It is rich and finely tasted, about two thirds as large as the Washington, and of similar shape; the leaves are, however, much smaller. It is a great bearer and fine for preserving; the tree is of very vigorous growth and luxuriant appearance, and the fruit ripens about the middle of August.

\section{FROST GAGE. Pr. Cat.}

This fruit is about the size and form of the Green Gage, and of a dark purple colour; it is not quite as sweet as the other Gage referred to, but has a more sprightly flavour, and is the best of the late plums found in our markets. It ripens about the first of October, and quantities have been sold in the New York market as late as the tenth of that month, but as these were from a more northern locality, they probably were a week or ten days later at maturity than they would have been in the immediate vicinity of New York. The tree is of thrifty growth and produces abundantly. It is a native of this State, and the circumstance of its ripening after nearly all the other fine varieties are past, renders it a highly valuable acquisition to our assortment of plums.

MaITRE ClaUdE. Pr. cat. Lang. Mil. LoNd. hort. CAT. For.

This fruit is of large size and round form; the skin is of a bright yellow colour, with some spots of dark red next the sun, 
and is covered with a thin white bloom; the flesh is pale yellow and firm, with sweet and sprightly juice, and separates from the stone. This plum is ranked in England among their best white varieties; it ripens in September, and the tree is productive.

Washington. Pr. cat. Pr. hort. Poy. mag. LOND. HORT. CAT.

Bolmer's Washington. Bolmore's Washington. Washington, or Bolmer. New Washington. Franklin. Washington Gage. Superior Gage, $\}$ of the Flushing Nurseries for Superior Green Cage, $\}$ about twenty years past. $\left.\begin{array}{l}\text { Double Imperial Gage, } \\ \text { Imperial Gage, }\end{array}\right\}$ of Albany.

This tree is remarkable for the size and vigour of its shoots and for the great dimensions, luxuriance, and beauty of its foliage, which presents a striking contrast to that of most other plum trees; the buds are also large and the shoulder particularly prominent: the fruit is of enormous size, and its form rather more round than oval; it is not surpassed by any other variety in richness, beauty, or exquisite flavour, and in its excellent qualities assimilates more nearly to those of the Green Gage than to any other plum. The origin of this fruit is involved in some obscurity; the title here adopted is of but recent application. The following details, from the pen of Wm. Prince, senior proprietor of the Linnæan Botanic Garden, may prove interesting:

"Some few years ago, Mr. Bolmer, a merchant of New York, finding a tree of this kind in his garden, and deeming it a new variety, presented some scions of it to a number of his acquaintances, from one of whom it received the appellation of Bolmer's Washington. Its extraordinary size and fine Gage flavour, caused it to attract much notice, and supposing it to be a novelty, I procured a tree myself, for which I paid three dollars, a price at which they were readily selling at the time; but to my great surprise, when its foliage and fruit were developed, I found it an old and familiar acquaintance, which had been cultivated in the Nurseries at Flushing during a long 
course of years, under the title of "Superior Gage ;" and of which trees of the thickness of a man's thigh were to be seen throughout the country, and particularly in the garden of $\mathrm{Mr}$. Van Sinderen, and others in this vicinity. Mr. James Bloodgood, of Flushing, (since deceased,) also made the same discovery about the same time. In the year 1824, happening to be on a visit at Albany, I was again surprised to meet the same plum in the garden of Isaac Denniston, Esq., under the name of the "Double Imperial Gage." The trees in his garden were of very large size, and he stated that he had obtained them under this name eighteen years before, from the vicinity of New York; it having been long an object with that gentleman, who is distinguished for his judgment and discrimination of fruits, to concentrate the most valuable varieties of the plum. I have taken some pains to ascertain the origin of this fruit, and particularly whether it was originally brought from Europe, being anxious to establish the native country of so superior a fruit, and I have come to the conclusion that it is of American origin, there being no such plum described in any European publication, and having been unable to trace it farther than to the Nurseries at Flushing. I will mention one circumstance which may throw some light upon the subject. It has always been the custom at the establishment of the writer, to plant annually the seeds of the finest fruits, for the purpose of originating new varieties; and about the year 1790, his father planted the stones of twenty five quarts of the Green Gage plum: they produced trees which yielded fruit of every colour, and the Red Gage, White Gage, Prince's Imperial Gage, and Prince's Green Gage, now so well known and so highly esteemed, form part of the progeny of the seeds then sown, and there seems a strong presumptive evidence to suppose that the Superior Gage, now called the Washington, was one of the same collection. John V. Brevoort, Esq. so well known for his intelligence and for his care in making investigations, also stated to me, some years since, that he had satisfactorily traced its origin to Flushing."

The following instance will serve to show the productive- 
ness of this tree and the size of the fruit: A few years since, a small branch with twenty four plums on it, was sent by $L$. Richards, Esq. of Nerw-Jersey, and exhibited to the New-York Horticultural Society, which probably presented the greatest weight of this fruit ever produced on so small a twig, the length of which I think was but twelve inches. Many plums on the same tree measured six and three quarter inches round, and in one or more instances, weighed four and a quarter ounces. The trees cultivated by Mr. Richards are called "Superior Gage," and were obtained by him from Flushing many years since, under that title. This plum is found also to succeed well in England; and the following details in regard to it I copy from the Pomological Magazine :

"The wood is pale brown on a wall, but darker on a standard; when young very slightly pubescent; leaves oblong, very large and shining, with a luxuriant appearance quite unknown in other plums; flowers very large, white; fruit, from a wall, one and three fourths of an inch long by one and five eighths of an inch wide, regularly oval, with a very obscure suture, except just at the stalk, where it is rather deep; stalk inserted in a shallow cavity, three fourths of an inch long, slightly pubescent. Before being cnt, agreeably perfumed like a Green Gage of the best quality ; skin dull yellow broken a little with green, assuming an orange cast on the sunny side, with a purplish bloom, and more or less mottled with crimson dots; flesh yellow, firm, very sweet, and luscious, separating freely from the stone; stone oval, acute at each end, wrinkled all over, and nearly even at the edges."

HULING'S SUPERB. Pr. Cat. Pr: hort.

Keyser's plum.

This plum is of monstrous size, and has measured six and seven eighths inches in circumference, and weighed nearly or quite four ounces. It is of a roundish form, and a greenish yellow colour ; its shape and appearance bearing an affinity to the Gage family, from the seed of one of the varieties of which it no doubt originated; the flesh is sweet, rich, delicious, and 
of very fine flavour, and the fruit has been pronounced "the first in rank among plums." It seems doubtful which will attain to the greatest dimensions, this or the Washington plum ; it is certain, however, that these two and the Prince's Imperial Gage, are the largest and most delicious varieties of the Gage or Reine Claude class, which are known either in Europe or our own country. This tree grows with great vigour, and the leaves are extremely large, broad, and luxuriant; the young shoots are very strong, and the buds are particularly large and prominent. It was raised from the seed by Mr. Keyser, of Pennsylvania, but was brought into particular notice by Dr. Wm. E. Hulings of that State, a gentleman distinguished as much for his zeal and perspicuity in the introduction of new and valuable fruits to proper notice, as for his extreme liberality evinced in their dissemination to others.

PRINCE'S IMPERIAL Gage. Pr. cat.

Prince's White Gage. Pr. cat. 26th ed. Prince's Gage. Pr. Hort.

By way of distinguishing the present variety from the other Gage plums, which are now so numerous, I have adopted the title which heads this article. This tree was originated at the Flushing Nursery, from a seed of the Green Gage. It is of more rapid and vigorous growth than any other of its class with which I am acquainted, and often forms shoots of seven to eight feet in height, the first season, from the graft. It may be readily distinguished from the Washington, by the growth of the young shoots, which attain to more than twice the length in a season that they do on that variety; the buds are also of much smaller size, and the shoulder of the bud does not project in that striking and peculiar manner which distinguishes the Washington and Huling's Superb. The tree appears to be the most productive in point of quantity of any of the large Gage varieties; the fruit is one of the largest of its class, and second only in size to the Washington and $\mathrm{Hu}-$ lings' Superb; the skin is a pale green previous to its ripen- 
ing, but becomes at full maturity of a fine yellow colour, dotted with red on the side next the sun; the flesh is rich, luscious, and of excellent flavour. In addition to the fruit being of the finest quality, and among those most highly esteemed for the table, it is also much valued for making preserves, and when used for this purpose, the fruit is gathered before it is mature. It ripens the latter part of the month of August. Mr. Samuel R. Johnson, of Charlestown, Massacliusetts, has a tree of this kind which I sent him, from which, according to a statement published in the New-England Farmer, he has sold fruit to the amount of fifty dollars a year for three years. "The Washington plum is sometimes called the Imperial Gage at Albany.

\section{YELLOW EGG. Pr. cat. Pr. hort.} $\left.\begin{array}{l}\text { Mogul. White Imperial. } \\ \text { White Magnum bonum. Egg plum. }\end{array}\right\} \begin{gathered}\text { Coxe, and of most Ame- } \\ \text { rican collections. }\end{gathered}$

Dame Aubert. Grosse luissante. Duh. For. syn.

Dame Aubert. Jard. fruit. Bon Jard.

Dame Aubert jaune, of some French catalogues.

Dame Aubert grosse luisante. Lond. Hort. cat.

Monsieur. Tourn. | Wentworth. Lang. Mil.

Monsieur. Wentworth. For.

Bonum Magnum. | White Holland.

White Bonum magnum. Large Yellow Egg. ’ of scme colHick's large Egg? Young's superior Egg? lections.

This is ranked by Duhamel, as the largest plum then in the French collections, and I have seen it as large as a hen's egg of medium size. It often measures two and a half inches in length, and in some instances even thirty-two lines, with a diameter of twenty-two to twenty-three, and occasionally of twenty-five lines; its weight is frequently three ounces, and those of the very largest dimensions even weigh four ounces. The peduncle is nine to ten lines long, and inserted in a shallow cavity; the skin, which is of a fine yellow colour, scattered over with numerous greenish dots, is not very tender; the suture, which divides the fruit on one side, is not deep; the flesh is yellowish, and rather sweet, with but little flavour; the stone, which adheres to the flesh until it is very ripe, is quite large in proportion to the size of the plum, being seventeen 
lines long and nine and a half broad. This fruit ripens at the end of August or the beginning of September; it cannot be ranked among the choice varieties, but deserves to be cultivated on account of its beauty and its enormous size. The tree is of very strong and vigorous growth, and is seldom or never attacked by the insects which cause large knots and excrescences on many other varieties. It is very productive, and the fruit is esteemed for making preserves. There exists much confusion in the application of the synonymes of this plum and the White Imperial ; for while this is the kind almost invariably cultivated in our gardens, the titles which belong to that variety are generally applied to it. Langley, it will be perceived, by referring to the synonymes, calls this the Wentworth plum, and he remarks that its form, colour, and taste, are exactly the same as the Mogul, (White Imperial,) but that the latter cleaves to the stone, and this parts freely from it, on which account this was the most esteemed for preserves. There are, at present, several varieties of this plum, producing red violet, and white fruit.

\section{WhITE IMPERIAL. Pr. car. Mr. For.}

Imperial blanc. Imperiale blanche. Duh. Imperiale blanche. Lond. Hort. cat. Mogule. White Bonum Magnum. ? White Holland. Dutch plum. $\}$ Lang. $\left.\begin{array}{l}\text { White Imperial. Bonum Magnum. } \\ \text { White Holland. Mogul, or Egg plum. }\end{array}\right\}$ Mil. For. White Egg plum.

This variety has been supposed by many to be synonymous with the Yellow Egg, but they are described as distinct by Duhamel, Langley, and other writers, and so enumerated in various French publications, and in the catalogues of their nurseries. The tree is of very vigorous growth, and resembles the Yellow Egg in its general appearance. The fruit is very large, of the form, and almost of the size, of an egg; the skin is whitish, or a pale yellow; the flesh is whitish, of a firm consistence, and dry, with an acid and unpleasant flavour ; the hesh adheres to the stone, which is long and pointed. This 
plum is not suitable for the table nor for prunes, but is used for preserves, and is particularly remarkable on account of its handsome form and extremely large size. It ripens in September, and is very productive. Miller copies his description of this fruit from the first edition of Duhamel, and Forsyth from the new edition of the same work, notwithstanding which it is more than probable that the Yellow Egg is the fruit that has been long cultivated, and generally known in England under the titles they give for this variety, as this is much the most rare in gardens and nurseries, and indeed but seldom to be met with, while the Yellow Egg is found in almost every collection.

\section{YELLOW IMPERIAL. Au'H.}

Imperial jaune. Imperiale jaune. Duh. Calvel.

This fruit is nearly as large as a small sized egg of the common fowl; the skin is yellow and of rather a deeper shade next the sun than on the other side; the flesh is yellowish, sweet, with a small degree of acidity, and separates readily from the stone. This Plum ripens the middle of August.

TOMLINSON'S CHARLOTTE. Pr. ca'. Pr. hort.

\section{Charlotte.}

This variety I received from my friend, Judge Tomlinson; it was originated by him from the seed of the Yellow Egg plum, and he gave it the name of Charlotte, after a lady of Schenectady, to which I have subjoined his cognomen. It is an early yellow fruit, of the shape of its parent, but different in quality, being sweet and agreeable in flavour, and better calculated for the table. It ripens about the middle of August. The growth of the tree is exceedingly vigorous, and perhaps not exceeded by any other of its class.

IMPERIAL VIOLET. Pr. cat. Duh. Coxe.

Purple Egg. Pr. Hort. Pr. cat. 26th ed.

Imperiale violetle. Duh. syn. Lond. Hort. cat.

Prune-œuf. Prune d'œuf. I Imperiale. Mil. Red Imperial. Red Bonum Magnum. Mil. For. Large Orlean.

This is a beautiful fruit, of oval form, nineteen to twenty lines long, and fifteen to sixteen in diameter; it is divided on 
one side for its whole length by a very conspicusus suture; the peduncle is slender, nine to ten lines long, and inserted in a small and rather deep cavity; the skin is a pale violet, covered with bloom, rather tough, and does not separate readily from the flesh, which is of a whitish green colour, firm, sweet, and of a rich taste; it does not adhere to the stone, which is ten lines long and six broad. Duhamel says this fruit ripens at Paris the end of August, and that it is subject to be wormy when the tree is planted in strong and cold soils. I received this plum from Scotland, under the name of Red Imperial. Most of the trees cultivated in American gardens for this variety, are the Blue Imperatrice, which is a much smaller fruit.

IMPERIAL VIOLET, with variegated leaves. Pr. cat.

Imperiale violette à feuilles panachées. Duh.

This variety is distinguished by its leaves, which are variegated with white and green, and thereby rendered quite ornamental. The fruit is generally deformed, and half blighted, for which reason Duhamel recommends it to be planted in gardens for ornament, rather than in orchards.

\section{BLUE IMPERATRICE. Pr. cat.}

Imperatrice. $\{$ Mil. Hook. Pom. Pr. Hort.
Lond. Hort. cat. Pom. Mag.

Red Magnum bonum, or Red Imperial. Coxe.

Imperatrice violette. Duh. I Prune d'Altesse?

Violet Empress. | Empress. | Late Red Imperial.

Smith's large October?

This tree is one of the most flourishing varieties cultivated in this vicinity; the fruit is of fine appearance, twenty lines in length and fifteen in its greatest diameter. The description given in the Pomological Magazine being very precise, I insert it here.

"Well known as one of the best of our plums, for keeping late in the season. Its usual period of ripening is in September, when it begins to shrivel, and will then keep, if well managed, till the middle of December, its flavour continuing to improve. 
It requires to be cultivated (in England) on an east or west wall, when it is a great and certain bearer. Some doubt has been expressed of the identity of the English Imperatrice and that of Duhamel, but we see no reason to believe they are different; branches long and slender, with blunt, flattened eyes, and very smooth bark; the lateral shoots are produced at nearly right angles with the main shoots; leaves middlesized, pointed at each end, finely toothed, closely downy; flowers small; fruit oblong, blunt at each end, but tapering rather more to the base than to the apex; foot-stalks rather less than three-fourths of an inch long; skin rieh deep purple, covered over with a thick bloom, which is more copious than on any plum in Covent Garden Market; flesh firm, yellowish green, rather dry, but exceedingly sweet and rich."

Coxe appears to refer to this fruit in his description under the head of Red Magnum Bonum, or Red Imperial.

WHITE IMPERA'TRICE. Poy. Mag. For. LoNd. hoRT. Cat.

Imperatrice blanche. Duh.

Die Weisse Kaiserpflaume. Kraft. Pom. Aust.

This plum is eighteen lines in length, and sixteen in diameter; the peduncle is four to six lines long, and inserted in a shallow but quite distinct depression; the side which is divided by the suture is somewhat flattened, as well as the extremity of the fruit, upon which a slight cavity is observable; the flesh, which is a pale yellow as well as the skin, is of a rather firm consistence, and of a sweet, perfumed, and agreeable flavour; it does not adhere to the stone, which has a somewhat rough surface. The fruit ripens at the end of August or beginning of September.

The following additional details I extract from the Pomological Magazine:

"A handsome and useful plum, but very different from the Blue Imperatrice, to the name of which it has little title. It does not shrivel, or keep well. Leaves rather larger than those of the common Imperatrice, and more shining; flowers somewhat smaller; fruit middle-sized, oval, with an indistinct 
furrow on one side, very blunt at each end; foot-stalk short, in a narrow cavity; skin bright yellowish ochre colour, with a slight evanescent bloom; flesh firm, juicy, sweet, abundant, and rather more transparent than that of most plums.

MONSIEUR. Pr. cat. DuH. Mil. For. Lond. hort. cat.

Late Monsieur. Pr. cat., 26th ed.

Monsieur, of the French collections generally.

Prune de Monsieur. Duh. Mil.

Monsieur ordinaire. Lond. Hort. cat.

This variety is the one which is the most extensively known under the title of Monsieur ; it is however very different from the Monsieur or Wentworth of the English. The plum is not perfectly round, being sixteen lines in length, and eighteen in diameter; the peduncle is large, seven lines long, and inserted in a rather deep cavity, from which a very conspicuous suture extends to the extremity of the fruit, and divides it into two parts ; the skin is purple with a moderate degree of bloom; the flesh is yellowish, melting, and rather high flavoured, provided the tree is in an elevated, dry, and warm soil; inferior in point of flavour, when it is in a low or wet location. The stone is somewhat rough, and does not adhere to the flesh; it is seven lines long, and of the same breadth. This plum ripens at the end of July; the tree is of strong and vigorous growth, the crops are very abundant, and it is very extensively cultivated in the orchards and gardens of France, where it is highly appreciated. Tournefort gives the title of Monsieur to a yellow plum, which is consequently a different variety from this, and Duhamel states that he does not know what variety he could have referred to, unless it be the Yellow Egg, (Dame Aubert jaune.) The character he gives, "Prunus fructu ovato, maximo, flavo," accords with that variety.

\section{EARLY MONSIEUR. Pr. cat.}

Monsieur hatif. Duh. Lond Hort. cat. | Monsieur hative.

This fruit is nearly round, seventeen lines long, and the same in diameter at the largest part, and a line less at the 
smallest section; the suture is not deep; the peduncle is only four to five lines in length, inserted in a narrow but rather deep cavity; the skin is of a fine purple colour next the sun, paler, and inclining to a reddish hue, on the side that is shaded; the flesh is yellowish green, somewhat firm, moderately melting, and of a rather pleasant flavour; the stone separates readily from it, and is nine lines long and six in breadth. This plum greatly resembles the preceding one, but ripens about two weeks sooner.

SURPASSE MONSIEUR. Pr. CAT. BoN. JARd.

This fruit originated at Paris, from the seed of the Monsieur, which is an esteemed French variety. It is of beautiful appearance, and more perfumed than its parent, and of excellent quality. The tree is productive, and the fruit is at maturity in August.

\section{SWISS. Pr. CAT.}

Prune Suisse. Duh. Lond. Hort. cat. Prune de Monsieur tardive. Duh. syn. Prune Suisse, or Swiss plum. Coxe. Monsieur tardive. Altesse. Bon. Jard.

This plum is flattened at the extremity; its diameter is greater than its length, the former measuring more than sixteen lines, and the latter but fourteen; the peduncle is six lines long, and inserted in a slight cavity; the skin is purple, covered with bloom, rather tough, but separates pretty easily; the flesh is greenish, melting, full of very sweet juice, which is rich, and of a very pleasant flavour; the stone adheres to the flesh, it is nine lines in length, seven in breadth, and has on each side a sort of projecting ridge. This fruit begins to ripen at the end of August, or early in September, and continues during the whole of the latter month. It is one of the finest kinds known, and is very superior to the Monsieur, with which some compare it. The tree is productive, although the flowers are in general produced singly. 


\section{EARLY TOURS. Pr. CAT.}

Précoce de Tours. Duh. Lond. Hort. cat. Prune de la Madeleine. Duh. syn.

Prune noire hative.

This fruit is perfectly oval, and very round in its circumference; it is thirteen to fourteen lines in length, and about two lines less in diameter; the suture, which runs parallel with the end of the stone, is scarcely apparent; the peduncle is slender, six lines long, and inserted in a very small cavity; the skin is a very dark purple, covered with bloom, rather tough, slightly bitter, and strongly adheres to the flesh, which is pale green, approaching to yellow, moderately melting, partially sweet, and of rather pleasant flavour, and even somewhat perfumed when the tree is planted in a dry and warm soil. The plum ripens the beginning of July, and is one of the best early varieties.

ROYAL TOURS. Pr. cat.

Royal de Tours. Royale de Tours. Duh.

Royale de Tours. Lond. Hort. cat.

This plum is nearly of the same colour, form, and size, as the Early Monsieur; its diameter and length are the same, it being eighteen lines in each direction; the suture is very conspicuous, although not deep; and the extremity of the fruit is somewhat flattened, or even depressed; the skin is very much covered with bloom, and of a rather pale purple colour next the sun; it is speckled with bright yellow dots, and rather reddish than purple, on the shaded side; the flesh is greenish yellow, sweet, rich, more melting, and superior to that of the Early Monsieur; it adheres to the stone, which is very flat and rough, ten lines long, and eight broad. This fruit attains its maturity at the end of July; the tree is very vigorous, and generally yields abundant crops.

White PERDRIgON. Pr. cat. Mil. Lord. hort. cat.

Perdrigon blanc. Duh.

This plum is fifteen and a half lines long, and fourteen and a half in diameter, and is rather smaller at the base than at the 
extremity; the peduncle is slender, eight lines in length, and inserted nearly even with the surface of the fruit; the skin is a greenish white, covered with a profusion of bloom, and speckled with red next the sun; the flesh is greenish rather than white, somewhat firm, melting, perfumed, and so swee that when the fruit is very ripe, it has the same taste as if it was preserved; the stone is seven lines long and five broad, and does not adhere to the flesh. This fruit ripens at the beginning of September; it is excellent for the table, and in France they make fine prunes of it. Duhamel states that the tree is subject to a blight of the blossoms, and therefore recommends that it be trained as the espalier. There is a variegated variety of this plum, which $I$ have received from France.

\section{EARLY PERDRIGON. PR. CAT.}

Perdrigon hatif. Perdrigon hative. N. Duh. Perdrigon hatif. Lond. Hort. cat.

This plum, which is borne on a peduncle eight lines in length, is of a perfectly ovate form, and fifteen lines long by eleven in diameter. The skin is of a violet colour, covered with a bloom, which gives it a grayish appearance; the flesh is greenish, melting, juicy, and acid before its maturity; afterwards it retains but little flavour, and even becomes flat and insipid. This fruit ripens about the middle of July, but as it is firmly attached to the peduncle, and that adheres strongly to the branch, the plums become half dried upon the tree; yet far however from becoming better in that state, they acquire on the contrary a rather disagreeable taste.

\section{NORMAN PERDRIGON. Pr. CAT.}

\section{Perdrigon Normand. Duh. Lond. Hort. cat.}

This plum is one of the best French varieties, and among those which are coloured, the Purple Gage is the only one that can be compared to it. The fruit is nearly round, but somewhat diminished at the base; it is eighteen lines or more in length, and the same at its greatest diameter, but only seventeen at its 
smallest part; being somewhat compressed in the direction of the suture, which is very shallow. The penduncle is nine lines long, and inserted in a slight cavity, scarcely apparent ; the skin is a light purple, with considerable bloom, and marked with fawn coloured dots; the flesh is yellowish, melting, abounding in juice, and of a bland, sweet and very pleasant flavour; it adheres strongly to the stone, which is ten lines long, and somewhat more than seven broad; it is rather smooth on both sides; one of its edges has a deep grove, but the other projects considerably. This variety is yet rare in the vicinity of Paris, and it is but a few years since it was introduced to our country. Duhamel remarks that it merits extensive cultivation on account of the great excellence of its fruit, which is at maturity the end of August.

\section{VIOLET PERDRIGON. AUTH.}

Perdrigon violet. Duh. Lond. Hort. cat. Violet, or Blue Perdrigon. Mil. For.

This plum is supported by a peduncle eight or nine lines in length, which is inserted in a slight cavity; its form is not perfectly round, being somewhat contracted at the base ; it is seventeen to eighteen lines in length, and a line less in diameter; the skin is purple, marked with fawn coloured dots and covered with bloom; it is unfortunately very tough, which prevents its being eaten with the fruit, as is usually the case with most other plums; the flesh is greenish, partially melting, and moderately sweet and rich; it adheres to the stone, which is very flat and small in comparison with the fruit. This plum may be ranked among the choice varieties; it ripens about the middle of August. I have received from France the Violet Perdrigon, of Provence, and the Violet Perdrigon, of Thoulouse, but am not aware to which the above description of Duhamel refers, or whether they may not be both distinct from the one here described. 
RED PERdRIGON. Pr. eat: For. Coxe.

Perdrigon rouge. Duh. Lond. Hort. cat.

This fruit is nearly ovate, very round in its circumference, and devoid of any apparent suture; it is fifteen to sixteen lines in length, and fourteen to fifteen in diameter, and supported on a peduncle eight or nine lines long, which is inserted in a very small cavity; the skin is of a very red colour, approaching somewhat to violet, covered with bloom, and marked with very small fawn coloured dots; the flesh, which is light yellow on the sunny side and greenish on the other, is somewhat firm, very sweet, rich and separates easily from the stone, which has a very wide and deep groove on one of its edges. This is an excellent plum, and does not ripen until September. The tree is more fruitful and the blossoms are less subject to blight than those of the two preceding varieties. I presume Coxe refers to this plum in his description, although he varies from its true character in some particular points.

Brignole. Pr. cat. Duh. Mir. Calvel. Loxd. Horr. CAT.

Perdrigon de Brignole?

This plum takes its name from the town of Brignole, in France, in the neighbourhood of which it is very extensively cultivated for the purpose of making those excellent prunes known under the same title, and which are exported to every part of Europe. Duhamel confounds this variety with the White Perdrigon, but it differs from it in several respects; the fruit is of larger size, the skin less tough, and the flesh is yellow and not of a greenish white hue. It ripens in the south of France about the middle of August. There are two varieties of this plum.

ORLEans. Pr. cat. Laxg, Mrr. For. Lond. Hort. cat. Coxe.

Old Orleans. Red Damask. English Orleans.

Common Orleans. Red Orleans. Large red Orleans.

The fruit is round and of medium size; the skin is of a deep red colour mingled with violet next the sun, and of a more 
clear red on the shaded side; it has a partial bloom; the flesh is pale yellow, juicy, of good flavour, and separates freely from the stone; one side of the fruit is marked by a suture which runs from the base to the extremity. The tree produces abundantly, and the fruit ripens in August. Miller and other writers consider this an indifferent fruit; and it is in fact but secondary in point of quality, its great merit being the abundance of its crops.

SMITH'S ORLEans. Pr. cat. Pr. Hort. Lond. Hort. CAl'.

\section{Smith's large Orleans.}

This is one of the most vigorous and flourishing trees that is cultivated in our gardens. I once measured a shoot which had grown ten feet the first season from the graft, and growths of seven and eight feet are very frequently met with. It is much less subject to the attacks of the insect which causes excrescences and knots to be formed on plum trees, than many other varieties. The fruit is round, with a deep suture on one side; the skin is of a reddish purple colour; the flesh is sweet, with a partial acidity, of a pleasant sprightly flavour, and separates freely from the stone. It ripens in the month of September.

WILMOT'S EARLY ORLEANS. Pr. cat. For. LoNd. Hort. trans.

\section{Wilmot's large Orleans.}

This plum is of medium size and round form, with a suture running through one side; the skin is of a dark purplish hue on the sunny side, covered with a fine bloom; the flesh is greenish yellow, with a tinge of amber when fully ripe; it is more soft and juicy than the Old Orleans, and of excellent flavour, it being sweet combined with a pleasant degree of acidity; it separates readily from the stone, which is of small size. The fruit ripens two to three weeks before the Old Orleans, and about as soon as the Morocco and Early Tours plums. 
WHITE DIAPER. Pr. CAT.

Diapré blanc. Duh.

Diaprée blanche. Juh. Lond. Hort. cat.

This plum is fifteen lines in length, and eleven in diameter ; it is perfectly round, without any suture, and with simply a green line running from the base to the extremity; the peduncle is four to five lines long, and inserted even with the surface of the fruit; the skin is a whitish green, covered with a bloom, and somewhat tough : the flesh is rather firm, of a very pale yellow hue, and of sweet and rich flavour; the stone is about nine lines in length, four in breadth, and two and a half in thickness. The fruit is at maturity the end of August or beginning of September.

\section{RED DIAPER. Pr. CA'T.}

Diaprée rouge. Lond. Hort. cat.

Diapré rouge. Diaprée rouge. Duh. Mil.

Roche Corbon. Duh. syn. Mil.

Roche Courbon.

This is one of the most beautiful plums, but its quality does not respond to its fine appearance; it is of oval form, commonly swollen at the extremity, and contracted at its base, which renders it nearly of the form of a pear. Duhamel himself appears not to have seen this fruit when at its greatest size, as he allows it to be but eighteen lines in length. The editors of the New Duhamel remark, that they have never seen any of such small dimensions, and that the largest they had measured were two inches long and twenty-one lines in diameter at the largest section, and nineteen at the smallest part; the peduncle is ten to thirteen lines in length; the skin is red and nearly of a cherry colour, with a partial degree of bloom, and speckled with dots of a deeper red; the flesh is of a very pale green or whitish hue, and slightly adheres to the stone ; it is at first rather firm, without any very pleasant taste, and becomes at full maturity soft and sweetish, but devoid of flavour. The stone is eleven lines to an inch in length, and 
seven in breadth. This plum ripens at the end of August or beginning of September; it is used for making prunes which are far superior to the fruit in its natural state. It is rarely met with in our American collections, and in some cases a different sort is cultivated under the same name. I obtained from one of the nurseries a tree for this kind, that proved to be the Little Reine Claude, which is a small green plum.

\section{VIOLET DIAPER. Pr. cat.}

Diapré violet. Diaprée violette. Duh.

Diaprée violette. Lond. Hort. cat.

This plum is perfectly oval, seventeen lines in length, eleven and a half in its greatest diameter, and six in its smallest section; the peduncle is at most six lines long, and inserted in a cavity scarcely apparent; the suture, which is parallel with the edge of the stone, is only distinguished by a line of a darker colour; the skin is a dark violet covered with bloom, and marked with very small dots of a lighter shade; the flesh is yellowish green, rather firm, without much juice, but of a sweet and pleasant flavour; it does not adhere to the stone, which is much compressed, and terminated by a very acute point. This fruit ripens during the first days in August, and may be ranked in the class of fine plums for the table; it also makes excellent prunes. The tree produces annually a multitude of blossoms, and almost invariably an abundance of fruit.

\section{EARLY APRICOT PLUM. AUTH.}

\section{Abricoté hatif. Abricotée hative. N. Duh.}

This is a very beautiful fruit, but its quality does not respond to its appearance; it is twenty-one to twenty-two lines in length, and the same in diameter; the suture is shallow, but rather broad; the peduncle is six lines long, and inserted in a distinct cavity; the skin, where shaded, is a very pale red, almost greenish, but next to the sun it is of a rather darker hue, and marked all over with small dots, which do not vary much from the colour of the rest of the skin, but are never- 
theless very apparent; the flesh is of a pale yellowish green, rather firm, moderately juicy, slightly acid, and adheres closely to the stone, which is oval and much compressed. This plum ripens during the month of July, and the tree seldom yields a large crop.

\section{WHITE APRICOT PLUM. Pr. CAT.}

Abricoté blanc. Abricotée blanche. N. Duh. Abricotée blanche. Lond. Hort. cat.

This fruit is rather larger than the Late White Damson, but not of equal quality; it is fifteen lines long, the same in diameter at its largest section, and thirteen to fourteen at the smallest part; the peduncle is four lines in length; the skin is at first of a greenish white hue, but changes to yellow when very ripe; the flesh before it is perfectly mature is rather firm, and its flavour slightly acid, but when in perfection it becomes more pleasant. The stone is very flat, rather rough and separates readily from the flesh. This plum ripens about the middle of August.

\section{APRICOT PLUM, OF TOURS. AutI.}

Abricoté de Tours. Abricotée de Tours. Duh. Abricotée. Jard. fruit. Bon Jard.

This plum is of larger size and superior in quality to the preceding one, its diameter exceeds its length and measures eighteen lines, while the latter is but sixteen or seventeen. The peduncle is short, and inserted nearly even with the surface of the fruit, in a very small cavity; the suture, which runs parallel with the edge of the stone, is broad and deep, especially towards the extremity of the fruit, where it terminates in a small depression; the skin is whitish green on the shaded side, and marked with red next the sun; the flesh is firm, yellow, musky, and quite pleasant, but possesses, even when perfectly ripe, a slight acidity, which it no doubt derives from its skin, which is sourish and tough; it does not adhere to the stone. This plum ripens at the beginning of September, and 
is an excellent fruit. There is another fine variety much cultivated and esteemed, which is called Yellow Apricot Plum.

RED APRICOT PLUM. Pr. cat.

Abricoté rouge. N. Duh. Lond. Hort. cat.

? This plum is eighteen to nineteen lines in length, and seventeen to eighteen in diameter; the skin is red approaching to violet, not deep coloured, but has a considerable bloom; the peduncle is six lines long, and inserted in a slight cavity; the suture is not very conspicuous; the flesh is yellowish, but quite distinct from the colour of the apricot; neither does the flavour particularly resemble that fruit, for it is rather flat than sweet, and without any peculiar perfume; the stone does not adhere to the flesh, it is ten lines long and seven broad. This fruit attains to maturity about the middle of August.

\section{ROYAL. Pr. cat. Mrr. For.}

French Royal. Pr. cat. 26 ed.

Prune Royale. Duh. | Royale. Lond. Hort. cat.

This fruit is sixteen to seventeen lines long, and fifteen in its greatest diameter; the peduncle, which is eight to ten lines in length, is inserted in a slight cavity, and the suture is marked by a single line; the skin is purple, covered with bloom and marked with dots of a lighter hue, approaching to a fawn colour; the flesh is greenish, approaching to yellow, rather firm, somewhat juicy, and of a sweet and pleasant flavour; it adheres a little to the stone, which is eight lines long and near six broad. This plum may be ranked among the choice varieties, and is at maturity the end of August.

\section{EARLY ROYAL. Pr. CAT.}

Royal hative. Bon. Jard.

This fruit is of a beautiful appearance and of much excellence; the skin is of the same colour as the Purple Gage, and the flesh also resembles that variety in quality and flavour. It is at maturity early in the month of July. 
COMMON SAIN'T JULIEN. Pr. Cat.

\section{Saint Julien. N. Duh. I French St. Julien. Petit Saint Julien. Saint Julien petit. St. Julian.}

This is the smallest of the violet-coloured plums; it is of rather an oval form, being ten to eleven lines long, and nine in diameter; the skin is of a dark violet colour, covered with bloom; the flesh is greenish, slightly acid, without flavour when over ripe, and does not adhere to the stone. This fruit is at maturity the end of August or beginning of September ; it is not much valued for the table, but is in France very extensively used for preserves, in the same manner as the smaller varieties of the Damson.

\section{LARGE SAINT JULIEN. AUTH.}

\section{Gros Saint Julien. N. Duh.}

This variety is not larger than the common Saint Julien, but is of a rounder form, being eleven or twelve lines in length and the same in diameter; the peduncle is four lines long; the longitudinal suture, like that of the preceding variety, is scarcely apparent; the skin is of a dark violet colour, covered with bloom; the flesh is greenish, more melting and juicy than the preceding one, of a sweetish but rather insipid taste, and the stone slightly adheres thereto. This fruit ripens about the same period as the preceding, say from the middle of August to the middle of September, and is not held in much esteem. There is a variety of this plum which has variegated leaves.

\section{WHITE VIRGINAL. Pr. cat.}

Virginal blanc. Virginal à gros fruit blanc. N. Duh.

This plum is smaller than the Green Gage, being but sixteen lines in length, the same in diameter at its smallest section, and seventeen lines at the largest part; one side is rather compressed, through which runs a slight suture, distinguished only by a line; the peduncle is short, measuring only 
five lines long; the skin is a whitish green, with considerable bloom; the flesh is of a pale greenish hue, very melting, and exceeding juicy, sweet, and pleasant; the stone cannot be separated from the flesh without tearing it, and in such case that part nearest to it continues to adhere; it is eight and a half lines long, seven broad, and quite smooth. This plum ripens at the beginning of September, and is a fine fruit.

\section{RED VIRGINAL. AUtH.}

Virginal Rouge. N. Duh. Lond. Hort. cat.

This fruit is fifteen to sixteen lines in length, and fourteen in diameter, the form being somewhat oval; the skin is of a reddish hue, and the colour is deepest next the sun; the flesh is yellow, and slightly acid. The fruit is at maturity the beginning of August.

\section{RED ST. MARTIN. Pr. Cat.}

St. Martin. Prunier de Saint Martin. N. Duh.

Saint Martin. Saint Martin Rouge. Lond. Hort. cat.

The title given to this plum is no doubt derived from the circumstance of its ripening so late in the season that the fruit is often found upon the tree at St. Martin's day. It begins to ripen, however, about the middle of October; but as the peduncles adhere strongly to the branches, the fruit does not readily fall off unless it is overtaken by the frosts. When the autumn is warm, it is not a rare spectacle to see the trees of this variety still loaded with fruit at the end of November, even after they have lost their foliage. This plum is red approaching a pale violet, and covered with bloom; it is thirteen to fourteen lines in length, and of nearly equal diameter; its peduncle, which is eight to nine lines long, is inserted within a shallow cavity; the suture, which extends on one side from the base to the extremity of the fruit, is but slightly apparent; the flesh is yellowish, rather firm, somewhat melting, and flavoured with a small degree of acidity; the stone is swollen on both sides, and does not adhere to the flesh. This 
truit is not particularly pleasant to the taste, but answers well for late preserves, and is interesting on account of its being the latest of all plums.

\section{DATE PLUM. Pr. cat.}

\section{Prune Datte. Duh. I Prune d'Autriche.}

D'Autriche. Lond. Hort. cat.

This plum is nearly round, fifteen to sixteen lines in length, fifteen in its greatest diameter, and fourteen at its smallest part; the side that is parallel with the edge of the stone is divided by a suture, which is rather flattened than hollowed; the peduncle is fifteen lines long and inserted in a narrow and rather deep cavity; the skin is yellow, often marked with small touches of very bright red on the sunny side, and entirely covered with a whitish bloom; the flesh is yellow, soft, and without flavour. The fruit ripens early in September.

\section{AGEN DATE. Pr. CAT.}

Prunier d'Agen. N. Duh. Calvel.

D'Agen. Lond. Hort, cat.

Prune d'Ante. Robe de Sergent.

This fruit is oval, and of large size; the skin is purple approaching to black; the stone is very flat, and rather smooth. This plum is often confounded with the Royal Tours, but may be readily distinguished by its darker colour, and by its stone being more flattened. It ripens about the middle of July. It is one of the best kinds used at Agen for making prunes.

DRaP D'OR. Pr. cat. Duh. Liang. Mil. Lond. hort. cat. Coxe?

Mirabelle double. Duh. syn. Yellow Gage, of some collections? Mirabelle la grosse, or Drap d'or.

Cloth of Gold. Mil. Grosse Mirabelle?

This plum is almost round, twelve to thirteen lines in length, and about a line more in its greatest diameter; the peduncle is slender, six lines long, and inserted within a small cavity; the skin is yellow, with but a slight bloom, and marked with 
small red spots on the side exposed to the sun; the flesh is yellow, melting, very sweet, pleasant without being particularly rich, and adheres to the stone, which is seven lines long and six broad. This fruit ripens the middle of August. It seems doubtful whether Mr. Coxe referred to the same fruit when making his description, which corresponds, however, in several particulars; I have followed Duhamel in the one above given.

\section{SMALL MIRABELLE. AUrH.}

Prune de Mirabelle. Duh. | La Mirabelle. Mil. Mirabelle petite. Lond. Hort. cat.

Petite Mirabelle. Little Mirabelle. Petit Drap d'or.

This plum is one of the smallest of its class; it is sometimes not larger than a cherry of ordinary size, being but nine lines long and eight in diameter; and it is deemed of extraordinary dimensions when it attains thirteen lines in length by twelve in diameter; the peduncle is long in proportion to the fruit, and measures seven to eight lines; the skin, at its perfect maturity, is of an amber colour, marked with some small reddish dots; the flesh is yellow, extremely sweet, not very rich, and adheres slightly to the stone, which is smooth, and six lines in length. This fruit ripens about the middle of August, and serves to make fine preserves and compotes, and also for prunes, which, although small, are esteemed. There is a variety of this plum with coloured fruit, called the Red Mirabelle.

St. Catharine. Pr. cat. Laing. Mrl. For. LOND. HORT. CAT.

Prune de Sainte Catherine. Duh. Mirabelle tardive.

Yellow St. Catharine. Saint Catherine.

This plum is of ovate form, swollen towards the summit, and smaller at its base, being seventeen lines long, and fifteen at its greatest diameter; it is somewhat flattened on one side, through which runs a slight suture, and the extremity of the fruit is quite compressed ; the peduncle is inserted almost even with the surface, and is eight lines in length; the skin is 
green, approaching a little to a yellow hue; the flesh is of a similar colour, rather firm, and even tough, with but little flavour unless the fruit is fully ripe; but when it has attained to perfect maturity it becomes partially melting, quite sweet, and of a pleasant flavour; the stone adheres but slightly to the flesh; it is nine lines long and six broad, and has a deep groove along one of its edges. This fruit ripens about the middle of September, and from it are made the most esteemed. prunes of Tours.

\section{GERMAN PRUNE. Pr. CAT.}

True large German prune. Large German prune. Prune plum. | Quetsche. Lond. Hort. cat. Quetschen. Couetche. Quetsche commune.

Zwetschen. N. Duh. | Prune d'Allemagne la commune.

This plum is of a singular form; it is oblong, somewhat flattened on two of its sides, with the other two of unequal dimensions, one being almost flat, and the other projecting; the side which projects is that which is parallel with the edge of the stone; and it is also marked by a suture whose sides are not uniform, one being more raised than the other. The whole length of the fruit is two inches, and its greatest diameter fifteen to sixteen lines; the peduncle is seven to eight lines long, and inserted nearly even with the surface of the fruit; the skin is purple, covered with a thick bloom, which imparts to it a bluish hue ; the flesh is of a greenish colour, and firm; the taste sweetish, with but little flavour; the stone is very flat, fifteen lines long, seven broad, and at most three and a half in thickness. This fruit ripens at the end of August or beginning of September; it is not extensively disseminated in France, and but partially so in the neighbourhood of Paris; but in Germany it is cultivated to a great extent, and in particular districts it is almost the only variety planted, to the exclusion of all other kinds; and in that country, as well as in Lorraine and in Switzerland, excellent prunes are made from it. The tree is of vigorous growth and healthy appearance, and seems to be well suited to our climate. The Prune plum of Coxe appears to be quite a different variety from the one 
here described. They cultivate in Europe several very choice varieties of the Prune, all of which have been introduced to our country: these are the Bremen prune, Monstrous prune, Green prune, Early prune, and Italian prune; the last of these is held in great estimation for its excellent qualities.

\section{GERMAN PLUM. AUTH.}

\section{Prunier Allemand. Prune Allemand. N. Duh.}

This fruit is oval, somewhat swollen on one side, and measures fifteen to sixteen lines in length, and an inch in its greatest diameter; the peduncle is inserted nearly even with the surface, and the suture, which is parallel with the edge of the stone, is distinguished only by a line slightly depressed; the skin is purple; the flesh yellowish, somewhat firm, quite sweet, and moderately rich; the stone, which scarcely adheres any to the flesh, is ten lines long and five broad; it is very flat, not being more than two and a half lines in thickness.

holland. Pr. cat. Coxe.

Blue Holland. Pr. cat., 26 ed.

Large Holland. Kensington Prune.

This tree is of vigorous growth, and the young shoots are downy; the fruit is of a blue colour, with a bloom; its form is round and rather compressed; its flesh is juicy, rich, of very pleasant flavour, and separates from the stone; the peduncle adheres so strongly to the branch, that the fruit frequently hangs on the tree after its maturity, and becomes dry without falling. It is, perhaps, more widely disseminated in our country than any other foreign variety, and is frequently met with in the gardens and enclosures of the Dutch inhabitants in the State of New-York. It is supposed to have been brought from Holland by the original Dutch settlers, and has obtained the name here adopted from that circumstance. A tree received from Philadelphia, under the title of Kensington Prune, has proved identically the same with this kind. 
White PRIMORDian. Pr. cat. Lang. Mil. For. LOND. HORT. CAT.

Early Yellow. Pr. cat. 26 ed.

Jaune hative. Duh. syn. Lang. Mil. For.

Lond. Hort. cat.

Prune de Catalogne. Duh.

Jaune de Catalogne. St. Barnabé.

Jean hative. Early John. Bilboa. London plum

Catalonia.

This fruit is about fourteen lines long, and an inch in its greatest diameter; it is somewhat contracted at its base, and usually divided on one side by a quite conspicuous suture; the peduncle is slender; and four to five lines long; the skin is pale yellow, with a bloom; the flesh is of the same colour, partially melting, and sometimes slightly perfumed, but generally deficient in flavour; it does not adhere to the stone. This plum is the first that ripens of the European varieties, and is commonly in eating the first part of July, which constitutes its chief merit. Duhamel states that very good compotes are made from it. The tree is productive, but grows slow; the young branches are slender, and the bark on them has a grayish appearance. There is another variety called the English Blue Primordian, and Langley mentions a Red Primordian as existing in his time.

\section{PRINCE'S PRIMORDIAN. Pr. CAT.}

Prince's Blue Primordian. Pr. cat. 26 ed.

This plum is of an oval form and blue colour; the flesh is of a pleasant flavour, but the principal value of this variety is its early maturity. It was raised by the father of the author of this work, from a seed of the White Primordian, and is of about the same size. It is one of the earliest varieties $I$ am acquainted with, being at maturity eight or ten days before its parent. The young branches are most generally of slender growth and of a grayish colour. 


\section{AMERICAN CHERRY PLUM. Pr. CAT.}

Cherry plum, or Mirobalan. Coxe. Lond. Hort. Cat. Myrobalan. Mil.

Prunus myrobalana, or Myrobalan. Duh.

Prunus cerasifera. Ehrh. Wild. Pursh.

Early scarlet. Cerise. Prune Cerise.

This is a distinct species, said to be a native of our country; but I am not certain that I have ever met with it in a wild state, though I have seen a tree closely resembling it growing in great numbers along some of the hedges in Maryland, and which may possibly be the same kind. The tree does not attain to so great a height as most other plums, but forms a bushy spreading head at a few feet from the ground. Its growth is vigorous, and it is particularly healthy and free from the knots or excrescences which are formed on most other plum trees by the attacks of insects. The leaves which are borne on petioles, are smooth on both sides, and do not expand until after the flowers, which bloom very early, and are white, and so extremely numerous as to render the tree highly ornamental during that period. The fruit is of good size and beautiful appearance, nearly globular, rather largest at the base, and terminated at the extremity by a partial projection, similar to a mamelon; it is of a rather deep red colour, and of pleasant taste when fully ripe, but not high flavoured; the stone is oval and terminates in an acute point. This fruit ripens about the middle of August. The tree bears well in situations where the blossoms are uninjured by frost; but as they expand so very early they are apt to be injured in this latitude, and the crops of fruit are therefore but small.

EUROPEAN CHERRY PLUM. Pr. CAT.

Prune Ceriset. Cerisette. N. Duh. Cherry. Cerizette. Mil.

This fruit is nearly globular, a little oblong, of small or medium size, and of a reddish colour; the flesh is yellowish green, partially melting, rather sweet, but not high flavored, 
and separates pretty readily from the stone. This plum ripens the middle of August; it is not particularly esteemed, and the trees are consequently not extensively cultivated for their fruit. They are much used, however, for stocks on which to inoculate the superior plums, and particular varieties of apricots.

STONELESS. Pr. CAT. LOND. HORT, CAT.

Pitless. Pr. cat. 26 ed.

Prunier sans noyau. Prune sans noyau. N. Duh.

This is one of the smallest plums, being but ten to eleven lines in length, by eight to nine in diameter; the peduncle is usually four to five lines long, and sometimes even nine lines; it is inserted nearly even with the surface of the fruit, there being no apparent cavity; the skin is a dark violet or purple, covered with bloom; the flesh is greenish, at first slightly acid, but at perfect maturity it becomes sweetish and devoid of flavour; the stone is most frequently deficient, and there is in its place a small bony substance, six to seven lines in length and two in breadth, which adheres strongly to the flesh; the kernel formed in the centre of the flesh is four and a half lines long, and three broad; in some cases the fruit has a perfect stone, six to seven lines in length, and four and a half in breadth. This variety is but rarely cultivated, as it is valuable only as a curiosity; the fruit being small and indifferent. It ripens during the month of August.

\section{MAUGERON DAMASK. Pr. CAT.}

Damas de Maugeron. Duh. Lond. Hort. cat.

This variety is of nearly a globular form, being seventeen lines in length, and sixteen and a half in diameter; it is flattened both at the base and at the extremity; the peduncle is ten lines long, slender, and inserted in the centre of a very small cavity; the suture which divides the fruit its whole length, is very slight and barely marked by a line; the skin is of a light purple colour, covered with bloom, and marked with 
very small fawn-coloured dots; the flesh is greenish yellow, rather firm, of a sweet and pleasant flavour, and does not adhere to the stone, which is nine lines long, and rather more and seven in breadth. This plum ripens from the fifteenth of August to the end of the same month, and is esteemed as an excellent fruit. It is said to be subject in France to the attacks of worms, but I am not aware that is particularly so'in our country, where, however, it has not been cultivated but a few years. There are two varieties, one producing larger, and the other smaller fruit.

\section{EARLY BLACK DAMASK. Pr. CAT.}

Damas noir hatif. N. Duh. Lond. Hort. cat. Saint Cyr.

This plum is small and flattened at its extremity; it is only twelve lines in length, and thirteen in its greatest diameter; the peduncle is five lines long; the skin is of a deep violet colour, covered with bloom; the flesh is greenish, melting, sweet, and of pleasant flavour; the stone is seven and a half lines in length, and six in breadth, and adheres but very little to the flesh. The fruit ripens about the middle of July.

MOROCCO. Pr. chit. Lang. Pohr. Mag. Lond. hort. cat.

Farly Damask, commonly called the Morocco plum. Mil.

Early Black Damask. For.

Black Morocco,

Black Damask, $\}$ of various collections.

Early Damask,

This plum appears to be distinct from the Damas noir hatif of Duhamel. I extract the following description from the Pomological Magazine :

"This is one of the very best of our early plums, and has long been an inhabitant of our gardens. In the time of Langley it was evidently common and well known. It is not, however, so much cultivated now as formerly, for which reason a figure of it is here given, in order that it may not be entirely lost sight of. It is very hardy, bears well as a standard, and ripens fullya month before the Orleans, coming in at the be- 
ginning of August; the juice is unusually rich ; wood downy; leaves middle sized, bluntly serrated, rather light green, shining on the upper surface; stalks from half an inch to an inch long, with globose glands; fruit middle sized, roundish; its suture moderately depressed along one side; the apex a little flattened; the stalk thick, scarcely half an inch long; skin deep blackish purple, covered with a light blue bloom; flesh greenish yellow, slightly adhering to the stone, juicy, rich, and high-flavoured; stone middle sized, oval, compressed."

\section{ITALIAN DAMASK. Pr. CAT.}

\section{Damas d'Italie. Duh. Lond. Hort. cut.}

This tree is of very thrifty and vigorous growth; the fruit is thirteen to fifteen lines in length, and nearly the same in diameter; the peduncle is eight lines long, and inserted in a slight cavity, the plum being somewhat flattened at that part; the skin is purple, with a bloom, and speckled with some very small dots of a lighter shade of the same colour; the flesh is yellowish green, melting, rather sweet, but in some cases inferior in point of flavour; the stone does not adhere to the flesh, and is eight lines in length, by six in breadth. This plum ripens during the latter part of August.

\section{SPANISH DAMASK. Pr. CAT.}

Damas d'Espagne. N. Duh. Lond. Hort. cat.

This fruit is of nearly a round form, its diameter being thirteen lines, and its length but half a line more ; the peduncle is very short, and inserted in a slight cavity; the groove or suture is not very conspicuous; the skin is a deep purple, covered with bloom ; the flesh is yellowish, not very rich, sweetish and without flavour; the stone separates entirely from the flesh. This plum ripens about the end of August.

\section{MUSK DAMASK. Pr. CAT.}

Damas musqué. Duh. Lond. Hort. cat. Prune de Chypre. Prune de Malte.

This fruit is almost globular, flattened at the base, and at the extremity; twelve to thirteen lines in length, and'fourteen in 
diameter ; the peduncle is six lines long, and placed in a depression scarcely perceptible ; the longitudinal suture is rather more apparent; the skin is dark purple, speckled with very small dots of a lighter colour, and covered with bloom; the flesh is greenish, melting, replete with juice, of a sweet and rather rich flavour; the stone is six lines long, and of the same breadth, it does not adhere at all to the flesh, but is smooth, with the exception of two or three projecting lines towards the base. This fruit ripens about the middle of August.

\section{SEPTEMBER DAMASK. Pr. cat.}

\section{Prunier des Vacances. Prune de Vacance. Duh.}

Damas de Septembre. Duh. Lond. Hort. cat.

This plum is almost globular; its breadth is rather greater than its length, it being thirteen and a half lines long, and fourteen in diameter; the peduncle is only three or four lines in length, and inserted in a pretty distinct cavity; the skin is dark purple, almost black, covered with bloom, which makes it appear of a blueish colour; it is marked from the base to the extremity of the fruit by a shallow suture; the flesh is greenish, at first rather firm and sourish, afterwards it becomes soft and sweetish without much flavour, unless there is a warm period at the time of its ripening, in which case it is rather more pleasant and more perfumed; the stone is much swollen and separates pretty readily from the flesh. This fruit ripens in the course of the month of September, and the tree is usually very productive.

\section{VIOLET DAMASK. Pr. cat.}

\section{Damas violet. Duh. Lond. Hort. cat.}

This fruit is thirteen to fourteen lines long, and two lines less in its greatest diameter; the peduncle is five lines in length, and inserted in a slight cavity; the suture is distinguished only by a line; the skin is of a violet colour, covered with bloom; the flesh is yellowish, melting, replete with juice, which is bland, sweet, and somewhat musky, it does not adhere 
to the stone, or but partially so; the stone is very much swollen on both its sides, and is seven lines long and five broad. This plum ripens at the end of July or beginning of August, and is one of the best among the small varieties. The tree is very vigorous, but is said to seldom yield large crops in the vicinity of Paris ; its introduction here is so recent that suffcient opportunities have not been afforded to decide whether it will be more productive with us.

\section{RED DAMASK. Pr. Cat.}

Damas rouge. Duh.

I. had supposed this variety to be the same as the Orleans of the English, but such appears not to be the fact. I intend, however, by further investigation to decide that point satisfactorily. This fruit is a rather regular oval, sixteen lines in length, and fourteen in diameter; the suture is very shallow; the peduncle is six lines long, and inserted almost even with the surface of the fruit; the skin is dark red on the side exposed to the sun, and of a pale red on the other, and is covered entirely with bloom; the flesh is yellowish, melting, very sweet, and separates readily from the stone, which is seven lines long, and five at its greatest breadth. The fruit ripens the middle of August. The French writers state that in their country it is subject to be wormy, and that the trees are far more productive in the south than in the north of France.

\section{LATE RED DAMASK. Pr. cat.}

Gros Damas rouge tardif. N. Duh. Damas rouge tardif. | Late red Damson.

The length and diameter of this plum are equal, each measuring eighteen lines; the peduncle is six lines long, and inserted almost even with the surface; the skin is a light purple colour, approaching to red, with a partial bloom; the flesh is yellow, melting, with abundance of juice, which is rather sweet and rich, and of very pleasant flavour; the stone is very flat, rather smooth, nine lines long, six and a half broad, and but three in thickness; one of its edges projects considerably. 
This plum is seldom at maturity before the 15 th of September; it is an excellent fruit, and also very beautiful, and is therefore gratifying both to the eye and to the palate. The tree is vigorous and very productive, and deserves to be widely disseminated, and would fill the places advantageously of many of the inferior kinds now in cultivation.

\section{LARGEST DAMASK OF TOURS. Pr. CAT.}

Gros Damas de Tours. Duh.

Damas de Tours gros. Lond. Hort. cat.

This plum is of rather greater length than breadth, the former being fourteen and the latter thirteen lines; the longitudinal suture presents only a line, without any depression; the flesh is whitish, firm, sweet, pretty rich, and of a very pleasant flavour; it is unfortunate that the skin, which is tough and somewhat acid, imparts a bad taste to it; the stone is rough, and adheres to the flesh. This plum is of a dark purple colour, covered with bloom; it ripens towards the end of July and is greatly cultivated in the neighbourhood of Tours, where the inhabitants make excellent prunes of it.

\section{DAMAS DRONET. Pr. cat. LoNd, hort. cat.}

This is a small fruit, of rather greater length than diameter, the former measuring twelve and a half lines, and the latter but eleven; the peduncle is ten lines long, and inserted in a very narrow and rather deep cavity; the skin has but little bloom on it, and is at first pale green, but afterwards changes to a yellowish hue when at perfect maturity; the flesh is greenish, somewhat firm, sweet, of a pleasant taste, and does not adhere any to the stone. This plum ripens during the latter part of the month of August.

\section{DAMAS DE PROVENCE. N. DuH. LoNd. hoRT. CAT.}

Damas de Provence hatif.

Early Damask of Provence. Provence Damask. Auth.

This is an oval fruit, of medium size, its length being nineteen and its diameter fourteen lines; the peduncle is large, and 
six lines long; the skin is purple, with considerable bloom; the flesh is greenish, rather firm, partially acid before fully ripe, afterwards pretty sweet, but not of a very rich flavour; the stone adheres considerably to the flesh. This fruit ripens very early, and is in France brought to the table in warm and favourable seasons at the end of June, which constitutes its greatest merit.

\section{SMALL RED DAMSON. Pr. CAT.}

Small red Damask. Pr. cat., 26th ed.

Petit Damas rouge. N. Duh.

This fruit is nearly globular, being eleven or twelve lines in length, and the same in diameter; the peduncle, which is four lines long, is inserted even with the surface of the fruit, and not in a cavity; the skin is red on the shaded side, and -approaches a violet hue on that next the sun; the suture is distinguished only by a single line; the flesh is melting, bland, sweet, of good flavour, and of a yellowish colour; it separates readily from the stone, which is five lines long, and rather more in breadth, and has a projecting ridge at the middle of one of its sides. This fruit attains its maturity during the month of September.

\section{PRINCE'S EARLY DAMSON. Pr. CAT.}

Prince's Early Purple.

This tree is of thrifty growth, and produces abundant crops; the fruit is of medium size, and of an ovate form; the skin is of a dark reddish purple colour, and the flesh of a pleasant flavour, and separates from the stone. It is much admired, being an excellent early plum, both for the table and for preserves. It ripens in the month of August. This variety was raised from seed by the father of the author.

LARGE EARLY DAMSON. Pr. cat.

Sweet Damson. Early Damson。 Horse plum.

This tree appears to have been brought to this country either by the early Dutch settlers, or by the French who 
settled here at the time of the revocation of the edict of Nantz. It is much disseminated throughout this section of country. The fruit is of good size, and of an oval form; its skin is of a black colour ; the flesh sweet, and of very pleasant flavour, separating freely from the stone. It is much esteemed, both for the table and for preserves. The fruit ripens in August. The name here adopted is that by which it is generally known; its original title I am unacquainted with.

\section{SMALL WHITE DAMSON. Pr. cat.}

Petit Damas blanc. Duh.

Damas blanc petit. Lond. Hort. cat.

This fruit is thirteen lines in length, and the same in diameter; the skin is of a yellowish white hue, with a partial bloom, and very slightly tinged with red on the side next the sun; the flesh is of the same colour as the skin, melting, of a bland, sweet, and rather rich flavour; it does not adhere to the stone, which is seven lines long and six broad, and has a kind of projecting ridge upon each side of it extending from the base to the point. This plum ripens at the end of August or the beginning of September.

\section{LARGE WHITE DAMSON. Pr. CAT.}

Large white Damask. Pr. cat., 26th ed.

Gros Damas blanc. Duh.

Damas blanc gros. Lond. Hort. cat.

This plum has great affinity to the preceding one; it is only a little larger and longer. In favourable situations it attains to fifteen or sixteen lines in length, and fourteen in diameter; the skin and flesh are also nearly of the same colour as the one before described, and its flavour does not differ, except that the present one seems rather sweeter. This fruit attains to maturity a few days the soonest.

LATE WhITE DAMSON. Pr. cat.

White Damascene. Coxe.

White Damson. Late Cluster. Winter Damson.

White Winter Damson. Frost plum.

This tree is of very strong and vigorous growth, and 
accords so well with our climate that it soon attains to a large size. It is exceedingly productive, the fruit hanging in numerous clusters along the branches. The form is rather more than an inch in length, and seven-eighths of an inch in diameter; the skin is a greenish white, marked with brown spots; the flesh is rather rich and juicy, of pleasant flavour, and adheres to the stone. This plum ripens in September, and sometimes continues on the tree until after frost appears, and in some instances a part of the fruit becomes partially shrivelled, in which case the flavour is much improved.

\section{LATE BLACK DAMSON. Pr. CAT.}

Damas noir. Damas noir tardif. Duh.

Damas noir tardif. Lond. Hort. cat. Black Damson.

This fruit is thirteen lines in length and twelve and a half in diameter, and is sometimes flattened in the same direction as the stone, being about a line less in its diameter where thus compressed; the peduncle is five to six lines long, and inserted in a very slight cavity; the skin is of a deep purple colour, almost black, and covered with bloom; the flesh is rather firm, yellowish green, acid when the fruit is not fully ripe, but sweet and slightly perfumed when it has attained to perfect maturity. The stone in some cases slightly adheres to the flesh; it is not quite seven lines long, and six in breadth, with a deep suture upon one of its edges. Duhamel states that the fruit ripens in France at the end of August.

\section{LATE PURPLE DAMSON. Pr. CAT.}

Purple winter Damson. Pr. cat. 26th ed. Damson. Winter Damson. Late Damson.

Blue Damson. Blue Damascene.

Common blue Damson.

This is the plum which is brought in the greatest quantities to our markets, during the fall season, under the name of Damson, and which is so much sought after for preserves. The tree is exceedingly productive, and in this respect is perhaps unsurpassed by any other variety. Those who cultivate this kind for the market find it very profitable, as the fruit is

VOL. II. 
in much request, and commands a high price. Unfortunately the tree is very subject to the attacks of insects, which cause knots and excrescences to be formed to a greater degree on this than on any other plum tree. This inconvenience may however be easily remedied by proper attention to pruning off all the wounded branches at the season of the year when the insect has taken shelter therein, taking care to burn them immediately; which course, if followed up for two years, or three at most, will effectually destroy them. I have noticed that this tree affords abundant crops when growing in sod ground along the sides of the highway. The fruit is about an inch in length, and three-fourths of an inch in diameter; it is of a dark purple colour, covered with bloom; the flesh has rather too much acidity for a table fruit, but this tartness gives an agreeable flavour to the preserves that are made from it. The growth of the tree greatly resembles the preceding variety, and $I$ have been inclined to think them the same; but as this does not ripen till September, and also differs in some other points from the description given of that variety by Duhamel, I have been unable, hitherto, to satisfy myself on this head.

\section{SHROPSHIRE DAMSON. LOND. HORT. CAT.}

Damson plum. For.

This is a large variety of the Damson, of fine quality and rich flavour; it is suitable for preserves. It ripens in October. The tree produces abundantly.

MIMM'S PLUM. Pr. cat. Pon. mag. Lond. hort. cat.

\section{Imperial Diadem?}

I copy the description of this fine fruit from the Pomological Magazine, in which it is admirably figured.

"This variety is said to have been raised many years since from a stone of the Blue Perdrigon plum, in the garden of Henry Browne, Esq. at North Mimm's Place, in Hertfordshire, and was exhibited at a meeting of the Horticultural Society, 
in 1819 , by $\mathrm{Mr}$. William Morgan, at that time gardener to Mr. Browne.

"The original tree was trained to a wall, with an eastern aspect, where it bears regularly and abundantly. The fruit is large and handsome, of a rich reddish purple colour, in size and figure approaching the Magnum Bonum, but more splerical. It is a pleasant dessert plum, but its great excellence is as a pie-fruit. It melts perfectly when baked, and possesses that just proportion of acidity and sweetness which is so essential to the confectioner, and so rarely to be found. The tree succeeds well as an open standard.

"There is a variety cultivated near Manchester, under the name of the Imperial Diadem plum, that apparently is in no respect different from this, with which it agrees in wood, foliage, period of maturity, size, colour, and quality. The origin of the Imperial Diadem is, however, probably not the same as that of the Mimm's plum, which suggests the possibility of some difference that has not yet been detected, for which reason the two are not actually combined in this place.

"Wood wiry, smooth, dull brownish purple, with short joints, the lower part of the young shoots is thickly covered with brown specks; the buds are dull blackish gray; leaves oblong, quite flat, obtuse, rather unequally crenated, smooth on the upper surface, pubescent on the under surface and petiole; glands two, globose, minute at the base of the leaf; flowers, rather early, above the ordinary size; fruit, oblong, with an oblique apex, and broad shallow suture, of the very largest size among plums, of a light clear purple colour, upon a greenish ground, which is fully exposed on the shaded side of fruit produced upon walls; bloom copious, easily rubbed off; skin thickish, a little marked with brownish specks; flesh pale dull greenish yellow, tender, juicy, and very agreeably flavoured, like an Orleans plum in perfection; stone separating freely, very rugged, with a thin, irregular edge; stalk pubescent." 
Fotheringham. Pr. cat. Lang. Mil. Lond. hort. cat. For.

Foderingham. Sheen plum.

This fruit is of excellent quality, in which respect there are but few which excel it; it is of large size, the form oblong, with a deep suture; the skin is of a deep red colour, a little spotted, and covered with a slight violet bloom; the flesh is white, firm and crisp, rich, juicy, and of fine flavour; it separates freely from the stone, which is of large size. It ripens in August.

Cheston. Pr. cat. Lang. Mil. For. Lond. hort. cat.

\section{Matchless.}

This plum is of oval form, and of a dark blue colour, with a partial violet bloom; the flesh is dark yellow, rich, and full of sweet and pleasant juice. The fruit ripens in September, and the tree produces abundantly.

\section{LARGE EARLY MONTREUII. Pr. CAT.}

Large early black. Pr. cat. 26th ed.

Noir de Montreuil. Duh. Lond. Hort. Cat.

Montreuil. Grosse noire hative.

Grosse noir de Montreuil.

This plum bears much affinity to the Damask of Tours. It is sixteen lines long and fourteen in diameter. The skin is dark purple, covered with bloom, coriaceous, and very acid; the flesh is firm, at first approaching a white hue, but becomes yellowish when fully ripe, and has a very pleasant taste, especially if pains be taken to separate it from the skin, which will otherwise impart to it an acid flavour; the stone adheres but very little to the flesh; it is eight lines long, five and a half broad, and three and a half thick. The principal merit of this fruit is its early maturity, which takes place about the middle of July; the flowers are liable to be injured by late frosts. Duhamel states that the title of Grosse-noire-hative is given to a round plum, of larger size than the one here described, of the same colour, and nearly as early; but whose flesh is coarse and without flavour. 


\section{MOUCHETÉ. N. Dur.}

Mouchetée. N. Duh.

This plum is of ovate form, an inch in length, and ten lines in its greatest diameter; the peduncle, which is long in proportion to the size of the fruit, and measures seven lines, is inserted nearly even with the surface; the suture is distinguished only by a line; the skin is greenish, with considerable bloom, and marked with whitish and yellowish touches; the flesh is greenish rather than yellow, somewhat firm, and at first devoid of flavour, but becomes rather sweet when well ripened, and does not adhere to the stone. This fruit is at maturity in September. In the New Duhamel, where it is described, the author remarks that they had only met with it in the Jardin des Plantes at Paris.

FRENCH COPPER. Pr.cat. Coxe. Lond. hort. cat.

\section{Copper.}

This fruit is not exactly round, but measures nearly the same in each direction, being about an inch and three-eighths in length, and the same in diameter; the skin is blue, with a tinge of copper colour; the flesh is of pleasant flavour, and separates from the stone. The tree is of thrifty growth, and produces abundant crops of fruit, which ripens in the month of July.

\section{TILLEMOND. AUTH.}

Prunier de Tillemond. Belle Tillemond. N. Duh.

This fruit is very large and oval, being twenty-six lines in length, and twenty in diameter; the peduncle is rather large, eight lines long, or nearly that, and inserted in a sight cavity; the skin is dark purple on the side exposed to the sun, and light purple on the other side; the flesh is greenish, somewhat melting, its flavour not very pleasant, being sharp and acid even when at full maturity. This plum is more pleasing to the sight than to the taste, and is scarcely eatable in a raw 
state, but is much better in preserves or compotes. It is a late fruit, and does not ripen until September even in the south of France, and always hangs on the larger branches. The tree is upright, rises to a considerable height, and never forms a very bushy head.

\section{ISLE VERTE. Pr. cat. DuH.}

Isle vert: Ile vert. Duh. Savoy. Prune de Savoye.

Ille verte. Lond. Hort. cat. Ile verte. Jard. fruit. Bon. Jard.

This fruit is of very oblong form, being two inches in length and twelve to thirteen in diameter at its largest section; one of its sides is nearly flat, and the other swollen or projecting; the peduncle is seven lines long, and inserted in a shallow cavity; the skin is greenish, approaching to yellow, and even a little to a reddish hue on the side next the sun; the flesh is greenish, soft and sweetish, and occasionally quite sweet and musky, but generally devoid of flavour, and not particularly pleasant; it strongly adheres to the stone, which is rather smooth, seventeen lines in length, seven in breadth, and very flat, not exceeding three lines in thickness. This plum ripens at the beginning of September; it is of no value as a table fruit, but Duhamel states that it is good for preserves and compotes, which another writer seems to doubt.

JaCinthe. Pr. cat. Duh. Coxe. Lond. hort. cat.

Hyacinth. Pr. cat., 26th ed.

This plum is oval, twenty lines in length and seventeen in diameter, somewhat swollen towards the base, and divided on the side which is parallel with the edge of the stone by a shallow suture, which terminates at the extremity of the fruit by a small depression ; the peduncle is short, inserted in a narrow but rather deep cavity; the skin is of a pale violet colour, with a bloom, and does not readily separate from the flesh, which is yellow, moderately firm, of a rich and sweet taste with a partial degree of acidity, and adheres but slightly to the stone. This fruit ripens at the end of August, and bears a great resemblance to the Purple Egg, or Imperial Violet. 
moyen de BoURgogne. Duh. Calvet. Lond. hort. cat.

Moyeu de Bourgogne.

This plum is of a large size and an oval form; the skin and flesh are both yellow; it is not a fruit of delicate flavour, but the tree produces an abundant crop. It ripens about the middle of September.

COE'S GOLDEN DROP. Pr. cat. LOND. hoRT. cat.

Coe's Plum. Pom. Mag.

Coe's Imperial. Golden drop $\quad$ of different

New Golden drop. Bury Seedling $\}$ collections.

Of all the plums of any modern origin, this and the Washington, already described in this work, are not only among the best, but perhaps superior to any of the oldest varieties. I extract the following from the Pomological Magazine:

"This was raised by a gardener of the name of Coe, at Bury St. Edmund's, in Suffolk, about twenty years since ; but from the stone of what variety is not known. It is very handsome, ripens about the end of September, and will shrivel and keep in a good state for more than a month later; indeed, if properly dried, it will keep as well as the best Imperatrice plums. It is a great bearer, but (in England) should be trained upon a west or east wall to insure a crop. Wood smooth, deep purplish brown, with a few paler spots ; leaves oval, flat, taperpointed, crenated, smooth, rather shining above; petioles short, slightly pubescent, with two globose glands near the base of the leaf; flowers middle-sized; petals roundish oval, imbricated; fruit oval, of the largest size among yellow plums, deeply marked with the suture, pitted at the point, abruptly tapering, and hollowed out at the base for the reception of the stalk; stalk from half an inch to an inch in length; skin greenish yellow, with numerous rich spots of bright violet-red next the sun; flesh greenish yellow, adhering firmly to the stone, and very sweet and delicious ; stone sharp-pointed."

JERUSAlEM. Pr. cat. Lond. hort. cat.

Prunier de Jerusalem. Duh. I Geil de Bœuf. De Bordeaux.

This large and beautiful plum is almost round, its length 
is twenty to twenty-one lines, and its diameter nineteen; it is supported on a peduncle six lines long, two-thirds of which extends within a deep cavity at the base of the fruit, from which a suture forming simply a line runs to its extremity, which is sensibly flattened; the skin is dark purple, almost black, with a slight bloom; the flesh is yellowish, a little inclining to bitter, its flavour is not particularly pleasant, or at best but moderately so, and is far from what might be expected from the fine appearance of the fruit; the stone is an inch long, very flat, and partially adheres to the flesh. This plum is not very common even in France, it ripens at the end of July or beginning of August, and is esteemed rather for its beauty than for its quality.

\section{CYPRIAN. Auth. \\ Prune de Chypre Duh. \\ De Chypre. Lond. Hort. cat.}

This is a very beautiful fruit, of almost a globular form, being nineteen lines long, and nineteen and a half in diameter; the longitudinal suture, which extends on one side for its whole length, is not very conspicuous; the peduncle is large, seven lines in length, and inserted in a rather spacious cavity; the skin is of a fine violet hue, covered with bloom, tough, acid, and separates with difficulty from the flesh, which is firm, greenish, with a sweet flavour, that is rather pleasant when the fruit is fully ripe, but before that period it is commonly acid and bad tasted; the stone adheres to the flesh, is very rough, swollen on one side, with very projecting edges. This. plum ripens at the end of July.

\section{GIFFORD'S LAFAYETTE. PR. cat.}

This fine variety of the plum is a seedling which bore last season for the first time. It was transmitted me by David Thomas, Esq. of our State, and was originated in his neighbourhood, by a gentleman whose cognomen is attached to it. Mr. T. remarks to me, that although the tree was very full, yet the fruit was large and fine. It ripens in August, and he 
states that although he has the Washington, Green Gage, two varieties of the Orleans, and other kinds of the first character, he deems it at least equal, if not superior in flavour to any of them, and that he is not singular in this opinion, as several of the first amateurs of fine fruit in that quarter think it excellent.

\section{COOPER'S LARGE RED. Pr. cat.}

Cooper's plum. Coxe.

Cooper's large. Lond. Hort. Cat.

Cooper's large American.

This plum is of extraordinary size, measuring within an eighth of two inches in each direction; the skin is of a fine dark purple colour ; the flesh is yellowish green, rich, juicy and of pleasant flavour. The fruit makes excellent preserves, but should be used for this purpose before fully ripe, and it has been also recommended to take off the thin outward skin. This plum is at maturity in August; its great defect is an inclination to rot, for which it is hoped a preventive may be discovered. It is a native variety, and originated from the stone of an Orleans plum, planted by Joseph Cooper, Esq. of Gloucester county, New-Jersey.

KIRKE'S PLUM. Pom. mag. Lond. Hort. cat.

This is said to be one of the best plums they have in England, and I copy the following description from the Pomological Magazine, published in London:

"It is very handsome, a most abundant bearer both as a standard and upon a.west or east wall, and its flavour is scarcely inferior to that of the Green Gage. It was first brought into notice by Mr. Kirke, whose name it bears, and was met with by that gentleman in a singular way. Passing along the street one day, he was struck with the beauty of a basket of plums in a fiuiterer's window. Upon tasting them, he was surprised to find that they excelled in flavour any purple plum with which he was acquainted. The fruiterer had received them from a gardener in the country, who, it afterwards appeared, had procured the variety from the garden of a gen- 
tleman in his neighbourhood, and to that garden it was said to have been introduced from some foreign country. We have in vain sought to trace it in the writings of foreign pomological authors; and we therefore figure it for the sake of making it known through the means of this publication. A plum as hardy and prolific as the Orleans, as handsome as the Damask, and as good as the Green Gage, cannot be too extensively cultivated; it ripens in the beginning of September; wood very like that of the Red Magnum Bonum; flowers resembling those of the Reine Claude Violette, which, however, this is not ; leaves like those of the Green Gage ; fruit large, roundish oval, rather broadest at the base; suture slightly depressed; stalk three quarters of an inch long, very little sunk at its point of insertion; apex not depressed; skin covered with a close, firm, copious, azure bloom, through which appear a few golden specks: this bloom is extremely remarkable, and does not readily rub off; flesh greenish yellow, firm, juicy, and rich; stone middle-sized, irregularly and broadly oval, flattened, with a groove or channel along one face. The accompanying figure was taken from a specimen grown on a wall. There is another plum in cultivation about London like this, purple, a great bearer, and also called Kirke's, but it is of very inferior quality. Purchasers will do well to bear this in mind."

ELFREY. Pr. cat. Coxe. Lond. Hort. cat.

\section{Elfreth's prune. Elfrey's prune.}

This tree is of very vigorous growth, the foliage is luxuriant and glossy, and has a particularly flourishing appearance; the fruit is about an inch and three-eighths in length, and an inch in diameter; the skin is blue; the flesh of a greenish colour, firm, rich, somewhat dry and of a pleasant flavour; the fruit frequently splits open when fully ripe. This plum is much admired and ripens in August; the tree is exceedingly productive. There appear to be two distinct varieties cultivated in gardens under the name of the present one. 


\section{LATE CHALONS. Pr. CAT.}

\section{Tardif de Chalons. Tardive de Chalons. N. Duh.}

This fruit is nearly oval, sometimes a little contracted at the base ; it is fourteen lines in length, and thirteen in diameter; the skin is at first of a whitish yellow hue, with a slight tinge of red next the peduncle; afterwards at its full maturity, the skin becomes wholly of a pale violet colour, covered with bloom; the flesh is yellowish, melting and very juicy; previous to its attaining its full maturity, it is slightly acid, and as it possesses more flavour when in that state, it is in reality better than when perfectly ripe, at which period it acquires a sweet taste, but is devoid of flavour; the stone is rather rough and adheres to the flesh. This plum is very late, not ripening until the first part of October. It is stated in the New Duhamel, that the authors had only met with this variety in the Jardin des Plantes, which shows that it is rare.

\section{LUCOMBE'S NONSUCH. Por. Mag.}

I extract the following description of this plum from the Pomological Magazine:

"This valuable variety has been lately raised from seed by Messrs. Lucombe, Pince, and Co., of Exeter, by whom we were favoured with the specimen now represented. It is undoubtedly the nearest approach that has as yet been made on the part of a seedling to the famous Green Gage of the English, or Reine Claude of the French, and although it cannot be said to equal, in all respects, that celebrated variety, it is nevertheless entitled to a character of very high excellence. It bears well as a standard, is remarkably handsome, as it were variegated with dull yellow and orange, and larger than the Green Gage usually is. We consider it an important acquisition to our varieties of plums; ripens about the end of August; wood very like that of the Green Gage, strong, short-jointed, smooth, brown, sprinkled in some places with a brownish epidermis ; leaves middle-sized, ovate or broadly oval, acuminate, 
doubly crenated, quite smooth on the upper surface; petioles strong, about an inch in length; flowers middle-sized; petals roundish oblong, somewhat concave at the top; fruit extremely like a Green Gage plum in colour, but more streaked with yellow, covered with a fine glaucous bloum, generally compressed in the direction of its suture, which is the reverse of the usual mode of compression in stone fruit; stone adhering firmly to the flesh, ovate, not very uneven; flesh firm, juicy, of the colour and consistence of a Green Gage plum; flavour between that and an Orleans, better than the latter, but perhaps not so good as the former, when in its highest perfection.

\section{ROGNON D'ANE. N. Duh. Calver.}

This fruit is of very large size, and also of a very dark purple colour, almost black; it greatly resembles the Yellow Egg in point of form, and attains its maturity at the beginning of September.

DUANE'S PURPLE FRENCH. Pr. cat. Pr. Hort.

Duane's large purple. Duane's large Orleans.

This plum I received from my esteemed friend James Duane, Esq. of Duanesburg, who obtained it originally from France many years since. Its colour is a pale purple or violet; its flesh is juicy and fine flavoured, and it is of monstrous size; indeed I never recollect seeing a larger purple plum; it ripens the beginning of August. The tree is of exceedingly vigorous growth, and the bark of the young shoots is downy and of a grayish colour. The fruit ripens in the month of August.

\section{PRUNE D'AST. N. Dur. Calvel.}

This plum, M. Calvel remarks, is very little known in the northern departments of France, but it is much cultivated and in high estimation in the south of that country for making prunes. It is preferred to the Agen Date, which it greatly resembles; it is however, of larger size and not equally good 
for eating. The period of its ripening is the middle of August; there is a sub-variety which has always a double kernel.

\section{Bingham. Pr. cat. Pr. Hor't.}

This fruit is of a large size, oval form, and yellow colour, and in its shape and appearance assimilates to the Yellow Egg, but is of smaller dimensions; the flesh is tender, juicy, and of good flavour; the tree is of luxuriant growth. There can be little doubt but this variety is also cultivated under a different title, as the one here adopted appears to be of local application, arising from ignorance of its true name. The fruit ripens early in August. I received this variety from Philadelphia, where it appears to have received its title from a family of the name of Bingham.

\section{WINE PLUM. Coxe.}

This fruit is above an inch and a half long, and about an inch and three-eighths in diameter at the largest part; the form is oblong, diminishing both towards the base and the extremity; the peduncle is long in proportion to the size of the fruit; the skin is of a pale green hue, and the flesh juicy, rich and of good flavour. This plum ripens in August, and Mr. Coxe makes the remark that it is less in size than the White Magnum Bonum, but otherwise much like it in appearance.

\section{WINESOUR. Pr. cat. Lond. Hort. cat. For.}

This plum is from Yorkshire, England, and is one of the best for preserving ; it is of oblong form, and somewhat larger than a Damson; the skin is of a dark purple or blackish colour when ripe; the flesh is yellow, juicy, of a pleasant acid flavour, and adheres to the stone. The fruit ripens in October; the tree produces abundantly, and will succeed in any soil, but flourishes most in limestone or gravel.

Wetherill's SWeET. Pr. cat. Pr. hort. LOND. HORT. CAT.

This fruit is of small size, being but little larger than the Late Purple Damson; the flesh is sweet, of delicious flavour, and adheres to the stone. It is at maturity in August. 


\section{NECTARINE PLUM. Pon. Mac.}

Caledonia. Goliath, of some collections.

Prune Pêche. Lond. Hort. cat. No. 190 syn. Howell's large.

The following details relative to this plum I copy from the Pomological Magazine :

"Two plums, which it is presumed will now be rendered very distinct, have hitherto been confused under the names of Nectarine plum, Goliath, and Caledonian. They are ranged as synonymous in Hooker's Pomona Londinensis, in Forsyth, seventh edition, and in the London Horticultural Society's Catalogue. The Nectarine plum will however be found superior to the other, which is more generally cultivated under the name of Goliath. The appearance of the two sorts of fruit is considerably alike, but in order to distinguish them very readily, it will be only necessary to observe that the shoots of this sort are glabrous, and those of the other very pubescent. This smoothness and pubescence extends also to the fruit stalks of the respective sorts, so that they may be known by them independent of the shoots. This is a good bearer and ripens in July, being considerably earlier than the Goliath.

"The wood is strong, shoots glabrous, brownish violet where exposed to the sun; leaves large, ovate, flat, or somewhat convex, with rounded serratures, and having large glands at the base; petioles strong, scarcely an inch in length on the young shoots; flowers large; petals roundish, much imbricated; fruit very large, like a nectarine in shape and size; footstalk smooth, about half an inch in length, and of moderate thickness; skin purple, covered with a fine azure bloom; flesh dull greenish yellow, somewhat adhering to the stone, but less so than in the Goliath, compared with which it is much finer and richer, being decidedly the best plum yet known of its size : stone middle-sized, oval, compressed." 
BRICETTE. PR. CA'T. LOND. HOR'T. CAT.

Bricet. Bricette. Duh.

Petite Bricette. Bon. Jard.

This plum is of a peculiar form, it is oval and partially compressed at the base, sixteen lines long, and twelve to thirteen at its largest section; the suture is marked only by a line which is scarcely apparent; the peduncle is nine lines in length; the flesh is yellowish as well as the skin, quite firm, rather more dry than juicy, of an acid flavour, and without any quality that is particularly pleasant, it separates readily from the stone, which is large in proportion to the size of the fruit, with quite a deep groove along one of its edges. This plum ripens in the course of the month of September, but as it strongly adheres to the peduncle and that does not detach itself readily from the branch, it often happens when people neglect to gather it, that the fruit remains a very long time upon the tree. Duhamel mentions having seen a considerable quantity hanging upon the branches after they were entirely stripped of their foliage, which was at the end of November. In this state the fruit becomes half preserved and somewhat improved in sweetness, but it does not acquire any very pleasant flavour.

\section{TWICE BEARING. Pr. cat.}

$\left.\begin{array}{l}\text { Prune de deux saisons. } \\ \text { Prunier qui fructifie deux fois par an. }\end{array}\right\}$ Duh.'

Deux fois l'an. Bon deux fois l'an?

Bifère. Prune bifère.

This fruit is oval, sixteen to seventeen lines in length, and thirteen to fourteen in diameter; the skin is at first greenish, but in ripening acquires a slight tinge of violet on the side next the sun, and at its full maturity is almost wholly of a pale purple colour, with some fawn-coloured dots, the extremity of the fruit being the only part which retains its greenish appearance; the peduncle is seven to eight lines long; the flesh is greenish, approaching to yellow, adheres strongly to 
the stone, and is soft, sweetish, and without flavour. It appears by the statement given in the New Duhamel, that this tree does not produce two distinct crops, but that the fruit ripens by degrees from August to October, and consequently a portion of it hangs on the tree for a long period after the earliest part has attained its maturity. The Jardin Fruitier describes a plum under the title of Bifère, as producing a crop in July, and a second one in September, and the Bon Jardinier copies from it, but the statement wants confirmation.

\section{RED CHICASAW. Pr. cat.}

Prunus Chicasa. Mich. Pursh.

Cherokee. Lond. Hort. Cat.?

Prunier de Virginie. Duh.?

Mandan plum.

This fruit is nearly round and of good size; the skin is of a fine cherry colour; the flesh yellowish, soft and melting when at full maturity, with a pleasant and peculiar flavour. This plum ripens from the 20th to the end of July. The tree is naturally low set and bushy, being inclined to spread its branches but a short distance from the ground. It also throws out short spurs, with leaves on them, each of which is terminated by a sharp pointed thorn. Numerous suckers spring up from the root and serve as a means of propagation; but the trees which are inoculated on other stocks attain the handsomest form and make far the best appearance, and they have also the advantage of not generating suckers to the same extent. There is another variety which produces yellow fruit, - but it differs only in respect to colour.

White PEar PLUM. Pr. cat. Mil. Lond. hort. cat.

This fruit is suitable for preserves, but is very unpleasant to eat in a natural state; it ripens very late in the season. The tree is seldom cultivated except for stocks to inoculate the other varieties of plums upon, and also the choice kinds of Peaches and Apricots. There is also a dark coloured variety called the Black Pear plum. 
MUSCLE. Pr. cat. Mrl. Lond. hort. cat.

Mussel.

The chief use made of this tree is also to form stocks on which to propagate the other varieties of plums, as well as peaches and apricots. The fruit is of an oblong form, and dark red colour; the stone is large in proportion, and the flesh is but thin, and not of good flavour.

BULlace. Pr. cal. Mir.

\section{Prunus insititia.}

This is a distinct species of the plum; the tree grows twelve to fifteen feet high or more, the branches are generally thorny, and the leaves are on short petioles; the fruit is acid, "but so tempered by sweetness and roughness as not to be unpleasant," especially after it is mellowed by frost. A conserve is made by adding to the fruit thrice its weight in sugar. An infusion of the flowers sweetened with sugar is a mild purgative, not improper for children; the bark of the roots and branches is considerably styptic. There are two varieties, called the White and the Black Bullace, which produce fruit of the different colours corresponding to their titles.

\section{BRIANCON. Pr. CAT. LoNd. hORT. CA'T.}

\section{Prunus Brigantiaca.}

This species grows only to the height of eight to ten feet; the leaves are oval and glabrous, bordered with unequal indentures, and terminate in a rather acute point. The flowers appear in the month of April, before the leaves; they are ranged along the branches in the same situations which were occupied by the leaves of the previous season, and there are usually three or four together. The fruit is nearly globular, smooth, of a pale yellow colour, with some reddish touches next to the sun; the flesh is yellow, partially acid before fully ripe, and even at maturity not very pleasant, but of a rather insipid flavour. The stone separates freely from the flesh, and

$$
\text { voL. II. }
$$


contains a bitter kernel. The Marmotte oil, (l'huile de Marmotte, which sells in France at double the price of olive oil, is extracted from the stones of this fruit; it is as sweet as that extracted from the almond, and more inflammable. The tree is of very easy culture, and its appearance is very different from that of other plum trees, being intermediate between the plum and the apricot.

SLOE. Pr. CAT.

White blossomed Sloe.

Black thorn. Prunelier. Prunus spinosa.

Prunier épineux. Epine noire.

Common Sloe. Prunallier.
Petit prunallier.

This is naturally a large shrub, rather than a tree; it sometimes attains to ten or twelve feet in height, seldom more, and frequently forms only a bush of a few feet high. The large branches form numerous small twigs, from one to three inches in length, each of which is terminated by a thorn; the bark is of a ruddy brown colour, and in some cases of a grayish hue; the leaves are numerous, small, and finely indented; the flowers, which are small and white, are produced in great numbers along the branches, and particularly on those which are thorny, and render the shrub very ornamental. The fruit is small, almost globular, of a dark violet colour, and covered with a thick bloom; it is very acid, powerfully astringent, and hangs on the trees until long after frost, which is said to somewhat ameliorate it; when made into a conserve it is very efficacious in cases of hoarseness and common colds. The Double-flowering Sloe is a very showy, beautiful shrub, of rather lower growth, and produces no fruit. The leaves of the Sloe are used in the vicinity of London to make an imitation of tea.

LARGE PEACH PLUM. Pr. cat.

Prune pêche. Duh. Calvel. Bon. Jard.

Peach plum. Pr. Hort.

This tree is of exceedingly vigorous growth, and appears to be particularly adapted to our climate. Although intro= 
duced but a few years since, it has produced fruit in a number of instances, some specimens of which were last year exhibited to the Massachusetts Horticultural Society. The fruit is of very large size, and of an oval form; the skin is of a fine purple colour, with a slight bloom; the flesh adheres to the stone, and resembles that of the Monsieur, but is not quite equal to it in quality. It attains its maturity in the month of August. The Pomological Magazine quotes the Peach plum of the Horticultural Society's Catalogue, as a synonyme of the Nectarine plum; but whether that synonyme refers to the kind here described, appears to be a point not adequately settled, otherwise the Prune pêche of Duhamel and other French authors would have been also quoted as a synonyme: such omission would be unpardonable if the point of identity had been satisfactorily ascertained by the authors of that work.

ISABELLA. Pom. Mag.

This plum is said to exceed most of the English varieties, and to be secondary only to the Green Gage, Coe's Golden Drop, the Washington, and other plums of primary excellence. The Pomological Magazine gives the following account of it :

"This tree is said to produce three crops a year. In the specimens we examined there was fruit perfectly ripe and half grown. The shoots are vigorous, brownish, and pubescent, like an Orleans; the leaves middle-sized, oval, crenated, slightly pubescent above; petioles of medium length and thickness; flowers middled-sized; petals roundish, obovate; the fruit two inches and a quarter long, and one and fiveeighths broad, oblong, and tapering towards the stalk, with very little apparent suture; stalk half an inch long, very slightly downy ; skin deep dull brownish red when nearly ripe, where shaded a little inclining to yellow, copiously covered with deep-coloured dots; flesh sweet, rich, and very agreeable, adhering to the stone, which is acute at each end, but tapering a good deal towards the base, and one and a quarter inches long." 
beach Plum. Pr. cat. Bignlow.

Prunus littoralis. Bigelow. | Prunus spherocarpa. Michaux.

This variety does not attain to much height, but throws out numerous branches at a short distance from the ground, forming a bushy shrub rather than a tree. The flowers appear before the leaves, in numerous umbels, comprising from two to five each ; the fruit is globular, often an inch in diameter, of a purple colour, with a glaucous bloom ; it is pleasant for eating, and in flavour similar to the common plum. Its natural location is near the salt water, along the coast and on islands. The fruit ripens in August and September. Gen. Dearborn, the enlightened and distinguished President of the Massachusetts Horticultural Society, has himself discovered several varieties of it growing in a wild state, two of which are purple, but vary in respect to size, and a third of a shining crimson colour; and it is to his liberality that I am indebted for the trees in my collection.

\section{PRINCE'S YELLOW GAGE. Pr. CAT.}

This excellent variety was originated by the grandfather of the author, in the year 1783, from a seed of the Green Gage, and from some cause was not until lately much increased in the nurseries. The tree is of strong and vigorous growth, far surpassing its parent in this respect; the fruit is also of larger size, and of a rather oval form, its length being somewhat more than its diameter. When the fruit has attained its perfect maturity the skin is a bright yellow, and of an almost transparent appearance, with veins of a darker colour under the surface; the flesh is sweet, rich, and high-flavoured. The fruit ripens rather later than the Green Gage, and is very highly esteemed. 


\section{CHERRIES.}

BLACK MAZZARD. Pr. cat. Lond. hort. cat.

Mazzard, or Common Black. Coxe.

Bristol cherry, of Rhode-Island.

Prunus avium. Willd. Pers. sinop.

Cerasus avium. N. Duh. Decand.

Cerisier Merisier. Duh. | Merisier.

Cerisier sauvage. Mazard.

Common Mazard. Black honey.

THIS is the natural species whence culture has obtained all the fine varieties known by the appellations of Heart cherries and Bigarreau cherries. It grows spontaneously in the forests of France, and some other countries of Europe, and is said to be found also in Africa. Although an exotic. in our country, it has become so much disseminated, that thousands of the trees are found growing wild in the forests of Long Island. It is of rapid growth, and attains a very large size, with a lofty conical shaped head rising to the height of thirty to forty feet, which renders its appearance particularly graceful. The fruit is small, being but four or five lines in diameter and five or six in height; its form is more ovate than heart-shaped; the skin is of a very dark red or blackish hue ; the flesh is of the same colour, acid and bitterish before maturity, but very sweet, without much flavour when perfectly ripe. This variety ripens after the Heart cherries and most other varieties are past, and is valuable on that account. The fruit is much used in this vicinity to make cherry brandy and cherry rum, for which purpose the juice is distrained, and then added to the liquor. Thousands of bushels are consumed in this way, the fruit being sold at about a dollar per bushel, at which price it affords a handsome profit to the owners of the trees, as the crops are exceedingly abundant. The trees of 
this and of the Yellow Honey cherry are planted in great numbers along the sides of the highways in many parts of Long Island, and hundreds of children regale themselve swith the fruit at the period of its maturity.

\section{LARGE BLACK MERISE. PR. CAT.}

Merisier à gros fruit noir. Grosse Merise noire. N. Duh.

Corone? Caroon? Kirchenwasser?

This tree does not attain so great a height as the smaller fruited varieties ; its leaves are, however, of a darker green, and their nerves are usually of a reddish colour. The fruit, in its size, approaches that of the smallest Heart cherries; it is oblong, and has a long peduncle; the flesh is tender, very dark red, and almost black, mild, sweet, but without much flavour. This variety is cultivated for its fruit, which is made use of in Europe to colour the ratafia; it is also used to make the famous Kirchenwasser.

\section{YELLOW HONEY. Pr. cat.}

Honey. Coxe.

Merisier à fruit blanc. Merise blanche. N. Duh.

Cerise blınche. Cerise anbrée, erroneously.

Large Yellow Honey. Lond. Hort. cat.

This tree attains to nearly or quite as great a height as the Black Mazzard, and is more spreading in its form; the fruit is round, about six lines in diameter, yellow, approaching to an amber hue, and partially tinged with red on the part exposed to the sun ; it is bland, sweet, and very pleasant, and much superior to the two other varieties of the Merise which immediately precede this, and to the one that is next after described. The fruit ripens late, and at about the same time as the Black Mazzard, which gives it additional value.

\section{YELLOW FRUITED MERISE. Auth.}

Merisier à fruit jaune. Merise jaune. N. Duh.

This variety is distinguished from the preceding one by the colour of its fruit, which is entirely of a yellow colour; its flavour is also considered to be rather inferior to the foregoing one. 
BLACK CARONE. Pr. cat. Lang. For.

Corone. Lang. Lond. Hort. cat.

Caroon. Coroun.

This is a large and improved variety of the Black Mazzard, which it resembles in form, colour, and general properties; the fruit ripens about the same time, and may be used for the same purposes; but its size renders it more suitable for the dessert. The tree yields plentiful crops.

\section{LARGE DOUbLE FloWERING. Pr. cat. Pr. hort.}

Cerasus avium, multiplex. Lond. Hort. Brit.

Prunus avium, flore pleno.

Prunus cerasus, flore pleno.

Merisier à fleurs doubles. Duh. Lond. Hort. cat.

This variety is of the same species as the Heart Cherries, and it consequently forms a large tree. In growth and foliage it resembles the Mazzard and the Black Heart; the flowers are from one to one and a half inches in diameter, and are composed of about forty perfectly white petals disposed in the form of a rose, with about thirty stamens, and a very large pistil which is abortive. These very double flowers are produced in great numbers, resembling clusters of small white roses, and render the tree one of the greatest ornaments of the garden; and when it has acquired to a considerable size, which its rapid growth enables it speedily to attain, the display of its great profusion of blossoms is peculiarly striking. I have never yet known this tree to produce fruit. Its flowers expand at about the same period as those of other cherries, but continue for a longer period.

\section{EARLY GUIGNE. Auth.}

\section{$\left.\begin{array}{l}\text { Guigne précoce. } \\ \text { Guigne de la Pentecôte. }\end{array}\right\}$ Duh.}

This fruit begins to ripen at the end of the month of May; it is then small, whitish tinged with light red, and almost devoid of flavour ; but, as it is one of the earliest varieties, it is esteemed as an appendage to the desert. About the middle of 
June, when it has attained its full size and perfect maturity, it. sometimes measures nine lines in diameter and seven in height, and the skin acquires a darker hue, and becomes of a fine red colour upon a pale yellow ground; the flesh is, at that period, rather firm, and of a pleasant flavour. There is a sub-variety of this Cherry, which differs only in being of much larger size.

RED GUIGNE. Auth.

Guigne rouge. Duh.

This fruit is more oblong than the early Guigne, and of rather larger size, being nine lines in height and the same in diameter; its skin is entirely red; the flesh soft and delicate, but not very high flavoured. It ripens in June.

\section{EARLY WhITE GUIGNE. Pr. cat.}

Guigne blanche.
Guigne à gros fruit blanc. Duh.

White Heart?

This variety is not so large as the preceding one, but more oblong; the side, which is shaded, is of a dingy white; that which is exposed to the sun is washed with red or flesh colour; and when the fruit is very much exposed, it frequently happens that a portion of it becomes tinged almost wholly with light red. The flesh is white, somewhat firm, and of an agreeable flavour. The fruit ripens about the middle of June.

\section{BLACK GUIGNE. АขTH.}

Guigne noire. Guigne ì fruit noir. Duh.

This variety is smaller than either of the two preceding ones; it has a thin skin, which is brown, and nearly black when the fruit is fully ripe; the flesh is of a very dark red colour, tender without being soft, and of good flavour. It is at maturity the beginning of June.

SMALL BLACK GUIIGNE. Auth.

Petite Guigne noire. Guigne à fruit noir. Duh.

This variety does not differ greatly from the preceding one; 
its fruit is, however, of less length ; its flesh is not of as deep a red colour, and it is also rather inferior to it in point of flavour.

\section{GUIGNE BIGAUDELle. N. DuH. Le Berr.}

This cherry resembles in its form the Early Guigne; but its skin is brownish red, and becomes nearly black at perfect maturity; the flesh is dark red, somewhat firm, and of a rich flavour in warm and light soils. It ripens at the end of June.

\section{LATE WHITE GUIGNE. AuTh.}

Guigne blanche tardive. Guigne de Dure Peau. N. Duh.

This variety is nearly round, but has a rather deep longitudinal suture; the skin is whitish, or of a very pale amber hue, tinged with light red; the flesh is firm, and of quite an agreeable taste. It is stated in the New Duhamel, that it does not attain its maturity in France until September. I have not had an opportunity of deciding that point as regards our country.

\section{LATE RED GUIGNE. AUTH.}

Guigne rouge tardive. N. Duh. Guigne de fer, ou de Saint Gilles. Iron Cherry.

This cherry is quite round, of a dark violet colour, approaching black; it is one of the latest varieties, and even in the South of France does not ripen till July. The French writers state, that in the northern part of that country it does not attain its maturity until September.

BLACK TARTARIAN. Pr. Ca'. Pr. hort. Pom. mag. LOND. HORT. CAT.

Black Circassian. Hook. Pom.

Fraser's Black Tartarian.

Fraser's Black Heart. Ronald's Black Heart. Superb Circassian. Black Russian.

Of various collections and gardens.

This very superior variety was long since introduced to our country by the father of the author, through whose exertions 
thousands of the trees have been disseminated in the Union. I copy the following description from the Pomological Manual:

"This cherry is generally considered to have been brought into this country by the late Mr. John Fraser, from Russia. In the account given of it in the Pomona Londinensis, it is stated to have been introduced from Circassia by Mr. Hugh Ronalds, of Brentford, in 1794. We have also heard it said that it originated in Spain, whence it was transmitted to the Russian Gardens, and through them into England. It is a cherry of great excellence, bearing well as a standard, but doing best on an east or west wall, on which its branches are usually loaded with a profusion of rich and handsome fruit. It has received in our gardens a variety of names, of which those given here are only a portion; but those which are omitted are readily referable to some of the above. The wood is vigorous; the branches upright, the bark of the young shoots light-coloured and spotted; leaves large, pendulous, waved on the margin, evenly serrated, deep green, veins prominent beneath ; flowers large; petals roundish oval, concave and imbricating; stamens shorter than the styles; fruit large, heart-shaped, with an uneven surface, and of a shining purplish black colour ; flesh purplish, juicy and rich ; stone middle-sized, roundish ovate."

White taRtarian. Pr. Cat. Pr. hoRt. For. LOND. HORT. CAT.

White Transparent. Transparent Crimea. Fraser's White Tartarian. White Transparent.

Lady Southampton's Duke. Yellow.

The cherry, long cultivated and most generally known by this title, I discovered, a few years since, to be entirely erroneous, it being nothing more than a half barren variety of the White Heart. The genuine kind is a beautiful fruit, of medium size, excellent quality, and of a transparent appearance. The tree grows rapidly, erect like the White Heart, and bears well; the fruit ripens in June, and is highly esteemed. 
PLack Heart. Pr. cat. Law. Mre. Lang. For. LOND. HOR'T. CAT.

\section{Large Black Heart. Coxe.}

This tree asquires the very largest dimensions attainable by any of its class; the branches spread widely, and frequently form a head of thirty-five to forty feet in diameter, the summit of which is about thirty to thirty-five in height. It grows vigorously, and is one of the most productive in its crops. This variety is more extensively cultivated in this vicinity than any other, probably from the circumstance of its early introduction, as well as from its good qualities already referred to, and fully one half of the cherries sold in the markets of NewYork are of this kind. The fruit is of fine size, of a heartshape, and blackish when at full maturity; but it is generally picked before it is ripe, when its colour is only red, and it has attained but two-thirds of its size; the flesh, when perfectly ripe, is very sweet, rich; juicy, and high flavoured, and it is even quite sweet before maturity, when the skin has only acquired its red colour. The tree is of the most vigorous growth, and the fruit ripens about ten days after the May Duke.

White heart. Pr. cat. Lang. Law. Mil. LOND. HORT. CAT. FOR. COXE.

This cherry ripens immediately after the May Duke; the tree attains to an erect and rather conical form, spreading much less than most other varieties; the fruit is of medium size, oblong and heart-shaped; the skin is of fine appearance, being a yellowish white on the one side, and tinged with pale red next the sun ; the flesh is rather firm, of pleasant flavour, accompanied by a honied sweetness. The tree bears very indifferently, but grows with rapidity until it has attained considerable size. I noticed, when on a visit to the vicinity of Boston, in 1826, that the cherry, to which some gave this title, was a late whitish firm fruit, entirely different from the present variety: that error has, however, most probably been corrected since 
the formation of the Horticultural Society there, whose labours appear to be most unwearied, and eminently successful.

Black Eagle. Pr. cat. Ponr. mag. Hort. Trans.

The following descriptive remarks I copy from the Pomological Magazine :

"This is as good a bearer as the Black Heart, and far superior to that variety in the quality of its fruit : it is not to be doubted that this will one day usurp the place of that ancient variety in our gardens.

" It was raised by Mr. Knight from a seed of the Ambrée of Duhamel, impregnated with the pollen of the May Duke; and it really combines all that is most worth raising in both these varieties. At least, such is the account of its origin as given in the Horticultural Transactions, vol. ii. p. 208, and it is probably the genuine history of the variety, notwithstanding a different account to be found at p. 302 of the same volume.

"This is another of the cherries raised by Mr. Knight which have been allowed an introduction into this work; and it is not too much to say, that the improved varieties of the distinguished horticulturist, to whom they owe their origin, are among the most valuable sorts that we possess. It ripens soon after the May Duke; the tree is spreading; branches strong, dark brown, partially sprinkled with a grayish epidermis ; leaves oblong, acuminate, broadest about twothirds from the base, doubly serrated, but not so deeply as those of the Heart Cherries generally are ; partaking also of the thick texture of the leaves of the Duke Cherries; from their larger size, pendulous growth, and somewhat wavy margin, they are rather more allied to those of the former; petioles longish, and moderately strong, with reniform glands; flowers middle-sized; stamens shorter than the style; petals roundish or roundish-oval, concave, imbricated; fruit between heart-shaped and round, flattened at top and bottom ; stalk short and thick, like that of the May Duke; skin black, when the fruit is fully ripe and well exposed; flesh tender, with a dark purplish juice, rich and high flavoured; stone small, round." 
ElKhorN. Pr. cat. Pr. hort. Lond, hort. cat.

Elkhorn, of Maryland.

This is one of the largest black cherries I have ever seen; its size varies little from that of the Black Tartarian, but it ripens two weeks later, and is peculiarly distinct from every other kind that has met my observation, the flesh, when eaten, having a liver-like consistence and being very solid. It is perhaps less highly flavoured than some others, but still a superior fruit ; and from its solidity is well calculated for transportation to the markets, and its ripening at a later period causes it to be very suitable for filling up the space between the ripening of the earlier Duke and Heart Cherries, and the later varieties. It was discovered by the father of the author on a tour through Maryland about thirty-four years ago, growing in a garden attached to a hotel, who finding it very different from any that he had seen, brought home some scions for inoculation. The landlord called it the Elkhorn, which name has been adopted for it. The tree is exceedingly vigorous, and its bark of so peculiar an appearance, that it may thereby be distinguished from the trees of other varieties.

REMington White heart. Pr. cat. Pr. hort.

This variety was presented to the father of the author in 1823, by Zachariah Allen, Esq. of Providence, Rhode Island, who transmitted a tree, which he stated was budded from the original one, accompanied by the following description :

"This is a new variety raised from a stone, planted about twenty years ago by Mr. Remington of this vicinity. It is remarkable for being in perfection very late in the season, when all other cherries are past. The colour of the fruit is yellow, tinged with carnation on the sunny side; the flesh is firm, and somewhat resembles a Bigarreau. The tree bears profusely in clusters, and the cherries are not perfectly ripe here until September."

In addition to the above, a branch was sent from Rhode Island about the 10th of September full of fruit, which was 
then but just ripe. The flavour of the cherries is pleasant, but not superior, their greatest merit being the very late period of their maturity. This is the latest variety which has originated in our country, and in this vicinity ripens at the end of July or in August.

Waterloo. Pr. car. Pom. hag. Hort. trans.

LOND. HORT. CAT.

This valuable variety was introduced to our country by the Hon. John Lowell of Massachusetts, to whose ardour, intelligence, and liberality in horticultural pursuits, his fellowcitizens are so largely indebted for numerous interesting acquisitions, and to whom I am happy to render this passing tribute of respect. I extract the following description from the Pomological Magazine :

"Raised by Mr. Knight, from the pollen of the May Duke and a seed of the Ambrée of Duhamel. It ripens in June. The tree partakes of the character of both its parents in a remarkable degree; the wood and leaves are those of the $\mathrm{Bi}$ garreau tribe, while the flowers are those of the May Duke, the stamens being shorter than the styles, a peculiarity which is universal in all the Duke Cherries. For this observation we are indebted to Mr. Thompson. The wood is strong, with a grayish cuticle; leaves drooping, large, wavy, with moderately deep serratures; flowers large; petals roundish, imbricated; stamens rather slender, usually shorter than the styles; fruit very large, broad and cordate at the base, convex on one side, flattened on the other with a broad suture; apex slightly depressed; skin dark, purplish red, or almost black, covered with numerous minute dots of a paler colour; flesh deep purplish red, darkest next the stone, from which it parts freely; tender, juicy, with a rich sweet flavour; stalks long and slender; stone small, roundish, compressed.

\section{LUNDIE GUIGne. Pr. cat.}

Lundie Gean. For. Lond. Hort. cat.

This tree is of vigorous growth, and attains to a large size; 
the fruit is black, about the size of a Black Heart, of fine quality and pleasant flavour. In some situations the tree does not bear very well.

\section{transparent GUigne. Pr. cat.}

\section{Transparent Gean. For.}

The word Gean, applied to a number of varieties of cherries by the English, is only a corruption of the French word Guigne, and should therefore be exploded, and give place to the correct appellation. The fruit of the present variety is of medium size, and oblong form; the skin is of a yellowish colour tinged with red; the flesh is of pleasant taste and good flavour. It has the advantage of ripening quite late, being at maturity in July, about the same period as the Honey Cherry. The tree is one of the most vigorous in its growth, and attains a large size and stately form; it is also one of the most productive, yielding abundant and regular crops.

\section{POINTED GUIGNE. Auth.}

\section{Guigne piquante. Guigne à piquet. N. Duh.}

This variety derives its title from the circumstance, that a part of the style becomes hard and ligneous, and forms a kind of sharp point at the extremity of the fruit, which is more of a heart-shape than any other Guigne cherry; its diameter is eight lines, and its height rather less; the skin is dark red on the sunny side, and light red and even yellowish on the other; the flesh is firm, crisp, of quite a rich taste, accompanied by a little bitterness. This variety is not much cultivated in France, because it ripens in June, at the same period as many other kinds which are preferable to it.

\section{DROOPING GUIGNE. AUrr.}

Guigne à rameaux pendans. N. Duh.

This tree is only remarkable for the peculiarity of its growth, the branches being pendent or weeping like those of the Allsaints' Cherry. It is of no particular value as regards its fruit, which is indifferent in point of quality. 
KNIGH'T'S EARLY BLACK. Pr. cax. Pom. mag. Hort. Trans. LoNd. hort. CAT.

I copy the following remarks and description from the Pomological Magazine :

"If we are called upon to state specifically the difference between this and the Black Tartarian Cherry, we should certainly be unable to do so; but, at the same time, we should not be the less of opinion that they were distinct. It is well known to fruit-growers, that slight shades of difference, fleeting characters which words are unequal to express, often alone distinguish varieties materially different from each other as objects of cultivation. In figure, size, colour, and flavour, this is nearly identical with the Black Tartarian, but it has the rare merit of ripening earlier : on a south aspect it will be ripe even earlier than the May Duke. The beauty of the fruit renders it particularly interesting, and its flavour is equal to that of most cherries. This was raised by Mr. Knight, about 1810, from seed of the Graffion impregnated by the May Duke; the same parentage as the Black Eagle and the Waterloo; the branches are spreading, brown with a grayish cuticle; leaves oblong, pendulous, nearly flat, of thin texture, with unusually prominent veins beneath; flowers middle-sized; petals somewhat imbricated ; fruit large, blunt, heart-shaped, with an uneven surface like that of the Black Tartarian, but it is less pointed, and has a thicker, shorter stalk, which is rather deeply inserted; skin nearly black, shining; flesh firm, juicy, very deep purple, rich and sweet; stone small for the size of the fruit, and nearly round."

bleeding heart. Pr. cat. Lang. Law. Mr. LOND. HORT. CAT. CoXe.

\section{Ox Heart. Coxe?}

This is one of the largest and most beautiful cherries; its form is a very long heart-shape, terminating in a point; the skin of a fine dark red colour, and its flesh very high flavoured, and delicious, perhaps none more so ; the stone is also oblong. Some of the largest cherry trees I have ever seen, were of 
this variety; they grow very vigorously, and it is unfortunate that they do not bear well.

gascoigne's heart. Pr. ca't. Liang. Lond. Hort. cat.

This tree is of thrifty growth, and attains a large size; the fruit resembles the preceding in form, but is not of so dark a colour; it ripens about the same time. This variety may be easily distinguished from the Bleeding Heart by examining the growth of the tree, which is quite different. It has, however, been confused with it by several writers on pomology; but it will be perceived, on reference, that it was stated to be distinct as far back as the time of Langley.

\section{HERTFORDSHIRE BLACK. Pr. cat. Mir.}

Late Black Heart.

Herefordshire Black. Lond. Hort. cat.

Hertfordshire. For.

This fruit considerably resembles the Black Heart, and is much esteemed for its excellent qualities; it is rather more firm, of equally fine flavour, and ripens much later, which renders it valuable, as it aids in keeping up the succession of fine cherries. The tree is particularly vigorous in its growth.

elton. Pr. cat. Pom. mag. Hook. pos. Lond. hort. cat.

I copy the description of this cherry from the Pomological Magazine :

"This invaluable variety was raised in 1806, by $\mathrm{Mr}$. Knight, from a seed of the Graffion or Ambrée Cherry which had been fecundated by the pollen of the White Heart. It was first made known by Mr. Hooker, in his Pomona Londinensis, and since by communications at various times to the Horticultural Society. Its merits can scarcely be too highly spoken of. In flavour it is considered by many the most delicious of cherries; in beauty it is scarcely surpassed by any other; and its hardiness and productiveness, whether upon a standard or against a wall, are now ascertained by the experience of all who have cultivated it. It ripens in the begin- 
ning of June, about the time of the Mayduke, or soon after; the tree is strong and healthy, with dark brown wood; the shoots are rather drooping; leaves very large, doubly serrated; petioles about two inches long on the young wood, with large reniform glands near the top; flowers large, opening about the second or third week in April ; fruit about the size of the Bigarreau, and a good deal like it, but much earlier, and with a longer stalk; heart-shaped, and rather pointed ; colour, on the shaded side, pale, waxy yellow, mottled and dashed with rich red next the sun; flesh firm, but not so much so as that of the. Bigarreau, very sweet and rich; stone middle-sized, ovate.

\section{TOBACCO LEAVED. Pr. cat. Pr. hort.}

Quatre à la livre. Lond. Hort. cat. Guigne de quatre à la livre. $\quad$ Duh. Guigne à feuilles de Tabac. Bigarreautier a grandes feuilles. Jard. fruit. Cerasus decumana. De Launay. Bon. Jard. Cerisièr à feuilles de Tabac.

Four to the pound.

This fruit is rather below a medium size, of a yellowish colour on the shaded side, and mottled with red on all other parts of it, somewhat in the manner of the Carnation cherry, but more closely resembling the China Bigarreau ; the part next the peduncle is much more deeply coloured than that towards the extremity. It is partially flattened on two sides, on one of which is a rather deep and very distinct suture, and on the other a more slight one ; the form inclines to oval, with a small point or mamelon at the extremity ; the leaves, which are generally pendent, are exceedingly large and vigorous, and on the young shoots of the first year's growth from the inoculation, they often measure a foot in length, and five to eight inches in breadth ; but this character is not so remarkable on trees of more advanced age, as the leaves then produced are of much smaller dimensions. The young shoots often present a flexile or undulated appearance, which they probably acquire from the rapidity of their growth, which advances in a degree 
disproportionate to their strength and to the weight of their foliage. The French received this variety from Germany, with (as Noisette says) the assurance that its fruit was as large as the Yellow Egg-plum, which he gives as an excuse for its being imposed on the public under the name of Quatre à la livre, or Four to the pound. But what excuse is there for its having been represented in the Bon Jardinier, a work republished annually at Paris, as the largest of all cherries, for several years after the deception was ascertained? The tree is far from being productive, and yields but sparingly, and the fruit ripens late in July: its foliage, however, renders it an object of curiosity, and distinguishes it from all other cherries.

\section{ALLEN'S LATE FAVOURITE. Pr. ca'r.}

This variety was presented to my father by Zachariah Allen of Providence, a gentleman distinguished for his intelligence in horticultural pursuits. The tree grows vigorously; the fruit is of fine quality, juicy and well flavoured, and ripens in Rhode Island at the same time as the Black Mazzard, which constitutes its particular value, as most of the finer varieties are then past. The fruit is sold in corsiderable quantities in the markets at Providence.

\section{GRIDLEY. MAss. HORT.}

\section{Maccarty. Apple Cherry.}

This variety was discovered thirty-seven years ago, by $\mathbf{M r}$. Wm. Maccarty, of Roxbury, near Boston, growing in the garden of Deacon Samuel Gridley of that town. He states that the tree was then five or six inches in diameter. The flesh is firm like the Bigarreau, sprightly, and fine flavoured; the colour is black; the size that of a medium Black Heart, but the stem is shorter and stone smaller. It comes into eating immediately after that variety, and is much esteemed as a market fruit, and possesses the advantage of bearing carriage well. Its only defect is, that when near maturity, if the weather be damp or wet, the fruit cracks open and spoils. The tree grows upright, 
and is vigorous when young, but is said to be subject to a premature decline from the abundance of its produce.

\section{COEUR DE POUle. N. Duh. Calvel.}

Guigne Cour de Poule: Cerisse Cœur de Poule. N. Duh. Cor dè Galino.

It is mentioned by Calvel, and in the New Duhamel, that this variety is not often met with in the environs of Paris, but is more cultivated in the south of France, and especially in the vicinity of Thoulouse, where it is known by the title last quoted as a synonyme. The tree acquires a lofty expansion; the leaves are long, dark green, with large nerves; the buds are large, and produce one or two flowers, which are also of large dimensions, their petals being of greater size than those of the Bigarreau class. The fruit ripens in July, and its form is precisely that of a heart; it is more than an inch in length, and in some cases fifteen lines, and measures almost as much at its greatest diameter. When at maturity it is of nearly a black colour, and its juice is highly coloured and dark red; the peduncle is eighteen lines in length.

DOWNTON. Pr. cat. Pom. hag. Hort. trans. LOND. HOKI. CAT.

This variety, which has been latterly introduced into our country, is described in the Pomological Magazine as follows:

"The Downton is ripe soon after the Mayduke, it bears well as a standard, and in richness of juice it yields to no cherry of any season. It was raised by Mr. Knight from a seed either of the Waterloo or the Elton, but from which is not certain. The wood is spreading and strong; buds pointed, ovate; leaves moderately large, oblong, acuminate, pendulous, somewhat waved at the margin, acutely serrated, rather thin in texture; flowers large; stamens weak, unequal, generally as long as the style; petals obovate, imbricated; fruit pale yellowish, much speckled with red, especially towards the sun, where the red spots run together; flesh light yellow, very tender, juicy, and high flavoured. It adheres slightly to the stone." 
YELLOW SPANISH. Tourn. Mil. For.

This variety I believe to be at present extinct, as it is not enumerated in any catalogue of the present day, not even in that of the London Horticultural Society. To awaken research, however, I mention it here, as it may be synonymous with one of the French or German varieties bearing a different title. It is described as being of an oval form and amber colour, sweet and pleasant, but not of a rich flavour; the tree an indifferent bearer, and the fruit ripening in England in August, which would make it a July cherry with us, our seasons being a month earlier.

LUKEWARD'S HEART. Pr. Cat, LaNg. LoNd, hort. oat.

Lukeward. Mil. For.

Miller and Forsyth describe this as a very good cherry, of middle size, and of a dark brown or black colour. A fine pleasant fruit and the tree a good bearer. It ripens in July.

\section{WHITE BIGARREAU. Pr. cAT.}

White Ox Heart. I Tradescant. Coxe. Apple Cherry. Amber. Bigarreau blanc?

Bigarreau commun? Common French Bigarreau?

Turkey Bigarreau? Hunnewell's Favourite.

This tree is of rather slow growth, and attains to a medium size; the fruit is heart-shaped, somewhat pointed, of a very large size, and beautiful appearance; it is one of the most firm cherries, and also sweet, and of an excellent flavour, being among the most esteemed varieties; the skin is yellowish white, tinged with red next the sun, and somewhat mottled. The fruit ripens late in June or at the beginning of July. The tree is rather more tender than other varieties generally, and bears but indifferently, far less than many other excellent varieties of the same class, which cannot fail to take precedence of it as they become better known. 


\section{RED BIGARREAU. Pr. cat.}

This tree grows vigorously and attains to a larger size than the preceding one; the fruit is oblong and heart-shaped, of a dark red colour, very firm, sweet, and pleasant. The tree is far more more productive than the foregoing variety, and frequently bears abundant crops. I have noticed that it is rather more regularly productive when budded on the Kentish and other stocks of a similar character, than when budded on the Mazzard. It ripens among the latest varieties towards the end of July, and in northern localities is often not mature until in August, which renders it of particular value.

\section{NAPOLEON BIGarreaU. Pr. cat. Pr. Hort.} LOND. HoR'r. CAT.

Napoleon. Lourman. Lond. Hort. cat. Gros Bigarreau de Lauermann. Dic. d'Agric.

This tree grows vigorously and attains to a large size. The fruit is large ; the skin mottled with red; the flesh firm, sweet, and of pleasant flavour; the juice not coloured. This variety being of recent introduction, the opportunities have not yet been sufficient to fully test its excellence, but the appearance of the tree is indicative of a superior fruit; and we may justly suppose that the French would not have given this title to any variety that did not possess superior merit.

\section{CHINA BIgarREAU. Pr. cat,}

China Heart. . Pr. Hort. Pr. Cat. 26 ed.

This variety was raised by the father of the author, from a seed of the White Bigarreau, and is very distinct from every other that has met my observation. The tree grows vigorously, and attains a lofty stature; the lower branches, as it advances in height, assume in many instances a drooping or somewhat pendent form. The fruit is of moderate size, beautifully mottled, much like a waxen preparation, or some representations on China ware; the flesh is between the solid and the melting, quite sweet, with a flavour peculiar to itself, and 
differing from all others. The tree is exceedingly productive, and the fruit ripens just after the Black Tartarian, Black Heart, and many other fine cherries are past, and forms a link between them and the later varieties. As it partakes more of the Bigarreau than of the Heart class of cherries, I have thought it best to connect it by title to the former.

\section{PIGEON HEART BIGARREAU. Pr. cat.}

\section{Pigeon's Heart. Pr. Hort. \\ Bigarreau Ceur de Pigeon.
Gros Bigarreau hatif. N. Duh.}

This fruit is nine lines in height and the same in diameter; it is nearly equally diminished at the base and at the point, so that it has rather the form of an abridged oval, than that of a heart; it is convex on one side, flattened on the other, and marked with a very conspicuous suture; the side exposed to the sun is dark red, the other is a yellowish white, with a slight tinge of rose colour; the flesh is firm, crackling, and of good flavour. The fruit ripens at the end of June.

\section{LARGE RED BIGaRREaU. Pr. cat.}

Gros Bigarreau rouge. Duh. Pr. cat., 26th ed. Bigarreautier à gros fruit. Duh. syn.

The fruit of this variety is larger than the preceding one, being ten lines in diameter and the same in height; it is a little hollowed at the extremity, and flattened upon the two principal sides, each of which is marked with a suture; the skin is shining, dark red on the part exposed to the sun, and of a more delicate shade of red on the other side; the flesh is whitish, firm, succulent, and of a very rich and excellent taste. This fruit is one of the best of its kind, and ripens at Paris towards the end of July.

\section{LARGE WHITE BIGARREAU. Pr. cat.}

$\left.\begin{array}{l}\text { Bigarreau blanc le gros. } \\ \text { Gros Bigarreau blanc. } \\ \text { Bigarreautier à gros fruit blanc. }\end{array}\right\}$ Duh.

This fruit is of the same form and size as the preceding; 
it differs, however, in a few other points; its skin is altogether of a paler hue, the side exposed to the sun, instead of being deep red, is only of a flesh colour, and the opposite side is whitish; the flesh is rather less firm, and of not quite as rich a taste.

\section{COMMON FRENCH BIGARREAU. Pr. cat.}

Bigarreau commun. Duh. Pr. cat. 26 ed. Belle de Rocmont. Duh. syn.?

This is less flattened and less oblong than the Large Red Bigarreau; it measures ten lines in height and eleven in diameter; the side, which is slightly depressed, does not present any distinct suture, but has merely a whitish line partially apparent ; the skin is smooth, shining, of a fine red next the sun, marbled or finely speckled with white in different places, and of a very light red, or almost wholly whitish on the opposite side; the flesh is firm, crisp, and of a very agreeable flavour. This fruit is intermediate in its period of ripening between the early and late varieties of the Bigarreau, and attains its maturity in the earlier half of the month of July. The trees of this and of the preceding variety produce abundant crops of fruit, which is the reason that they are cultivated in preference to all the other kinds of Bigarreau, the majority of which produce much less fruit.

\section{FLESH COLOURED BIGARREAU. AUTH.}

\section{Bigarreau couleur de chair. N. Duh.}

This is an excellent fruit; it bears a strong resemblance to the preceding one, of which it is but a subvariety, distinguished by the variation in the colour of its skin, which is of a rose colour : it ripens at the end of July.

\section{LARGE LATE RED BIGARREAU. Pr. CAT.}

Gros Bigarreau tardif. N. Duh.

Bigarreau gros rouge tardif.

This fruit is, according to M. Le Berriays, of somewhat smaller size than the Large Red Bigarreau, and much later 
at maturity; the skin is of a rather dark red on the shaded side, and on the other is a brownish red, almost black, which causes this to be sometimes called the Black Bigarreau; the flesh is firm, juicy, and of excellent flavour. I imported this tree, a few years since, from France, and there are now some hundreds in the Flushing nurseries.

\title{
LARGE HEART SHAPED BIGARREAU. AurH.
}

\author{
$\left.\begin{array}{l}\text { Guigne noire luisante. } \\ \text { Guignier à gros fruit noir luisant. }\end{array}\right\}$ Duh. \\ Grosse guigne noir luisante. \\ Bigarreau Gros Coeuret. Jard. fruit. \\ Bigarreau Couret.
}

The skin of this variety is black, smooth, and shining; its flesh is red, tender without being soft, and of a rich and quite pleasant flavour; the fruit is said to be of very large size; it ripens in July, and, if it was earlier at maturity, would be preferred to most others.

\section{EARLY WHITE BIGARREAU. Auth.}

\section{$\left.\begin{array}{l}\text { Petit Bigarreau blanc hatif. } \\ \text { Bigarreautier à petit fruit hatif. }\end{array}\right\}$ Duh.}

This variety is of moderate size, measuring about eight lines in height, and rather more in diameter; the suture, which is quite conspicuous upon most other Bigarreau cherries, is, on the present one, marked but by a simple line, and this is only rendered apparent by a partial variation of colour; the skin is a light red next the sun, and white, blended with a very slight tint of rose colour, on the shaded side; the flesh is white, and not as solid as that of most others of its class, but crisp, and much more firm than that of the White Guigne, to which it bears a great resemblance in other respects; its taste is rich when at full maturity, which it attains about the middle of June; but it is somewhat acid if the fruit is not perfectly ripe.

VOL. II. 


\section{EARLY RED BIGARREAU. AUTH.}

$\left.\begin{array}{l}\text { Petit Bigarreau rouge. Cceuret. } \\ \text { Bigarreautier à fruit rouge, hatif. }\end{array}\right\}$ Duh.

This Bigarreau, according to M. Le Berriays, is rather larger than the preceding one, and a little more pointed than any other; the skin is tinged with a light red upon a whitish ground; the flesh is white, somewhat firm, and of a pleasant taste. This fruit ripens fifteen days later than the Early White Bigarreau, say about the end of June. Duhamel expresses some doubt as to its being distinct from the preceding variety, and thinks that when any difference exists, it arises from the fruit being more fully exposed to the sun, and from its being left longer on the tree, which causes it to acquire more colour.

\section{BLACK BIGARREAU. AUTh.}

Bigarreau noir. Cerise de Norwege. N. Duh.

The leaves of this tree support themselves better than those of many other Bigarreau varieties; the fruit is not distinctly flattened as many other kinds are; it measures nine lines in height and the same in diameter; its form is rather oblong without being cordate; the skin, when fully mature, is as black as that of some particular Heart cherries; the flesh is very firm, somewhat juicy, of a red colour, and not particularly rich in point of flavour.

\section{LATE BLACK BIGARREAU. Pr. сAT.}

Bigarreau noir, tardif. N. Duh.

This fruit is not as large as the preceding one, being scarcely nine lines in diameter by eight in height; it is not heartshaped, but.almost equally contracted at its base and its point, partially flattened on one side, and very rarely marked with a suture; the skin is at first a very dark brownish red, but becomes black when it attains its perfect maturity, which, at Paris, is not until the end of August ; the flesh is red, rather dry, and very firm. I have recently imported this variety, which has since been considerably increased. 


\section{hildesheim BIGarReaU. Pr. cat.}

Bigarreau marbré de Hildesheim. Dic d'Agric. Bigarreau tardif d'Hildesheim. Pr. cat. 26 ed.

This variety is of but recent introduction, and was imported by the author. The fruit is marbled with red; the flesh firm, sweet, and of pleasant flavour, and the juice free from colour; it ripens very late, not being at maturity in the north of France until the month of August.

EARLY MAY. Pr. Cait. Mil. LoNd. Hort. cat.

May Cherry. Law. Lang.

Cerisiêr nain à fruit rond précoce. Duh.

Griottier nain précoce. Griottier nain.

Of all the varieties, the fruit of this is the smallest; the tree seldom attains to more than six to seven feet in height, if inoculated near the ground; and for this reason, as well as on account of the flexibility of its branches, it is well calculated to be trained in espalier form, which is the course usually adopted in France. The only point of value in this variety is its early maturity, it being ripe before any other; it is of quite small size; its taste acid, but pleasant; and the skin of a red colour. This cherry is much cultivated at Montreuil, near Paris, for supplying the markets; and, being the first ripe, the fruit is tied in little bunches, interspersed with sprigs of the lily of the valley, \&c., and serves to gratify children.

\section{EARIY GRIO'TTE. AUTH.}

\section{Cerisier hatif. Duh.}

This tree attains a much greater height than the preceding one, but less than most other varieties of its class; it forms a head of but moderate dimensions, and its branches are drooping, especially when they are greatly loaded with fruit, which happens frequently from it being very productive. It is not uncommon to see the peduncles of six or eight cherries united in one umbel. As this tree is a great bearer, and 
its fruit quite early, it is much cultivated in the vicinity of Paris, and is the earliest, after the preceding variety, that is met with in the markets of that city. The fruit is generally gathered as soon as it acquires a pale red colour, and before it is ripe ; it is then very acid and inferior in taste ; but, when left to attain its full maturity, it becomes of a quite dark red colour, and is much better and of finer flavour.

\section{MARASQUIN. N. DUH. \\ Cerisiér Marasquin.
Griottiêr Marasquin. N. Duh.}

This variety was brought from Dalmatia. It has been suggested by Professor Bosc, that it was probably the original species; but the information possessed in regard to its growth in its native country, is too limited for a decision of that point. The fruit is small and of an acid taste, and it is supposed to be from it that they manufacture at Zara that excellent liqueur, denominated Marasquin de Zara.

\section{PROLIFIC CHERRY. AU'H.}

$\left.\begin{array}{l}\text { Cerise à trochet. } \\ \text { Cerise très fertile. }\end{array}\right\}$ Duh.

Griottier à trochet.

This tree is intermediate in height between the Early May and Early Griotte; the fruit is of moderate size, and dark red when at full maturity; the flesh is tender, but has rather much acidity. The tree is very productive, and the crop of fruit is often so abundant, that the branches, which are long and slender, bend beneath its weight.

\section{Cluster. Pr. cat. Law. Lang.}

Cerise à bouquet. Duh.

Griottier à bouquet.

Prunus Cerasus polygyna.

This tree resembles the preceding in appearance; it forms a bushy head, and its branches are in like manner feeble and pendent; but its flowers have a peculiar character, which is, 
without doubt, a monstrosity arising from cultivation. They are produced in umbels similar to the other varieties; the calyx and petals present no peculiarity, but in the centre of the flower there are several pistils, varying in number from one to a dozen, a part of which blight; but there are often several which become perfect fruits. These fruits, to the number of three, four, five, and sometimes more, are sessile at the extremity of the peduncle, closely set to each other, compressed at the sides where they touch, but perfectly distinct, and each containing a stone. Duhamel states that it is only on old trees that clusters of eight to twelve cherries are met with, and that on young trees, but one, two, three, or at most five grow upon the same peduncle. The fruit ripens about the middle of June ; the flesh is white, but too acid to be pleasant for eating, unless with sugar or in preserves. It does not appear to have been ascertained whether this tree can be reproduced from the stone with all its peculiarities of character.

MAY DUKE. Pr. cat. Law. Mil. For. Hook. Pox. LOND. HOR'T. CAT. COXE.

Duke. Lang.

Cerise Royale, hative. N. Duh.

Cerise d'Angleterre, of the Parisian gardens.

Cerisier Anglois. Royal hatif.

Early May Duke.

The present variety and the Black Heart are more extensively cultivated in this vicinity than any others, arising, no doubt, from their being among the first that were introduced from Europe. This tree attains to the height of thirty feet or more, forming a head commonly more conical than spreading; the fruit is usually the first that is met with in our markets, it being gathered for that purpose as soon as it has acquired a red colour, and before it has attained its maturity and attendant excellence. From this circumstance few are aware of its real quality when fully ripe, or even of the colour it then attains, having drawn their conclusions from seeing such as has been prematurely gathered. This cherry, when perfectly ma- 
ture, is of a very dark red colour, and of large size, often measuring two and a half inches at its greatest circumference, by nearly nine lines in height; it is compressed at both ends; the peduncle is rather long; the flesh is white, with a slight tinge of red when very ripe; tender, melting, very juicy, and high flavoured, with a partial and highly pleasant acidity. Duhamel states that there is a small leaflet on the peduncle. I do not recollect noticing that point; but it may be so. This variety is one of the most productive, the crops being very abundant. It usually attains its red colour during the last days of May, and perfects its maturity early in June. One peculiarity of this tree is, that there are almost invariably a few branches, whose fruit is quite green when the other part is ripe, and which does not come to maturity until two or three weeks later. I think Mr. Coxe labours under a mistake when he states that there are "several varieties." I have never known but one.

\section{LATE DUKE. Pr. cat. Pom. Mag. For.}

Cerise Royale. Cherry Duke. Duh.

Cerise Angloise tardive. Bon. Jard Lond. Hort. cat. Royale tardif. Bon. Jard. | Kolsmanduc. June Duke?

I copy the following remarks and description from the Pomological Magazine :

"Though this cherry is only known to us through the French gardeners, yet its name is evidence of its English origin. We have not, however, been able to discover it in cultivation in any of our own gardens, except that of the Horticultural Society, where the drawing was made, in the present year, from fruit produced on a tree received from Paris.

"Our old writers of authority, Switzer and Hitt, mention a Late May Duke, or Late Duke Cherry, which is probably the one before us ; but these names, although now to be found in the nurseries, are certainly there applied to trees in no respect different from the original May Duke. We have consequently given the name of Late Duke to the present variety, as being perfectly appropriate. The fruit ripens, on a standard, 
in August ; and, independently of its value from the period of its maturity, is of considerable excellence on account of its appearance, size, flavour, and productiveness.

" The branches are of vigorous growth, but more spreading than those of the May Duke cherry, and the leaves are larger; flowers large, and resembling those of the May Duke, but opening later; fruit large, the size of a May Duke, bluntly heart-shaped, somewhat compressed, with a shallow depression on one side ; skin a rich shining red; flesh tender, juicy, amber-coloured, and rich, of the same quality as the May Duke; stone rather large, roundish-ovate, compressed."

ARCH-DUKE. Pr. Cat. Mre. For. Lond. Hort. Cat.

Royal Archduke? Late Arch.Duke.

Arch-duc. Royal Archiduc.

Griotte de Portugal. Duh. Roz.

Portugal Duke?

The Portugal. Coxe.

This tree is thrifty, of medium size, and produces pretty good crops; the fruit is of a very large size, flattened at its base and summit, and on one side ; it measures nearly an inch at its greatest diameter, and eight or nine lines in height; the peduncle is of medium length, and rather large, especially at the section which joins the fruit; the skin is crisp, brownish red, approaching to black; the flesh is firm and crisp, of a dark red hue, devoid of acidity, but has a slight degree of bitterness, which does not prevent it, however, from being very pleasant, and even excellent in the opinion of a great many persons, who esteem it as the best of all cherries, it being also one of the largest size. It ripens during the earlier part of July.

HOLMAN'S DUKE. Pr. cat. Lang. Fur. Lond. hort. cat.

I have always suspected that this tree was synonymous with one of the other varieties of the Duke, but as several authors describe it as distinct, I insert their description of it. The branches are more spreading and loose than the Mayduke; 
the fruit is larger, of equally fine flavour, and ripens about two to three weeks later. Forsyth remarks that the tree does not bear equally well; but Langley states that it is a great bearer, and as early as the Mayduke. Mr. Coxe observes that it is an early variety of the Mayduke; so that there is much confusion in the several opinions. I shall endeavour to solve all doubts by a critical examination of the fruit produced by the trees now growing in my experimental orchard.

PRINCE'S DUKE. Pr.cat. Pr. hort. Lond. hor't. Cat.

Of all the varieties that I have seen, this cherry excels in point of size, though not greatly exceeding some of the other largest varieties. It was raised by the father of the author, from the seed of a Carnation cherry, and consequently belongs to the Griotte class. The fruit is of a red colour, shaped like that of its parent, and much compressed; very rich and luscious when at perfect maturity, but previous thereto possessing a little of the bitterness peculiar to its parent when in the same state. The tree in its growth and foliage partakes of the appearance of the Carnation cherry, and the fruit ripens about the same period. The original tree is not a good bearer, but budded on other stocks may perhaps prove more productive.

\section{SPANISH GRIOTTE. PR. CAT.}

\section{Griotte d'Espagne. N. Duh. Le Berr.}

This cherry greatly resembles the Archduke, of which it is perhaps but a sub-variety; it is still larger, being sometimes more than an inch in diameter, by eleven lines in height; the form is oblong, of smaller size at the extremity than towards the base, somewhat flattened in its diameter, but with less of a cordate form than the Heart Griotte; the peduncle is very large, and of medium length; the skin is a very brownish red or dark violet approaching to a black hue, slightly tinged with blue; the flesh is red, somewhat firm, and less melting than fine cherries usually are, sweet and rather rich. This beautiful fruit ripens the beginning of July, and if the weather be rainy when at its maturity, it causes the cherries to crack open and rot. 
belle de Choisy. Pr. cat. N. Duh. Pom. mag. JARD. FRUIT. BON JARD. LOND. HORT. CAT.

Cerise doucette. Belle de Choisy. Griotte de Palembre. N. Duh. Belle de Palembre. De la Palembre.

The following description is taken from the Pomological Magazine.

"This cherry is of French origin, and is said to have been raised at Choisy, near Paris, about the year 1760. It has sufficient merit to induce us to recommend it as deserving cultivation in this country, being hardy and bearing well as a standard. We know no other cherry of a similar character which is equally sweet. The general habit of the tree has a strong resemblance to that of the Mayduke, but the branches are rather more spreading, and the leaves are more evenly serrated; the flowers large; petals roundish, concave; stamens strong, shorter than the styles; fruit middle-sized, roundish, depressed at the apex; skin transparent, red mottled with amber colour, especially on the shaded size; flesh amber coloured, tender, and sweet ; stone middle-sized, round."

\section{GRAFFION. Pr. cat. For.}

Bigarreau. Hook. Pom. For. and of the English publications generally, and of some American collections.

Bigarreau. Graffion. Lond. Hort. cat.

Cerise ambrée. Guindoux blanc.

Cerisier à fruit ambré, à fruit blanc. $\}$ N. Duh.

Amber, or Imperial. Coxe.

Yellow Spanish, of most American collections.

Harrison heart, of some Eng!ish gardens, according to Forsyth.

This tree is one of the largest of all the varieties that belong to the same species; its branches are strong and vigorous, and form a handsome and well supported head. The growth of the young trees is particularly thrifty; their lateral shoots are remarkable for taking an almost horizontal direction, and the bark is marked with small dots. The fruit is the largest I have ever seen, except the Prince's duke; it is round at the extremity and somewhat flattened at the base, borne upon peduncles of from fifteen to twenty-four lines in length; the skin

VOL. II. 
is delicate, a little firm before maturity, of an amber yellow, partially tinged with red in small spots when at full maturity, and especially on the side exposed to the sun; the flesh is white, bland, and luscious, with a honied sweetness. This fruit ripens in June, and if there are long continued rains at the time of its maturity, it is apt to rot. It is remarked in the New Duhamel, that this cherry is but partially disseminated in France, and that it would merit culture more than any other, on account of its excellence, if it were not for the defect of its fruit not being apt to set well. On this point, so far as my opportunities have allowed me to judge, and they have been rather numerous, as the tree is much cultivated in this vicinity, I have found it to produce good crops and to be a constant bearer. This tree was imported from London, by the father of the author, in the year 1802, under the name of Yellow Spanish, and one of the original trees is now growing in his garden, where it produces abundantly, and there is little doubt that from his stock have originated most of the trees of this kind now in our country, as he has taken much pains to recommend it. During a visit to the vicinity of Boston, in the year 1826, at the period when the cherry trees were in fruit, I noticed that this variety was by some called the Bigarreau, and by others the Carnation, but the error has no doubt been corrected ere this, through the great intelligence and accuracy of their Horticultural Society. There is another European cherry, called Ambrée or Amber, which is far smaller than this, and also very inferior in flavour; its only advantage being that of ripening at an earlier period.

Carnation. Pr. cat. Law. Lang. Mrl. For. LOND. HORT. CAT.

Late Spanish. Wax Carnation. Wax Cherry. Griotte d'Espagne, erroneously.

This fruit, which derives its title from its colour, is of a large size, and nearly of a round form; the skin is a yellowish white, beautifully mottled with red; the flesh yellow, rather firm, and of a pleasant taste, but less sweet than manv other 
varieties; the juice is sprightly and of a pale colour. If eaten before it is fully mature, it has a slight degree of bitterness. This cherry ripens among the late varieties in July, and is held in high esteem for preserves. The tree is of low stature, being more spreading than lofty, and its branches have often somewhat of a horizontal or even a drooping appearance. Its foliage indicates much vigour, and the fruit is less subject to the attacks of birds and insects than most of the other fine varieties of cherries, and also remains without decay or rottenness for a longer period than other sorts usually do. The tree bears tolerably well, but not abundantly. A tree imported from London, some years since, as the Late Spanish, and one from the north of France, under the title of Griotte d'Espagne, have both borne fruit of this kind ; the latter variety, however, is in fact a dark coloured fruit, and the above circumstance must have arisen from error.

\section{LONG STEM MONTMORENCY. Pr. cat.}

\section{$\left.\begin{array}{l}\text { Cerise de Montmorency, ordinaire. } \\ \text { Cerisier de Montmorency. }\end{array}\right\}$ Duh. \\ Kentish? Common Red?}

This tree resembles the Early Red Griotte in its growth, form, foliage, fertility, etc. The fruit is not as large as the Short stem Montmorency, and its peduncle is of greater length, measuring fifteen to sixteen lines. The skin is dark red at full maturity, the flesh white, not too acid, and of pleasant flavour. This fruit ripens the beginning of July. It is preferred in France to the short stem variety, on account of the tree being so very productive, although inferior to that in size and quality.

\section{SHORT STEM MONTMORENCY. Pr.cat.}

Gros Gobet. Gobet à courte queue.

Gros Gobet. Gobet à courte queue.
Montmorency à gros fruit. Cerise de Kent.
Kentish.

Cerisier Coulard, of some French cultivators.

Cerise de Vilaine.

This tree produces abundance of flowers, but the French complain that the fruit does not set well, and that the crop is usually but small. The cherry is large, flattened at both ends, 
its diameter eleven lines, and its height rather more than eight; the peduncle is veryshort, being but five to seven lines in length; the skin is of a brilliant red, and not very dark; the tlesh is yellowish white, slightly acid, and highly pleasant. This excellent fruit, which is one of the best that is cultivated, is but partially disseminated even in France for the reason before stated, it being found only in the gardens of those who prefer the fine quality to the quantity of fruit. It ripens about the middle of July, and it is possible that in our climate it may prove more generally productive than in France. Forsyth places this as synonymous with the Kentish cherry of England, but $I$ think there is some doubt as regards the point of identity. The Kentish cherry is mentioned by the earliest English writers, and Langley gives a plate of it.

\section{VILLENNES. Pr. CAT.}

Cerise de Villennes. Guindoux rouge. N. Duh. Cerisier à gros fruit rouge pale. O.Duh. Roz.

This tree is one of the very largest of its class of Cherries; the shoots are twice the size of those of the preceding variety, and its leaves are terminated by a long acute point. The fruit is eleven lines in diameter, and ten in height, borne on a strong peduncle, from ten to sixteen lines in length; the skin is delicate, and of a light red colour; the flesh white, succulent, slightly acid, and of a very pleasant flavour. This beautiful cherry is one of the best for the table; and Duhamel remarks that it ought to be preferred to all others for preserves. It ripens at the end of June or the beginning of July.

\section{PARISIAN GUINDOUX. AUth.}

Guindoux de Paris. Guindoux rose. N. Duh.

This tree becomes moderately large, but its branches do not preserve a handsome form; the fruit is of the same size as the preceding, but ripens rather sooner; the skin is of a still paler red, assimilating to a rose colour; the flesh is pleasantly sweet and excellent. 
HOLLAND GRIOTTE. Pr. cat.

Cerisier de Hollande. Coulard. Duh. Griotte de Hollande.

This tree is the largest of its class of cherries; it produces abundance of blossoms, but a paucity of fruit. A great part of the flowers blight, which no doubt is caused by the pistil being a great deal longer than the stamens, which prevents their fertilizing the germs with facility. It is to be regretted that the tree possesses this disadvantage, and that it should on such account be neglected, for the cherries are large and excellent. The peduncle is fifteen to twenty lines in length; the skin is of a fine red colour; the flesh delicate, sweet, and white with a little of a reddish hue. The period of their maturity is the end of June.

\section{WILlow LEaVED. Pr. cat.}

Balsamine leaved. Hinterose.

Cerisier à feuilles de Saule, ou de Balsamine. Duh.

Griottier de Hollande à feuille de Balsamine.

Griottier à feuilles de Pêcher. Dic. d'Agric.

This is but a sub-variety of the preceding, characterized by its longer and narrower leaves, which are of peculiar appearance; its fruit does not differ in any respect. It merits cultivation on account of its singular foliage, but more especially because it yields fine fruit; the leaves sometimes change their form when the tree grows with great vigour, and in such case they resemble those of other cherries.

\section{SHORT STEM GRIOTTE. Auth.}

Cerise à courte queue. Gobet. N. Duh.

This tree much resembles the Early Red Griotte in its growth, its slender and drooping branches, and the dimensions and form of the leaves. Its fruit is rather above the medium size, nine lines in diarneter and eight in height; its form is spherical, flattened at the extremities, and often divided on one side by a deep suture; its skin is a light red, and does not become dark coloured even at its fullest maturity; the stem is 
six to eight lines long; the flesh possesses rather much acidity. The tree seldom produces an abundant crop, and the fruit ripens in the first part of July.

\section{EARLY RICHMOND. Pr. CA'. LOND. HORT. CAT.}

\section{Early Kentish. Virginian May.}

This variety was brought by the father of the author from Richmond, Virginia. The tree is thrifty, and attains to the usual size of its class, being generally about 15 to 18 feet in height, with a round and well formed head, rather more spreading than elevated : a part of the branches take a somewhat drooping inclination, but whether this is natural, or is caused by its great crops of fruit, I cannot decide. The fruit is of large size, nearly round, and of a beautiful red colour; the flesh exceedingly tender, rich, juicy, of a fine flavour, and pleasant sprightly acid taste. When fully ripe, if the fingers in plucking the fruit, press only upon the flesh, it will strip off, leaving the stone and peduncle attached to the tree; the latter is quite short, and adheres to the branch rather more strongly than is usually the case. This tree is exceedingly productive, and the fruit becomes red nearly or quite as soon as the Mayduke, and being in very great estimation for tarts, \&c. it commands a high price at market; and it is said by those who cultivate the trees for that purpose, that they yield a greater profit than any other variety.

KENTISH RED. Pr. cat. Coxe.

Late Kentish. Pie Cherry. Common Red.

Kentish, of American collections.

This is a variety of the Montmorency, but I have not yet been able to identify it with any of those I cultivate of that class. It is propagated in this vicinity from seeds and from suckers. The young trees spring up along the hedges, and large numbers aie planted along the sides of the highway. They attain only to moderate dimensions, seldom over fifteen feet in height, with a small, round, and compact head; the fruit is of medium size, of nearly a round form, too acid 
to be pleasant for eating, except in tarts and preserves, for which purpose it is greatly used and much esteemed. It ripens in July, about a month after the earlier varieties of cherries, and is the latest that is met with in the markets, the people who pursue the avocation of supplying them, having totally neglected to cultivate the finer late varieties. The present variety appears to be a smaller fruit than the Kentish cherry of Forsyth, which is described by him as synonymous with the short stem Montmorency.

\section{COMMON MORELLO. Pr. CAT.}

\section{Black Morello. Pr. Cat. 26th ed.}

This tree attains but moderate dimensions, and forms a round head, with innumerable small slender branches; the fruit is only of medium size, but its flavour, when fully ripe, is peculiarly sprightly, rich, and highly pleasant to the taste. It is one of the finest for drying, and also for tarts, preserves, and brandy, and when bottled may be preserved for a long: period, without spirits or sugar. It attains its maturity late in July; is seldom attacked by insects or birds, and often becomes shrivelled and dry, while still hanging on the branches. It is unfortunate that this variety is more subject than any other cherry to the attacks of the same insect which so frequently stings certain varieties of the plum, and which often perforates the branches of this tree to such an extent that they are covered with the numerous knots and excrescences which arise therefrom. The only remedy is to prune off all branches thus attacked $:$ at the period when the insect or its eggs are concealed therein, and to burn them immediately, for if they are left to increase annually, they present a most disagreeable appearance, and in time entirely destroy the tree. The same course may be adopted with success for all other trees attacked in a similar manner ; and if it was adopted generally throughout our country, it would in a few years nearly or quite annihilate this formidable depredator on our gardens and orchards. Formerly this variety of the Morello was very common in this vicinity, and frequently met with planted along the sides of 
the highway; but the depredations of the insect referred to, and a total inattention to all remedies have rendered it at the present period quite a rare tree.

\section{LARGE MORELLO. Auth.}

English Morello. Pr. cat. 26th ed. IMerella. Law. Morella. Lang. | Morello. Mil. Lond. Hort. cat. Large English Morello. Milan.

Griottier du nord. Dic. d'Agric.

This tree attains a moderate size, with a round compact head; its shoots are stronger than our common Morello, and the branches are never attacked by the insect which so often perforates the common variety, and causes large and numerous excrescences to be formed. The fruit is of large size, round, and of a dark red colour, almost black, and when perfectly ripe is tender and juicy, with a sprightly and pleasant acidity. In England they preserve the fruit on the trees till September and even October, and it is then highly esteemed for the dessert. It is not, however, properly speaking, a table fruit, but best suited for tarts, preserves, and cherry brandy. It ripens among the latest varieties in July, and the tree is productive.

\section{PLUMSTONE MORELLO. Pr. cat. LONd. hoRT. cat.}

This is the largest variety of the Morello that I have yet seen, but it is stated that some of the kinds from the north of Furope exceed it in size. It is round in its diameter, somewhat pointed at the extremity, and has a long stone resembling that of a plum, on account of which circumstance it received the title here adopted. When perfectly ripe the skin is of a dark red colour ; the flesh very rich and high flavoured, with a sprightly and agreeable acidity. It is a most excellent fruit for preserves, tarts, and brandy ; and as it ripens late in July, after most other cherries are past, it also serves as a pleasing appendage to the dessert. The tree is thrifty, but, like the other varieties, attains only a moderate size, being seldom over twelve or fourteen feet in height, with a round wellformed head; it is quite productive, and I have never seen it 
attacked by the insect that depredates to such an extent on the Common Morello, which circumstance, together with its great excellence, gives it high claims to that general estimation in which it is held.

\section{SOFT STONE CHERRY. Auth.}

Cerise à noyau tendre. Duh.

Although several authors make mention of cherries which contain no stones, and even propose the means of having them, yet such statements may be justly deemed apocryphal. The present variety has obtained its name from a real or supposed claim to the quality its title indicates, but the peculiarity on which it is based seems rather to be doubted by some writers. Duhamel describes this fruit as being eighteen lines in diameter ; the peduncle very slender, and thirteen to fourteen lines in length, and the stone thin and easily broken. It is stated in the New Duhamel, that it greatly resembles the Holland Griotte, and that it is perhaps only a sub-variety of that cherry. The tree is productive, but the fruit is said to be indifferent in point of quality.

\section{GRIOTTE D' OSTHEIM. Pr. Cat.}

Cerise d'Ostheims. Pr. Cat. 26th ed. | Griottier d'Osteims.

This variety was recently introduced into our country by the author, and sufficient opportunities have not yet been afforded to fully test its merits. It is described in the Dictionnaire $d^{\prime}$ 'Agriculture as follows : The skin is of a dark colour, and the juice is also coloured; the flesh is sweet, with some acidity; and it is deemed an excellent fruit. The branches of the tree are drooping, or somewhat pendent, and the leaves small. In the north of France it ripens at the end of July.

LATE LARGE BLACK GRIOTTE. Auth.

$\left.\begin{array}{l}\text { Grosse Griotte noire, tardive. } \\ \text { Cerisier à gros fruit noir, tardif. }\end{array}\right\}$ N. Duh.

M. Le Berriays in his Traité des Jardins, and the New Duhamel, describe this variety as follows : The tree is of modevOL. II. 
rate size, with numerous slender branches, which do not support themselves well, and many of which perish when it is not pruned; its leaves are small, finely indented and almost as acute towards the petiole as at the point; its fruit is borne on very long peduncles, measuring from two to two and a half inches; it is quite round at the extremity and in its diameter, but partially flattened at the base; it is slow in gaining its full size, but will attain to a circumference of thirty-eight lines; the skin becomes a very dark red colour, nearly black; the flesh is red, full of very acid and bitter juice, which is somewhat ameliorated at extreme maturity. It is stated that at Paris this cherry will continue on espalier trees facing the north until in October, which circumstance, joined to that of its beauty, is worthy of consideration.

\section{NORTHERN GRIOTTE. Pr. cat.}

Griotte du Nord. Cerise du Nord. N. Duh. Brune de Bruxelles?

This variety appears to bear great resemblance to the preceding, and perhaps it varies but little, or is not at all different. The fruit is borne upon a peduncle one and a half to two inches long; its form is almost spherical, the diameter being eleven lines, and its height ten; the skin and flesh are both of a dark red colour. This is a beautiful cherry, and acquires sometimes the size of a medium Green Gage plum, but it is very acid, and even somewhat bitter. There is a sub-variety, which is much more pleasant, being of more mild taste, and less austere. This fruit is yet rare in the vicinity of Paris, but is very much disseminated farther to the north. In Holland it is almost the only cherry which is extensively cultivated, and its culture is also attended with great success in Belgium. In those countries they make use of its fruit for preserves, and especially for a kind of wine, which is very pleasant, and of which the higher classes consume large quantities. The Dutch obtained this variety from Russia. 


\section{RATAFIA GRIOTTE. Pr. cAT.}

Griotte à ratafia. Cerisier à petit fruit noir. Duh. Common Morello?

The branches of this tree grow pretty erect, and free from irregularity. The leaves are of medium size, and well supported on their petiole; the flowers have the divisions of the calyx indented, as is the case with those of most of the seedling cherries of the Griotte class. The fruit is small, being only seven to eight lines in diameter, by six to seven in height ; its skin is thick, dark red, and almost black; the flesh is also dark red, acid and bitter at its full maturity, which it attains at $P$ aris during the month of August. This cherry is seldom eaten, but is almost wholly used to make ratafia and cherry wine.

\section{SMALL RATAFIA GRIOTTE. Auth.}

Petite Griotte à ratafia. Cerisier à très petit fruit noir. Duh.

This cherry is smaller than the preceding one; its peduncle is longer, and often attended by a small leaflet at the base; the skin is, like the foregoing, of a dark red colour, and its, flesh has still more acidity, sharpness, and bitterness; it is made use of for the same purposes, but is later at maturity, and at Paris does not ripen until the end of August.

\section{GERMAN MORELLO. Pr. cat.}

German Griotte. | Griotte d'Allemagne. Griotte de Chaux. Duh.

The branches of this variety are long and slender, and do not support themselves well; the leaves are broad, and its flowers take a moderate expansion; the fruit, whose peduncle measures fifteen to twenty lines in length, is eleven in diameter, and nearly the same in height; its skin is brownish red, approaching a black hue, and its flesh dark red. This is a handsome cherry, and it is to be regretted that it is subject to blight, and is also too acid, and even sour, when planted in a cold and humid soil. It ripens in the first part of July. 


\section{COMMON FRENCH GRIOTTE. AUTH.}

Griotte commune. Griottier. Duh.

This tree is of large size, and supports its branches well; it is very productive, and is one of the kinds most worthy of culture for the crops; the fruit is of medium size, compressed at its base, and supported by a peduncle eighteen to twentyfour lines in length; it is nine to ten lines in diameter, by rather more in height; the skin is shining dark red, and almost black at its extreme maturity; the flesh is of the same colour, and both sweet and pleasant. This cherry ripens in July, and is deemed an excellent fruit.

\section{LARGE GRIOTTE. Pr. cat.}

\section{Grosse Griotte. N. Duh. Le Berr.}

This variety resembles the preceding one, but it ripens rather sooner, and is of larger size ; the skin is delicate, black, and shining; its flesh of a very dark red colour, firm, sweet, and of a pleasant flavour.

\section{POITOU GRIOTTE. Auth.}

Griotte de Poitou. Guindoux de Poitou. N. Duh. Le Berr.

This tree is described in the Traité des Jardins, and in the New Duhamel, as somewhat larger than the Villennes cherry; its branches are less numerous, but of rather larger size; its leaves are of much greater dimensions, broader, with larger and deeper indentures on their edges; the fruit is similar in form, and of nearly the same size; it is washed with pale red at the commencement of its maturity, but afterwards becomes of a very dark red hue, though not as blackish as the other Griottes; the flesh, which is also dark red, is tender, and replete with juice of an excellent taste; the stone is small; the stem quite large, and of medium length. It ripens at the end of June, and the tree has, like some other Griottes, the defect of producing only a small quantity of fruit, even when trained in the espalier form. 
GRIOTTE GUIGNE. DUH. Roz.

Cerise-Guigne. Cerise d'Angleterre. Duh.

This tree attains to a rather large size, and is very productive; the flowers are large, disposed in umbels of three to five each, and these umbels are grouped, to the number of ten or fifteen, at the extremity of the branches; the fruit is ten lines in diameter, and nine in height; it is larger at the base than at its summit, and also partially flattened at its sides, which gives it the form of a contracted Heart cherry; the peduncle is slender, and one and a half to two inches in length; the skin at perfect maturity becomes dark red, but has less of a blackish hue than most of the other varieties of Griottes; the flesh is red, sweet, and pleasant, but not very rich. This cherry ripens towards the end of June, and is one of the varieties that are most extensively cultivated in France.

\section{HEART-SHAPED GRIOTTE. AUTH.}

\section{Griotte Cœur. Cerise Cœur. N. Duh. Le Berr.}

This tree attains to a rather large size, and its branches are of ordinary dimensions; the leaves, which are of a thin substance, finely but not deeply indented, are not well supported, in consequence of the petioles being feeble; they are not of very large size, and the most of them are of a rhomboid form, being almost as narrow next the petiole as at the point, which is short, their greatest breadth being about the middle; the fruit, which is more heart-shaped than any other of its class, is ten lines in diameter and nine in height, flattened at its sides; the skin is of a brownish red, but not very dark, and the flesh red, moderately melting, and sweet, accompanied by a slight degree of bitterness. This cherry ripens in the earlier part of July.

LARGE GUINDOLLE. AUTH.

Grosse Guindolle. $\quad$ N. Duh. Le Berr.

This tree, which is cultivated in the neighbourhood of Poitiers in France, has no peculiarity of appearance. Its leaves, 
which are of moderate dimensions, and broad, are pretty deeply indented, and even double toothed; the fruit, whose stem is eighteen lines in length, and inserted in a small and slight cavity, is of large size, flattened at its extremities, and measures an inch in diameter by only nine lines in height; its colour is a fine pale red; the flesh is white, very melting, with abundance of sweet and rich juice. It ripens at the end of June or beginning of July.

\section{PRUSSIAN CHERRY. AUth.}

\section{Griotte de Prusse. Cerise de Prusse. N. Duh. Le Berr.}

This fruit, which is borne on a slender peduncle fifteen to eighteen lines in length, is seldom more than nine lines in diameter by eight in height; it is partially heart-shaped, and marked occasionally on one side by a suture; its skin is dark red, approaching to black at its extreme maturity, and its flesh red, sweet, and pleasant, but less firm than that of many Griottes, and less melting than that of others. In favourable expositions this variety ripens during the earlier part of June. It is remarked in the New Duhamel, which was published in 1825, that this tree is not much disseminated in France, but that it merits to be so, on account of its abundant crops, although they are not quite equal to those produced by the Griotte-Guigne, and also because its fruit is intermediate among the varieties of its class.

\section{POPE'S CHERRY. AUTH.}

\section{Cerise d'Italie. Cerise du Pape. N. Duh.}

This variety, which has been cultivated of late years at Montmorency, and other parts of France, was obtained from Italy. The following description is given of it in the New Duhamel :

"The leaves have no striking peculiarity; the fruit is round, of a fine red colour, and of the largest size; the peduncle is very long, and the flesh similar in quality to the Shortstem Montmorency, but has more firmness." 
This cherry does not there become fully ripe until about the 15th of July, at which period the tree presents a great singularity, which is that of still having some cherries on it entirely green, whereas the greater part of the others have acquired their full maturity.

\section{PEACH.BLOSSOMED. Auth.}

Cerisier à fleur de Pêcher. N. Duh.

This variety is in no wise remarkable, except as respects the colour of its blossoms, which, instead of being white, as is the case with other kinds, are of a rose-colour.

\section{STRIPED.LEAVED. AUTH.}

Cerisier à feuilles panachées. N. Duh.

Griotte à feuilles panachees. Dic. d'Agric.

This variety, as well as the preceding, is cultivated for ornament, its peculiarity consisting merely in its striped foliage, the fruit having no particular claims to superiority or merit.

\section{DWARF DOUBLE.FLOWERING. PR. сat.}

Small Double-flowering. Double-flowering Kentish.

Cerisier à fleur double. N. Duh.

Prunus caproniana flore pleno.

Griottier à fleurs doubles. Griotte double.

Prunus Cerasus flore pleno.

Cerasus caproniana, multiplex. Loud. Hort. Brit.

This tree is of the same species as the Kentish, Morello, and Duke cherries, and unlike the other double-flowering variety described, attains to but a moderate size, and when inoculated near the ground seldom forms more than a large shrub or very low tree. The blossoms are exceedingly double, very showy, of even greater diameter than the other variety, but the petals project less and make less display; the blossoms often have some small leaflets intermingled with the petals, and frequently present the appearance of several flowers concentrated in one. This species is not so beautiful as the other, but as that forms a large tree and this but a shrub, the two serve to occupy very 
different locations in the garden or pleasure ground; this also has the advantage of blooming much later than the other, and scarcely begins to expand its bloom until that has faded. Duhamel describes a semi-double variety, which I have never seen nor been able to procure. Miller mentions a doubleflowered cherry, but without any particulars, so that it is impossible to decide whether he referred to this variety, or to the one before described.

\section{ALL-SAINTS. Pr. CaT. LoNd. HJRr. Cat.}

Pendent flowering. Ever-flowering. Weeping cherry.

Cerise tardive. | Prunus semperflorens. Willd. Pers. synop.

Cerasus semperforens. N. Duh. Decand. Lond. Hort. cat.

Prunus serotina, $\}$ of most European collections, erroneously,

Cerise de la Toussaint. Cerise de St. Martin.

Cerisier à la feuille.

This variety forms naturally a tree of but medium size, with very thickly-set branches, which are slender, feeble, and partially pendent; its leaves are alternate, of an oval and somewhat lanceolate form, indented on their borders, and have usually a gland on each of the teeth next the petiole; the flowers are produced on slender pendent peduncles, and are attended by bractes; they do not begin to expand till June, and continue to bloom in succession for a long period. The appearance of the tree, with its weeping or drooping blossoms, is peculiarly striking; in addition to which circumstance, the period of their expansion is when the other varieties of cherries are mostly at maturity. The fruit is of the size of our smallest cherries, and in taste somewhat resembles the Common Morello, being acid, and not very pleasant; the skin is firm, and of a pale colour, and the flesh white. The cherries ripen in continuation, from the month of July to a much later period, and the ripe fruit, green fruit, and flowers, may be often seen on the tree at the same time. The quantity of fruit produced is however so very small, that the tree is not of value except as a curiosity. It is a hardy variety, but requires to have a portion of the branches thinned out, or they will become too 
dense. It acquired the title adopted in consequence of its producing ripe fruit at All-Saints day.

\section{DWARF SIBERIAN. Pr. CAT.}

\section{Prun:ts chamæcerasus. | Ceritsus chamacerasus. N. Duh. Cerisier de Silerie.}

This variety attains at most but three to four feet in height; its. branches are very numerous, forming a dense shrub; the leaves are of a long-oval form, with short petioles; the flowers have rather long peduncles, and are sometimes solitary, but most generally united in umbels of from three to five each, which are sessile and axillary ; the fruit is globular, of a bright red colour, and about the size of our smallest cherries; the flesh is red, very acid, but not disagreeable when perfectly ripe. The flowers expand in April, and the fruit ripens about two months afterwards. It is deemed the most suitable species to furnish stocks for dwarf trees of the fine varieties, being exceedingly hardy, and requiring no particular care. It was introduced by the author about eight years since.

\section{WEEPING. Pr cat. \\ Prunus pendula. Fern-leaved.}

This variety seems nearly allied to the All-Saints and Dwarf Siberian, but its branches are far more pendent than those of any other cherry. The tree is usually ingrafted at six or eight feet from the ground, when it forms a round and very compact head, which is rendered dense by the innumerable slender branches which shoot forth in every direction; this head seldom exceeds four or five feet in diameter, and from it the delicate branches weep on all sides until they trail upon the earth, thus presenting to the view a most interesting and singular spectacle, highly ornamental to the pleasure-ground. The fruit is of medium size, and when fully ripe is of a pleasant acid flavour, similar to the Morello, and ripens about the same time. Two trees imported from London, one under the name of Fern-leaved, and the other under that of Prunus pendula, have proved to be the present variety.

VOL. II. 


\section{EUROPEAN BIRD CHERRY. Pr. cat.}

Prunus padus. Lin. Willd. Pers. synop. \&c.

Cerasus padus. Duh. Decandolle. | Prunus avium. Mil.

This tree attains to a height of nine to ten feet, or twelve at most ; the leaves are alternate, and of an oval-lanceolate form; the flowers are white, disposed in long clusters, or racemes, which are somewhat pendent, and being very numerous, they render the tree highly ornamental at the flowering season; the fruit is round, red, or black, according to the variety, and similar in size and appearance to our common Bird cherry, ( $P$. Virginiana,) which it resembles in quality, and is therefore suitable for the same purpose, which is that of making what is called cherry-bounce, or cherry-brandy. The birds are equally as fond of the fruit as of our native species, and the tree is so hardy that it is said to flourish in Sweden and in Kamschatka. There are several varieties, which vary in the colour of the fruit, and in other respects; one of these has gold-striped, and another silver-striped leaves.

\section{DAVENPORT. Pr. cat.}

Davenport's New Mayduke. New Mayduke. American Red Heart.

This fruit is of the same colour as the Black Heart, and of pleasant flavour. The tree is said not to attain to so great a size as that variety; the body and limbs are apt to have swellings or excrescences on them, and the bark, on young shoots, is covered with small white specks. Mr.Davenport states that the fruit ripens two weeks before the Black Heart, which it equals in size and quality, and that it is less subject to rot in wet weather. If the tree sent to me under this title be correct, it belongs to the class of Heart cherries.

\section{DOWNER'S LATE RED. Pr. cat.}

This tree grows vigorously, and belongs to the class of Heart cherries, as its growth evidently indicates. The fruit is red, of good size, and fine flavour. It is one of the late varieties in point of maturity, and much esteemed as a market fruit. The tree is very productive. 


\section{A L M O N S.}

\section{LARGE-FRUITED. AUTH.}

Amandier à gros fruits. N. Duh. | Jordan?

THIS variety is remarkable for the size, sweetness, and firmness of its almonds, and is said by Duhamel to merit cultivation more than any other. The leaves are at least a third larger than those of the wild or common almond, and acuminate at their extremities; the shoots are large and vigorous; the flowers are large; the petals very much hollowed at their summits, and more or less undulated on their edges; the drupe is covered with a pretty thick skin; the shell is rather hard, and the almond large and of excellent taste; the peduncle is very short and thick, and inserted obliquely in the fruit.

\section{SMALL-FRUITED. AUtr.}

Amandier à petits fruits. N. Duh. | Common Almond.

This differs from the preceding in the size of its fruit, being smaller, more or less oblong, covered with a whitish green skin, which is coated with thick down. The stone terminates in an acute point, and the almond it encloses is sweet, and of a very pleasant taste; the leaves are narrow and oblong; the petals are very broad, and somewhat furrowed, and there are sometimes as many as six of them to one flower. This almond, which is the most common in the French gardens, produces quite good crops. There is another variety, that has white blossoms, but with whose fruit I am unacquainted. 


\section{LADIES' THIN-SHELL. Pr. CAT.}

\section{Amandier des Dames. N. Duh.}

This variety is principally characterized by the shell, which is far more tender, and is easily broken between the fingers; the almond enclosed in it is sweet and very delicate; the leaves are only of moderate size, supported by large petioles; the flowers are of medium dimensions, the petals but half as broad as they are long, rather deeply hollowed at the summit, of a lively red at the base, and sometimes entirely red on the outside, and white within. This tree blossoms later than the other kinds, and its first leaves expand at the same time as the flowers, whereas the other varieties expand their flowers before the development of their leaves; the stone is formed, like that of other almonds of two parallel coverings, the interior one of which is thin and rather hard, and the exterior one thicker, but so easily broken that when transported to a considerable distance the friction of the almonds against one another reduces it to powder; it does not attain its formation until a long time after the interior covering, so that if about the middle of August the skin of the fruit be taken off, it will be found scarcely apparent, and will detach itself with the envelope; and it is this backwardness in its formation which prevents it from becoming hard. This is one of the varieties that most deserve to be cultivated, althougl Duhamel mentions that in France its flowers are a little subject to be blighted. The same author also states that old trees sometimes produce almonds with a rather hard shell, but far less so than those of the common almonds.

\section{SULTAN. Pr. Ca'T.}

Sweet Sultan. Pr. cat., 26th ed. | Amandier Sultane. N. Duh.

The principal difference between this and the Ladies' almond, consists in the size of the fruit, which is smaller in the present case. This variety is common in Provence, where 
they also greatly estimate another kind of almond, which I will proceed next to describe.

\section{PISTACHIA ALMOND. Pr. CAT.}

\section{Amande Pistache. N. Duh.}

This is nearly of the same size and form as a Pistachia nut, and is therefore still smaller than the Sultan almond. The stone terminates in a point, and the shell is very tender; the almond is firm, and of good taste. The tree differs only from other almonds by the small size of its fruit and leaves.

\section{GREAT FRUITED. Pr. cax.}

\section{Large fruiled. Pr. cat. 26 ed.} Amygdalus macrocarpa, of English collections.

A variety of the almond has been recently brought into particular notice in England under the botanic title quoted above, and was imported by the author under the impression of its being a novel acquisition; but on examination it has proved to be one of the fine varieties which his father has cultivated at Flushing for more than thirty years. The tree is of more vigorous growth than most other almonds; the bark is of a yellowish brown colour, and the growth quite peculiar on account of the young branches often taking an undulating form, similar to that of the Tobacco leaved cherry, which probably arises from their very rapid growth, without a proportionate increase of strength. The leaves are larger, and the whole tree presents a much more thriving appearance than the Ladies or Sultan almonds, and is also much more hardy. It is the only one of the sweet soft-shell varieties that has ripened its fruit well in this vicinity, as they do not generally succeed in this respect to the north of the Potowmac, and even the present one only attains its perfection in our most favourable seasons. The late Dr. Bard, of Hyde Park, had a fine crop from a tree growing on his grounds, and he described the fruit as extremely large and of the finest quality. This is the farthest to the north that perfect fruit has yet been produced, and 
it must be attributed to a most advantageous location, or to a very favourable season. As the almond can, however, be cultivated very profitably in Virginia, it is probable that but few years will elapse ere extensive orchards are planted in that state for supplying our citizens with a fruit which is now imported in such great quantities.

\section{COMMON BITTER HARDSHELL. Pr. CAT.}

This tree has leaves of greater length and of a darker green than most of the sweet fruited varieties; the flowers are also of much larger size, and make a greater show when the tree is in bloom, which takes place before the blossoms of peach trees have expanded, and about the same period as the Apricot. The drupe is oblong, and terminates in a long acute point. The tree is very productive, and the fruit ripens regularly in the gardens of this vicinity. There is quite an extensive consumption of this fruit in the confectionary establishments of our cities.

\section{LARGE BITTER HARDSHELL. Pr. CAT.}

\section{Grosse Cassante.}

The fruit of this variety bears considerable resemblance to the preceding, and so does the growth of the tree; but on a close comparison of the latter, it will be perceived to be different; the leaves are long, and the flowers of large size and showy; the fruit, like the foregoing one, has a hard shell and a bitter kernel, as its name indicates.

\section{SMALL BITTER ALMOND. AขTh.}

Duhamel states that this variety has much smaller fruit than the one previously described, it being but an inch in length, and seven lines in diameter. The flowers also distinguish it; they are seventeen to eighteen lines in breadth, and the petals are very narrow in proportion to their length, the latter measuring eight and a half lines, while their width is but five and a half; they are deeply cleft, and slightly tinged with red at the base. 
BITTER SOFTSHELL. AUTY.

Amandier à noyau tendre et amande amère.

This variety, Duhamel remarks, differs only from the Ladies' almond in respect to its taste and its flowers, the latter of which are fourteen to fifteen lines in diameter, and more resemble those of the Common almond than the Ladie's almond, but expand at the same period as those of the latter variety.

\section{PEACH ALMOND. Pr. cat. Lond. hort. cat.}

Amandier Pêcher. N. Duh.

There is nothing that more strikingly proves the great affinity of the almond and the peach than this variety. It partakes both of the Common almond and the peach, but generally rather more of the former than the latter. The fruit is sometimes covered with a dry and thin skin similar to that of almonds generally, and other times with a thick and succulent pulp resembling that of the peach, but of a bitterish taste. It often happens that these two kinds of fruit are produced on the same tree, and sometimes upon the same branch; they are in both cases large, round or somewhat oblong, greenish, slightly downy, and enclose a large stone which is almost smooth, and contains a sweet almond. This variety appears to be one of those hybrids, which, according to $\mathrm{Du}$ hamel, are produced by an almond when its flower has been fertilized by the pollen of a peach-blossom. M. Bernard thinks that ingrafting may have had great influence in producing this peculiar variety, and founds his opinions upon the statement of Dr. Beal in the Transactions Philosophiques; but this opinion of M. Bernard will, to say the least of it, admit of much argument, and my present opinion is decidedly adverse to his position. The tree is of strong and vigorous growth; its leaves are smooth and narrow, and finely indented on their edges; being intermediate in their form between those of the peach and the almond. The blossoms are white, washed with red, rather large, and partially hollowed at their summit. 


\section{SILVERY ORIENTAL. Pr. CAT.}

Amygdalus argentea. N. Duh. Amygdalus orientalis.

This is a distinct species, and is cultivated only for ornament. It is a handsome shrub, or small tree, and attains to the height of eight to ten feet ; its limbs spread in every direction, from which spring numerous slender, supple branches, most of them inclined or bent, and which are covered with a whitish pubescence; the leaves are not closely set, but scattered over the branches; they have petioles, and are reflexed, of a long-oval form, with very entire edges, white and downy on both sides, shining and almost of a silvery hue, partially acute at the extremity, and contracted at the base; they are about an inch in length by half an inch in breadth, and do not fall off until very late in the season. The flowers expand during the first fine days of spring, a short time before the appearance of the leaves, and are small, of a delicate rosecolour, ranged along the branches on short petioles, either singly or two or three together; the fruit is small, somewhat oval, terminating in a long sharp point. This species is a native of the Levant, and grows in the vicinity of Aleppo. Its appearance is particularly ornamental to the pleasure ground in the spring on account of its flowers, and in autumn its foliage is so from its long continuance. This shrub will not bear our winters much farther north than New-York.

\section{DWARF SINGLE FLOWERING. Pr. cat.}

Amygdalus nana. N. Duh. Lin. Mil., \&c.

This is a small and very ornamental shrub, with running roots; the body is slender, with many small branches, and from one to two feet in height; the leaves have petioles, and are alternate, lanceolate, almost linear, green, palest on the under side, and glabrous on both, finely indented, three to four inches in length by four to six lines in breadth, and somewhat decurrent on the petiole. The flowers are numerous, 
almost sessile, solitary, or sometimes by pairs, of a fine bright red, or of a deep rose colour. The fruit is small, oval, somewhat rounded; the skin is covered with thick down, and contains an almost smooth stone; the kernel or almond is small, and of a bitterish taste. This shrub, though naturally so very dwarf, can be elevated to a standard by inoculation on a tall stock of some other species. The present, as well as the preceding species, was introduced to our country by the author a few years since.

\section{DWARF DOUBLE FLOWERING. Pr. cat.}

\section{Double dwarf Almond. Amygdalus pumila. Lin. Prunus sinensis. Desf. Prunus sinensis pleno.}

This most beautiful ornamental shrub attains to the height of two to two and half feet, and is not surpassed by any other in the profusion, beauty, and brilliancy of its rose-coloured blossoms, which are produced in wreaths on the whole length of its slender branches. It throws up numerous suckers, by which it is readily increased, and by being budded on a high stock of some other species, it may be converted into a standard; but its appearance is much the most pleasing in its natural dwarf state. It does not produce any fruit. No garden should be without this interesting shrub.

\section{LARGE DOUble FLOWERING. Pr. gat.}

Amygdalus communis, pleno.

This tree was introduced to our country by the father of the author, about nine years ago, and was by him sent to England, and it is not, even to the present day, to be met with in the catalogues of the English nurseries. The growth is the strongest and most vigorous of all almonds ; and there are few peach trees that surpass or even equal it in this respect. The blossoms are very large, of a delicate rose colour, and highly ornamental, affording a brilliant display early in the Spring. The leaves bear some affinity to those of the bitter

vOL. Ir. 
almond; but the whole appearance of the tree is strikingly distinct from every variety of the almond and the peach. It is very hardy, which renders it still more valuable. There are many other fine varieties of almonds. Among those with sweet fruit are the following, which are much cultivated in Provence, in France: Amande à flots, Balotte, Aberame douce, Farisienne, Materonne, Marseilles, De la race, Grosse verte, Round fruited, Boutière, \&c. ; also the Aberame-demiamère or Half-bitter almond, which is cultivated in Provence for its fruit, and the Striped leaved, Caucasian, and Silvery Oriental, which are cultivated in gardens for ornament only.

\section{FILBERTS AND HAZELNUTS.}

\section{IARGE SPANISH. Pr. CAT.}

\section{Barcelona nut.}

THIs variety of the filbert grows with exceeding vigour, and forms a large shrub or small tree, rising to the height of twelve to fifteen feet or more. It is exceedingly productive, and one tree, that has been kept as a specimen by the father of the author, has produced half a bushel of nuts in a single season. These nuts are of the same kind as those that are imported in large quantities and sold in our markets, being of large size and of excellent quality. They command a high price; and if some of our intelligent farmersw ould plant hedges of this tree, and of the English White-skin and Redskin filberts, they would find themselves greatly remunerated by the produce. 
FRIZZLED. Pr. cat. Pon. mag.

Frizzled nut:

The following description is extracted from the Pomological Magazine :

"Of all the nut tribe, this is among those most deserving cultivation, whether we consider its hardiness, beauty when in the husk, or abundant produce. In flavour it is not materially different from the White filbert. It originated in a garden at Hoveton, near Norwich, where it is well known for its annual crops, when all the bushes near it are almost destitute of fruit. It has been, within a few years, extensively disseminated, and is now far from uncommon. Its name is derived from the singular appearance of the husk or involucrum. The branches are spreading; the clusters of fruit usually in threes or fives, sometimes more; the involucrum much and deeply divided, spreading open at the mouth, large, extending twice the length of the nut; the nut rather small, oblong, and flattened; shell of moderate thickness, filled with the kernel, which is of good flavour ; ripens rather late."

COSFORD NUT, PoM. MAg. LoNd. HORT. CAT.

In regard to this variety the Pomological Manual makes the following remarks :

"It highly deserves cultivation, being a great bearer, and having a remarkably thin shell, both of which qualities entitle it to attention. The tree grows vigorously, and the branches upright; the involucrum is nearly the length of the nut, slightly hispid at the base. When the nut is ripe, which happens early, the involucrum expands, but is not reflexed; its segments are deeply divided. The nut is large, oblong, cylindrical at the base, rather broader and slightly compressed towards the apex, with stripes of dark and light brown, of which the former are the narrower; the shell thin, and breaking easily; kernel white, filling the shell, sweet, and of excellent flavour. 
There are many other fine varieties of this fruit; among these are the Red-skin, White-skin, and Prolific filberts, which are very extensively cultivated in England, and highly esteemed; also the Clustered filbert, the Tubulose or Lambert's nut, the Constantinople nut, which forms a large tree, and several others of less note, or more recently brought into notice.

Of the hazelnut there are several species, producing excellent fruit; but as the nuts are of much less size than the filbert, they are but little cultivated. The best are the Common hazelnut, the Cuckold nut, and the English hazelnut.

\section{R A S P B E R R E S.}

RED ANTWERP. Pr. cat. Ponr. mag. LoNd. hort. cat.

Large Red Antwerp. For.

THIS variety is held in the highest esteem, and is much cultivated in the gardens of select fruits in this vicinity, and in many other parts of our country. In frequent instances, however, varieties altogether different and very inferior are called by the title belonging to this, a circumstance that leads to incorrect impressions, and to disappointments. In Europe it is much cultivated for the market, and is deemed one of the most profitable by the growers, on account of its abundant produce, its early ripening, and its bearing carriage well. As yet, but small quantities have found their way to the public markets of our own country; and it is a matter of surprise, that none of our intelligent cultivators have formed plantations of so excellent a fruit, as it, could not fail to readily command a much higher price than the kinds they at present cultivate for the market. 
The Pomological Magazine gives the following very correct description of this valuable variety : "Canes strong and long, yellowish green, slightly glaucous, occasionally tinged with purple, covered below with dark brown bristles, which decrease in quantity upwards : early in the autumn the canes change colour and become entirely brown sooner than those of most others; bearing wood vigorous and nearly smooth ; leaves large, slightly rugose, plaited, irregularly serrated, dark green; clusters large; fruit large, conical, dull red; grains middle-sized; flavour rich and sweet."

"In situations where the plants grow with much vigour, a crop is sometimes produced in the autumn on the shoots of the year; this is however at all times but a scanty one, and too small to entitle the kind to the name of a double bearing variety."

\section{YELlOW aNTWERP. Pr. cat. Lond. Hort. cat.}

White Antwerp. Large Yellow Antwcrp. For.

This fruit is of large size, and of the same form as the red variety. It is in high repute for its excellence and delicate flavour, and merits general cultivation. The canes differ from the preceding, in being of a much lighter colour, and the bristles or spines on the young shoots are of a similar hue.

\section{BaRnet. Pr. cat. Poir. mag. Lond. hort. cat.}

\section{Cornwall's Prolific. Cornwall's Seedling.}

This variety, which bears a considerable resemblance to the Red Antwerp, is distinguished from it by its canes being much inclined to branch, and the prickles being long, slender, and reddish. It is very productive, and one of the earliest in ripening, but from its not bearing carriage well, it is not culti- + ed even in Europe for the supply of the markets ; its excelhowever, renders it one of the most desirable for family gardens. This superior variety is said to have been raised from seed by a person named Cornwall, at Barnet in Hertfordshire, England, from which circumstance it has obtained 
its different titles. The London Pomological Magazine describes it thus :

"Canes long, yellowish green, frequently tinged with purple, and branching towards the ground; they are thickly covered with slender bristles, which become stronger towards the upper extremity, and assume a dull brown colour early in the autumn; bearing wood strong and nearly smooth ; leaves large, rugose, slightly plaited, and irregularly serrated; clusters large ; fruit of a greater size than in any variety except the Red Antwerp, globular, inclining to conical, of a bright deep transparent purplish red; grains large ; flavour extremely rich and pleasant, without much acidity."

In some seasons this variety produces a second crop of fruit, which ripens in August.

\section{COMMON RED. Pr. cat.}

Rubus americanus. Pr. Cat. English Red.

This variety is a native of our state, and grows naturally in the Catskill mountains, but notwithstanding this fact, it is very frequently denominated English Red. The shoots are of a dark red hue, and grow to a great length, often attaining to ten or twelve feet, and even more. On the shoots of the same year the spines at and near the base are of a purplish colour, and those on the upper part, greenish with brown or purplish barbs or points. The fruit is one of the earliest at maturity, of medium size, fine flavour, and held in great estimation, as well for the dessert as for making cherry brandy, \&c. Indeed this is the only variety at present cultivated to a great extent for the supply of the New-York market, and there are probably near one hundred acres of land on Long Island appropriated to its culture. The plants do not throw up suckers during the summer season as most other varieties do, but in the spring, young plants shoot up in great numbers, from the small roots on all sides of the main stock. The American Black raspberry, or Black-cap, as it is commonly denominated, forms long shoots in the same manner as the foregoing; but 
has much stronger spines, and is altogether a more rustic plant; the fruit is of peculiar flavour, and esteemed by many persons. The American White, resembles the black in the growth of the plant and in the form of the fruit, but the latter as well as the canes are of a pale yellow or straw colour.

\section{BRENTFORD RED. Pr. cat.}

The fruit of this variety is of excellent quality, and possesses a high flavour, when at full maturity; it is of a rather oval form, of good size, and dark red colour. The plants are productive, and the berries ripen in continuation for a considerable period. The canes are set with purplish spines; those on the new shoots when they first come out of the ground, are of a reddish colour, but they afterwards attain a purplish hue. (In all the descriptions I have given of the canes, colour of spines, \&c. of the different varieties, I refer to the shoots of the same year, and to their appearance during the summer season.) This variety often produces a second crop in August.

\section{VIRGINIA RED. Pr. cat.}

Rubus strigosus. Pursh. Rubus coccineus.

The fruit of this species is round, or a little inclining to an oval form, of larger size than the Common Red, and of good flavour. The canes rise to the height of four or five feet or more, and in favourable locations produce good crops.

\section{PENNSYLVANIAN. Pro cat.}

\section{Rubus pennsylvanicus.}

The canes of this variety are of peculiar appearance, and the young shoots are set with red hairs, which extend from the base to the extremity. The fruit is of a very dark red colour when at maturity, its form rather oval, and its flavour indifferent. The plants are very productive, the berries are produced in numerous clusters, and ripen in succession. An after crop is frequently produced even as late as the month of 
October. I obtained this variety from a London nursery, under the title of Rubus pennsylvanicus, but have since found it to be identical with plants received from the forests of the State of Maine.

\section{CANADA RED. Pr. CAT.}

Rubus canadensis. Pr. Cat.

This fruit is of medium size, being about as large as the Common Red, to which in point of quality it assimilates more nearly than to any other. It possesses a high and rather peculiar flavour. The canes are very thickly set with brownish spines, which extend from their base to the extremities. I first noticed this variety growing along the road sides, a few miles from Montreal, where the plants are to be met with in great abundance. The fruit is collected from them by the country people, and large quantities sold in the markets.

\section{TALL RED CANe. Pr. cat.}

This variety produces good crops; the fruit is of a round form, of good size and quality, but not of a high flavour; the berries detach themselves so easily from the hull when fully ripe, that if not gathered in time, very many of them fall to the ground. The canes are covered at the base and the extremities with numerous fine spines or hairs, but these are much more sparsely set on the intermediate portion of the shoots.

\section{SHORT-JolNTED CANE. Pr. cat.}

The canes of this variety are almost spineless, and are peculiar on that account, as well as for the closeness of the joints. There are a few small spines on the peduncles and on the midrib of each leaf. The fruit is of a pleasant taste, rather larger than the Common Red, but not quite equal in size to the kind last described, though it is superior to it in flavour. The berries part very easily from the hull when they have attained their full maturity. This and the preceding variety are later in ripening than the Common Red, and produce good crops. 


\section{CRETAN RED. Pr.cat.}

Rubus creticus.

This variety, the Alpine, and the Flesh-colored raspberries are of quite recent introduction to our country, and appear to belong to the same species. The plants are readily distinguishable from other varieties; they, however, bear much affinity to the Antwerp class in their foliage, but their canes have a much less number of spines. The fruit is of good size, and of a very high and peculiar flavour: it is produced during several successive months, usually ripening from June to September. I obtained the three varieties above referred to from the Mediterranean.

\section{PROLIFIC RED. PR. CAT.}

This variety is of more dwarf stature than most others; the canes are slender, and set with small spines, which are rather numerous, even at their extremities. The fruit is of good size and quality, and a second crop is usually produced in the month of August.

There are many other valuable varieties that merit culture, among which are the Double bearing Red, Double bearing Yellow, Old English Red, Old English Yellow, Brentford Cane, Twice bearing, Sc. The Canada Purple flowering, the Large White flowering, and the Rubus spectabilis, are cultivated for their flowers only, their fruit being of little or no value. 


\section{STR A W B E R R I E S.}

KEens' SeEdLiNG. Pr. cat. Pon. hag. Lond. hor't. traty,

$\left.\begin{array}{l}\text { Keens' New Pine, } \\ \text { Keens' Black Pine, }\end{array}\right\}$ of some collections.

ThIs variety was raised from the seed of Keens' Imperial, thus affording a proof that like produces like in the vegetable kingdom, and that the seeds of a fine variety will most probably produce fine varieties; but my own opinion in relation to this point is that one parent at least should be of such character.

The great merits of this strawberry are, that the fruit is very large, very good, and that it is a very prolific bearer; it also carries well, and bears its fruit high enough above the earth to keep it free from the soil, and it is one of the most vigorous varieties. Its leaves are broad and dark green, and the healthiness of its appearance is scarcely equalled by any of its class, except the Old Pine, and if this be inferior to that in flavour, it is much more than equal to it in size and productiveness. The following description of it is given in the London Horticultural Society's Transactions:

"A most excellent bearer, ripening early, soon after the Scarlets, and before any other of the Pines; the fruit is very large, round or ovate, some of the largest assuming a cockscomb shape; when ripe of a very dark purplish scarlet next the sun, the other side paler, slightly hairy; seeds (grains) a little embedded in the polished surface of the fruit, which has usually a furrow at the apex; the flesh is firm, solid, scarlet, without any separable core, tolerably high flavoured; calyx is of moderate size, hairy, incurved; the footstalks of the leaves are tall, slightly hairy; the leaflets very large, roundish, for the most part flat, reclined, of a very smooth shining dark 
green, with coarse serratures, which are large and rounded; the runners are small, numerous, greenish yellow, and slightly hairy; the scapes are of moderate length, sometimes very short, branched, with short weak clustered peduncles middlesized, opening early."

\section{BLaCK Hadtbois. Pr. cat. Lond. Hort. cat. Lind.}

\section{New Hautbois.}

The appearance of this plant is much the same as the other varieties of its class; its growth is quite strong, and indicative of health and vigour; the fruit is oblong and pointed somewhat obtusely; it is a profuse bearer, and one of the best of its class for a market fruit.

\section{KNIGH'T'S NARROW LEAVED SCARLET. Pr. CAT.}

\section{Knight's No. 14.}

The fruit of this variety greatly resembles the old Pineapple strawberry, in flavour, form, and manner of growth, and the plants also assimilate in their proportionate produce; the berries are rather compressed or flattened, and are rounded at the extremity; they generally trail near the earth, and may, in point of flavour and excellence, be ranked among the best.

\section{PROLIfiC haUtbois. Pr. cat. Pom. mag.}

Prolific, or Conical Hautbois. Lond. Hort. cat.

Double Bearing. Hermaphrodite. Spring Grove.

The following remarks relative to this exceedingly valuable variety are contained in the Pomological Magazine, and I find them to agree precisely with my own views, and with my own notes made on the same subject:

"It is a common observation that good Hautbois strawberries are nearly lost. This position is not correct. The Hautbois, which has male flowers on one plant and female on another, is frequently found in our gardens, and as the sterile plants of it are more vigorous than the fertile ones, the unpro- 
ductive runners become in time more numerous, and gain the ascendency, and then the whole are considered as being deteriorated. This variety having perfect stamens in all its flowers, is consequently not liable to the inconvenience above mentioned, and it is very productive of fruit. It frequently in good seasons yields a second crop in autumn, the berries of which are much larger than those of its regular produce, but they are not very numerous. It is the best Hautbois we possess, and was first described under the name of Prolific or Conical Hautbois, being distinguished, by the latter appellation; from the Flat Hautbois, which is also very prolific. It may be cultivated in good garden soil, in an open situation, and will continue to produce well for many years, even if not removed. Leaves light green; footstalks long, hairy; leaflets middle sized, oblong, with coarse serratures; hairy. Scapes long, raising the flowers above the leaves, with branched peduncles; calyx small, reflexed; petals broad, at first imbricated, afterwards folded together; stamens strong, higher than the stigmas, remaining after the fruit ripens; anthers perfect. Fruit large, conical, dark dull purple, grains slightly imbedded; flesh solid, greenish, high flavoured, and musky."

\section{SWEET CONE. Pon. Mag. Loxd. Hort. trans.}

This variety was raised by Mr. Knight in 181\%, from a seed of the Old Pine, impregnated by the Old Black, thus combining the qualities of the two best flavoured varieties then existing in the English gardens. Its greatest affinity is to the male parent, and it has consequently been placed by the London Horticultural Society in the class of Black Strawberries. It is a moderate bearer, but produces fruit more abundantly in a shaded and moișt situation than when exposed to much sun. It is hardier than the Old Black variety, and the plants grow bushy and produce few runners. This deficiency is however frequently supplied by the first scapes forming young plants, which when put into the ground emit roots. The leaves are yellowish green, footstalks erect and slightly hairy; 
leaflets small, oval, coarsely serrated, convex, their upper surface very slightly hairy, scapes as long as the leaf stalk, upright, partially pubescent, with short pedicles; calyx large, reflexed; petals rather large, obovate; stamens of moderate length, with perfect anthers; fruit of good size, with a neck, a lengthened cone in shape, bright shining scarlet; grains prominent; flesh firm, red, very rich and high flavoured.

ROSEBERRY. Pr. cat. LoNd. hort. сat. LiNd.

\section{Rose Strawberry. Scotch Scarlet.}

This is a very high flavoured and productive variety; the fruit has a neck and separates readily from the hull; its form is oblong and pointed; the plant is not of tall growth, and the berries are of medium size. It is very extensively cultivated near London, for the supply of the markets of that city, and is also deemed one of the best for forcing during the winter.

old Pine, or Carolina. Pr. cat. Poir. Mag. LOND. HORT. CAT. LIND.

This strawberry, although but a tolerable bearer, has been long held in estimation; and a fact which goes to prove its extensive dissemination in Europe, is, that there are twentyone synonymous titles quoted for it in the catalogue of the London Horticultural Society. It is claimed in the Pomological Magazine to be of British origin, and mention is there made that it is not found in the gardens of France, being distinct from the Frasier Ananas of the French writers. The following description I extract from the same publication:

"Its merit and value are universally admitted, and amidst the diversity of opinions which must exist as to which is the best strawberry known, there can be no doubt that this will always receive the greatest number of suffrages to its superiority. In many situations it bears abundantly, in most well, and continues to produce on old beds for several years. It forces well under strong heat. Leaves very deep green; footstalks long and upright; leaflets small, roundish, with rounded 
serratures, upper surface nearly smooth; scapes shorter than the footstalks, upright, stiff, with long branching peduncles; calyx large, spreading; petals large, much imbricated; stamens moderately long; anthers perfect; fruit large, ovateconical, sometimes cockscombed, of a rich bright scarlet; grains slightly imbedded; flesh pale scarlet, rich and juicy, with a very grateful flavour."

\section{FRENCH MUSK HAUTBOIS. Pr. CA'P.}

This fruit is more round or globular than most of the other Hautbois varieties I have seen; it is very dark when fully ripe, being of a blackish purple colour. The plants are exceedingly productive, and yield some fruit after the regular crop is past, and flowers may even be here and there seen, when the main crop is at perfect maturity. The flavour is high and musky, and the fruit is much esteemed by those who are partial to this class of strawberries.

\section{DOWNTON. Pr. cat. Pon. mag. Lond. hort. cat.}

This strawberry comes into bearing about eight or ten days later than the other varieties most cultivated, and is particularly valuable on that account. The plants are distinguishable by their foliage, which is of a pale green hue. This is a tolerably productive sort, and the fruit when fully ripened is of excellent quality, possessing a highly aromatic flavour. Some of the berries are cockscomb shaped, but the greater part are ovate, and have a neck. The preserves and jam made from this kind are excellent. For the acquisition of this variety, the world is indebted to Mr. Knight, who originated it from seeds of a large Scarlet strawberry, at present little valued, after having impregnated it with the Old Black. Its male parent, although of a superior flavour, is very little cultivated, as it seldom flourishes or produces well. The Pomological Magazine describes the Downton strawberry thus : "Leaves pale green, footstalks very long; leaflets of thin texture, moderate size, with large coarse serratures; scapes very long, stiff, and 
upright, with short crowded peduncles; calyx large, greatly incurved, sometimes spreading, or slightly reflexed; petals oval, tapering to the claw; stamens moderately long; anthers perfect. Fruit rather large; when fully ripe, a dark purplish scarlet; grains but little imbedded; flesh scarlet, firm.

\section{SOUTHBOROUGH SEEDLING. Pr. cat.}

The fruit of this variety is of the very largest size, and it ripens gradually, some portion being much later than others. The growth is remarkably upright, and of the most vigorous character; the leaves are very large, supported on long and strong petioles; the fruit stems are also very large and strong, elevating the berries much more than is usually the case, which from these causes seldom or never touch the earth. In point of shape the fruit resembles the Hudson, but is of larger size.

GROVE-END SCARLET: Pr. cat. Pom. mag. Lind.

\section{Atkinson's Scarlet. Wilmot's Early Scarlet. Early Scarlet.}

This valuable strawberry $I$ have had under cultivation for several years, and find it to realize all my anticipations. It does not attain a size equal to many of the other varieties, but in abundant produce it can scarcely be exceeded. It has supplied the market of London with forced fruit for several years past, under the name of Early Scarlet. The following descriptive remarks are extracted from the Pomological Magazine :

"This excellent variety was raised from seed, in the garden of William Atkinson, Esq. at Grove-End, near Paddington, in 1820, and was exhibited to the London Horticultural Society in 1822. It is now to be found in most gardens where choice fruit is cultivated."

As a variety of the class of Scarlet strawberries, it possesses peculiar merit; it is a most productive bearer; the fruit is supported stiffly above the earth; it forces as well as, if not better than, any other sort; bears carriage securely; is remarkably handsome, and though slightly acid, is very 
well flaroured. Footstalks long and nearly smooth; leaflets small, oblong, very deeply and sharply serrated, of a light clear green colour, and slightly hairy on the upper side; scapes shorter than the footstalks, peduncles long, elevating the fruit clear of the leaves; calyx large and reflexed; petals unusually large, with a marked tendency to exceed the usual number five, having frequently eight or nine; filaments strong; anthers perfect; fruit large for a Scarlet strawberry, of a flattened, spherical figure, and a bright vermilion colour; grains deeply sunken, with the intervals between them flattened; flesh pale red, and firm. This is a genuine variety of our native Scarlet strawberry, Fragaria virginica, and nearly approaches it in foliage, \&c.

NAIRN'S SCARLET. Pr. CAT. LONd. hort. Cat. LiNd.

This strawberry, judging by the foliage, is evidently of the same class as the old Hudson variety; the fruit is also about the same size, but much less pointed; and although this kind bears well, it does not equal that variety in abundance.

\section{KEEN'S IMPERIAL. Pr. Cat. LoNd. hoRt. Trars.}

\section{Kreens' Black. Keens' Black Pinc.}

The fruit of this plant is large and rounded at the extremity, but with somewhat of a point. Its growth and general appearance denote its alliance to the Pineapple class of strawberries. It was originated by Michael Keens, an intelligent cultivator of fruits, living near London.

\section{BLACK ROSEBERRY. PoM. Mag. LoNd. HoR'. Cat.}

The present variety is figured in the Pomological Magazine, whence I extract the following description :

"This is a singular fruit in its appearance, and peculiar in its character and flavour. It was obtained by the London Horticultural Society from the garden of John Williams, Esq. of Pitmaston, under the name of Black round-fruited Roseberry, having been raised from the Common Roseberry, impregnated by the pollen of the Early Pitmaston Black, from 
which it derives the remarkable dark colour of its skin. It may be cultivated in any good garden exposed to the sun, and is a tolerable bearer, ripening about the middle of the season of the Scarlets, to which class it belongs. Leaves dark green; footstalks of moderate length, slightly hairy; leaflets middle-sized, roundish, with obtuse and wide serratures, the upper surface hairy; scapes short, with long and numerous spreading peduncles; calyx small, incurved; petals roundish, small, somewhat tinged with pink; stamens of middling length; anthers perfect; fruit of good size, bluntly conical, dark purplish red and shining; grains slightly sunken, with the intervals between them flattened; flesh dark red next the outside, solid, buttery, and juicy, with a very excellent flavour, differing much from other strawberries."

\section{LONG CONICAL WOOD. Pr. Cat.}

Raspberry flavoured.

This variety I raised about three years since, from seeds received from Paris, under the title of Raspberry flavoured strauberry; it differs from the other kinds in my collection, the fruit being of a very long conical form. It produces well, and I have noticed that some of the plants have blossoms on them when the main crop is fully ripe.

\section{NEW HUDSON. Pr. cat.}

This strawberry was raised from seed about eight years since, in a garden near New-York. The fruit is large, being about the same size as the old Hudson, from which it probably originated, but it is more rounded and less pointed at the extremity; the fruit stems are also more upright, and seldom fall down and settle near the earth, as is often the case with that variety: on the other hand, it is not so great a bearer, and consequently less valuable.

\section{LARGE EARLY SCARLET. Pr. CAT.}

The fruit of this variety is quite large, being of the size and form of the Hudson, from the seed of which it is supposed to 
have originated in a garden of this vicinity. The great advantage it claims over its parent, which is one of the largest, finest, and most productive market strawberries, is that it ripens a week to ten days earlier than that variety-a circumstance of great import in regard to the value of a fruit at market. It is of high flavour, and of a paler and brighter red colour than the Hudson, and is a most prolific and regular bearer; in fact, since its introduction to notice it has become a general favorite, and no one thinks of having a good collection without this to commence the season.

\section{LARGE SCARLET LIMA. Pr. CAT.}

This variety is of a very vigorous growth, with large leaves, and strong stalks and stems; the fruit is very distinct in its character, and has commonly a long neck; its form is oblong, somewhat flattened on two sides, and terminating in an obtuse point. I have noticed that the berries are generally formed on the first blossoms towards the base of the peduncle. It is a tolerably good bearer, and repays any deficiencies by its large fruit of most excellent flavour. This variety is not described in any European publication that I have met with; and I have been informed that it was originally brought from South America to Rhode Island, and it was there that I accidentally found it, under the name of Lima strawberry, and obtained plants for propagation. The garden in which I first noticed it was that of Captain Jacob Smith, of Newport, the same gentleman who plucked scions from the willow which droops over the tomb of Napoleon, at St. Helena, and to whose politeness I am indebted for a portion of them, which have now become flourishing trees, nearly twenty feet in height.

\section{AUSTRIAN SCARLET. Pr. Cat. Lind.}

Duke of Kent's Scarlet. Lond. Hort. cat. Pr. cat. 26 ed. Globe Scarlet, Cluster Scarlet, Nova Scotia Scarlet, Prolific Scarlet, (of English catDuke of Yorl's Scarlet, Oatland's Scarlet,
Early Prolific Scarlet,

This variety is said by Mr. Lindley to have been introduced 
to England from Germany in 1798, and also from Nova Scotia in 1802. The fruit is nearly of a globular form, of a moderate or a medium size and of a rich bright scarlet colour; the seeds are deeply embedded, with sharp ridged intervals; the flesh solid, pale scarlet; the flavour peculiar, sharp and pleasant. This is one of the very earliest varieties, and a most profuse bearer. The runners are produced very early, they are numerous, small, and of a redish colour.

\section{ENGLISH RED WOOD. Pr. CAT.}

Fraisier des bois. Caperon? Montreuil? of the French gardens. Fragaria vesca. Lin.

This species is a native of Europe, and has been long an inhabitant of our gardens, where in former years it was more frequently to be met with than any other variety. The fruit being of but moderate size, its culture has been rejected by many persons who have substituted the larger varieties in its stead. There may be a question whether we are gainers by a total rejection of this ancient and more humble representative of a favorite class of fruits. The plants are exceedingly productive; the berries ripen in gradual succession, and although of small size, contribute by their abundance to make up in part for their deficiency in this respect. The flavour of the fruit is very agreeable; and this old friend of our gardens, which makes so little display, and has appeared for some time to be sinking into utter neglect before its congeners of greater magnitude and beauty, is with me still a great favourite. The English White Wood strawberry is similar to the one here described in almost every point except colour.

\section{elton seedling. Pr. cat. Ponr. Mag. Lind.}

This variety has been recently brought to notice, and has proved one of the very first class in point of excellence, and on a par with the celebrated Keens' Seedling. It is a healthy plant, bears most profusely, and the fruit is very large and 
handsome. It ripens so late as to furnish a supply of Pine strawberries, to which class it belongs, long after all other pine-like sorts are over; and finally, it possesses the great merit of packing well, and being peculiarly suitable for preserving - a quality which very few strawberries possess.

"It comes after the Old Pine, Downton, and Keens' Seedling; it is larger and a much more abundant bearer than either of the former; and like the latter, keeps ripening its berriesin long succession. The leaves are middle sized; the leaflets

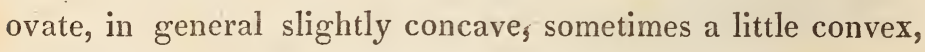
obtusely serrated; upper surface somewhat hairy; deep green; the younger light grass green, with a slight tinge of yellow; leaf-stalks upright, moderately strong, rough, with hairs, spreading horizontally, which is also the case with the scapes, but on the peduncles the hairs are adpressed. It may be observed, that all strawberries with rough leaf-stalks contain more acidity than those with smooth. The flowers are large, petals roundish, concave; stamens rather short, with anthers generally perfect; calyx middle-sized, incurved, sometimes partially reflexed; scapes strong, nearly as long as the footstalks; branchlets or peduncles rather short. The fruit is large, ovate, often compressed or cockscomb shaped, of a rich, shining, dark red; grains yellow, regularly imbedded between ridged intervals, which are flattened or rounded on the tops; flesh firm, with a small core, deep red, juicy, and having a sharp rich flavour."-Pom. Mag.

\section{RED ALPINE. Pr. CAT。}

Monthly. Everbearing.

Fraisier des Alpes, à fruit rouge, $\quad$ of the French

Fraisier des quaire saisons à fruit rouge, $\}$ collections.

The fruit of this variety greatly resembles that of the English Red Wood strawberry, in colour, size, and quality. It sends out numerous runners early in the season, and these as well as the older plants produce moderate crops of fruit, until the severity of the weather arrests vegetation. I have culled a dish of the fruit even at Christmas, and this is not an un- 
common circumstance, when the autumn is prolonged by fine weather. The White Alpine, with runners, is similar to the preceding, except in point of colour.

The habits and general character of the Alpine and Wood strawberries are very similar; the principal difference is in the shape of the fruit, and in the period of production. In the former the berries are usually conical, and in the latter more globose. The Alpine varieties continue to produce fruit after the main crop has passed, in greater or less quantities, until the severity of the weather prevents, but the Wood strawberries do not.

\section{IVHITE BUSH ALPINE. Pr. Cat.}

Fraisier des Alpes sansfilet, à fruit blanc, of the French $\left.\begin{array}{l}\text { Fraisier des quatre saisons sans filet, à fruit blanc, } \\ \text { Fraisier buisson des quatre saisons, à fruit blanc, }\end{array}\right\}$ collections.

The fruit of this variety is similar in size and quality to the English White Wood strawberry. The peculiarities which distinguish it are the following: It forms no runners, but continues flowering and producing fruit until the winter sets in. The crop produced towards the close of the season is, however, far less abundant than that produced in June. The Red bush Alpine is only distinguished from the white variety by its difference in colour. Both are interesting appendages to the fruit garden, and their being devoid of runners renders them suitable for borders.

\section{TRUE CHILI. LOND. HORT. TRATS. Lixv.}

Fraisier de Chili. Duh. Patagonian.

Greenwell's New Giant. Large Hairy Chili. Bourbon.

This is the original species from which several seminal varieties have been produced. The fruit is particularly large, of irregular shape, but generally ovate or bluntly conical, and when ripe of an uniform dull varnished brownish red; the seeds are dark brown, and projecting; the flesh slightly tinged with red near the outside, the other part whitish, very firm, hollow in the centre, with a small core. The fruit ripens 
late, and the foliage mostly perishes during the winter, and frequently a large proportion of the plants also, unless they are well covered with straw, \&c. The two succeeding varieties, which have been raised from the seeds of this, are more hardy, and usually retain their leaves perfect.

WILMOT'S SUPERB. Pr. cat. Lind. LoNd. Hort. trans.

The berries of this variety which ripen first are very large, irregularly rounded, ovate or flattened, and sometimes of a cockscomb shape; the others are invariably round; all are hairy, of a pale scarlet hue, appearing as if polished; the seeds are brown, and projecting; the flesh very firm, pale scarlet next the outside, and whitish within, with a small hollow at the centre, and a core; the flavour is very good, buttery, and rich, mingled with acid.

\section{YELLOW CHILI. Lomp. Hort. trans. Lind.}

The fruit of this variety is of a very large size, irregularly ovate, frequently compressed, and sometimes cockscomb shaped; of a brown hue on the sunny side, and yellow on the other; the seeds are brown, slightly embedded, with flat intervals; the flesh very firm, buttery, yellowish, with a core, flavour very rich, with some acidity.

COMmon haUtBois. Pr. cat. Lond. hort. trans. Lind,

English red Hautbois. Pr. Cat. 26 ed.

Capron Demelle. Duh.

Diacious Hautbois. Old Hautbois.

English Hautbois. Musky Hautbois.

This variety is more commonly met with in our gardens than any other of its class, and yet it is the least worthy of cultivation. It has been very frequently complained of, on account of its propensity to overrun the beds with male or barren plants, thereby rendering the plantations of it partially or entirely unproductive. The fruit is rather small or of medium size, spherical, of a pale greenish white tinged with dull 
brownish purple; the seeds are slightly embedded and the flavour musky. The flowers called males produce occasionally small imperfect berries with projecting seeds, and it is requisite that the plants which yield flowers of this description should be eradicated as useless.

GLOBE HaUTBOIS. Loxd. HORr. trans. Lind.

The fruit of this variety is of nearly a spherical form, small, becoming dark purple when ripe; the seeds prominent; the Alesh greenish, firm, with a separable core; the flavour good, with the aroma or perfume peculiar to its class

\section{LARGE FLAT HAUTBOIS. LoNd. HoRt. trans. Lind。}

Bath Hautbois. White Hautbois. Formosa Hautbois. Weymouth Hautbois.

This has large fruit, of a roundish form, depressed, light red, and pale on the under side; the flesh is greenish, without core, and juicy; but though delicate, it is not so high flavoured as the other; the seeds are embedded in the skin.

DWARF WHITE CAROLINA. LoNd. hoRT. trans. LiND.

This has large fruit, of an irregular ovate form, hairy, brownish on the sunny side, white on the other side; the seeds are scarcely embedded, prominent, and darker than the fruit; the flesh white, soft, woolly, with a large core, and the flavour indifferent. Although English pomologists attach the title of "Carolina" to this variety, I have not been able to discover such a one among our natives.

ROUND WHITE CAROLINA. LoNd. hort. trats. LIND.

Large White. White Chili. White Pine. Large pale Chili. Large blush Pine. Large fesh-coloured Chili.

This fruit is of large size, irregularly ovate, sometimes roundish, having a tendency to form a neck, of a brownish colour towards the sun, and white on the opposite side; the seeds deeply embedded, with ridged intervals; the flesh is soft, white and woolly, with a large core; the flavour is indifferent. 
BLOOD PINE. LOND. HORT. TRANS. LIND.

This is a sub-variety of the Old Pine or Carolina. Its scapes are considerably longer, and it is disting uishable by its leaves being of a darker colour and thicker texture, with stronger footstalks.

CHINESE. LoNd. HoRT. TRANS. LiNd.

Bourbon blush. North's large scarlet. Red Chili.

This fruit is apparently compressed, nearly round, of medium size, and of a pale varnished red colour; the seeds are brown and prominent; the flesh soft, light pink, with a large core, and woolly; the flavour indifferent.

\section{MULBERRY. LOND. MORT. TRANS. LIND.}

\section{Mohone. King. Cherokee.}

This fruit is of ovate form, with a short neck; it is of medium size and a deep purplish red hue; the flesh is soft, red, coarse, with a long core, and the seeds are slightly embedded in the skin; the flavour is but moderate.

VARIEGATED PINE. LoNd. Hort. trans. LiNd.

This variety is cultivated more for ornament and curiosity, than for usefulness; the leaves are prettily mottled or variegated with white, but the plants being weakly, the fruit produced by them is of little or no importance.

\section{SURINAM. LOND. HORT, TRANS. IIND.}

Devonshire Scarlet. Oldaker's New Pine. Red Chili. Red. Pineapple. Sutton's large.

This variety produces very large fruit, of an irregularly ovate or round form, without a neck, of a light shining red on the sunny side and pale.coloured on the other; the seeds are yellow and prominent, the flesh firm, pale red, with a large core ; the flavour indifferent. The fruit is entirely concealed. by the leaves. 
BULLOCK'S BLOOD. LOND. HORT. TRANS. LIND.

This fruit is of large size, of ovate form and of a light shining red hue; the seeds are dark red on the sunny side, yellow on the other, projecting from a polished surface; the flesh is pale red, firm, juicy, and of indifferent flavour.

DUTCH. Lond. hoRt. tRans. Lind.

This fruit is of a brilliant red colour, of round form, and large size; the seeds project from a smooth varnished surface; the flesh is pale red, downy, hollow at the centre, with a core, and of indifferent flavour.

BOSTOCK. Pr, cat. Lond. hort. trañs. LiNd.

Caledonian. New-Bath. Prolific Bath. Rostock.

Rostock Pine. Whitley's Pine.

This variety produces very large fruit, of nearly round form, slightly hairy, with a small neck; the largest berries are irregularly swelled towards the base, and terminate in a point which is of a dark polished red next the sun, and light scarlet on the opposite side; the seeds are prominent, brown on one side of the fruit, and yellow on the other; the flesh is of a pale scarlet hue, firm, coarse, with a small hollow arid core, and without any particular flavour.

\section{GLAZED PINE. LOND. HORT. TRANS. LIND.}

Scarlet Pine apple. Knott's Pine.

The fruit of this variety is variable in point of form; the largest berries often appear as if compressed, but are generally conical, with a neck; large, hairy, of a darkish varnished scarlet, and the seeds prominent; the flesh is of a pale scarlet hue, firm, with a large core; the flavour good, but inferior to that of the Old Pine.

BATH SCARLET. Pr. cat. LoNd. hoRT. Trans. Lind. Devonshire. North's seedling. Golden Drop. Milne's seedling.

This variety produces scarlet fruit of a roundish or ovate form, with a short neck, small for its class; the flesh is soft,

VOL. II. 
with a large core, pale scarlet, and very coarse, without any particular flavour; the seeds are very prominent and of a dark shining red hue.

\section{BLACK PRINCE. LONd. HORT. 'LRANS. LIND.}

\section{Wilmot's Black Imperial.}

This fruit is of a very dark purplish hue, hairy, and of medium size; its form depressed, spherical, with a furrow at the apex; the seeds slightly embedded; the skin highly polished; the flesh solid, firm, of a rich dull scarlet with a small core; the juice dark and highly flavoured.

GIBBS' SEEDLING BLACK. LoNd. HoRT. TRATS. LiNd.

The fruit of this variety is small, conical, and hairy, with a neck; and of a dark purplish red colour; the flesh scarlet, firm and very high flavoured.

OLD BLACK. LONd. HORT. TraNs. Lind.

Black Pine. Turkey Pine. IIulberry. Black Canterbury.

This fruit is of a medium size, conical form, elongated, and pointed, with a neck, hairy, and very dark purplish red; the flesh is scarlet and firm, with a buttery core, very rich and high flavoured.

PITMASTON BLACK. Pr. Cat. LoNd. HoRt. trans. Lind.

\section{Late Pitmaston Black.}

This fruit is of medium size, ovate, with a neck, slightly hairy, and of a very dark purplish red hue; the flesh scarlet, solid and very firm, buttery and of a rich flavour; seeds are slightly embedded.

\section{EARLY SCARLET. Pr. CAT.}

$\left.\begin{array}{l}\text { Morrisania or } \\ \text { Early Scarlet, }\end{array}\right\}$ of Prince's Catalogues for the last sixty years. Morrisania scarlet. Lond. Hort. Trans. Lind.

Fragaria virginiana. Lin. Pursh. For. Nut. and other botanists.

This is the type or original species of the class termed "Scarlet strawberries." The plants in the garden of the 
London Horticultural Society, denominated "Morrisania scarlet," were sent to them by the father of the author, and were collected in the woods of Morrisania, the seat of the late Governeur Morris, Esq. They are identical with the common Fragaria virginiana, found so common in our woods and uncultivated fields. The berries are small, but occasionally attain a medium size; their form is roundish, the colour red, and they are produced in clusters; the seeds are not numerous, rather deeply embedded, with wide rounded intervals; the flesh whitish, soft, with a detached core; the flavour when in a wild state is superior, but perhaps not equal when the plants are cultivated in gardens.

AMERICAN SCARLET. LoNd. HORT. TRANS. LIND.

Black American.

They cultivate in England a variety by the above title, which I presume originated there from seed of the preceding one, though it may possibly have been transported from our forests. The fruit is large, conical, and pointed, with a neck, of a deep rich shining blood red, and rough; the seeds numerous, brownish; not deeply embedded, with sharp intervals; the flesh dark scarlet, firm, with a core; and the flavour rich and agreeable.

\section{AUTUMN SCARLET. LOND. HORT, TrANS. LIND.}

The fruit of this is of medium size, and ovate form, with a neck, and of an uniform dark shining red; the seeds yellow, deeply embedded, with ridged intervals; the flesh solid, firm, of a pale scarlet hue and good flavour.

BISHOP'S SEEDLING SCARLET. LOND. IHORT. TRANS. LIND.

This variety produces fruit of a moderate size, round, with a neck, hairy, and of a light scarlet colour; the seeds deeply embedded, with ridged intervals; the flesh solid, firm, and pale scarlet, with a moderate flavour. 
CARMINE SCARLET. LOND, HORT. TRANS. LIND.

\section{Carmine Roseberry.}

This fruit is of a large size, bluntly conical, with a neck, and of a brilliant shining varnished red; the seeds are slightly embedded, with sharp ridged intervals; the flesh is of a pale scarlet hue tinged with red, firm and of a very high flavour.

MELON. Pr. cat. Loud, gard. mag.

Loudon gives the following description of this variety. It is a seedling, raised at Aberdeen, which has been declared by Dr. Dyce of that city, to be "the finest variety in existence." "The size and shape of this fruit in a great measure resemble the Roseberry but rather larger ; the colour is very dark, the flavour exquisite, and the plant is an abundant bearer and forces well." The above description (Mr. Loudon observes) was sent to London together with two or three plants, by Mr. Alexander Diack, secretary to the Aberdeen Horticultural Society; and Mr. L. further states that he had tasted in Mr. Groom's garden what are there called Diack's No. 1 and No. 2, which are excellent strawberries and great bearers.

\section{GARNESTONE SCARLET. Hort. trans. Lind.}

This fruit is of medium size, round, hairy, with a short neck and of a rich glossy scarlet hue; the seeds are red, deeply embedded, with round intervals; the flesh scarlet, firm, with a sharp agreeable flavour.

\section{GRIMSTONE SCARLET. HoRT. TRANS. LIND.}

This fruit is of medium size, conical, with a neck, and of a dark scarlet colour; the seeds are numerous, variously but deeply embedded, with regular acutely ridged intervals; the flesh solid, pale scarlet, of excellent flavour, and possessing a peculiar sweetness. 
HUDSON'S BAY. Pr. CAT.

Hudson's Bay Scarlet. Hort. Trans. Lind. American Scarlet, Late Scarlet, ? of English Hudson's Pine, York river Scarlet, $\}$ Catalogues, \&c. Hopwood's Scarlet.

This variety is more extensively cultivated for supplying the markets of New-York than any other. The Large Early Scarlet is the only one preferred to it for the same object, but that is of recent origin, and has not yet become generally disseminated, owing in a great measure to the unwillingness of the person who raised it to allow it to go out of his possession. The fruit of the present variety is quite large, with a neck, irregularly shaped, approaching to ovate, and of a dark rich shining red hue; the seeds are unequal in size, deeply embedded, with ridged intervals; the flesh is a pale scarlet, firm, hollow, with a core; of good flavour with some acidity. The berries should not be gathered until they assume a dark colour, and are fully ripe, as otherwise the acidity of the fruit predominates, and injures its flavour. This is an exceedingly productive strawberry, and its culture for market is found to be highly profitable. The New-Hudson is a seedling variety raised from the one here described.

\section{CHARLOTTE. Hort. TraTs. LiNd.}

\section{Princess Charlotte's Strawberry.}

This fruit is of medium size and round form, hairy, and of a purplish red hue; the flesh scarlet, firm, and high flavoured. It is a very moderate bearer, but ripens early.

\section{CLUSTERED SCARLET. Hort. trans. Lind.}

\section{Clustered Wood Pine.}

This fruit is of a moderate size, obtusely conical, or nearly round, very dark purplish red; the seeds are of the same colour as the fruit, unequally embedded between the intervals, which are sometimes flat, and at other times bluntly ridged; the flesh is scarlet, firm, and well flavoured. 
COCKSCOMB SCARLET. HoRT. trans. Lind.

This fruit is large, compressed, with a furrow along the apex, which appears as a simple indenture when the berry does not put on a cockscomb-shape ; the early berries are completely cockscombed, so much so as to enclose the calyx within the fruit by surrounding the end of the peduncle; the colour is a bright scarlet; the seeds are pale, slightly embedded between flat intervals; the flesh is of a pale scarlet hue, solid, with a large core, well flavoured but without acidity.

WILMO'T'S LATE SCARLET. Pr. cat. Hort. trans. Lind.

Wilmot's Scarlet, Wilmot's New Scarlet, Wilmot's Seedling, Large Scarlet,

Late Scarlet, Late Virginian,

of English

Catalogues, \&c.

This fruit is very large, bluntly conical, irregularly shaped, and of a shining light red colour; the seeds are small, deeply embedded, with ridged intervals; the flesh white, hollow, in the centre, and of moderate flavour. It is a good bearer, ripening late enough to succeed the Old Scarlet, and producing its berries in succession, so as to afford a continued supply. In order to taste it in perfection, it should be eaten as soon as gathered.

\section{SIR JOSEPH BANKS' SCARLET. Hort. trans. Lind.}

\section{New Scarlet. Ib.}

This fruit is of a bright scarlet colour, of moderate size, oblong, with a neck, the apex blunt; the seeds are nearly prominent, with very flat intervals; the flesh is a brilliant scarlet, firm and high flavoured. Mr. Lindley remarks, that this variety is very closely allied to the Austrian scarlet, with which it has probably been sometimes confounded; it ripens nearly at the same time, and though not so prolific, has a superior flavour.

VERNON'S SCARLET. HoR'. trans. Lind.

White's Scarlet. Ib.

This fruit is of medium size, round, dark red, rather hairy, 
the seeds are slightly embedded, with flat intervals; the flesh is of a pale vermilion hue, white at the centre, solid and well flavoured. It is a good bearer, and ripens early.

KNIGHT'S LARGE SCARLET. HuRT. TRANS. LIND.

Hairy leaved Scarlet,

Great American Scarlet,
Large Scarlet,

This fruit is about the medium size, roundish or slightly conical in its form, and of a light vermilion colour; the seeds are deeply embedded, with ridged intervals; the flesh is nearly white, soft, and of a pleasant fiavour.

\section{LEWISHAM SCARLET. Hort. TraNs. LIND.}

\section{Scarlet Cluster. Ib.}

This fruit is of small size, roundish, with a short neck, slightly hairy, of an uniform dark shining purplish red and grows in clusters; the seeds are embedded, but not deeply so, and with flat intervals; the flesh is scarlet, firm, and solid; the flavour very moderate.

\section{METHVEN SCARLET. Pr cat. Hort. trats. Lind.}

ILethven Scarlet. Soutiampton Scarlet.

Lindley and others thus describe this variety. The fruit very large, cordate, compressed, inclining to cocliscomb shape in the earliest fruit, the late berries conical: the colour dark scarlet; the seeds pale yellow, not deeply embedded, regularly and closely set with ridged intervals; the flesh of a scarlet hue, very woolly, and tasteless, with a large hollow in the centre.

\section{OBLONG SCARLET. HoR't. trans. Lind.}

$\left.\begin{array}{l}\text { Long fruited Scarlet, Long Scarlet, } \\ \text { Padley's Early Scarlet, }\end{array}\right\}$ of English catalogues, \&c.

This fruit is of a rather large size, oblong, with a long neck, which part being without seeds, has a peculiar glossy or shining appearance, of a bright light scarlet colour; the the seeds are few, deeply embedded, between ridged intervals; 
the flesh is nearly of the same colour as the outside, but of a little paler hue, firm, and of good flavour.

\section{PITMASTON BLACK SCARLET. HoRt. TRANS. Lind.}

\section{Early Pitmaston Black. Ib.}

This fruit is of moderate size, oblong, with a neck, slightly hairy, and of a dark purplish red colour; the seeds on the sunny side are of a similar hue, but on the other they are yellow, not deeply embedded, and the intervals are rather flat. The flesh is tinged with scarlet, tender, with a small core, sweet mingled with a pleasant acidity, and partaking a little of the raspberry flavour.

\section{SCONE SCARLET. HoRT. Trans. Lind.}

This fruit is of moderate size, round, without a neck, hairy, of a light shining red on the sunny side, and paler on the other; the seeds are dark brown, deeply embedded, with round intervals; the flesh firm, and of a pale pink hue; the flavour sharp, with abundance of acid. It is a great bearer, ripens late, and the fruit contains more acidity than any other known variety.

\section{Remarks.}

The varieties of strawberries here described are deemed sufficient in point of number for the purpose of selection; the author has, however, a number of linds under culture of which he cannot at present define the peculiarities with sufficient precision, and he therefore defers noticing them until his investigations are perfected. In the descriptions given in this work, where the size of the fruit is mentioned, it is to be understood that the comparison is only made between the varieties belonging to each particular class, and that it does not comprise the varieties belonging to other classes; and where it is stated that the fruit has a core, the idea intended to be conveyed, is, that the core readily separates, adhering to the calyx, when the receptacle is removed. 


\section{PEARS.}

\section{AMBROSIA. Switz. Livd.}

\section{Early Beurré. Lond: Hort. cat.}

"Fruit middle-sized, of a roundish and somewhat flattened figure. Eye rather sunk. Stalk an inch long, slender, and a little bent. Skin smooth, greenish yellow and full of small gray specks. Flesh tender, with a rich, sugary, and perfumed juice. Ripe the middle of September. This pear was brought from France soon after the restoration, and planted in the Royal Gardens in St. James's Park. It is a very good pear, but will not keep long." - Lind.

\section{LAMMAS. LOND. HORT. CAT. LIND.1}

"Fruit rather small, of a pyramidal shape. Stalk half an inch long, straight. Skin pale yellow, tinged and slightly streaked with red on the sunny side. Flesh melting, juice plentiful, of a very good flavour. Ripe the beginning and middle of August. This is a very excellent pear for the market gardener, as it is not only a very good bearer, but the first strong pear that comes to market, and the tree is hardy, and an erect handsome grower." - Lind.

\section{LONDON SUGAR. LixD. and of European catalogues.}

"Fruit below the middle size, turbinate, and rather narrow at the crown, about two inches long, and one inch and three quarters in diameter. Eye small with a connivent calyx, rather prominently placed, and surrounded by irregular, puckered, apparently blistered plaits. Stalk an inch long, slender, inserted in a small oblique cavity. Skin pale green, approaching to pale lemon colour when fully ripe, with a slight brownish tinge when fully exposed to the sun. Flesh tender and melting; juice saccharine, of a rich musky fiavour. Ripe the end of July 
and beginning of August. The branches of this tree are long, slender, and for the most part drooping, in the manner of the Epargne. It is an excellent early fruit, and a hardy bearer, and may be found in great plenty in the Norwich markets, under this name. It is very much like the Madeleine, figured in the Pomological Magazine; but its branches are pendulous, in the Madeleine they are ascending." - Lind.

\section{SABINE D'ÉTÉ. Pr. Cat. Lond, hort. trays. Lind.}

"Fruit of a pyramidal form, broadest at the crown, and tapering to a round blunt point at the stalk. Eye small, not deeply sunk. Stalk an inch long, inserted in a shallow cavity. Skin perfectly smooth and even, of a yellow colour on the shiaded side, and of a fine scarlet, minutely dotted when exposed to the sun. Flesh white, or nearly so, melting, juicy, and highly perfumed. Ripe the beginning and middle of August. Raised in 1819 , by M. Stoffels, of Mechlin, and named by him after Mr. Sabine, at that time Secretary to the Horticultural Society of London." - Lind.

\section{SEIGNEUR D'ÉTÉ. LOND. HORT. TRANS. LiNd.}

\section{Lord of summer.}

Fruit above the middle size, of a blunt oval figure. Skin of a fine orange, with bright scarlet on the sunny side, sprinkled with brown spots, and partially marked with larger ones of the same colour. Flesh melting, with an extremely small cone, and a rich high flavoured juice. Ripe the beginning and middle of September. This very beautiful pear has been known in Flanders many years, and the fruit was sent to this country by M. Stoffel's of Mechlin, and exhibited at the Horticultural Society in 1819." - Lind.

\section{YAT. LIND.}

Yat, or $Y u t$, of the Dutch gardens.

"Fruit rather small, turbinate, about two inches long, and one inch and three quarters in diameter, generally a little flattened on the opposite sides. Eye small, opens with a very 
short calyx, seated in a rather shallow uneven basin. Stalk an inch long, rather slender, obliquely inserted, without any cavity. Skin of a very thick russetty brown, thickly covered with round gray specks, and generally a little coloured when exposed to the sun. Flesh breaking and tender, with a very sugary, rich, and highly perfumed juice. Ripe the middle and end of September. The trees of this very valuable variety grow large, and the branches are drooping like those of the Epargne, but much more slender and numerous. A very hardy bearer, brought from Holland by the late Thomas Harvey, Esq. and planted in his garden at Catton, near Norwich, about sixty years ago, along with some plants of the Dutch Mignonne Apple, both sorts of which are now growing." - Lind.

CHARLES D'AUTRICHE. Pr. cat. LoNd, mort. Trans, LINd,

Charles of Austria.

"Fruit large, very handsome, about three inches and a half long, and three inches broad, in colour something like a White Beurré, but in shape more convex and irregular. Eye in a confined hollow, not deeply sunk. Stalk an inch long. Skin greenish yellow, profusely sprinkled with brown specks, and partially russetted. Flesh white, melting, very juicy, with a rich high flavour, but with little perfume. Ripe the beginning to the end of November. A fine and beautiful fruit, raised by Dr. Van Mons, and sent to the Horticultural Society, where it was exhibited in November, 1816."-Lind,

DOUBLE D'AUTOMNE. LOND. HORT. CAT. Lind.

\section{Double Autumnal.}

"Fruit middle-sized, in the form of a Bergamot, handsomely rounded, without angles, and tapering towards the stalk. Eye small, open with very short segments of the calyx, sunk in a handsome, round, shallow basin. Stalk three quarters of an inch long, inserted in a small oblique, slightly-lipped cavity. Skin an entire cinnamon russet, through which a little green 
appears, the whole covered with numerous light gray specks. Flesh white breaking, a little gritty, but mellow. Juice saccharine, very excellent, with a little perfume. Ripe the end of October, and good all November. A very handsome new pear, and very excellent when in perfection."-Lind.

\section{ELTON. Pr. cat. Lond. hor's. trass. Lind.}

"Fruit middle-sized, of an oval figure, a little broader towards the crown. Eye very small, nearly free from the segments of the calyx, and very slightly imbedded. Stalk rather stout, straight and deeply inserted. Skin of a greenish russetty gray, with numerous specks of a darker russet, and tinged with orange on the sunny side, which is generally towards the stalk, as the fruit is mostly pendent, from the extremities of the branches. Flesh crisp when in perfection, and of an excellent flavour; but will be mealy if kept too long upon the tree. Ripe the middle of September, and by gathering at different times, may be kept five weeks. Its season generally terminates with the commencement of the Autumn Bergamot. In 1812, the original tree about one hundred and seventy years of age, was standing in an orchard in the parish of Elton, in Herefordshire, from whence it received its name from Mr. Knight, who thinks it may remain in health three centuries, as it is now in a very vigorous state of growth. It is much better as an open standard, than if cultivated against a wall."-Lind.

\section{MOORFOWL EGG. Pr. cat. Lond. hor'. cat. Lind.}

"Fruit rather small, of a globular ovate figure, abruptly tapering from the middle, both to the crown and to the stalk, about two inches and three quarters deep, and the same in diameter. Eye small, open, with a short, slender, strigose calyx, placed in a rather narrow and shallow basin. Stalk one inch and a half long, slightly inserted by the side of a sinall elongated lip. Skin pale yellow, mixed with green, and tinged on the sunny side with a lively orange-brown, interspersed with numerous minute russetty spots. Flesh yellowish 
white, a little gritty, but tender and mellow. Juice sugary, with a slight perfume. Ripe the end of September, and will keep two or three weeks. This is a Scotch variety, and partakes something of the Swan's Egg. It is a desirable and hardy fruit."-Lind.

ALEXANDRE DE RUSSIE. Pr. cat. Lond. HOR'T. CAT. LiNd.

Poire Alexandre.

"Fruit above the middle size, somewhat obliquely pyramidal, with a very uneven knobby surface, about three inches and a half long, and two inches and three quarters in diameter. Eye open, with short narrow segments of the calyx, placed in a shallow, narrow plaited, hollow. Stalk half an inch long, thick, almost horizontally inserted under an elongated knobby lip. Skin greenish yellow, but almost wholly covered with a cinnamon gray russet. Flesh almost white, gritty, but tender and mellow. Juice saccharine, with a slight musky perfume. Ripe the beginning and middle of October, but will not keep more than two or three weeks. This is a very fine Bonchretien-shaped variety, which has been lately raised in Flanders, and sent to the Horticultural Society, in whose garden, it in 1830, produced some uncommonly fine fruit upon an open standard, from which this description is taken."-Lind.

\section{AUTUMN COLMAR. LIND. HoRT. GARD. COL.}

\section{Beurré Colmar d'automne? Colmar d'automne?}

" Fruit middle-sized, oblong, its shape that of a Colmar, but irregular in its outline, about three inches long, and two inches and a half in diameter. Eye small, with a short converging calyx, slightly sunk in an uneven depression. Stalk an inch long, straight, inserted in a small uneven cavity. Skin pale yellow, sprinkled with russetty specks, which become broader on the sunny side and spread into a thin russet. Flesh rather gritty but mellow, with a sugary and slightly perfumed juice. Ripe the beginning of October, but will not keep more than two or three weeks in perfection. This is another of the new Flemish pears, grown in the Horticultural Society's garden 
at Chiswick, and bears extremely well upon an oper standard.-Lind.

BELLE LUCRATIVE. Pr. cat. Lotd. hort. cat. Lixd.

Fondante d'automne, Lond. Hort. Cat.

"Fruit middle-sized, round in its outline, tapering to the stalk, and a little uneven in its surface, about three inches deep, and two inches and three quarters in diameter. Eye open, with a very short calyx, in a shallow rather oblique impression. Stalk an inch long, strong, curved, inserted in a very narrow, oblique, shallow cavity. Skin pale yellow, mixed with green, slightly russetted. Flesh a little gritty, but very soft, mellow, and tender. Juice abundant, sugary, with a slight musky perfume. Ripe the beginning and middle of October, but will not keep above two or three weeks. Another of the new Flemish pears, grown in the Horticultural Society's garden at Chiswick, on an open standard. It is good and handsome."-Lind.

BEURRE KNOX. Pr. CAT. LONd. mort. cat. Lind.

Kñox Beurré.

"Fruit above the middle size, oblong, in form somewhat like the Brown Beurré, about three inches and a quarter long, and two inches and three quaters in diameter. Eye small, open, in a very narrow shallow depression. Stalk an inch long, crooked diagonally inserted under a short, knobby elongated lip. Skin pale green, witl a little thin brownishgray russet on the sunny side. Flesh a little gritty, but mellow. Juice saccharine, but without any peculiar flavour. Ripe the middle and end of October, and will keep a few weeks in perfection. Another of the newly raised Flemish pears, grown in the Horticultural Society's garden at Chiswick, upon an open standard." - Lind.

BEZY VAE'T. Pr. cat. Lond. Hont. Trans. Lind.

\section{Bezy uaat.}

"Fruit somewhat of the shape of a Swan's egg, but larger. Eye a little sunk. Stalk an inch long. Skin dull green, 
covered with russetty spots. Flesh yellowish, perfectly melting, remarkably sweet, and very agreeably perfumed. Ripe in November, and will keep a month or more. Raised by M. Parmentier, at Enghien, and exhibited at the Horticultural Society in 1820." - Lind.

\section{BISHOP'S THUMB. Pr. CAT. LONd. HORT. CAT. LINd.}

"Fruit long, rather slender, slightly tapering from the crown to the stalk, having an irregular and slightly knobby outline, in the manner of the Calebash, about three inches and three quarters long, and two inches in diameter. Eye small, open, with slender segments of the calyx, slightly sunk in an uneven hollow. Stalk one inch and a half long, slender, recurved, and obliquely inserted in a two-lipped cavity. Skin dark green, almost wholly covered with an iron-coloured russet, on the sunny side of a dark rufous brown, thickly sprinkled with gray russetty dots. Flesh greenish yellow, melting, with an abundance of rich, saccharine, high flavoured juice. Ripe the middle to the end of October. A very excellent pear, although its figure is far from being handsomé. Decidedly distinct from Calebash." - Lind.

BONCHRË'TIEN FONDANTE. LOND. HORT. CAT. LIND.

\section{Melting Bonchrêtien.}

"Fruit above the middle size, oblong, with a pretty regular outline, ábout three inches and a half long, and two inches and three quarters in diameter. Eye small, with a closed calyx, slightly sunk in a narrow and pretty regular hollow. Stalk three quarters of an inch long, rather stout, curved, and slightly inserted in a narrow round cavity. Skin pale green, a good part of which is covered with a deep cinnamon russet, thickly sprinkled with light-coloured russetty specks. Flesh yellowish white, a little gritty, but rich and buttery, and full of a highly saccharine rich-flavoured juice. Ripe the end of October, and will keep a month. This most excellent pear is also a newly raised Flemish variety, grown in the Horticultural Society's garden at Chiswick, on an open standard."-Lind. 
DARIMONT. LOND. HORT. CAT. LIND.

"Fruit míddle-sized, oblong, in some specimens slightly pyramidal, tapering a little towards the stalk, about three inches long, and two inches and a quarter in diameter. Eye small, open, the segments of the calyx generally falling off before the fruit is fully grown, placed in a very narrow shallow depression, and surrounded by a few slightly radiated plaits. Stalk three quarters of an inch long, inserted in a small uneven cavity, sometimes obliquely inserted under a small elongated lip. Skin a complete yellowish gray russet, sprinkled with numerous scabrous specks. Flesh white, gritty, but melting, with a saccharine, slightly musky, and somewhat astringent juice. Ripe the end of September and beginning of October. This is another of the new Flemish pears, grown in the Horticultural Garden at Chiswick, upon an open standard." - Lind.

\section{DILleN. Pr. cat. Lond. hort. trans. Lind.}

Gros Dillen. Lond. Hort. cat. and of other catalogues.

"Fruit ovate, irregularly turbinate, about three inches and a half long, and nearly three inches in diameter. Eye flat. Stalk short and thick. Skin yellowish green, slightly speckled with brown. Flesh white, with a slight musky flavour, and very little core. Ripe early in October, and will keep a few weeks. A fine buttery pear of the first order, and very handsome. It was received by the Horticultural Society from Dr. Van Mons, of Brussels, in 1817."-Lind.

DOYENNÉ PANACHÉ. Pr. Cat. Lond. hort. TraNs. LiNd.

Striped Doyenné. Pr. cat.

"Fruit in form the same as the Gray Doyenné, but tapers a little more towards the stalk. Skin a bright, clear yellow, faintly striped with green and red, and sprinkled all over with small russetty brown dots. Flesh white, melting, sweet, and very agreeable, but is not so high-flavoured as the Gray Doyenné. In eating from October till Christmas." - Lind. 
DOYENNÉ SANTELETE. LOÄD. HORT, CAT. LIND.

"Fruit above middle size, pyramidally oblong, not much unlike a Chaumontelle in shape, but narrow at the crown, and more compressed towards the stalk; about three inches and a half long, and two inches and a half in diameter. Eye small, open, and a very short strigose calyx, slightly sunk in a narrow obtusely angular hollow. Stalk an inch long or more, curved, very slightly inserted, sometimes a little obliquely, in a narrow base. Skin pale green, thinly covered with detached specks of gray russet, which are more numerous around the stalk. Flesh white, a little gritty, but tender. Juice saccharine, with a slight musky perfume. Ripe the beginning of October, and will keep till the end. This is a very fine hand'some pear from Flanders, grown in the Horticultural Society's garden at Chiswick upon an open standard."-Lind.

\section{GENDESEIM. LoNd. HORT. CAT. LiNd.}

"Fruit middle size, pyramidal, a little uneven in its outline, about three inches and a quarter deep, and two inches and a half in diameter. Eye small, rather open, in a narrow, shallow depression. Stalk an inch long, crooked, diagonally inserted, under a large, curved, elongated lip, and slightly covered with thin patches of gray russet. Flesh a little gritty, but mellow, and full of saccharine, rich, and slightly musky juice. Ripe the end of September and beginning of October. This is another of the new Flemish pears which is grown in the Horticultural Garden at Chiswick, upon an open standard."Linil.

\section{HACON'S INCOMPARABLE. LIND.}

"Fruit middle-sized, somewhat turbinate, and a little irregular in its outline, occasioned by one or two slightly protuberent angles near its crown; about two inches and a half deep, and three inches in diameter. Eye small, open; segments of the calyx, short and narrow, slightly sunk in a rather wide, uneven depression. Stalk an inch long, rather stout, inserted 
in a somewhat lipped and rather deep cavity. Skin rugose, pale yellow, or yellowish white, a good deal mixed with green, and partially covered with a grayish orange russet, particularly round the stalk. Flesh yellowish white, slightly gritty, but very buttery and melting. Juice abundant, very saccharine, extremely rich, and possessing a high, musky, and perfumed flavour. In perfection in November and December. This very valuable and excellent pear was raised by Mr. James Gent Hacon, of Downham Market, in Norfolk, from a seed that is called in that neighbourhood, Rayner's Norfolk. The tree is an open standard, about sixteen years old, and sixteen feet high, with pendulous branches, which reach nearly to the ground. It bears most abundantly, and may be justly considered one of the best pears ever raised in this country. It was exhibited at a meeting of the Horticultural Society in Norwich on the 17 th November, 1830, when it obtained the silver medal as a prize." - Lind.

HaZEL. Pr. cat. LoNd. hort. trains. Lind.

"Fruit rather small, oval, somewhat turbinate, about two inches long, and one inch and a half in diameter. Eye small, with a short acute calyx, placed in a rather shallow basin. Stalk an inch long, obliquely inserted. Skin yellowish, very much freckled. Flesh nearly white, with a very pleasant and agreeable juice. Ripe the end of October, and will keep a few weeks only. It is uncertain where this pear originated. It is now extensively cultivated in the Scotch nurseries; and for its early bearing and abundant produce it is by them highly esteemed."-Lind.

HENRY THE FOUR'TH. Pr. cat. Lind.

Henri quatre. Lond. Hort. cat. Pr. cat., 26th ed.

"Fruit below the middle size, pyramidal and somewhat oblique at the crown, about three inches long, and two inches and a quarter broad. Eye small, open, with a short slender calyx, slightly sunk in a narrow, shallow, oblique depression. 
Stalk an inch long, crooked, curved, obliquely inserted under a small elongated lip. Skin pale yellow, mixed with green; on the sunny side of an orange-brown, and full of gray russetty specks, which are the more numerous as they approach the crown. Flesh pale yellow, a little gritty, but very tender and melting. Juice abundant, highly saccharine, with a slight musky perfume. Ripe the end of September, and will keep a few weeks only. This is a very excellent dessert pear, and is grown in the Horticultural Garden at Chiswick upon an open standard." - Lind.

\section{INCOMMUNICABLE. LoNn, HORT. CAT. LIND.}

L'Incommunicable. Lond. Hort. trans.

"Fruit above the middle size, pyramidal, and compressed towards the stalk, about three inches and a half long, and two inches and a half in diameter. Eye small, closed by a very short slender calyx, and placed in a very slight narrow depression. Stalk half an inch long, stout, bent, diagonally inserted beneath a small elongated lip. Skin pale grass-green, thickly sprinkled with small gray russetty specks. Flesh yellowish white, tinged near the cone with a slight shade of orange colour, a little gritty, but melting. Juice saccharine, with a slight musky perfume. Ripe the middle to the end of October. It is difficult to conceive the origin of this singular name. It has been attached to one of those newly raised Flemish varieties which bear so well and so regularly in the Horticultura Garden at Chiswick upon open standards."-Lind.

\section{KEIZER. LOND. IIORT. CAT。 LIND.}

"Fruit middle-sized, turbinate, gradually tapering from the middle to the stalk, about three inches deep, and two inches and a half in diameter. Eye small, with very short erect segments of the calyx placed in a very narrow depression. Stalk three quarters of an inch long, thick, and woody. Skin pale green, becoming yellowish green, thickly sprinkled with small gray russetty specks, and russetty round the stalk. Flesh 
greenish white, a little gritty, but melting. Juice saccharine, without any peculiar flavour. Ripe the middle of October, and will keep some weeks. This is also another of those hardy pears which bear so plentifully upon an open standard in the Horticultural Garden at Chiswick."'-Lind.

\section{NAPOlEON. Pr. cat. Hort. trans. Pom. mag. Lind.}

Medaille. Lond. Hort. cat. Lind.

"Fruit large, the form of a Colmar, angular about the eye, a good deal contracted in the middle, about three inches and three quarters long, and three inches in diameter. Eye small, with a connivent calyx, a little depressed. Stalk half an inch long, thick, straight; in some specimens diagonally inserted under a large, elongated, curved lip. Skin smooth, bright green, in which state it remains for some time after the fruit is gathered; it finally changes to a pale green, when the fiesh becomes very melting, with a most unusual abundance of rich agreeable juice. Ripe the middle of November, and remains in perfection several days. This succeeds equally well upon the pear and the quince. The Napoleon pear is an excellent variety, raised by Dr. Van Mons at Louvain, and thence sent to this country in 1816. It is a profuse bearer upon an east or west wall; it also succeeds as an open dwarf grafted upou the quince, and as a common standard." - Lind.

NEW BRIDGE. LOND. HORT. CAT. LIND,

"Fruit below the middle size, of a turbinate figure, about two inches and three quarters long, and two inches and a half in diameter. Eye small, with a short slender calyx. Crown flat, not depressed. Stalk an inch long, a little obliquely inserted. Skin dull gray, covered with thin gray russet, and of a light, lively, shining brown on the sunny side. Flesh melting, a little gritty, with a sugary juice, but without any peculiar flavour. Ripe the end of September and beginning of October, and will not keep longer than a few weeks. This is another of the new hardy pears which are produced upon 
open standards in the Horticultural Garden at Chiswick."Lind.

POIRE DE LOUVAine. Pr. cat. Lond. hort. cat. Lind.

Bezi de Louvain?

"Fruit middle-sized, pyramidal, uneven on its surface, three inches long, and three inches and a half in diameter. Eye small, closed with small short segments of the calyx, sunk in a narrow hollow. Stalk half an inch long, curved, obliquely inserted. Skin dull green, mixed with yeliow, full of russetty spots, and a little russetted round the eye. Flesh very tender, slightly gritty, and full of a rich, very saccharine, musky juice. Ripe the beginning of October, and fine till the end. This is a very excellent pear, and one of those cultivated in the Horticultural Garden at Chiswick as an open standard. It highly deserves cultivation."-Lind.

\section{POIRE NEILL. LoNd. HORT. CAT. LIND.}

6" Fruit large, pyramidally turbinate, generally a little flattened on its opposite sides, and tapering to the stalk. In some specimens the outer side is considerably more elongated than the inner one next the branch on which it grows, nearly four inches long, and three inches and a half in diameter. Eye open, rather deeply sunk in an irregular hollow. Stalk three quarters of an inch long, obliquely inserted in a narrow uneven cavity. Skin pale yellow, intermixed with green, a good deal mottled and marked with thin gray russet. Flesh white, a little gritty, but soft and mellow, abounding with a saccharine and slightly musky juice. Ripe the beginning of October, and good to the end. This very fine and handsome pear is one of those lately introduced from Flanders into the Horticultural Garden at Chiswick, where it is grown as an open standard."-Lind.

RICHE DEPOUIlle. Pr. cat. Lond, hort. mrans. Lind. Riche d'Apoie. Lond. Hort. trans.

"Fruit somewhat resembling the Saint Germain in shape and size, and tapering considerably towards the stalk. Eye 
prominent. Stalk one inch and a half long, rather thick. Skin of a clear citron yellow, with a slight tinge of bright red on the sunny side, a little mottled with russet, and rough like the skin of an orange. Flesh white, melting, not perfumed, but sweet and very pleasant. Ripe in the autumn and winter months. This succeeds on both the pear and the quince. Raised some years ago on the continent, and was brought into this country under the name of Riche d'Apoie." - Lind.

URBaniste. Pr. cat. Lond. hort. trans. Lind.

"Fruit pyramidally ovate, very even in form, but compressed towards the stalk; about three inches and a half long, and two inches and three quarters in diameter. Eye a little sunk in a very narrow crown. Stalk an inch long, obliquely inserted in a moderately deep cavity. Skin pale green inclining to yellow, profusely sprinkled with greenish specks, with small patches of gray russet dispersed over its whole surface, but more particularly round the eye and the stalk. Flesh white towards the outside, but deepens to a reddish yellow next the core, which is large, and possesses a small quantity of grit; it is, nevertheless, quite melting, juicy, and very sweet, with a little perfume. Ripe the end of September and the beginning of October. Raised by the Count de Coloma, of Malines, and specimens of the fruit were exhibited at the Horticultural Society from that gentleman in 1823."-Lind.

\section{FLEMISH BONCHRETIEN. LIND.}

\section{Bon Chrêtien nouvelle espèce. Hort. Gard. col.}

"Fruit large, oblong, turbinate, tapering towards the stalk, where it is slightly compressed; about four inches and a half long, and three inches and a half in diameter. Eye open, with a very short calyx, sunk in a rather shallow, round, even depression. Stalk one inch and a half long, embossed next the fruit, a little curved, and obliquely inserted under an elongated single or double lip; in some specimens which are more conical, the stalk is direct and straight, and not obliquely 
inserted. Skin green, becoming yellow, thickly sprinkled with gray russetty specks, and which form a mottled russet on the sunny side. Flesh yellowish white, breaking, a little gritty, but becoming mellow when matured. Juice saccharine, with a slight musky perfume. In eating the beginning of November till the middle or end of January. It succeeds very well upon the quince stock. ' This very fine pear has lately been raised in Flanders, and sent to the Horticultural Society of London, in whose garden at Chiswick it (in 1830) produced some uncommonly fine fruit upon an open standard, from. which this description was taken." - Lind.

GLOUT MORCEAU. Pr. Cat. LONd. hort. Cat. Lind.

Gloux Morceau. Lond. Hort. trans.

"Fruit very like the Beurré d'Aremberg, but larger, more oval, not so turbinate in its shape, about four inches long, and three inches and a half in diameter. Eye small, deeply sunk in an uneven oblique hollow. Stalk an inch long, rather deeply inserted in an oblique cavity. Skin pale, dull olive-green, a little inclined to yellow, and covered with numerous gray russetty specks, with russetty blotches round the stalk. Flesh whitish, firm, very juicy, but a líttle gritty at the core. Ripe in November, but will keep till February or March. This very beautiful and fine variety was sent to the Horticultural Society by M. Parmentier, of Enghien, along with the Beurre d'Aremberg, in November, 1820. It requires an east or southeast wall to grow it in perfection; but very fine specimens were (in 1830) grown upon open standards, in the Horticultural Garden at Chiswick, three inches and a half long, and three inches in diameter."-Lind.

\section{GRUMKOWER. LIND.}

\section{Grumkower Winterbirne. Lond. Hort. cat.}

"Fruit middle-sized, in shape somewhat like a Bonchrétien, having a few obtuse angles or ribs extending from the middle of the fruit to the crown, and narrowed towards the stalk; 
usually about three inches long, and two inches and a quarter in diameter. Eye narrow. Stalk half an inch long, inserted without any cavity. Skin smooth, pale green, sprinkled with a few gray specks. Flesh melting. Juice plentiful, saccharine, with a good deal of musky flavour. Ripe in November, and will keep till Christmas." - Lind.

LEN'T ST. GERMAIN. LOND. HORT. CAT. LIND.

Easter Saint Germain, of some gardens.

"Fruit pretty large, of an oblong figure, broadest in the middle, and tapering to each extremity. Eye small, and prominently seated. Stalk an inch long, slender, obliquely inserted under an elongated lip. Skin pale green, full of small white specks. Flesh firm and breaking, with a very good flavoured juice. In eating in March and April. This, although not a high-flavoured pear, deserves cultivation, as it comes into eating when most winter pears are gone." Lind.

TILlington. Pr. Cat. Lond. mort. trans. Lind.

"Fruit of the shape and size of the Gray Doyenné, but more perfectly rounded at the crown; about two inches and three quarters long, and two inches and a half in diameter. Stalk short, fleshy at its insertion. Skin dull green on its shaded side, but of a dull brick-dust red where exposed to the sun, the whole a good deal russetted. Flesh white, nearly buttery, with a little grit at the core, particularly rich and sweet, though not very juicy. Ripe the middle of November, and will keep a considerable time without spoiling. This hardy pear, for orchard purposes, was raised from the seed of an autumn Bergamot, the blossom of which had been impregnated with the Epargne, in the village of Tillington, near Hereford. Its fruit was sent to the Horticultural Society by Mr. Knight, of Downton Castle, in the autumn of 1820 , the first year of the tree producing fruit." - Lind. 
Barland. Pr. cat. Ponr. heref. Lind.

"Fruit rather small, of an oval figure, but broadest towards the crown. Eye prominent, and the segments of the calyx nearly erect. Stalk half an inch long, slender. Skin dull green, russetted with a muddy gray. Specific gravity of its juice 1070. The Barland pear appears to have been extensively cultivated prior to the publication of Evelyn's Pomona, in 1674, and many hogsheads of its perry are yet made annually in Herefordshire and the adjoining counties, in a productive season. It may be mixed in considerable quantity with new port, without its taste becoming perceptible. It sells well while new to the merchants; and as it is comparatively cheap, it probably forms one of the ingredients employed in the adulteration of this wine. The original tree grew in a field called the Bare Lands, in the parish of Bosbury, in Herefordshire, whence the variety obtained its name, and was blown down a few years previous to 1811."-Lind.

HOLmore. Pr. cat. Pom. heref. Limd.

\section{Holmer. Holmar. New Holmar.}

"Fruit small, globular, frequently growing in clusters of three and four together, with a very stiff, half-closed calyx. Stalk short and thick. Skin muddy, yellowish olive-green, thickly reticulated, with a thin epidermis, and tinged with a fine red on the sunny side. Specific gravity of its juice 1066 . The original tree, in 1811 was growing in a hedge, on the estate of Charles Cooke, Esq. of the Moor, in the parish of Holmore, between Hereford and Leominster, and appeared then to be seventy or eighty years old. The young trees are very productive, and the perry is of excellent quality." - Lind.

\section{HUFFCAP. Pon. heref. Lind.}

"Fruit middle-sized, oval, somewhat broader at the crown, and drawn towards the stalk. Eye with the segments of the calyx slender and pointed. Stalk long, irregular in its thick- 
ness, and curved, having now and then a small leaf growing upon its lower part next the branch. Skin pale green, marked with gray russet. Specific gravity of its juice about 1070 . There are several varieties of the Huficap pear in Herefordshire, such as the Brown, Red, and Yellow; but this is by far the most deserving of cultivation. Its perry is rich, strong, and said to be very intoxicating. It is of great excellence." Lind.

LONGLAND. Pun. meref. Lind.

"Fruit very handsome, not much unlike the Swan's Egg in shape, except being broader towards the crown. Eye somewhat large, with a converging calyx. Stalk short, stiff, and inserted into an unequal basc. Skin bright gold colour, tinged and mottled all over with a russetly, lively orange. Specific gravity of its juice 1063. The tree of this sort grows handsome and upright. It is hardy when in blossom, and consequently an abundant bearer. The name of Longland is supposed to have been derived from the field in which the original trec grew."-Lind.

\section{OLDRIELd. Pr.cat. Pon. miref. Lind.}

"Fruit below the middle size, turbinate, somewhat narrowed at the crown. Eye small, converging. Stalk half an inch long, slender. Skin pale green, spotted and marbled with a darker colour, and intermixed with a thin gray russet. Specific gravity of its juice $106 \%$ The perry produced from this pear is cxcellent; and from its being a very hardy tree, and an abundant bearer, is more extensively planted in Herefordshire and the adjoining counties than any other pear. Its name is believed to have originated from an inclosure called the Old Field, near Ledbury, a noted place for the finest perry." - Iind.

TEINTON SQUASH. Pr.cat. Ponr. heref. ILINd.

Taunton Squash. Squash.

"Fruit middle-sized, of angular shape, somewhat like that of a Bergamot, hat more tapering at the stalk. Crown even, 
divisions of the calyx spreading. Stalk half an inch long, slender. Skin a muddy, russetty green, marbled on the sunny side with a pale brown or dull orange, interspersed with a few ash-coloured specks. Specific gravity of its juice not mentioned. Its name of Teinton is supposed to have originated from Teinton, in Gloucestershire, where it has been much planted. There are some very old trees of it in this neighbourhood and in Herefordshire, and the perry they produce is of the very highest quality, something approaching in colour and briskness to Champagne, for which fine samples of it have sometimes been sold. It is always in demand, and at a high price; but from the great uncertainty of the crop, the supply is very limited." - $\mathbb{L i n d}$.

\section{ST. GERMAIN BRANDES, VAN MOYS.}

Pyrus Brandesia. Van Mons.

The original tree of this new variety is of large size and pyramidal form. It was raised from seed in the garden of Dr. Van Mons about seventeen or eighteen years since, and has produced fruit for the last thirteen years. The shoots are short, slender, feeble, and quite numerous ; the buds are small, pointed, and closely pressed against the wood; the leaves are shining, deep green, long and narrow; the flowers are small, and resemble those of the Doyennê. The fruit is in form intermediate between the Urbaniste and the St. Germain, and like the latter, its skin is a ruddy green, changing to yellow at maturity, its flesh delicate, with a cool juice, flavoured with vinous acidity. It seems to assimilate so much to the St. Germain when that variety is eaten in perfection, that it will serve admirably as a substitute for that ancient variety. Dr. Van Mons named this fine pear in honour of Professor Brandes, of Salzuffin.

\section{FREDERIC DE WURTEMBERG. VAN Movs.}

\section{Pyrus Wurtembergia. VAN MoNs. Roi de Wurtemberg?}

This fruit is very large, shaped like a top, and contracted 
next the stalk; it is rounded at the summit, considerably swollen at the middle, and decreases gradually towards the stem, where it terminates in an acute point. The skin is rough, hard, pale green, with fine specks of a reddish or a russet hue, and often tinged with rose colour; the green changes to yellow at its maturity, which is about the period of the autumnal equinox. This tree is a twice-bearing variety, but the fruit of the second crop only attains to a third or a half of the usual dimensions. The leaves are of elliptical form, smooth on both sides, with the edges partially indented; the petiole is long and slender; the flowers are large, single or semidouble, very fragant, with rounded fringed petals, and endure a long time before they fall off; the summit of the stamens is of a bright rose colour. The tree is of vigorous growth, and attains to lofty dimensions. Dr. Van Mons dedicated this superior pear, by particular request, to the late ling Frederic of Wurtemberg, and he also makes the following remarks. This pear has much affinity to the Colmar, which in its turn has a similitude to the Passe Colmar. The Sylvestre d'hiver and the Colmar-Delvigne have also an affinity to the present variety, and are in respect to it what the Colmar-epineux, Precel, and Souveraine are to the Passe Colmar. All these varieties are descendants from the Colmar, and are its respective congeners.

FONDANTE DES BOIS. VAN NONS.

Boschier. Boschpeer. Poire des bois. Poire de persil.

Petersilie-peer. Poire de Deftinge. Beurré de Deftinge.

Dr. Van Mons states that this is incontestably a Belgian variety, supposed to have originated in the woods from a seed chance sown. The fruit is large, nearly round, usually fiattened at the middle of its summit, and swollen at the middle of the base, with some slight protuberances, its greatest diameter being about midway of its height. The skin is rough, of a dull green hue, with large reddish specks, and next the sun acquires a reddish brown colour. The flesh is white and delicate, enriched as much as possible with sweet juice, and an 
exquisite flavour. The fruit should be gathered shortly after the skin begins to change from green to yellow, for if gathered too soon, it rots; and if too late, it becomes soft and loses its excellence. The branches of the tree are drooping; the shoots of the year are short and slender, with small grayish spots scattered over at intervals; the leaves are oblong, coriaceous, shining, and nearly as smooth on one side as on the other, with numerous small oblique indentures; the peduncle is entirely woody, curved at its summit, with numerous furrows, which extend even on the end of the branch to which it is attached, and its other extremity is inserted in a broad open cavity. This pear has an affinity to the Beurre Spence.

\section{SOVEREIGN COLMar. Pr. Cat.}

\section{Colmar souverain. La souverain. Rejentin.}

This tree is of vigorous growth, but the branches usually assume a curved or drooping direction. The fruit is of large size, and turbinate form, diminishing gradually towards the stem; the skin is at maturity of a beautiful golden russet hue ; the flesh is delicate, rich, and high flavoured. The tree produces abundantly, and the fruit which ripens in October and November is one of the most beautiful in appearance and delicious in quality, and is highly esteemed by all who cultivate it.

\section{INNOMINÉE. VAN Mons.}

\section{L'Innominée. Pyrus innominata. VAN Mons.}

The leaves of this variety are narrow, pointed at each extremity, and of a pale green colour. The flowers are remarkably white, and the petals rounded. The fruit is very large, of a rather pyramidal form, rounded at the summit, swollen at the middle, and terminating in an obtuse point, where there is a swelling that partially covers the peduncle, and which is thereby pressed towards the opposite side; the peduncle is long and large, inserted even with the fruit; the skin is light green, mottled with pale fawn colour, and becomes yellow on some parts when at maturity. The flesh is delicate, melting, 
sweet, and enriched with an agreeable odour. This fruit attains its maturity between summer and autumn, and is not inclined to rot.

\section{FUL'TON. Pr. Cat.}

This native pear is of small size, and of a golden russet colour. When gathered at the proper period, which is a short time before its maturity, and ripened in the house, the flesh is sweet, juicy, meltirg, and of a delicious flavour. The tree is an abundant bearer, and the fruit is at maturity in October.

\section{DEARBORN'S SEEDLING. Mass. Hort.}

This pear is rather under the medium size, the skin smooth, fair, and of a pale yellow colour; the flesh is very melting, and of excellent flavour, being deemed equal in this respect to the ancient and delicious White Doyenné or St. Michael. It originated from seed in the grounds of General Dearborn, President of the Massachusetts Horticultural Society. Its period of maturity is the month of September.

\section{CABOT.}

This pear was raised by J. S. Cabot, Esq. of Salem, from a seed of the Brown Beurré. It has a short stem, and is of much smaller size than its parent, but resembles it in shape and colour, and has a faint red cheek on the side next the sun.

\section{GREEN WINTER SYLVANCHE. Pr. CAT.}

Sylvanche vert d'hiver, of various catalogues.

Winter Sylvanche.

This is a vigorous growing tree, and one of the most productive. The fruit is of good size and much excellence, and as it is a winter pear, it will serve as a most valuable acquisition to our collection of fine fruits for the table, during that part of the year.

RAYMOND. PR. CAT.

This was raised from seed by Dr. J. Wight, of Raymond, Maine. It resembles in form the White Doyenné, and is of a 
pale yellow colour. It is deemed of fine quality and good flavour, and ripens in the month of August.

\section{WILliams's DOUBLE BEARING. Pr. CAt.}

This variety was raised in the garden of Mrs. Williams, of Salem, Mass. from a seed of the St. Germain. It is a large pear and resembles its parent, but is of rather greater diameter, and its skin is of a lighter shade. The flesh is of fine quality, melting, but not high flavoured. This tree has the peculiarity of producing, as it were, two crops; the fruit of the first is of the size above stated, and ripens early in October, that of the second is of much smaller size, and ripens from two to four weeks after.

\section{BLEEKER'S MEADOW. Pr. Cat.}

\section{Meadow Pear.}

This variety originated in Pennsylvania, and is said to be a seedling from the far-famed Seckel, which is highly probable, as the tree greatly resembles that variety in the appearance of the wood, foliage, \&c. Its growth, however, is much more rapid and vigorous, and it will perhaps attain to double the size in the same period. The trees in my grounds have not yet produced fruit, but some specimens sent from a distance, and stated to be of this variety, were more than double the size of the Seckel, and of a yellowish or russet colour, resembling somewhat in shape a large bergamot pear, not compressed next the stem; they were also of much excellence as regards quality and flavour, and of beautiful appearance. The period of its maturity is the month of October.

\section{ORANGE。 Pr. CAT.}

This variety is considerably cultivated in some parts of Rhode Island, under the above title, where it is held in great estimation. Whether it is a foreign or a native variety, is not yet precisely ascertained. It ripens ten or twelve days before the White Doyenné, and is more buttery but less melting than that variety, and inferior to it. In respect to 
form, it is not as long a fruit as the White Doyenné, being between that and a bergamot pear in shape, but at its greatest diameter, it equals in size a large fruit of the Doyenné.

\section{BLODGET. Pr. CAt.}

This variety was raised from seed by Deacon David Blodget, late of Camden, Maine. The original tree is now thirtytwo years old, in a vigorous state, and a good bearer. The fruit is of medium size and pyriform, and at maturity is melting, juicy, and of a very pleasant vinous flavour. It attains its maturity here in the month of September.

\section{HONEY. Pr. CAT.}

This variety is considerably cultivated in the state of Maine, and claimed by some persons there to be a native. The fruit is under a medium size; the flesh melting, very juicy, and of a rich, sweet, musky, and sprightly flavor, and deemed by the gentleman who sent it to me, to be equal to the White Doyenné. The tree bears abundantly, and in its form is rather more spreading than lofty. The period of maturity is the beginning of September. I am informed by Jacob Patch, Esq. of Maine, that this and the preceding varieties are found to be exceedingly hardy and well suited to the severe climate of that state.

\section{ERRATA.}

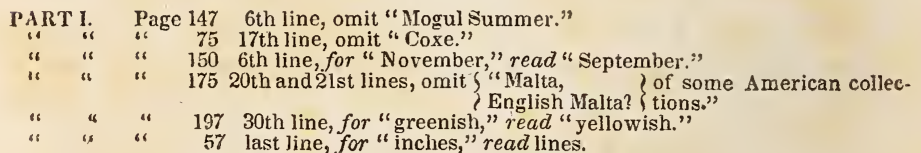

PART II. Page 22 at 27th and 28th lines, omit "towaris the end of September," and " " 29 read "from the first to the twelf th of November."

" " $" 89 \mathrm{~d}$ line, for "The form," read "This plum." 




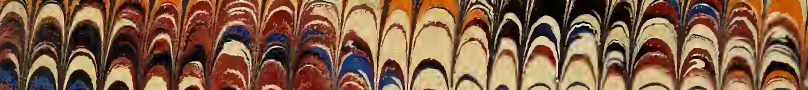

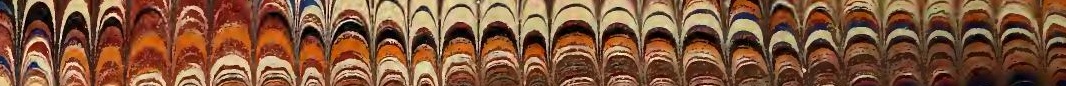

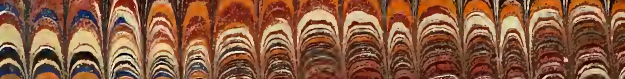

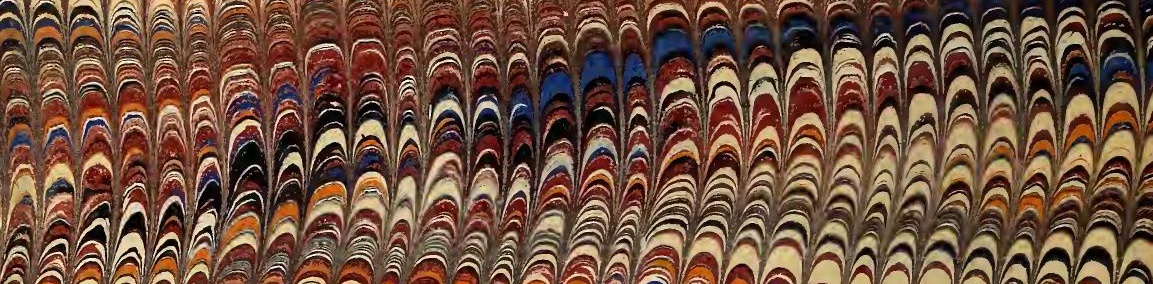
的 年

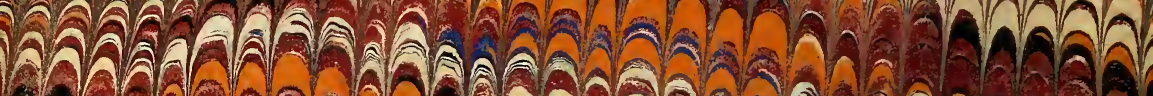

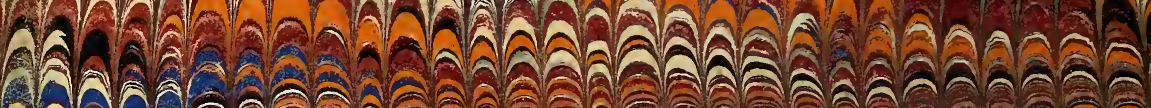

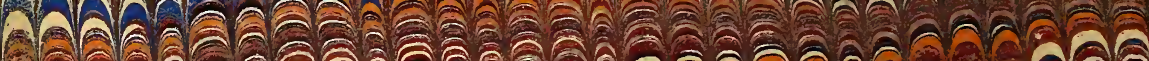

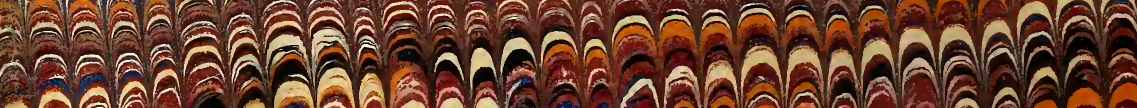

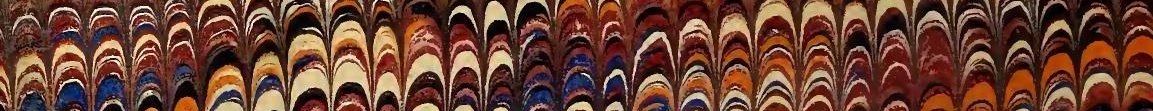

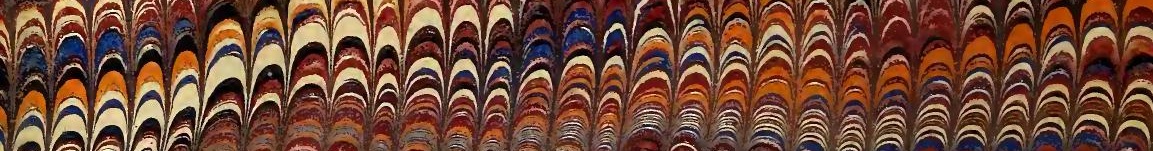

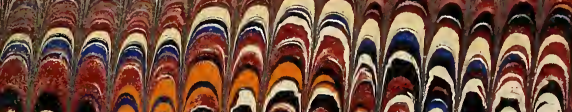

ลำลㄴ.

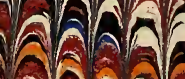

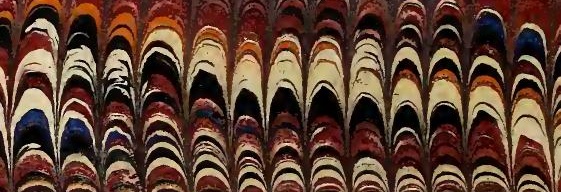
ลำลว

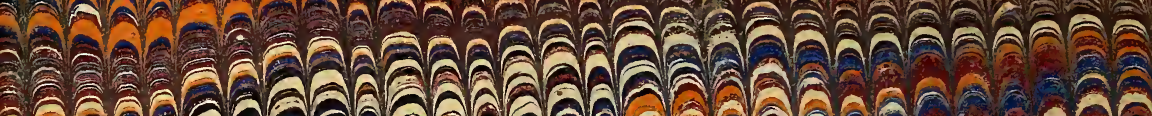
1

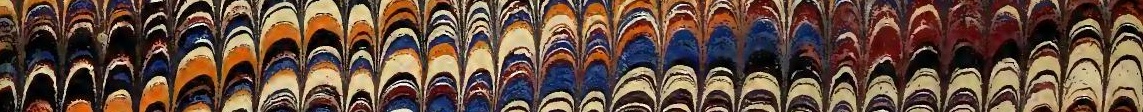

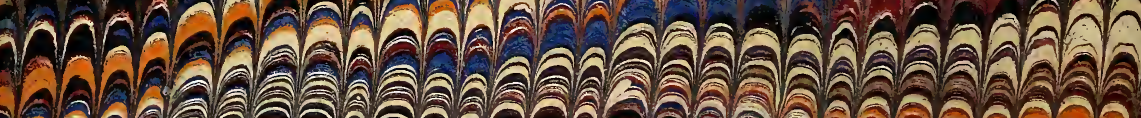
ง

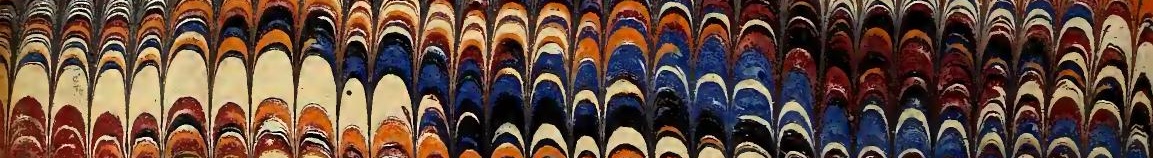
-

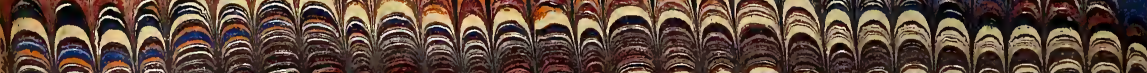

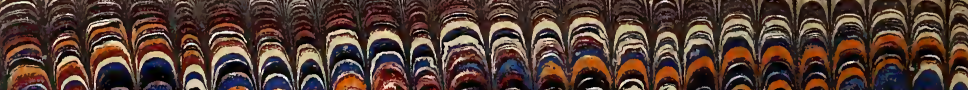

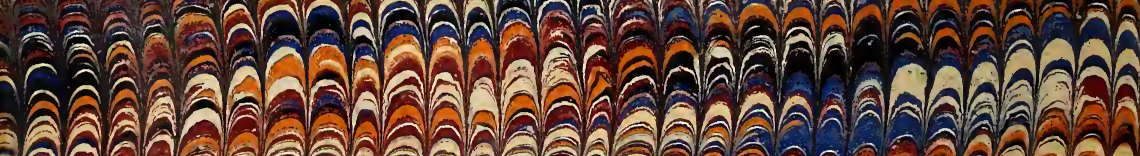

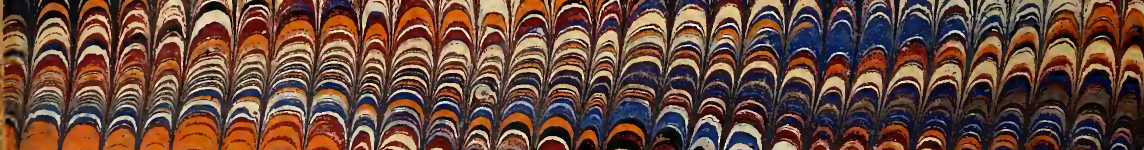





\section{LIBRARY OF CONGRESS}

|||||||||||||||||||||||||||||||||||||||||||||

||||||||||||||||||||||||||||||||||||||||||||||||||||||

000091?199A 